\title{
Bordering On Fear: A Comparative Literary Study of Horror Fiction
}

by

Aalya Ahmad, B.A. (Hons), M.A.

\author{
A thesis submitted to \\ the Faculty of Graduate Studies and Research \\ in partial fulfillment of \\ the requirements for the degree of
}

Doctor of Philosophy

Institute of Comparative Studies in Literature, Art and Culture:

Cultural Mediations

Carleton University

Ottawa, Canada

January, 2010

CC2010, Aalya Ahmad 


\section{$1 * 1$ \\ Library and Archives \\ Canada}

Published Heritage Branch

395 Wellington Street

Ottawa ON K1A 0N4

Canada
Bibliotheque et

Archives Canada

Direction du

Patrimoine de l'edition

395 , rue Wellington

Ottawa ON K1A ON4

Canada
Your file Votre reference

ISBN: 978-0-494-63864-4

Our file Notre reference

ISBN: 978-0-494-63864-4
NOTICE:

The author has granted a nonexclusive license allowing Library and Archives Canada to reproduce, publish, archive, preserve, conserve, communicate to the public by telecommunication or on the Internet, loan, distribute and sell theses worldwide, for commercial or noncommercial purposes, in microform, paper, electronic and/or any other formats.

The author retains copyright ownership and moral rights in this thesis. Neither the thesis nor substantial extracts from it may be printed or otherwise reproduced without the author's permission.

In compliance with the Canadian Privacy Act some supporting forms may have been removed from this thesis.

While these forms may be included in the document page count, their removal does not represent any loss of content from the thesis.

\begin{abstract}
AVIS:
L'auteur a accorde une licence non exclusive permettant a la Bibliotheque et Archives Canada de reproduire, publier, archiver, sauvegarder, conserver, transmettre au public par telecommunication ou par I'Internet, preter, distribuer et vendre des theses partout dans le monde, a des fins commerciales ou autres, sur support microforme, papier, electronique et/ou autres formats.
\end{abstract}

L'auteur conserve la propriete du droit d'auteur et des droits moraux qui protege cette these. $\mathrm{Ni}$ la these ni des extraits substantiels de celle-ci ne doivent etre imprimes ou autrement reproduits sans son autorisation.

Conformement a la loi canadienne sur la protection de la vie privee, quelques formulaires secondaires ont ete enleves de cette these.

Bien que ces formulaires aient inclus dans la pagination, il n'y aura aucun contenu manquant. 


\begin{abstract}
The emerging academic field of horror studies that has been mapped out by die work of cultural studies, film and feminist theorists tends to emphasize horror films while neglecting all but a handful of novels. Academic horror criticism, in producing theory, has also tended to ignore the role of horror fans. In literature, horror has become almost entirely subsumed under the category of the Gothic. Beginning with a comprehensive overview of the scholarship to date, this dissertation takes issue with the "Gothic consensus" that written horror fiction is covered by the Gothic, arguing that more analysis of horror literature, and particularly more acknowledgement of the importance of short horror stories, is required in order to better represent the field. This issue is situated within the context of what the dissertation calls "fan(g)dom," referring to the range of practices that constitute, condition and distinguish both individual and collective responses to horror, including discourses of affect. The dissertation explores theories of the representation of generic figures, arguing that changes in the horrific affect of these creatures occasioned by shifting cultural and political discourses must be taken into account. In order to analyze what Edgar Allan Poe proposed as a "unity" of affect in written horror, the dissertation employs narrative theory to identify recurring affective elements as they appear in a wide range of short modern horror stories. This dissertation makes a significant contribution to the field by demonstrating that the marginalized short horror story which has never relinquished its ties with oral narrative is central to the Ango-American horror tradition. In keeping with its project of breaking down the scholar-fan divide, the dissertation offers an interpretive framework towards a poetics of horror that is informed by both scholarly and fan knowledge, and that can be used to compare and contrast horror fictions of all kinds.
\end{abstract}




\section{Acknowledgements}

To paraphrase the Grateful Dead, it has been a long, strange trip. My gratitude goes to the people who kept on believing in the project despite the many lengthy delays, roadblocks and dry spells to which it has been subjected since I first embarked upon my research. These people have sustained this work over the course of many years. They have brought me cups of coffee, cooked, cleaned and babysat, filled in for me in various capacities, typed and formatted, and offered encouragement in difficult times. Without them, this dissertation would never have been completed.

Firstly, I must thank my supervisor, Dr. Brian Greenspan. His unfailing support and confidence, and his keen observations have made all the difference. I have enjoyed Brian's sense of humour throughout, and will always treasure the draft of one chapter where my inept use of semicolons was noted in bright red ink in the margins with deathly groans, scribbled sketches of dripping knives and severed limbs, and even a bloody cutlass on page forty-two. I am immensely grateful to Dr. Greenspan for seeing this dissertation through to the end with me and for being there at the defence on a day where he was scheduled to undergo surgery. Such dedication both humbles me and makes me proud to be his student.

To the internal members of my committee, Dr. Gurli Woods and Dr. Andre Loiselle as well as Dr. Brian Johnson, your thoughtful comments were greatly appreciated. In particular, I would like to thank Dr. Woods for all her kind words of encouragement over the years. I also appreciate the input of Dr. William Beard, my External Examiner. I also acknowledge the assistance of Olga Cada, Administrator at the Institute for Comparative Studies in Literature, Arts and Culture.

My colleague and friend, Dr. Victoria Bromley deserves a special thanks for her constant encouragement and willingness to nag me to finish this project. I would also like to thank Dr. Sean Moreland, Poe scholar and fellow ghoul, as well as all the ghouls in Ottawa, both on and off-campus for many enjoyable screenings and discussions about horror. At a recent conference we attended together, Sean kindly provided valuable feedback on the dissertation and reminded me of Poe's principle of the unity of effect. Dr. Zhigang Huang generously volunteered her time for some last-minute editing and formatting.

The fans, writers, scholars, directors, and various lurkers and posters from all walks of life on the Horror in Film and Literature listserv which is based out of the University of Indiana have been part of my fan(g)dom for many years now. Some fantastic conversations have occurred on this list and I have learned much from all the contributors, but I would like to particularly acknowledge the kind encouragement and valuable comments of Kate Laity, Pearce Duncan and Todd Mason, talented folks all, who have probably between them forgotten more about horror than I will ever know, as well as thank Mildred Perkins, the "Demon Den Mother," for moderating the listserv. 
Just when I had begun to despair of ever finishing "die beast with four chapters," as I had begun to call it, I had the good fortune to be able to explore some of my ideas for the dissertation with the "Monstrous Feminist: Gender and Horror" class I taught at Carleton University in the summer of 2009. These wonderful and enthusiastic students gave me an important and timely reminder of how rewarding academic work can be. To them, I am more grateful than I can express as well as to the Pauline Jewett Institute for Women's and Gender Studies for giving me the opportunity to share my passion for horror fictions, to teach and to learn.

My extended family members have excused me on occasions too numerous to count for being flaky, irritable, absent-minded, self-absorbed and generally making myself scarce and unavailable to them during the course of this work, especially during its last stages. I look forward to spending a lot more time with them now that it's finished at last. To my sister Nadya Ahmad, to Giovanna Gossage, Maha Zimmo, Heidi Rimke and Kristin Cavoukian, to Nelson Ford, Joanne Burbidge and Mark Stephenson, to Bianka Lambert, Paul Reich, Pat Gouthreau, Jocelyn Chandler and Sean Good, to Glen Kit and JoAnne D'Aoust, Krim Cole, Linde Behr, J-Ho, Bob D'Errico, Liz Kim, Andrew, Lisa and the girls, Adrian and family, Zoe, Fiona and the Octo-crew, Kier Sider, Cathy Tillsley, MJ Houle, and many others whom I am truly blessed to have in my life, thanks for your patience, assistance, love, support, encouragement and understanding at all stages of this journey.

I am also blessed by the unconditional love of Elizabeth and Khalid Ahmad, my parents.

Finally, I owe deepest, humblest and most heartfelt thanks to my beloved Dietrich Sider, who in his devoted way, has seen this through to the end with me, and without whom I could never have finished it, and to our daughter Sophia, my little wisdom and much joy. 


\section{Table of Contents}

Chapter One: Problems of the Horrific.

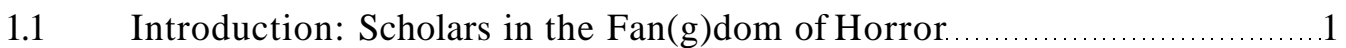

1.2: Overview, Part One: Disputed Definitions of Horror ............................. 38

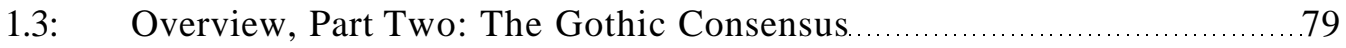

Chapter Two: Genre Mutations in Horror's "Monster Narratives" ..............................104

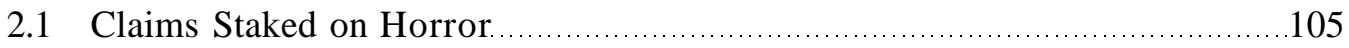

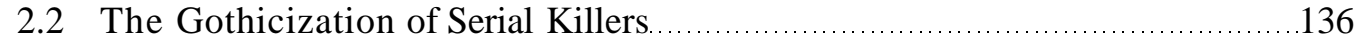

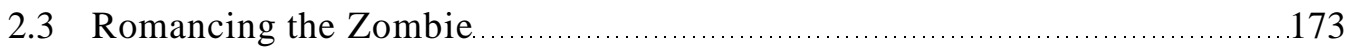

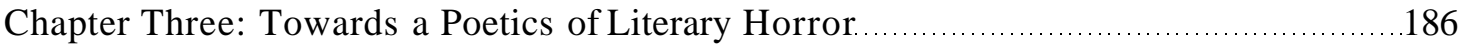

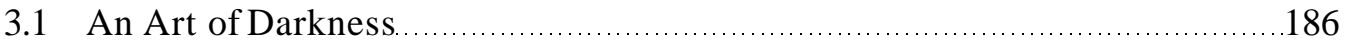

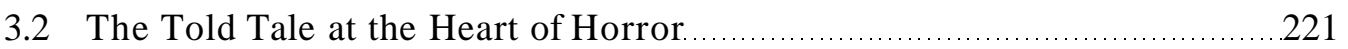

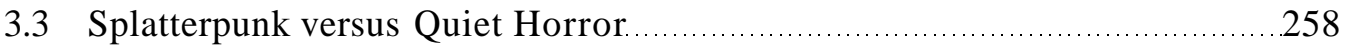

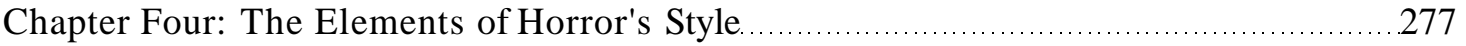

Conclusion

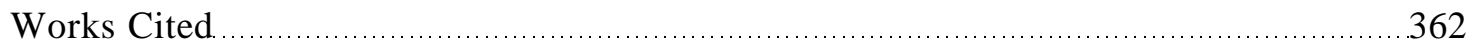

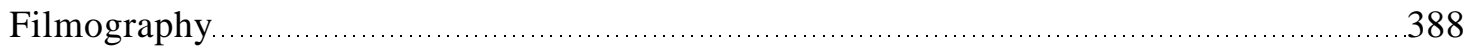




\section{Chapter One: Problems of the Horrific}

"What remains to be done? Nothing other than to destroy the present form of civilization. In this field, 'to destroy'. . . means to destroy spiritual hierarchies, prejudices, idols and ossified traditions. It means not to be afraid of innovations and audacities, not to be afraid of monsters ..."

- Antonio Gramsci, "Marinetti the Revolutionary," UOrdineNuovo, 1921

\subsection{Introduction: Scholars in the Fan(g)dom of Horror}

Horror fiction has always invited powerful reactions from its readers and audiences. These reactions have generated numerous commentaries, interpretations and attempts to explain horror's popularity despite, and possibly even because of, horror's lowly status as art. Up until quite recently, this lowly status was accepted uncritically by most scholars of literature and accorded also to horror's readers and audiences. Moreover, until recently, scant resources were available for the study of horror literature as an academic field. The implicit consensus has been that written horror fiction, regarded as a popular rather than a literary genre, does not merit scholarly attention.

Given that horror fiction constitutes such a strong tradition in the English language, it is unfortunate that a dearth of critical reflection exists in this area. While many film critics and theorists since the 1980s have embraced and explored the rich history of horror cinema, beginning with the very first moving pictures, (Kauffmann 12) horror in print form has for the most part been treated as a subject to be handled gingerly, preferably with reinforced rubber gloves, as one might touch a putrefying corpse. While horror film's visual spectacles 
of violence and "the body fantastic" (Badley 1995) are endlessly debated by public policymakers, fans, scholars and moralists, the corresponding discussions of written horror fiction's graphic prose are notably absent, with one or two exceptions, such as Bret Easton Ellis's American Psycho, which occasioned protests by some feminists. Robert Bloch stated the case admirably in his contention that "the few horror stories approved by the literary establishment [have] dealt almost exclusively with polite antiquarians and retired English gentlemen encountering a ghost" ("Heritage of Horror" xvii). Examples of the latter, whether they are penned by Montague Rhodes or Henry James, are not commonly dealt with by the academic establishment as horror fictions perse. Rather they are classified as "classic" short stories and are handled accordingly, with little mention of what makes them particularly "classic" as horror other than acknowledgement of the presence of the supernatural. Horror can thus be set aside or placed sous rature as an unpleasant side-effect of a classic literary work.

One reason for such a wholesale shunning of the horrific elements of a text might be the prevalence in the field of what Matt Hills has termed "horror-as-schooling" or using horror to illustrate a particular pet theory. This "theory-first, pleasure-second" tendency, Hills argues, has been a recurring habit for academics who study horror:

All such theories (including sociologies and cognitive philosophies of horror) appear to proceed from the basic notion that horror's pleasures stand in need of explanation, whether this is done by relating horror texts to the 'real' cultural anxieties of a time period, or to transhistorical notions of 'the unconscious'. I am suggesting here that theoretical approaches to horror have 
explained (away) the genre's pleasures by invoking their own disciplinary and theoretical norms. ${ }^{1}$ (Pleasures of Horror 2)

Hills argues that taking pleasure in the text's affects ${ }^{2}$ is too redolent of fandom for the established hierarchies of knowledge that distinguish academic work: a claim which is borne out by my own research. When I first began to read scholarly horror criticism in the nineties which was and still is overwhelmingly dominated by film criticism, I found that the few literary critics who had tiptoed at all into the field unanimously struggled to distance themselves from what Steffen Hantke calls "the shady territory of fandom" (n.pag.). The inference here is that horror fandom is a shadowy realm infested by monstrous, mindless morons slavering bestially over their prurient spectacles of gore, dismemberment, occult possession and cannibalism. As others have noted (Gelder; Hills: 2002; Laity), allusions to horror's "sick-making" pleasures raise the spectre of Bourdieu's theory of cultural capital, where the taste or distaste for horror more properly "classifies the classifier" (6). For Bourdieu, taste becomes

the basis of all that one has - people and things - and all that one is for others, whereby one classifies oneself and is classified by others. Tastes. . .

${ }^{1}$ As Hills notes, this practice will tend to radically over-simplify crucial aspects of the texts: "At worst, theoretical answers seem to be determined in advance of critics' encounters with horror texts, while at best scholarly theories continue to be accorded discursive primacy (that is, academic texts routinely offer pop-cultural examples that somehow mirror, 'prove' or allegorize the writer's chosen / favoured theory") (2).

${ }^{2} 1$ deliberately use "affects" instead of "effects" to describe the horror responses evoked by the text in order to avoid confusion with the debate, to which I will briefly allude later on, about horror's "ill effects" on society. See for example III Effects: the media/ violence debate, eds. Martin Barker, Julian Petley, Routledge, 2001. 
are the practical affirmation of an inevitable difference. . In matters of taste, more than anywhere else, all determination is negation; and tastes are perhaps first and foremost distastes, disgust provoked by horror or visceral intolerance ("sick-making") of the tastes of others. $(56)^{3}$

In this famous formulation, it is interesting to note how quickly the language of horror surfaces as a sort of primal response to "the tastes of others," which "negation" is then regulated into the positive shaping of one's own taste. As scholars and fans proudly stake out a claim on horror's territory, they are enacting, as Hills points out, a connoisseurship of horror that demarcates the border between "Them" (non-horror fans) and "Us" (74). Both scholars and fans profess to "get" horror, rather than it "getting" them, and to possess special knowledge in the field. Horror, then, "first and foremost" can be expressed as a reaction through distaste, where its "sick-making" strategies, as we have seen, becomes a way to classify and to determine "negation" as a yardstick for measuring and determining distances between subjectivities. Rooted in the notion of the fan is the connotation of the cultish, subliterate "fanatic": the person unable to maintain the proper critical distance from his or her obsessive interests. By contrast, the scholar follows the rule

${ }^{3}$ Gelder, Kermode, Laity, Jancovich, Hills and others have also taken up Bourdieu's theory of cultural distinctions to discuss horror production and the cultural capital wielded by horror fans, and to weigh the pleasures of horror connoisseurship, reading and viewing against the broader expression of distaste for horror in mainstream reception, which is often evinced as distaste for its fans. Before Bourdieu, the Frankfurt School defined a "culture industry" where the differentiation between "A and B films" serves as a mechanism for "classifying, organizing, and labelling consumers" (Horkheimer and Adorno 5). With its figurative feet firmly placed on the "B" side, horror defines us, not the other way around. 
of academic decorum in keeping a "healthy," detached, tasteful and objective stance vis-a-vis her or his subjects of research. ${ }^{4}$

A certain habit of genteel avoidance of borders thus pervades scholarship on horror fiction. These fictions might be said to hold the danger of contaminating or polluting purely objective literary scholarship with the taint of forbidden pleasures taken in the reading of the texts themselves. ${ }^{5}$ Ironically, then, academic studies of horror fiction often dance around the issue of the horrific as it appears in the text, presenting such issues only coyly and obliquely. In order to be effective and taken seriously, the scholar must scrupulously avoid lingering upon the narrative elements of graphic violence, mutilations and madness, deformities and deaths, monstrous spectacles and tormented victims that abound in the pages of horror literature. Instead, the disturbing impact of these images and narrative affects is either taken for granted or merely hinted at, and so the resonant core of the texts — indeed their constitutive meaning as horror - becomes obscured between the decorous lines of analysis and theory. This oblique approach means that die distinguishing attributes of horror fictions themselves have seldom been directly addressed, as my overview of the existing scholarship

${ }^{4}$ This idealized distance has been critically interrogated and dismantled by cultural studies scholars. Following the trail blazed by Henry Jenkins (Textual Poaching, 1992; Science Fiction Audiences with John Tulloch, 1995), Hills proposes that the fear of fandom in the academy arises from the devaluation of fandom as "pseudo-knowledge," " inappropriate learning" and "uncritical engagement with the media" (2002). Hills points out that much academic work is premised upon die tidy compartmentalization of messy cultural production into worthy and unworthy objects of study. Such "decisionist" thinking, as Hills terms it, fails to question the hegemonic processes whereby "good" and "bad" instances of popular culture are singled out for scholarly attention.

${ }^{5}$ Diana Brydon speaks of "contamination" as a literary device of the "cross-cultural imagination" (136). 
in the first chapter will show. As an institutionally unacceptable form of knowledge, horror's burgeoning presence in the academy continues to create confusion and uncertainty. The shocking imagery and graphic excesses of many horror fictions, moreover, engender acute discomfort, which further challenges the established protocols of how "good" and "bad" cultural objects may be handled. Often, the discomfort itself is all that can be agreed upon in the absence of a sanctioned space or language for expressing this knowledge as well as resistance to fan appreciation. Thus, Hantke describes the reaction of an academic audience attending a conference on popular culture to the screening of a clip from a graphic Japanese horror film. The audience settles down, prepared for a "familiar experience," and is then treated to "roughly four minutes of extremely skillful and convincing special effects, suggesting, among other things, on-camera self-cannibalization." As their conventional expectations were disrupted, Hantke writes,

most audience members seemed generally uncertain as to what exactly would constitute a correct response to such footage. There were those who were bewildered and too insecure to speak, and those who were offended but had little else to articulate other than their anger. And there were those who, physically repulsed to the point of nausea, obviously had other things to worry about for the moment. There may have even been some audience members who liked what they saw. But by and large, they kept their enthusiasm to themselves, recognizing that this admission would disqualify them from academic discourse and move them into the shady territory of fandom. (n.pag.) 
As Hantke suggests, academic discourse makes literally no place for any enthusiasm about horror's graphic imagery of violence, mutilation and death, or any other affective or aesthetic quality. For Hantke, horror's powerful sensory and affective impact resists attempts to canonize its texts and thus confounds academic attempts at mediation between the text and the reader. The "imagined subjectivity," as Hills puts it, of the scholar as antithetical to a fan simply does not permit such room to be made. I urge scholars to take a page from the horror fan's book and turn their attention to studying horror's narratives, its aesthetics and its literary forms as well as its cinematic spectacles in order to express responses that venture beyond anger and disgust.

This dissertation contributes an analysis of these aesthetic and narrative characteristics to the emerging field of horror studies. ${ }^{6}$ As such, the dissertation both builds on and departs from the work of most other scholars in this field. Taking up Matt Hills's resounding challenge to the hegemonic practices informing the scholar-fan divide, I will interrogate the commonplace given that horror literature is an oxymoronic proposition or, at best, a seedy and disreputable topic, by examining a wide selection of short horror stories, taken from the "golden age" of pulp fiction publishing at the turn of the twentieth century to the present. In so doing, I hope to build upon the valuable work and insights produced by film scholars and to draw critical attention to a rich, but neglected realm of literary production that currently only dares to whisper its name - the modern, short, horror story. I

${ }^{6}$ While, as I stated above, critical work on horror film has appeared at least since the 1980s and in one or two cases (Wood, White) earlier, an identified field of horror studies has only recentiy taken shape. The publication by Routledge of The Horror Reader, edited by Ken Gelder, in 2000, can be said to have ushered in a more defined approach to the field which remains, however, strongly oriented towards film criticism. 
argue that the short story form is essential to understanding horror fiction and that the neartotal neglect of the short horror story in the scholarship to date has entailed a skewed and severely limited vision of the field. In both film and literature, the centrality of what I will call the Gothic consensus with its emphasis upon the historicity of horror's "origins" in the eighteenth century has decentred Edgar Allan Poe's aesthetic principle of the "unity of effect" expounded in his essay "The Philosophy of Composition" (1846). Poe, describing the process which led to his poem "The Raven," stated that "[i]f any literary work is too long to be read at one sitting, we must be content to dispense with the immensely important effect derivable from unity of impression — for, if two sittings be required, the affairs of the world interfere, and everything like totality is at once destroyed" (163-4).

Poe's "unity of effect" was an idea which subsequendy had a strong influence upon H. P. Lovecraft's doctrine of "cosmic horror" elaborated in "Supernatural Horror in Literature" (1925-27). Lovecraft remarked: "Truly may it be said that Poe invented the short story in its present form" (396) and praised the "faultless unity throughout and thunderous effectiveness at the climactic moment" (399). For Poe, for Lovecraft and for coundess practitioners of the short story form after them, "Atmosphere is the all-important thing, for the final criterion of authenticity is not the dovetailing of a plot but the creation of a given sensation" (368). The emphasis that has been placed upon horror film and where literature is mentioned, the horror novel, has created an overly narrow view of horror fiction.

It is my contention that any study of horror in literature worthy of the name should ideally engage with at least some of horror's specific narrative elements prior to proceeding to more general theoretical formulations. The work of too many scholars in the field, insofar as this work fails to take up horror's narrative affects, only serves to reveal their lack of 
appreciation of the richness of the horror tradition beyond a handful of shopworn examples derived mostly from film. Hastening towards formulations, they offer only a passing nod to another handful of canonical and well-known horror novels such as Frankenstein or Dracula before proclaiming that fictional horror is really "about" Kristevan abjection, "about" gender normativity, "about" counter-discursivity, "about" Deleuzian schizoanalysis or some other enticing theoretical blank. Many of the theories produced in this way are both compelling and clever, but do not adequately cover the field. While they may raise intriguing and provocative questions about horror fiction, they ultimately subordinate it to theory. Such "accounts" ${ }^{7}$ of horror, I argue, are the reason why so many horror fans and writers scorn academic work, instead preferring to produce their own analyses, reviews, publications, conferences and anthologies. ${ }^{8}$ Again, it is astonishing that no scholars in the academy refer to any of this copious work, beyond a few references to Stephen King's Danse Macabre (1981) and one allusion to Les Daniels's Living in Fear (1975). ${ }^{9}$

Theorists of fan cultures such as Tulloch, Jenkins and Hills may point out that this alternative production of knowledge is a scornful gesture on the part of fans who are positioning their own knowledge as superior to that of the scholars: however, they wisely

${ }^{7}$ Throughout this dissertation, I critique the word "account" and avoid using it as much as possible, except where it appears in quotes, for the reason that I think such an overused term connotes a rather dry and business-like view of "accounting for" literature with which I do not agree, particularly in a climate where literature and the arts are constantly called on to "account" for their "value."

${ }^{8}$ See Kermode (1997) and Hills (2005) for a discussion of how extensive fan culture's horror connoisseurship and knowledge production can be.

${ }^{9}$ Few references exist to this non-fiction survey of horror by a well-known horror writer, with the exception of Yvonne Leffler's study Horror as Pleasure (2000). 
contend that room should indeed be made for fan knowledge. In the ever-expanding field of horror, so much fan knowledge has been and continues to be generated that it is absurd not to acknowledge it. The opposition between fandom and scholarship has in fact been viewed as somewhat artificial and reflective of a "torn social dynamic" between fans and scholars (Hills Fan Cultures 2). Both communities have constructed mutually marginalizing boundaries around particular ways of knowing: a false dichotomy that can be challenged by "coming out" as a fan. Despite die groundbreaking work that has been done on fan cultures and the possibilities of hybrid audience / reader positions - "scholar-fans" and "fan-scholars" - the breach of academic boundaries by the "absolute Other" of fandom, and particularly horror fandom, remains suspect, particularly outside cultural studies.

This dissertation, in taking up a neglected area of horror studies, poses a challenge to persistent scholarly assumptions about the horror field by offering research and analysis that is unapologetically grounded in the "soil" of my own horror fandom. In so doing, I am not merely indulging in "position-taking" as a scholar-fan or what Hills rather patronizingly and unfairly disparages as "a petulant revolt aimed at building symbolic capital" (15). ${ }^{10} 1 \mathrm{am}$ attempting to work within a paradigm of hybrid, organic intellectualism that does not

Outside the comfort of the horror habitus - be it listserv, movie theatre or less likely, the classroom - real consequences remain attached to being consigned to the field of horror fan(g)dom, politically, socially and academically. This is rather conveniently overlooked by Hills when he remarks that the figure of the academic-fan is actually less "scandalous" than those who seek to build "symbolic capital" (reputations) would admit (Fan Cultures 15) and insists that horror and horror audiences have not been neglected in the academy but, on the contrary, that the horror fan has been "theorized to death" \{Pleasures of Horror 13). Certainly, within Hills's own terrain of British cultural studies, this terrain may have become "rather conventional," but, again, academic cultural studies itself functions as another privileged and cozy habitus where it is possible to devote research time to such topics without facing the scandalized censure and ridicule of Outside. 
denigrate literary criticism at the expense of fan knowledge or vice versa, but seeks rather to broaden, enrich and invigorate literary criticism by bringing my fan knowledge to bear upon some of its precepts and methods. In keeping with what I am going to call my fan $(\mathrm{g})$ dom, I will try to avoid "spoiling" the pleasure of the texts I discuss for potential readers. Hills draws attention to this practice, often employed in horror fan discourse to avoid giving away the scares inherent in a horror text for somebody who may not yet have viewed or read it, remarking that academics "reserve the right to spoil" fictions for readers in the name of their "deeper" investigations (Hills 43). Hills himself unhesitatingly goes about "spoiling" the fictions he mentions for his audience by freely revealing the plot twists and endings of the texts he discusses. In rescinding this right for my own work, I wish to do more than simply gesture at the torn social dynamic between fandom and scholarship. I wish to repair such a dynamic. Although the nature of my discussion entails that I must occasionally disclose some important plot twist or ending in some of the lesser-known texts under discussion, my overall aim is to preserve the pleasure of the texts under discussion for those who read this dissertation and are motivated by it to read further afield.

In a related departure from most existing accounts of horror, rather than focusing exclusively upon a particular genre, sub-genre or theme, or examining one particular author or text, I will note as I go along the play of intertextualities between texts, discourses and tropes that both Hills and Kermode have identified as a significant pleasure of horror fan(g)dom. Such intertextualities, which also invoke Philip Brophy's useful concept of 
"Horrality - horror, textuality, morality, hilarity" (to which I would add "orality"11) tend to resist easy or "decisionist" compartmentalization of any sort. The relationship that an implied and accepted intertextuality bears to the production of horror as an affect and an essential attribute of the horror text is an important topic that I will take up in my own textual analysis. ${ }^{12}$ Can horror films, novels and short stories be read together as intertexts, taking into account their differing strategies of generating fear? In my textual analysis of short stories, I will show that these disparate media are indeed intertextual, employing close reading that has been thoroughly informed by the extant scholarship and fan knowledge of the field in order to draw attention to not only the ways in which horror can be produced affectively and effectively in literature, but to comment on how certain narrative strategies are translated or re-mediated onscreen or in print in short story adaptations.

My approach could perhaps best be described as a "historical poetics" of the sort that Stephen Jay Schneider calls for in "Toward an Aesthetics of Cinematic Horror". Schneider employs Henry Jenkins' description of historical poetics as going against the grain

${ }^{11}$ Linda Badley makes reference to the orality of the horror story, citing Walter Ong's Orality andUteracy: the technologi^ng of the word (1982). Badley asserts that "[i]n preliterate culture you knew only what you could recall, and the oral performer functioned as a library or computer whose information could be accessed by a key word or sound formula .... the horror phenomenon, especially in the 1980s, was [her emphasis] postliterate culture in process of becoming .... King changed the Gothic novel into a postliterate text and a language for an age of secondary orality" (37). Badley, however, does not mention King's many collections of short stories which, as I shall argue in Chapter Three, convey, along with the works of many other writers, a more primary orality than the novel and one not necessarily derived from the Gothic but conveyed through narrative devices such as framing.

${ }^{12}$ The term "intertextuality" has been broadly expanded since Julia Kristeva, interpreting Bakhtin, launched the concept in 1967. Here I take it in its original sense as indicating the connections between texts, discourses and traditions as "a mosaic of quotations" (Desire in Language: 66-69). 
of much film criticism which excavates either "the world-view of a particular film-maker" or "dominant ideological assumptions in the culture at large":

Historical poetics forestalls this search for meanings in order to ask other questions about how film narratives are organized, how films structure our visual and auditory experience, how films draw upon the previous knowledge and expectations of spectators. (134)

Schneider comments that, "what is needed is an in-depth understanding of those principles, techniques, and devices that have proven most capable of eliciting horror responses in audiences" (134). Informed by reception and reader-response theories as they have been elaborated by Michael Riffaterre, Wolfgang Iser, Roman Ingarden and Stanley Fish, as well as the morphology of folk narratives pioneered by Vladimir Propp, my dissertation attempts to produce such understandings in the realm of literary rather than cinematic horror.

Fish's reader-response theory raises interesting questions about the experience of reading horror fiction. Fish confesses that "in general I am drawn to works which do not allow the reader the security of his normal patterns of thought and belief and writes also that, if he had to deal with questions of value, he might "erect a standard of value on the basis of this preference - a scale on which the most unsettling of literary experiences would be the best" [my emphasis] (51). The most "unsettling of literary experiences" is a good way to describe much horror fiction, which upsets conventional values of taste and decorum in literature. The frequent references to audiences and knowledgeable horror fans as well as the debates over women's positioning as horror viewers and horror's possible effects upon society, that fill the pages of the critical texts I have been describing indicate that written horror should respond exceedingly well to a reception-oriented approach. 
Reader-response solves horror's dilemma of "high" versus "low" literary status by pronouncing literature itself "a conventional category ... a function of a communal decision as to what will count as literature" (10). The reader-response approach is useful for horror in that it frees criticism from the deterministic task of having to impose "a correct way of reading," allowing it to determine, instead, "from which of a number of possible perspectives reading will proceed" (16). Rather than having to try on ill-fitting subjectivities, such as Carol Clover's idea of cross-gender identification with respect to horror fan $(\mathrm{g}) \mathrm{dom}$, a readerresponse approach accommodates the fluidity which one might expect of an audience that is simultaneously laughing and screaming at horrality or a reader who is thoroughly enjoying her graphic tale of terror at the same time that she is wincing in fear and disgust. ${ }^{13}$

Fish urges us to consider meaning as a function of "what does this sentence do?" Rather than seeing it as "an object, a thing-in-itself," we are asked to look at the sentence or the film as "an event, something that happens to, and with the participation of, the reader" (25). Reader-response can thus be employed to bridge a distance from film theory to literary theory, another reason it is useful for horror studies. The emphasis upon "temporal flow" and "meaning as an event" is also peculiarly suited to horror which presents its affect as a frightening or shocking "event" that precedes deeper analysis. A "new look at the question" of what a text does, Fish writes in "Literature in the Reader," "may result also in a more accurate account of works whose formal features are so prominent that the critic proceeds directly from them to a statement of meaning without bothering to ask whether their high

${ }^{13}$ Men, Women and Chainsaws (1992). I will be referring to Clover's influential theories of horror throughout this chapter. 
visibility has any direct relationship to their operation in the reader's experience" (41). Again, it is undeniable that horror's "formal features" - its fear-evoking strategies and G-factors are perhaps the most prominently visible of all. In keeping with Fish's theory, these features are least dwelt upon by horror's critics.

The question of definition of horror is far from a simple matter. In the next section of this chapter, I will devote a lengthier discussion to this question, but for clarity in this introduction, I hereby define horror fiction as texts that contrive through their narrative strategies to create, contemplate and cultivate these "horror responses," including fear, dread and revulsion responses, to make these responses their focus and their raison d'etre. As Jack Sullivan, the editor of The Penguin Encyclopedia of Horror and the Supernatural'puts it, "horror is unusual in that it is both a genre and a subject, one treated in all the arts." How, then, might one distinguish it? Sullivan's prompt response is: "Fear, in fact, in its many forms and intensities" (vii). Horror writers such as H. P. Lovecraft and Stephen King have voiced a common definition of horror as fundamentally affective, as fear-inspiring, as out "to get you" (Danse Macabre 176), as inducing a response, rather than a scholastic enumeration of elements that may or may not distinguish a horror text. As Yvonne Leffler, Hills and Schneider have noted, the affective function of horror has long been under-theorized. One notable exception is Noel Carroll's influential theory of "art-horror" which I shall discuss at length later on.

By "horror responses," I mean not only the immediate and recognizable response of startling characterized by a fight-or-flee response to the jumps and shocks of cinematic horror techniques and the recoiling of a theatre audience in their seats at the sudden shocks and repulsive sights in which fans and connoisseurs of horror delight, but responses that call 
into question the borders between mind and body, how we "know" our fears. These questions have been raised in film studies rather than literature: for example, Anna Powell has related affective response to horror films to Deleuzian concepts of body and faciality. Martin Barker ("The Newson Report") has also drawn attention to the ways in which cinematic narratives offer a variety of memorable textual experiences, including "resonant" moments that linger in the viewer's mind as well as "punctuation" moments that hammer a particular sight, spectacle or scene home. Dennis Giles has discussed what he calls, following Lyot\&td, figures in film, techniques that create an "anticipatory vision" and thus cause the audience or viewer to experience fear although nothing fearful is visible. Such insights can be adapted to horror texts in literature, providing a fuller sense of how "horror" as an affective response may be elicited and sustained. In thinking about responses to horror literature, I want to include here not only Noel Carroll's "art-horror" emotion, but also Lovecraft's celebrated "cosmic fear" (367) as well as the creeping dread caused by a fiction, which often lingers long after the text has been read. Again, the short story form is pertinent here as a fiction that can be read in one sitting but that resonates long after it has been read.

In this dissertation, I will attempt to avoid "decisionist" issues of whether or not a given horror fiction is "good" (literary) or "bad" (trashy) and on what grounds such judgments can be made. Of course, the assumption of horror's lowly status is not confined to academics and other authoritative curators of cultural capital. Horror and horror fans are also regarded with suspicion by mainstream and popular culture audiences even as they queue for the latest blockbuster thriller. In The Pleasures of Horror (2005), Hills argues persuasively that "the pathologization of horror's pleasures as a 'problem' - and hence also the genre's fans - never seems far from the surface of literalist readings" such as those that 
would assign an immoral taint to horror texts (4). While I take Hills' point that the need for answers to horror's "problem" is somewhat suspect because this tends to validate the insinuation that horror is a sort of "mimetic infection" or "pollution" (3), I argue that it is not appropriate to simply dismiss the "problem" of horror's pleasures as always fortifying a "literalist" reading. In fact, many horror texts compel and foreground the sort of pathological problematization that Hills denounces. While Hills insists that we should not ask any fan audience to "account for its pleasures" (5), I suggest that horror texts often more or less playfully and consciously invite such accountings and pressurized readings as part of both their pleasure and their cultural work.

A good example of such an invitation can be found in the film Henry, Portrait of a Serial Killer (1986). Henry features one of the "most piteous and appalling sequence in memory," in the words of one reviewer (quoted by Isabel Cristina Pinedo 97). Henry and his accomplice Otis are shown watching a home video recording of their home invasion, torture and murder of a family. At first, the home invasion appears to be "a live event unfolding in real time" but then the killers stop and rewind the tape because Otis exclaims, "I want to watch it again." Pinedo succinctly describes the dizzying horror of this moment: "What seemed to be a scene in which the audience stands apart from the killers and looks voyeuristically at their deeds is shown to be one in which the audience watches the videotape in the company of the killers" (102-3). Phil Hardy in the authoritative The Overlook Film Encylopedia: Horror similarly describes the film as "resolutely unexploitative" and dwells upon this scene in particular in detail:

The strongest, hardest-to-sit-through sequence is a videotaped home invasion which, when the image becomes static because Henry has dropped 
the camera so he can kill the interloping son, strongly recalls A Clockwork Orange (1971) as it adopts the view of the torture, murder and rape ... in Kubrick's film .... The most horrific moment is Otis's line "I want to watch it again", which leads him to reshow on frame-advance the sequence of images an audience must be relieved to think over. (419)

The unmentioned portion of Henry's promotional slogan — "He's not Freddy. He's not Jason. He's real" - positions the film and its audience through both intertextuality and realism. Simply invoking the names of horror fiction monsters "Freddy" (A Nightmare on Elm Street [1984]) and "Jason" (Friday the Thirteenth [1980]) is all that is needed to summon the connotation of stalking and slashing whereas the claim "He's real" positions this particular (fictional) monster as being even more frightening than his fictional counterparts (the "Henry" of the film is based upon the convicted serial killer Henry Lee Lucas). The "documentary feel" that Pinedo mentions is underscored by Henry and Otis's own amateur camerawork in recording their brutal assault upon a nameless family, made memorable only by their appearance and degradation as victims who are not only beaten, molested and killed, but whose deaths in the mechanistic culture of serial killers, as Mark Seltzer points out (1998), are repeatedly fast-forwarded and rewound. Most critics who have seen Henry identify this horrific sequence as the key to the film's potential interpretations. As Pinedo observes, both the "extratextual" ("He's real") and intertextual allusions to more easily recognizable horror ("He's not Freddy") disrupt the comfort of generic landmarks. This conflation of the documentary with fictive and supernatural slashers such as Freddy and Jason further blurs the boundaries between reality and fiction. 
The film continually reminds the audience of its own complicit glee, its own knowledge of monsters, its own desire to "watch it again" and its own engagement with the ongoing mythology of killers: in short, its own frightening fandom. ${ }^{14}$ The eagerness of Otis to "watch it again" becomes audience participation. Insofar as the slasher narrative and the horror narrative have diverged has been precisely in the increasing rapidity and sanitization of the former's imagery, away from diachronic realism and more towards the swift, stylized and symbolized grotesque, epitomized in tableaux of bleeding bodies, bringing the slasher further into the realm of the detective mystery thriller. This is why films such as Dressed To Kill(De Palma 1980), and even Silence of the Lambs (1991) or Se7en (1995) can be produced and marketed as mainstream thrillers, (although the prolonged torture scenes in Silence of the Lambs render the film authentically horrifying) whereas the notorious and frequendy censored rape-revenge film I Spit on Your Grave (1978), with its painful, lengthy sequences of repeated gang rape, is indisputably horrific. ${ }^{15}$

${ }^{14}$ In another hard-to-watch sequence, Henry smashes a television set over the head of a victim, simultaneously killing him and fusing him as a "talking head" within the television in another nod to the audience's voyeurism. Similarly, Henry's prior murders are recorded for the viewer in the opening sequence of the film through "still life" tableaux of his victims, with audio footage superimposed over the gruesomely suggestive scenes. The viewer is then "filling in" the details in another cinematic ploy that draws attention to his or her complicity as a consumer of serial killer fictions.

${ }^{15}$ Noting Henry's reception and censorship as an X-rated film, which means "death at the box office for nonpornographic films" (9), Pinedo raises the problematic issue of gender and the slasher film as follows:

A weighty argument for the misogyny of the slasher film is that the voyeuristic camera work which keeps the killer offscreen during much of the stalking and slashing also aligns the viewer with the killer's point of view. If. . . the horror film audience is primarily male, then this camera work locates 
Engaging in such readings and accounts as the example above invokes what Mark Jancovich calls the "cultural politics of shocking images,"16 signifying a particular kind of fan subjectivity that is characterized not only by a certain glee in surreal, graphic and taboo images, but by an ongoing concern with horror's special "affects," not only on pages and screens, but horror's effects on readers and their societies. Fan audiences and readers knowingly and lovingly partake of a multiplicity of texts, intertexts and adaptations in keeping with the special knowledge they perform as "intertextual subcultural capital" (Hills The Pleasures of Horror 188; Kermode 129). Building upon Hills's theorizing of fan culture, I suggest that horror, then, calls not for fandoms, but rather for "fan (g) doms," historicized, politicized, productive and self-conscious performances that simultaneously demarcate territories and eradicate borders between texts. Why should I add a (g) to fandom? To the account of the fan who finds pleasure in horror's "scare quotes" or series of intertextual references, and following Hills's and my insistence that we consider narrative elements and

largely male viewers in a sadistic position. (74)

Nevertheless Henry, which combines, as I noted, acoustic flashbacks and camera work with graphic detail such as assault and dismemberment is, for Pinedo, also an "opportunity" to explore the terror and rage of a misogynist capitalist society through discursive realism: "The routine character of Henry's violence is never explained, but unlike the violence of other monsters, it is couched in the context of a larger life" (99).

${ }^{16}$ Jancovich notes somewhat ruefully that horror films (and those who study them) have become less "disreputable " and implicitly less interesting and subversive, ignoring the struggles against censorship and regulation of horror that characterized a more "underground" era of horror scholarship: "Oh the horror!" <http://www.guardian.co.uk/ commentisfree/2007/nov/26/ohthehorror>. This lament echoes Hills's dismissal of the "now rather conventional" scholar-fan and is equally oblivious to the world outside the charmed circle of British cultural studies. By wearily implying that they have "done it all," both Hills and Jancovich are rather prematurely cordoning off the field of horror fiction from the critical interventions of Others. 
"affect-functions" as an integral part of horror, I add the submersed and subversive (g), standing in for the gory, the gross, the gut-bucket(y), the gruesome, the gratuitous and the graphic: in short, all the "visceral" and "non-intellectual" stylistic excesses of horror that are enjoyed and performed by its fans in the process of measuring (and bridging) distances, of Othering and themselves being Othered.

The process of Othering taken by the horror fan may well be a defensive performance, as Hills calls it, against the taint of deviance; an attempt to elevate the imputed deficiency into a richer and more refined aesthetic perception. For example, H.P. Lovecraft claimed that the "appeal" of his "weird tales" would, far from being universally experienced, apply only to "minds of the requisite sensitiveness ("Supernatural Horror in Literature" 365). However, Lovecraft's weird tale was rather precisely located within the "literature of cosmic fear" as opposed to physically "gruesome" narratives, and it is debatable whether or not the success of the undeniably gruesome films that have been made of his stories (such as The Curse of the Crimson Altar [1968], Re-Animator [1985], Necronomicon [1992], and more recently Dagon [2001]) confirms or refutes this theory of the special horror-reader. Still, in identifying critical antagonism to horrific fiction, which he passionately described as "the shafts of a materialistic sophistication . . . which deprecates the aesthetic motive and calls for a didactic literature to 'uplift' the reader towards a suitable degree of smirking optimism" (365), Lovecraft was also situating himself within the habitus of horror fan(g)dom and establishing a distance between the aficionado of weird tales and Others. Like Lovecraft, horror fans, in line with their "imagined subjectivity" as such, often distinguish themselves from mere consumers, a characteristic of fans in general as Hills has observed (Fan Cultures 27). Horror 
fans may knowingly celebrate their relegation to a deviant habitus which remains an uncanny (unheimlich) place out of bounds for "normal" society. ${ }^{17}$

Fans of horrific media are frequently classified as deviants, suspect or on the margins, and dangerously prone to acting out the violence and excess which horror graphically portrays: the more graphic the violence and excess, the more suspect the pleasure; and thus, implicitly and sometimes explicitiy, the more suspect the reader. Going back to the popularity of the penny dreadfuls, G.K. Chesterton wrote at the turn of the twentieth century: "It is the custom, particularly among magistrates, to attribute half the crimes of the Metropolis to cheap novelettes" (77), while Robert Bloch writes defending H.P. Lovecraft's work which was kept in print due to the tenacity of a handful of fans, but labelled "sick" by certain critics: "If safeguarding our mental health requires us to avoid the work of those whose life-styles depart from the accepted norm, then our bookshelves would soon be stripped bare" (BestofLovecraft, viii). Barker and Pedey have also drawn attention to the class inequities and oppressions masked by high moral indignation whipped up against

${ }^{17}$ K. A. Laity draws our attention to this concept of the fan habitus in her discussion of the internet group Horror in Film and Literature (HFL) as a virtual space where horror fans find a home to share their views on numerous texts ("From SBIGs to Mildred's Law of Inverse Trailers: Skewing the Narrative of Horror Fan Consumption" in Horror Film: Creating and Marketing Fear, ed. Steffen Hantke. Jackson, MS: University Press of Mississippi, 2004. 173-190). Laity describes the discussion group as a space where fans of horror can challenge and enrich each other, from an "authoritative (hegemonic) view" (Hills' "fan-scholar ") to "recognizing, even valorizing, the visceral, and decidedly non-intellectual, qualities" of horror consumption; the latter often distinguished by what Hills calls "micro-narratives" that document the fan's personal encounters with and connoisseurship of horror (78). Within the habitus of HFL, Laity writes, academics, filmmakers, writers, "lurkers" and those who fall into more than one of the above categories, produce and share a "sophisticated and directed discourse" that makes an alluring retreat of the habitus, at once removed from and situated within the ebb and flow of the "mainstream" of cultural consumption. 
horror texts that are said to instigate crimes, such as the Child's Play III (1991) movie that was famously blamed for the 1993 murder of James Bulger, a toddler lured away and killed by two ten-year-olds. Barker argues that the narrative of Child's Play III, far from being an incitement to murder, involved "an essentially gentle boy" confronting evil in order to keep a small child safe from harm ("The Newson Report" 33). In an older example, the 1866 "penny dreadful" magazine, Wild Boys of London, was considered depraved because it concerned the plight of "orphans and the urban poor" (35). ${ }^{18}$

Isabel Cristina Pinedo reminds us that class and ethnicity are also implicated in the dictates of taste, recounting her own experience as a member of two different movie audiences viewing the same film (Aliens [1986]). Following social historian Lawrence Levine, Pinedo makes an interesting distinction between the "boisterous audience ... a racially and economically mixed group" which "unabashedly let out loud screams, laughter, gasps, sarcastic remarks and exclamations," and

the more affluent and white . . a audience [that] quietly murmured to their viewing companions and barely let out a scream .... These two contemporaneous movie theater audiences parallel what. . Levine describes in Highbrow/Lowbrow: the emergence of cultural hierarchy in America as the raucous audience and the passive audience. Levine chronicles the process by which the unruly audiences of the eighteenth and nineteenth centuries were disciplined into the docile audiences of today. By the twentieth century,

${ }^{18}$ Dr. William Beard notes the campaign against David Cronenberg's Crash in the United Kingdom drew on similar moralizing tendencies. 
"audiences in America had become less interactive, less of a public and more of a group of mute receptors." (Pinedo 42-3)

Pinedo makes an exception to the "mute receptors" rule for horror movie audiences, even parodically so, as the cult status of The Rocky Horror Picture Show (1975) demonstrates. Hills' concept of "good" and "bad" intertextualities as well as Brophy's "horrality" surface here. The responses of a raucous fan $(\mathrm{g}) \mathrm{dom}$, rather than subjecting the graphic horror text to a disapproving silence and anxious discipline, celebrate, interact with and participate in that text and what diverse and indeed contradictory pleasures it may afford. Indeed, Tania Modleski has also questioned horror's location on the Frankfurt School's divide between "pleasure" and "jouissance" once again reminding us that horror fans do not necessarily comfortably inhabit the prevailing taste culture's distinctions.

The moral panics in Anglo-American culture over "video nasties" in the 1980s and school shootings in the 1990s are just two examples of how the transgressive excesses of horror become attributed to the characters of the horror reader / fan / consumer themselves. The term "video nasties" refers specifically to a list of seventy-four films which were banned in the United Kingdom under the Video Recordings Act, which was introduced as a private member's bill in the British Parliament in 1982 and became law in 1984. In The Pleasures of Horror, Hills, like Jancovich, theorizes the horror fan as inherendy anti-censorship, arguing that censorship in fact functions as a kind of "engine" of performative horror fandom, and using the "nasties" panic to support this argument (98). Hills uses the example of Kim Newman's story "Where the Bodies are Buried 3: Black and White and Red All Over" which situates its horrific events explicitly and ironically against a narrative of tabloid 
journalism and the "nasties" panic. ${ }^{19}$ The fictional film of the title, Where the Bodies Are Buried is also an intertextual nod to the Nightmare on Elm Street horror franchise with its wisecracking, knife-clawed, Freddy Kruegeresque monster Rob Hackwill. Hills contends that, not only in mobilizing subcultural capital or fan knowledge (of the intertexts of his stories) and the discourse of horror censorship, but in engaging the cultural politics of horror, often in the form of academic theories about literary appreciation as well as horror's meanings and effects, "Newman's fictions thus intertextually occupy a specific 'space of possibles' in the field of horror, indicating a multiple series of bids for cultural value, not all of which are strictly embedded in a neatly 'bounded' field of horror" (178).

Newman's story Actively parallels the events of the "nasties" moral panic, which was sparked by a tabloid crusade against horror films such as The Driller Killer (1979), and taken up by a group (now called Mediawatch) led by Mary Whitehouse. As an elderly journalist character in Newman's story satirically remarks: "Punters don't want blather about philosophical illnesses. They want something to blame. It's usually in the water. Maybe Satanic Heavy Metal" (Dark Terrors, 287). In the case of the video "nasties" panic, accusing fingers were pointed at a number of horror films newly available on videocassette for private home rental. As a result, these films were banned for many years. In mapping similar instances in an unfolding plot that blurs the fiction of the film and the fiction of serial murder within the fiction of Newman's story, the cultural criminalization of horror fandom

${ }^{19}$ See also Hills (2005:177) for a discussion of Newman's fiction. Hills is virtually alone in devoting time to some interpretation of popular contemporary horror prose outside the pop-canon of Anne Rice, Clive Barker and Stephen King, albeit in the service of theorizing them, rather than looking at their style. Hills uses the writing of Kim Newman as a case study of Bourdieuian intertextuality (Pleasures of Horror 164). 
is subverted by inviting the reader to participate in the constant slippage between the supernatural monster Hallwill, the mobs engaging in moral panic egged on by authorities, and a "true crime" discourse of discovering the killer's bodies and gradually uncovering the "real" monster:

Another important example of the cultural criminalization of horror "style" is documented in Michael Moore's Bowling for Columbine (2004), in which Moore seeks to uncover the reasons for the appalling school shooting at Columbine High School in Littleton, Colorado in 1999. In his film, Moore alludes to the mainstream media emphasis upon the incorrect allegation that mass murderers Eric Harris and Dylan Klebold were fans of shock rocker Marilyn Manson, who uses horror iconography as part of his stage performance and persona. When Moore interviews Manson on the subject of the Columbine killings, Manson, his demonic makeup notwithstanding, is cogent, lucid and reasonable, far from the drooling, anti-social madman urging disturbed fans to slaughter as he was depicted in some of the media attempts to blame him for Columbine.

Although Manson published a riposte to bis accusers in the June 1999 edition of Rolling Stone, ${ }^{20}$ the persistence of "cultural criminalization" adheres and the ColumbineMarilyn Manson link has become entrenched in the cultural memory as much as the killers' connection with violent video games such as Doom. For Manson, this had certain repercussions, both for his fans and for certain American youth who became even marginally associated with horror fan $(\mathrm{g}) \mathrm{dom}$ : for students, for example, who wore punk,

${ }^{20}<$ http://www.rollingstone.com/news/story/5923915/columbine whose fault is it $>$, accessed March 2009 
Goth or heavy metal styles or who produced "writing reflecting an interest in the 'dark side' of life," surveillance and FBI "student profiling" became routine (Muzzatti 150). An article published in the New York Times following the massacre (Goldberg) reveals the fascination and stigmatization associated with the renewed monstrosity of the "Goth" subcultural style as producing amoral "superpredators in waiting." 21

As Muzzatti notes, this construction of the dangerous, abnormally-dressed young horror fan serves the policing strategy of a neo-conservative discourse that works to obscure"the greatest threat to young people in the U.S.": "the concentration of wealth, the hijacking of government by Christian supremacists and the transnational classes, and an adult population so distracted or paralysed by unwarranted fear that it. . . acquiesces to policies and practices more indicative of a corporate-fascist state than a liberal democracy" (151). A political connection is thus established between horror fiction, its readers, and what Brian Massumi calls the "politics of everyday fear" (Massumi 1993): a connection which contemporary horror often exploits.

Horror fan(g)dom's "guilt by association" also haunts scholars who are interested in the field. Often critics from other disciplines than popular cultural studies, following the

${ }^{1}$ Dick Hebdige theorizes "subculture," exemplified by '70s British punk and street youth culture revealing an ongoing dialogue between British youth of West Indian descent and white working-class youth, as that which simultaneously opposes and operates within the mainstream, insistently calling attention to the ideological underpinnings of "normal" facades (12), thereby contradicting the "naturalness" of dominant discourses. Style is therefore the vehicle of a subtle "challenge to hegemony": "expressed obliquely," style operates "at the level of signs" (17); "pregnant with significance" and connotation, style is the bearer of "hidden messages inscribed in code on the glossy surfaces" (18): "It is on the plane of aesthetics: in dress, dance, music; in the whole rhetoric of style, that we find the dialogue between black and white most subtly and comprehensively recorded, albeit in code" (45). 
dictates of taste and the imagined subjectivity of the scholar which forbids any expression of fan $(\mathrm{g})$ dom, will shamefacedly describe their engagement with horror as an inherendy agonistic struggle to define the relationship between their enjoyment of and interest in the texts, and their perceptions that they are viewing or reading material that may not be compatible with the progressive concerns they voice. These concerns, as we shall see, are especially acute for feminist critics. I disagree with Hills's position that such self-reflexive struggles are always just another bid for (sub)cultural capital within the closed circles of academic disciplines. Often a real anguish and discomfort over what Hills terms "positiontakings" is evident, particularly in feminist attempts to come to grips with horror's pleasures. Such descriptions frequently take the form of an apologetic attempt to find a redeeming value that validates these concerns in the sub-text of the horror fiction in question. This makes horror, as previously noted, particularly susceptible to Hills' "theory first-pleasure second" or "horror-as-schooling" approach.

Horror fan $(\mathrm{g})$ dom is also collective in that "a curious communal sense exists among those who enjoy the pleasures of terror" (Sullivan vii). A community of horror fan(g)dom often generates sub-cultural styles that adopt horrific iconography as a form of expression: the much-maligned "Goth" sub-culture, for example, which has adopted fictional vampire lore and styles in fashion, music and occasionally sanguinary practice, constructing, as with the Goth cult film The Hunger (1983), a fantastic vision of lived and experienced quotidian 
horror textuality. My (g) therefore also includes the Goth subculture as an example of a particular fan(g)dom of horror literature expressed through a particular set of styles. ${ }^{22}$

At the same time, the (g) acknowledges the prevalence in literary studies of what I critically call the "Gothic consensus," signifying a contested and paradoxical play of differences within horror's realm. In fact, too often, serious analysis of horror has been marred by such purifying projects of horror apologism, the attempt to either rescue horror as a low genre from the disrepute in which it is commonly held by literary scholars and to make it "literary." Often this is accomplished by re-naming horror "Gothic," "New Gothic," or "Modern Gothic"; or, conversely, to remain defiantly "popular" in one's interpretation, thereby resisting any speculation as to horror's possible merits as fiction.

Some critics have hung on so fiercely to the low culture status of horror that they deny it can be critically viewed as "art" at all. Morris Dickstein, for example, argues that: "[t]he 'art' of the horror film is a ludicrous notion since horror, even at its most commercially exploitative, is genuinely subcultural, like the wild child that can never be tamed, or the half-

22 "Style" has often been a dirty word in literary criticism, denoting merely technical details, the "glossy surfaces" of language and form. If we take style in Hebdige's sense, however, as a performance that encodes the cultural politics of enmeshed discourses, it becomes possible to look at, for example, the perpetual and cyclical panics over horror's latest stylistic excesses as instances of "beautifully broken codes" and "cut-up" styles (26) as Hebdige characterized the spectacle of British punk as it burst upon the mainstream media in 1977. Punk and Goth are closely related. Horror's connection with punk has also been noted by Kermode. In Chapter Three, I will have more to say about the punk aspect of extreme horror or "splatterpunk." Hills is quite correct to point to the "affect-function" (in a play on Foucault's "author-function" (Pleasures 84) as a much-maligned and oft-neglected aspect of horror texts, but to some extent, he ignores the role of the "affect-function" as a type of Hebdigean "styling" (rather than simply "performing ") horror. These affects are the styles and strategies that connote "horror" for fans and non-fans alike; however, what fans do with them marks them as subcultural in the Hebdigean sense. 
human mutant who appeals to our secret fascination with deformity and the grotesque" (68). Reading through the discursive intersections and shifts between "high culture" and "popular culture ," between literature and horror, and between "classic" and "exploitation" horror may be particularly fruitful within changing socio-cultural contexts, particularly in an age of globalization, where we are reminded that the critique of "literary" versus "low" culture has come to us out of post-colonial studies that question the subjugation of oral traditions and storytelling to western philosophical ideals of art. As Robin Wood puts it, the "seemingly innocuous" texts associated with generic horror "can be far more radical and fundamentally undermining than works of conscious social criticism" because, in Wood's view, the framing of a horror text as "just entertainment" allows for the relaxation of the psychological "censor" which governs deep-seated ideological beliefs (Britton American Nightmare 13). Similarly, Carol Clover argues that the qualities that locate the slasher film outside the usual aesthetic system that indeed render it, along with pornography and low horror in general, the film category 'most likely to be betrayed by artistic treatment and lavish production values' - are the very qualities that make it such a transparent source for (sub) cultural attitudes toward sex and gender in particular. (22) These critics do not, however, take into account the fact that not all horror, even slasher films, remain on the "outside." A particular type of interpellation occurs with the vesting of cultural capital in horror by curators and scholars. With the acquisition of George Romero's film Night of the Living Dead (1968) and Tobe Hooper's The Texas Chainsaw Massacre by the New York Museum of Modern Art, for example, a place in the "aesthetic system" has been 
established for at least these horror texts. What lies truly outside the "usual aesthetic system," however, are the tastes, knowledge and discourses of the horror fan(g)dom.

Through a critical interrogation of the Gothic consensus, this dissertation argues that a horror fiction is neither necessarily literary nor popular, neither high culture nor low culture, neither necessarily "art" nor inescapably "trash." It does not need rescuing by cultural capitalists. Rather it can be interpreted in a variety of ways and analyzed, like other texts, according to the formal strategies that it deploys, including aesthetic and narrative strategies. Therefore, the conflicts that have raged around, for example, whether The Texas Chainsaw Massacre (1974) is "authentic art," as Robin Wood deems it (Britton 22), or a "vile little piece of sick crap," as Stephen Koch pronounces it, become irrelevant. The distinction between the popular and the literary is, as we have seen, not particularly useful for an analysis of horror fiction in its contemporary form. Horror's designation as a low-status form of cultural production tends to affect judgements of this sort, either in an apologist or a condemnatory guise. This designation invariably obscures horror's ability to manifest itself in varying texts across stratified levels of culture.

Distinctions between the highbrow and lowbrow that outline what forms of horror are culturally acceptable are also necessarily contingent upon the state of the art and the conditions of reception at a particular cultural and historical moment. Judith Halberstam and Linda Badley have both noted that "[fjhe body that scares and appals changes over time" (Skin Shows 8). In addition to the decentering of the Gothic consensus, Chapter Two of this dissertation explores certain shifts in the depiction of horrific cultural iconic figures such as 
vampires and a latter-day updated vampire, the fictional serial killer. Of late, attention has shifted away from these monstrous figures towards the shambling, undead zombie as an iconic monster of our time. These monsters have not remained static in their scariness but have mapped and in turn been mapped onto particular areas of repression and reception. Much of this change has to do, I argue, with fluctuations in taste and the reception of horror as an appropriate medium for conveying certain socio-cultural ideas. I discuss these "genre mutations" as they have appeared through certain monstrous bodies, from the vampire to the serial killer to the zombie. ${ }^{24}$ However, rather than focusing thematically, as Halberstam and other gender theorists have done, upon the compellingly monstrous bodies themselves, I examine the narratives and intertexts that have informed and shaped the affect-functions of such figures.

The chapter begins by examining the vampire as a case study of cultural understandings of and affective responses to generic codes of horror. Under the Gothic killer.

See also Jorg Waltje's Blood Obsession (2005) which links the vampire and serial

${ }^{24}$ In "The Gothic on screen," Misha Kavka notes the transformation from Lugosi's Dracula to the creature portrayed by Gary Oldman in 1992: "For us, however, Lugosi's Dracula has become absorbed into our own culture and serves as an icon of Gothic representation rather than as a figure caught between two worlds; he is thus more pleasurable than terrifying. The "stock" nature of such figures in our time, indicates that the historical and cultural anxieties animating their visualization no longer hold for us. On the other hand, Gary Oldman's Count from Bram Stoker's Dracula (Coppola 1992), when we first see him dragging a bloodied razor across his tongue, produces a much more uncanny effect, for his Dracula speaks to the anxieties and thrills associated with social transgressions that are recognizable to an early 1990s audience" (The Cambridge Companion to Gothic Fiction. Ed. Jerrold E. Hogle. Cambridge: Cambridge University Press, 2002. 209-228, 212). 
consensus, horror is constructed as low-status in opposition to the "New Gothic" which occupies a privileged canonical position. I insist that the distinction between horror and the Gothic seems to be largely made according to the presence and degree of the "g" factor (in this case gore and graphic imagery). "Genre mutations" in horror fiction, I argue, have more to do with the intertextualities celebrated by horror fan(g)dom. Drawing upon the work of Mark Seltzer and Richard Tithecott, which position the serial killer as the emerging archetypal Western monster of the post-war, industrial period, I argue, following Waltje, that certain fictional accounts of serial killers, such as the bestselling Hannibal Lecter novels by Thomas Harris, appropriate a particular affect-function from the vampire as they stylistically expand the serial killer's powers to near-supernatural proportions.

In recent years, the omnipresence of serial killer narratives has in turn been challenged by a figure derived from the zombie films of George Romero, which have been widely imitated by both Italian and Latin American directors and been celebrated by critics such as Wood for their radical, "apocalyptic" quality. While more attention of late has been paid to zombie films, less has been accorded to the proliferation of written zombie narratives, many of which are inspired by Romero's vision of America as wasteland. I will conclude Chapter Two with a brief discussion of the zombie narrative's satirical splatterpunk portrayals of consumer capitalism, using examples such as those found in Max Brooks' recent and hugely successful World WarZ. The figure of the zombie is an ideal archetype with which to consider post-colonial critiques of capitalism, since zombie myths originated in the colonized lands of Africa and the Caribbean. Indeed, the zombie is increasingly a useful metaphor for a contemporary, trans-cultured horror itself: in an increasing spate of horrality-laden zombie narratives that envision hell as other people, "gray" is the new black. 
It must be briefly noted here that "horror" as a label serves to conceal the creep of gory violence into more mainstream and nongeneric productions, including primetime television. This situation contains its own paradoxes. People who will quite happily watch or read about Thomas Harris' famous monster Hannibal Lecter concocting a gourmet repast by the piecemeal scooping-out of the brains of a villainous FBI agent while he is kept alive by Lecter's (Hannibal, 1999, film 2001) surgical skill will also emphatically refrain from viewing more obvious horror films such as the zombie films of Lucio Fulci, even though it might be argued that they are actually much less graphic and gory than the scene from Hannibal. This type of selective rejection, therefore, must be based upon the recognition of horror as a (g) eneric act, rather than any essential element of the text in question and needs to be considered equally as another (g) factor answering to the prevailing hegemonic dictates of taste. $^{25}$

In Chapter Three, I will devote more space to examining the specific narrative strategies and structures of horror short stories, mainly derived from the Anglo-American tradition, but with one or two references to other cultural horror fictions. I have deliberately chosen a wide range of short stories taken from various anthologies produced over the past century in order to demonstrate the recurrence of certain strategies and structures over time. This recurrence is related to horror's close tie with oral storytelling traditions: a tie which it maintains, I argue, far more closely than many other contemporary forms of fiction.

I will relate this particular G-factor to my discussion of the mainstream mutations of vampires, serial killers and zombies in Chapter Two. 
Although scholars of the genre such as Stephen Jay Schneider have opened up horror's international frontiers to Western scholars in such important work as Fear Without Frontiers: Horror Cinema Across the Globe (2003), a collection which examines certain national horror cinemas, there has been little to no scholarship in the comparative area, certainly in the literary realm, and recent social and historical contexts, as well as the ongoing resurgence of what are often called "horror cycles," call for such critical reflection. The question of why horror as a popular form either does or does not appear in diverse cultures is wrapped up with the question of how it might vary in effectiveness according to cultural specificity. Horror is cross-cultural in the very real sense that writers and film-makers are often influenced by horror fictions from other cultures. One notable example is the Japanese writer Edogawa Rampo (Hirai Taro) whose nom deplume is a Japanese verbal translation of the American writer Edgar Allan Poe's name and who wrote a Japanese Tales of Mystery and the Imagination (1956); the very title proclaiming its influence. Yet Rampo's Poe-inspired Tales, as his translator James B. Harris argues, are not imitations of the American author but create a Japanese mystery story tradition "rather than merely copying . . . Western predecessors and contemporaries" (x). Horror, as I have argued, abounds with such examples of the fan-writer and the fan-director. ${ }^{26}$

This cross-cultural aspect of horror reflects the cultural politics of our rapidly changing times: both literally, in the development of new technologies and new special

Another good example is the work of Thai-American writer (Somtow Papinian Sucharitkul) S. P. Somtow, who really deserves a dissertation of his own. 
effects; and figuratively, in the proliferation of ways in which we can or cannot be influenced and affected by horror from other cultures. The possibilities are fascinating and have barely begun to be mapped. Phil Hardy notes in the Overlook Encyclopedia of Horror that the 1960s marked the modern horror film and was also the decade of the emergence of the international horror film on the market. In spite of Hardy's insight, many critics continue to debate texts that, in their view, exemplify the "American Nightmare" as if it were the only form of horror available to readers: an imperial, all-consuming and omnipotent fear that, as Schneider remarks, is constructed as "uni-directional" rather than "in a dynamic process of cross-cultural exchange" ("Bringing It All Back Home"). "Oversight of Others", it is important to note, excludes horror fictions that may not register as such to a North American or British critic who writes about horror from within the parameters of the Gothic consensus, in much the same way as some critics do not regard slasher films or post-slasher horror films as horror because they have a preconceived expectation of what horror can be "about." In Redefining the American Gothic, Louis Gross remarks that "American gothicists do not remove their characters to Italy, Spain, France, or the other centers of English Gothic mystery; they shriek and faint in familiar surroundings and near the readers' own time." (23) This use of familiar settings is not specific to American horror, however, as numerous "foreign" horror fictions, including Canadian texts, work within their own locales while reproducing hybridized versions of "monster narratives" such as werewolves, vampires and zombie apocalypses that have become familiar to global audiences.

In the context of technological advances such as the rise of the Internet, and of socio-economic processes like globalization, which daily shape national cultures for better or for worse, understanding the ways in which cultures may intersect, respond to and adopt 
each other's discursive horror practices takes on a renewed sense of urgency. Fixating upon levels of terror in a meritorious sense, or upon the status of horror either as a genre or as a representation of social anxieties, can blind us not only to the understanding of what a given horror fiction does and how it does it, but also to the increasingly important appreciation that horror as a perennially-changing set of discursive practices may slip in "under the radar," so to speak, of our cultural expectations, thereby achieving its most intense and memorable effects. The success of "J-horror" films such as Ringu (1995) and Ju-On (2000), and Hollywood's subsequent obsession, not only with what Isabel Cristina Pinedo calls the "spectacle of the ruined body," but with remaking these tales of vengeful Japanese ghosts (Ring [2002], The Grudge [2004]), is but one example of how horror may be reproduced and replenished through multiple cross-cultural encounters and migrations within the fan(g)dom. ${ }^{27}$ This dissertation does not aim to provide some "conclusive" and "authoritative" account of cross-cultural horror fictions. Rather, in indicating certain recurring narrative strategies in short horror fiction, it presents a transcultural framework for how such horror fictions might be compared.

In sum, modern short horror stories are fictions that can be understood in a comparative, intertextual context and with reference to what I call fan(g)dom: the discursive practices which define and redefine our responses of fear, repulsion and horrality. The rhetorical strategies, narrative forms and symbolic structures of these horror stories examined by this dissertation take on both cultural specificities and transcultural homogeneity according to how recurring elements of the horror story are used. This

${ }^{27}$ See. Japanese Horror Cinema (McRoy 2005) for some excellent interpretations of Jhorror as well as Fear Without Frontiers (Schneider 2003) and Mondo Macabro (Tombs 1997). 
dissertation demonstrates that short stories are central to the Anglo-American horror tradition and uses numerous examples of these stories to offer an interpretive framework towards a poetics of horror informed by both scholarly and fan knowledge.

\section{2: Overview, Part One: Disputed Definitions of Horror}

One striking characteristic of horror fiction is that although the examples used to illustrate it, generally beginning with the Gothic novels of the eighteenth century, show that we all seem to recognize it when we see it, the meta-discursive question of what horror actually is remains contested. Definitions of horror can vary wildly among scholars and artists in the field, demonstrating perhaps the bewilderment of those who seek to categorize and classify something often regarded as so irrational that it attempts to evade language itself, residing, instead, in more visceral signs (the flow of blood, the knife-wound) or perhaps hinting only at a graphically terminal alienation and the intimation, as Lovecraft put it, of "cosmic fear" (368). Lovecraft himself had a set of precepts for "the really weird" tale, based upon affect and excluding other forms such as "the literature of mere physical fear and the mundanely gruesome" (368), the "Symbolist and Decadent Schools" (392) or "the conte enter (393):

The one test of the really weird is simply this — whether or not there be excited in the reader a profound sense of dread, and of contact with unknown spheres and powers; a subtle attitude of awed listening, as if for the beating of black wings or the scratching of outside shapes and entities on the known universe's utmost rim. (368-9) 
To Lovecraft's distinctions, we should add the more common definitions to be found in the academy. These definitions may allude to the excess which is celebrated in "physical fear and the mundanely gruesome," but this G-factor is ultimately too distasteful. Those who shrink from gory details and graphic imagery are generally in favour of defining horror by an identified underlying source, some amorphous "It" (like Stephen King's shapeshifting subterranean monster in the novel of the same name [7/1986]), whether "It" is modern Western culture's morbid fear of death, theories of the occult or nineteenth-century reactions to unfamiliar practices such as hypnotism. One immediate difficulty, then, when it comes to defining horror, is the decision of whether to emphasize implied horror or obvious horror. This difficulty has been complicated by the appearance of what I would call oversaturated horror, such as the much-maligned "torture porn." 28

Constructions of such categories more often than not fulfill the agenda of privileging one form of horror over another, such as the ghost story over the slasher narrative, the slasher narrative over "torture porn" or the classic horror film over the contemporary. In this process, certain textual strategies are subordinated or ignored in favour of others which serve to support the particular theory of "terror," "dread," or "horror" which is being advanced. Lovecraft, for example, adhered firmly to his doctrine of "cosmic horror," which emphasizes the suggestion of unknown and barely glimpsed forces over the "mere" depiction of "physical horror." However, his writing often derives its affective creation of the former from the gradually revealed depiction of the latter.

See page 71 for a fuller discussion of "torture porn." 
The gruesome and physically horrific story "The Thing on the Doorstep" (1933) illustrates this connection between implied and obvious horror. In "The Thing on the Doorstep," Lovecraft's narrator recounts how his best friend, Edward Derby, is gradually seduced and destroyed by Derby's lover Asenath, a practitioner of forbidden arts and, in Lovecraftian cosmological terms, a degenerate (and miscegenate) worshipper of the Elder Gods. Edward is forced to exchange personalities with Asenath, who borrows his body in order to participate in her unholy revels. This narrative culminates not when the narrator resolves the situation by shooting Edward's Asenath-infested body, a dreadful enough act to contemplate, but rather when the narrator describes how his compulsion to do so originates with die appearance of "the thing on the doorstep," which is in fact Asenath's "rotting carcass," bearing the written injunction to "kill it." The final lines of the narrative describe the contents of the clothes that the hunched and rotting "thing on the doorstep" had been wearing as "mostly liquescent horror" (276-302). In the context of how Lovecraft's story unfolds, the horror of this text is engendered neither through the build-up of subde hints (including Asenath's ability deriving from her father, to possess bodies, and the numerous reports of Edward Derby's changing personality), nor through the "gross-out" technique of revealing the repulsive thing that awaits the narrator upon his doorstep. Rather, all these elements, the hint of horror, the disclosure of horror and the display of horror, intertwine and succeed one another for the overall effect of dread and lurking, incomprehensibly alien Otherness that Lovecraft sought to convey. This is one example to illustrate die problem of definition. In Chapter Four, I will offer multiple examples to show horror's affective techniques at work. 
The oscillation from hint to disclosure, from a fearful whisper to a full-blown scream, echoes Stephen King's assertion that the horror story is "a dance - a moving rhythmic search. And .. . it's looking for what I would call phobic pressure points (Danse Macabre 18). In Danse Macabre (1981), his non-fiction treatise on the genre for which he has become famous as a best-selling author, King argues that horror can best be understood as the more-or-less successfully crafted work that will touch those pressure points. While he calls rigorous definition "a trap," he demonstrates an overly reductive reliance upon the formulations I have criticized above, although his confessed willingness to employ any strategy that works might account for his phenomenal popularity:

The closest I want to come to definition or rationalization is to suggest that the genre exists on three more or less separate levels .... The finest emotion is terror .... It's what the mind sees that makes these stories such quintessential tales of terror .... The horror comics of the fifties still sum up for me the epitome of horror, that emotion of fear that underlies terror, an emotion which is slightly less fine, because it is not entirely of the mind. Horror also invites a physical reaction by showing us something which is physically wrong .... But there is a third level - that of revulsion. (35-36) King calls this sub-level "the gross-out" and defines it as a last resort for the writer of horrific fiction: "If I find I cannot horrify, I'll go for the gross-out. I'm not proud" (37). In Chapter Four, I will have more to say about the "gross-out" affect: the explicit graphic displays of such revolting processes as tearing a body apart (Day of the Dead [1985]); eyegouging (The Wizard of Gore [1968] or any Lucio Fulci film); torture by acid-bath or hot tempura grease (the novel Exquisite Corpse [1996] or Koroshiya Ichi /Ichi the Killer [2001]); or 
brain-eating a la Hannibal Lecter. The gross-out is what many people point to when they either attempt to refute horror's claim to be an art-form or allege that it, along with pornography, has a deleterious "nasty" effect upon society. It is what underlies the revulsion against "torture porn" and, as I will discuss in Chapter Three, the written horror known as "splatterpunk."

Most accounts of horror, including King's, are founded upon the idea that fictional horror is a genre, with formal conventions, typologies of monsters and sub-genres. Such a notion appears to be borne out by the classification systems used in bookstores and the film industry, where the "Horror" sections are populated by familiar authors, directors and movies. "Slasher," "occult," "ghost," "vampire," "(rape)-revenge," "thriller," "zombie," "werewolf: all of these designations may be placed upon a given film in order to situate it within an array of similar texts featuring similar creatures or events. A trip to the local movie rental outlet will confirm that a "horror" section is often clearly demarcated although some distributors such as Blockbuster have shelved their horror sections, placing the films into "drama" and "action" categories. In this move, horror film crosses "into the mainstream" as Phil Hardy's Overlook Encyclopedia of Horror claims that it had begun to do in the 1990s with "repetitive" big-budget productions and sequels (458). Regardless, the generic label of horror persists in studies of the subject.

Sub-generic designations such as "slasher" and "rape-revenge" are used too frequently in film to list all the writers who employ them but, most famously, Carol Clover bases her analysis in Men, Women and Chainsaws upon precisely such distinctions between horror films. In such an analysis, a tale about demonic possession might be regarded as always, on some level, an intertext of the film The Exorcist (1973), which has spawned 
countless imitations across the world with its terrifying, graphic portrayal of a demonic possession and the ravages it wreaks upon the body of the young girl Regan (Linda Blair), who metamorphoses into a pasty-faced, yellow-eyed, guttural-voiced, murderous monster. Many critics have remarked upon this particular serial quality of horror, its ability to produce sequels, spin-offs and copies in an endless chain of reanimation.

Seriality has also become a vehicle of parody as Western society grows familiar with certain horrific conventions to the point of contempt. Lately, the question has become more complicated with the appearance of numerous remakes of horror films. For example, there has been a re-emergence in the twenty-first century of the "monster redneck family" once hailed by critic Robin Wood as a radical vision from the American Seventies in a series of remakes of cult films such as The Texas Chainsaw Massacre, as well as in the lovingly intertextual tributes by fan and horror musician Rob Zombie to those films, House of'1000 Corpses (2003) and The Devil's Rejects (2005). The recent spate of horror film remakes from Hollywood has revived interest in the horror film genre at the same time as it has prompted denunciations of an "exhausted" and over-saturated field. ${ }^{29}$ Setting the commercial appeal of such remakes aside, I would argue that these film remakes signify not so much "exhaustion" in John Barth's sense (1967) but can also be interpreted as performances of fan $(\mathrm{g}) \mathrm{dom}$. The

${ }^{29}$ The outpour of horror film remakes from Hollywood shows no signs of abating at the time of this writing and now includes 1980s films such as A Nightmare on Elm Street $(1984,2010)$ as well as earlier Universal classics such as The WolfMan $\backslash 9 A \backslash$, remake scheduled for 2010). Some of the remakes that have been pouring out of studios in the last five years are: The Texas Chainsaw Massacre (original 1973, remake 2004); The Hills Have Eyes (1977, 2006); Dawn of the Dead (1978, 2004); Black Christmas (1974, 2006); TheAmityville Horror (1979, 2005); It's Alive (1974, 2008); The Last House on the Left (1972, 2009); The Wicker Man (1973, 2006); When a Stranger Calls (1979, 2006); The Fog (1980, 2005); Poltergeist (1982, 2011); Halloween (1978, 2007); Friday the Thirteenth (1980, 2009); and The Stepfather (1987, 2009). 
wistful elitism (not to mention ethnocentrism) inherent in the notion of literary exhaustion also characterizes what Linda Hutcheon calls "fidelity criticism" which measures how well or how poorly the remake or adaptation "lives up" to its "original" according to traditional standards (A Theory of Adaptation 8).

A "fidelity criticism" that focuses upon the verisimilitude of an adaptation in relation to its original conceals the power of intertextuality as a process of audience reception (and the mark of the reader-responsive text) as Hutcheon's example of the Hellboy DC comic series, the Guillermo del Toro film adaptation and the 2004 Yvonne Navarro novelization shows (8). In Fear, Cultural Anxiety and Transformation: Horror, Science Fiction, and Fantasy Films Remade (2008), Scott A. Lukas and John Marmysz identify different categories with which to interpret film remakes: the remake as a nihilistic category demonstrating the futility of the search for an evasive truth (for example, Gus Van Sant's notorious frame-by-frame remake of. Psycho); the remake as palimpsest and technological intervention (for example, demonstrating advances in computer-generated images [CGI] or gore FX in horror); the remake as repetition (storytelling, adaptations of stories and video games); the remake as engaged in a dialogue with its original(s) (Peter Jackson's 2005 King Kong); and the remake as a barometer, measuring fear as indicative of cultural anxieties, which Lukas and Marmysz, like many others, find most intriguing.

Most interesting from a comparative literary perspective are the remakes of texts from Othered cultures, such as "J-Horror" (Japanese horror). Examples include the previously mentioned Bang and Ringu which are film versions of Koji Suzuki's novel Ring (1991). If Rampo is compared to Poe, Suzuki is, according to his publishers, known as "the Stephen King of Japan" (inside jacket copy). It is noteworthy that some of the most 
venerable and well-known instances of written horror partake of this serial intertextuality, endlessly being rewritten, reworked and remade. Jane Austen's Norfbanger Abbey (1818) is a famous example of a text that mocks this tendency to reproduce and exploit the successful elements of a tale of horror. In the following passage, Austen makes fun, through her heroine's love interest Henry Tilney, of the staler conventions of the Gothic novels that had, by her time, been proliferating for a generation, following the huge success of such writers as Ann Radcliffe, Matthew "Monk" Lewis and Harold Walpole. Austen's heroine, Catherine Moreland, the devoted reader of such texts as "Udolpho ... Castle ofWolfenbach, Clermont, Mysterious Warnings, Necromancer of the Black Forest, Midnight Bell, Orphan of the Rhine, and Horrid Mysteries," earnestly asks her friend Isabella, purveyor of the above reading list, "are they all horrid, are you sure they are all horrid?" (35) In demanding that the novels be "horrid," Catherine demonstrates her fan $(\mathrm{g})$ dom. ${ }^{30}$ Tilney humorously comments on her insistence upon casting a "horrid" aspect upon events:

But you must be aware that when a young lady is (by whatever means) introduced into a dwelling of this kind, she is always lodged apart from the rest of the family ... formally conducted by Dorothy the ancient

In her introduction to The Female Gothic, Juliann E. Fleenor writes:

When Jane Austen wrote Northanger Abbey, the Gothic form and its conventions had been popular with women readers for nearly half a century. Austen's parody assumes that her audience is familiar with earlier Gothic novels and, in fact names several. . . which are remembered now for being mentioned in Northanger Abbey (3-4). AH these titles vanished into obscurity relative to the success of the Ann Radcliffe books they emulated, but the "classic" status of Austen's text and the passage of time has since rendered them respectable. In fact, Valancourt Books has recendy proudly reissued the seven horrid titles from Austen's novel, turning Gothic trash into literary treasure. 
housekeeper up a different staircase, and along many gloomy passages, into an apartment never used since some cousin or kin died in it about twenty years before. $(125)^{31}$

Perhaps it was this passage outlining the staler conventions of the Gothic novel which Lovecraft had in mind when he remarked acidly that the immense popularity and resulting "multitudinous and mediocre profusion" of Gothic romances made Northanger Abbey "a by no means unmerited rebuke to a school which had sunk far towards absurdity" (379). Indeed, the enormous success of the contemporary films Scream (1996) or Scary Movie (2000), which flaunt a similarly satirical knowledge of the "rules" of horror-as-genre (in each case, it is the slasher film that is parodied), suggests that Austen's impulse to topple the over-determined cliches of horrific representation is alive and well in our time.

Parody is often interpreted as sounding the death-knell of a particular generic convention. Stephen King describes the "particularly messy and embarrassing way" in which "the great Universal Studios monsters of the Depression days - Frankenstein's monster, the Wolf man, the Mummy and the Count" passed from the sublime to the ridiculous through the fusion of the horrific and comic genres: "Hence Abbot and Costello met the monsters, as did the Bowery Boys, not to mention those lovable eye-boinkers and head-knockers, the Three Stooges" (41-2). Some parodies are more respectful, if equally parasitic, than others.

${ }^{31}$ Austen herself has recently been "adapted" to horrality, given an Extreme Zombie Makeover with Seth Grahame-Smith's parodic Pride and Prejudice with Zombies (2009), cannily marketed as transforming "a masterpiece of world literature into something you'd actually want to read" (paperback back cover copy). In Chapter Two, I call this cycle "gothicization." 
Mel Brooks' Young Frankenstein (1974) pays loving tribute to the James Whale film it mocks to the extent of using actual props and designs from the original (300).

Yet, a case has been made for the horror genre's openness to such parody, at least in film. Scream, for example, managed to be both parodic and an effective horror film in its own right. Philip Brophy's neologism "horrality" was coined to describe the differences between horror films post-1975 and their "more traditional generic" predecessors. Brophy observes that "the modern Horror film ... is involved in a violent awareness of itself as a saturated genre" and exhibits the tendency, often in a grimly funny fashion, to "recklessly copy and redraw [its] generic sketching" (Brophy 277-8). It is interesting to consider how far "horrality" actually diverges from Austen's "textuality, morality, hilarity" in Northanger Abbey, although Catherine Moreland, despite her fondness for the "horrid," is never compelled to experience the actual materialized horrors of her imagination, only social mortifications and trials which end with a rueful, chastened yet happy heroine rather than a bloodied, staring and traumatized Final Girl (Clover 1992).

Brophy points to the Sam Raimi film, The Evil Dead (1982), as a particularly strong example of "horrality": "a gore movie beyond belief that has one simultaneously screaming with terror and laughter." EvilDeads sequel, Evil DeadII (1987), while generally considered not as frightening as its predecessor, delivers one memorable example of parody. The hero, Ash (Bruce Campbell), finds his hand possessed by the demons he has unleashed for a second time: the film's setting in a decrepit and isolated cabin and its formal premise is almost exactly the same as in the first Evil Dead, invoking familiar codes or, in Joseph Campbell's terms, "the magical threshold" which is crossed as soon as the hapless protagonists visit the lonely cabin with its creaking doors in those ominous woods that are 
somehow alive (90). Ash's demon-possessed hand swiftly becomes leprous and cracked in appearance, emits bizarre squeaking noises, and attempts to kill him by smashing plates over his head, knocking him out in some spectacular pratfalls, and dragging his unconscious body across the floor by the fingertips to reach for an axe. At the last minute, Ash regains consciousness and pins his own hand to the floor with a knife, then severs it with a chainsaw in the cabin's workshop. The hand manages to escape from where Ash has confined it in an urn (weighted down punningly, as Pinedo observes, by a pile of books with Hemingway's $A$ Farewell to Arms on top), and scutdes around like a large white rat, launching attacks on him. At one point, it stops and gives him "the finger," emitting a sound resembling the "nyeh nyeh" taunt of the schoolyard bully.

This achingly funny sequence, hailed as a classic example of "over-the-top" horror "splatstick" by Pinedo, following McCarty (Recreational Terrors 47), evokes the "textuality" aspect of Brophy's "horrality," drawing upon a long cultural repository of mains malevolents, beginning, perhaps, with the biblical tale of King Belshazzar and the "writing on the wall," continuing with Lady Macbeth's obsessive hand-washing, and proceeding to the crawling, dismembered limbs in Lovecraft's "Herbert West, Reanimator," filmed by Brian Yuzna as Re-Animator (1985). Horror hands have variously been depicted as Max Schreck's taloned, unnaturally long claws in Nosferatu — Eine Symphonie des Grauens (1921), the clutching, menacing hands of both versions of The Cat and the Canary (1927 and 1939), and of course MadLope or The Hands ofOrlac (1935), starring Peter Lorre and based upon the 1920 novel Les Mains d'Orlac by Maurice Renard, not to mention The Beast with Five Fingers (1946), "that hoary old classic The Monkey's Paw" (King Danse Macabre 34), Dr. Strangelove's creeping fingers (1964), and the stretching, clutching claws of monsters everywhere, including those 
of the zombies bursting through the boarded-up shutters of the farmhouse in Night of the Living Dead (1968). ${ }^{32}$

That the crawling hand in Evil Dead II displays all the sinister traits of its fantastic ancestors is to be expected, given its horrific intertextualities invoking the humour of The Addams Family (cartoon [1938-88], television series [1964-66] and films [1964,1991]), which also used the device of the severed and animated hand in the (literally) bit character "Thing." The parodic peculiarity of Evil Dead ITs hand, however, is that it takes the long-established fantastic potential of its animation to a contemporary and crassly literal extreme by the visual pun of giving "the finger" to its hapless former owner even as it performs the more traditionally villainous tasks of dispatching at least one victim and lending itself to the bloodshed. Such idiosyncrasies differentiate particular instances of the intertext but leave their mark nonetheless on all in the series. For example, the popular "knowledge" that zombies are partial to brain-eating is derived not from the George Romero films that inspired the contemporary apocalyptic zombie narrative but from one of the re-versionings of Romero's films, Return of the Living Dead (1985), based upon a novel by John Russo, Romero's original screenwriter. To the initial definitional issue of horror-as-imaginative-text versus horror-as-displayed-text, therefore, we must add horror-as-gtf/zmV-intertext, a text that is engaged in a constant exchange with its intertextual environment every time it is read or watched anew. This referential quality is evident in such a film as Brian Yuzna's Dagon

${ }^{32}$ For an entertaining column on horror hands, see <http://www.horrorwood.com/digit.htm>. Dr. Matthew Killmeier of the University of Southern Maine has also drawn my attention to an "old-time" radio drama series entitled Hall of'Fantasywhich featured an episode "The Hand of Botar" (aired June 08,1953). 
(2001), a version of the Lovecraft tale "The Shadow over Innsmouth" (1936) that pays tribute to such diverse horror films as A. Nightmare on Elm Street, Night of the Uving Dead and The Texas Chainsaw Massacre, while attempting to duplicate the cosmic fear lurking in Lovecraft's monstrously inbred little fishing village in which outsiders are menaced by halfhuman, half-aquatic creatures who worship the Elder Gods. ${ }^{33}$ Although the thread of the original Lovecraft story is quite evident, resonances of the other films appearing in the forms of a Freddy Krueger look-alike menacing the protagonist trapped inside a car, which he is attempting to steal in order to escape, and hordes of hollow-eyed and ravening Galician villagers emitting inhuman sounds - not to mention their penchant for flaying the faces of their visitors and wearing them as masks a la Leatherface — may be discerned by anyone who is familiar with the horror genre. Such intentional or even unintentional "knowing winks" are, as Kermode writes, one of the chief pleasures of fan(g)dom (60). Thus, the Nazi zombies of Ded Sno (2009) gorily slaughter a victim (whose brain splatters on the floor) who is wearing a Braindead $\mathrm{t}$-shirt which, as a fan on the Horror listserv notes, is the original title of Peter Jackson's notoriously gory Dead Alive (1992). ${ }^{34}$

However, the generic conventions or intertexts of a horror fiction do not account for what horror does. One cannot explain the affective techniques of horror by enumerating familiar generic conventions, although the work of some critics who attempt to do just that

The short story collection Shadows over Baker Street (Del Rey, 2003) mixes Lovecraft's Mythos with the Sherlock Holmes stories, while Hardboiled Cthulhu: Two-fisted Tales ofTentacled Terror, written by James Ambuehl (2006), adds another layer of detective fan $(\mathrm{g})$ dom to the Mythos.

See Chapter Two "Romancing the Zombie," for more on this film. 
comes to mind (see for example Manuel Aguirre's insistence upon the closed space as horror's fundamental convention or Noel Carroll's emphasis on monsters). On the other hand, Victor Sage argues in Horror Fiction in the Protestant Tradition (1988) that "horror is not a literary genre, in the narrow sense, at all," but rather "a cultural response, which implies a broad series of relationships with the whole of the culture in which it is produced. The narrower the conception of genre, the more one is moving away from the possibility of explaining it" (xiii). Such a definition is valuable in that it frees horror from the strict confines of genre and may go some way towards explaining the proliferation of horror fiction in general. It also allows for a comparative approach to horror literature. However, it does not explain the particular manifestations of such a cultural response which can vary so widely from text to text.

Horror is often located by critics within the realm of the fantastic, which, in Alberto Manguel's words, "makes use of our everyday world as a facade through which the undefinable appears, hinting at the half-forgotten dreams of our imagination" (xvii). This is a watered-down classification which one can readily find in bookstores (rather than film rental stores) where horror fiction rubs shoulders with science fiction, sword-and-sorcery novels and all other fiction which is not considered "literary." Although there is much to be said for this broader definition of horror as fantasy, often the lumping together of "fantasy" with "horror" as genetically all-encompassing terms tends to obscure important aspects of the latter: its reliance upon the oral storytelling form, for example, which I will take up in Chapter Three.

Often, too, the unwillingness to associate such a value-laden term as "literature" with the products of a recognised (g)enre-system will serve to isolate those texts. Furthermore, as 
systems of literature are staked out around national parameters, horror and fantasy may bear different names according to national literary canons. Surrealism, magical realism, Southern Gothic, German Expressionism, the Kafkaesque, Japanese anime, Italian giallo narratives and the absurd have all partaken of the stuff of the fantastic as a discourse in contemporary Western culture. Can the fantastic, then, be seen as a universal genre? Or is it a phenomenon that manifests itself differently, and with different degrees of intensity according to the cultural contexts in which it is produced?

Sometimes "dark" is added to "fantasy" as a way of describing horror; for example, in Douglas E. Winter's 2002 biography of Clive Barker entitled The Dark Fantastic, or in the essays on Harlan Ellison and Kurt Vonnegut in The Dark Fantastic. Selected Essays from the Ninth International Conference on the Fantastic in the Arts (1997). Another telling instance is of Don Hutchison's introduction to the first volume of the Canadian horror anthology series Northern Frights (1992-1999). Hutchison insists "I label our series 'dark fantasy' rather than 'horror' not because I'm fond of euphemisms or embarrassed by the depreciated V word but simply to announce a wider range of possibilities" (3). This disclaimer notwithstanding, Hutchison's distinctions between the "top-drawer fiction" in Northern Frights which produces "true shudders" and what he calls the "trash" of "false shocks," "formulaic horror," and "junk-food fiction saturated with nihilism, sadism and adolescent morbidity" speaks volumes about the more tasteful label he chooses as well as the stigmatization of horror-fantasy in the cultural context of the Canadian identity quest which, as Caelum Vatnsdal argues, has privileged the realist documentary tradition as its defining form (11). The ongoing silencing and disciplining of the degraded and degrading, unruly cultural object of horror into smooth, acceptable channels where it is forced to sport more tasteful aliases such as "supernatural," 
"Gothic" or "dark fantasy" leaves horror fiction mired in a perpetual struggle with questions of genre and canonicity.

The boundaries between "dark fantasy" and "the 'h' word" in practice become blurred to the point of meaninglessness, even though the adjective is a reigning signifier of contemporary fiction, including "black" or "dark" comedy and ultra-violent television. The diffusion of horrific elements in the warp and weave of fantastic fictions, indeed, as I stated earlier, the stealthy creep of horror into the "mainstream" of popular culture cannot be ignored, but neither does it give the whole picture. Tzvetan Todorov's structural analysis of the fantastic supports the idea that "the literature of horror in its pure state," rather than belonging to the fantastic, "belongs to the uncanny," which "is not a clearly delimited genre, unlike the fantastic. More precisely, it is limited on just one side; on the other, it dissolves into the general field of literature" (The Fantastic 46-7). Yvonne Leffler has justly criticized both Todorov and Carroll's definitions of horror as being far too narrow, remarking that "[i]f Todorov's definition of "the uncanny" and Carroll's definition of "horror" were to be applied, every horror story in which the unknown or the monster cannot in the end be explained naturally or supernaturally respectively would be excluded from the genre" (19).

Scholars such as Victor Sage, David Punter, Ken Gelder and Judith Halberstam share Todorov's view of horror, arguing that it should be seen less as a genre than as a dissolving discourse that embodies aesthetic representations of cultural anxieties and fears. Todorov also cast a critical eye upon the "naturalness" of the European classification of certain types of fictions (and not others) as "literature" (5-16). In "The Notion of Literature" Todorov begins with the structural definition of literature as a fiction, tracing its development back to a point "somewhere in the eighteenth century" when the aesthetic 
category of the beautiful heralded the ascendancy of "intransitive, noninstrumental" Art, "defined by its nonutilitarian [sic] nature." Criticism of the literary text, according to traditions established in the eighteenth century, has thus been inextricably bound up with the sense that it must conform to the beautiful. Then, "later on" (Todorov does not say when but implies that the shift coincides with the ascendancy of Formalism in the early twentieth century), "the term beautifulwas replaced by form, which in turn came to be replaced by structure" (5). Horror, then, is by this definition anti-literary in the traditional sense of the term as it does not conform to the harmoniousness demanded by classical standards of beauty. Its structures, however, as I will show, are worth examining.

Todorov proceeds to examine key Formalist definitions of the "literary," mentioning Rene Wellek's distinctions between the "literary," "everyday," and "scientific" uses of language, as well as Northrop Frye's distinction between centrifugal and centripetal textual orientations. Again, it is easy to see where a "low" non-literary value of horror might come in. As Hills observes, echoing Fish, horror is a text that does something to its reader. It produces an undeniable response and so cannot be theorized as an "inward" (centripetal) direction of meaning. Horror is one of Clover's "body genres" that Linda Williams identifies in "Film Bodies: Gender, Genre, and Excess." Producing a response on the part of its readers and audiences is central to its discursive practice. Williams suggests that this may be why horror - a "fear jerker" rather than a tearjerker (5) - is regarded with such suspicion; "what may especially mark . . . body genres as low is the perception that the body of the spectator is caught up in an almost involuntary mimicry of the emotion or sensation of the body on the screen" (4). 
The work of feminist scholars such as Williams who have approached horror films is an instructive case study of how complicated and yet how important defining horror can be. Integral to feminist definitions of horror has been a struggle with horror's use of violence and pain. The problem that Pinedo sets herself in Recreational Pleasures, for example, is to untangle the relationship between horror and feminism, which has often seemed to entail a skeptical if not downright hostile approach to the former as replete with depictions of victimized women: "My short-lived response to this quandary was to boycott the genre" (2). Eventually, Pinedo, as a formerly "closeted female horror aficionado," to borrow Rhona J. Berenstein's phrase (4), returns to the enjoyment of horror "in good conscience." Her task then becomes to explain (account for) women's guilty pleasure in horror through "gynesis," excavating potentially feminist horror films such as The Stepfather(1987).

With Pinedo, I face the reconciliation of frowned-upon tastes with feminist principles; however, unlike her, I want to resist essentializing formulations such as the following, in which she makes the case for justifying female pleasure in certain horror films that she has defined as "postmodern":

Postmodern horror compels its heroes, many of whom are women, to both exercise instrumental rationality and to rely on intuition; it requires them to be . . violent and to trust their gut instincts. As such, postmodern horror defies the Cartesian construction of reason that reduces it to instrumental rationality and pits it against emotion and intuition. (25)

As Pinedo implies, "instrumental rationality" cannot always be distinguished from "emotion and intuition" on the level of the text. When one is suddenly grappling with the "beast" of Henry James's The Turn of the Screw, or cowering in a cellar, menaced by the 
hideous Dr. Freudstein in Lucio Fulci's The House by the Cemetery (1981), rationality and emotion collide and collapse. On the level of the experience of the horror text, unless it explicitly foregrounds and interrogates gendered binaries, as does the clever Canadian Third Wave feminist horror film Ginger Snaps (2000), such meditations are largely meaningless. It does not follow that this binary-bending is why women in particular are drawn to horror, and we ought to be suspicious of any account that outlines an essentially female response. As Berenstein shows, the widespread critical assumption that a rare female patron of classic horror would "cower in fear" is faulty (2). It is equally faulty to presume that all women are going to cheer on their post-Cartesian onscreen sisters and forego the pleasure of performing either fearful responses or what Kermode has described in gendered terms as a type of macho endurance of horror. Horror's appeal for women could equally well lie in the fact that 'gender itself is often placed sous rature by the immediacies of how the horror text may be experienced. When heroines (and heroes) are dealing with pressing dangers such as ridding themselves of ravenous zombies, predicting the course of a deadly menace or confronting the shocking beast that has been hitherto unrevealed, gender becomes part of the play of horror's narrative technique, which takes immediate and enthralling precedence.

The contemporary obsession with what Pinedo calls "the spectacle of the ruined body" (51) creates a significant debate among feminist critics. Some scholars view contemporary horror, and the slasher film in particular, as inherently misogynistic, drawing upon Laura Mulvey's celebrated exposure of the male gaze. In her classic essay "Visual Pleasure and Narrative Cinema" (1975), Mulvey argues that traditional cinema reflects men's status as "bearer of the look" and "builds the way" that "a woman is to be looked at into the spectacle itself. . . cinematic codes create a gaze, a world, and an object, thereby producing 
an illusion cut to the measure of desire" (346-351). This formulation of the male look as essentially active and the female image as inevitably passive is used by Linda Williams in order to argue that, when 'the woman' looks at horror, she invariably "is punished ... by narrative processes that transform curiosity and desire into masochistic fantasy" ("When the Woman Looks" 15). Williams argues that the reason that women don't look at horror is because "they are given so litde to identify with on the screen" (15). According to her application of Mulvey to horror film, the woman "exists only to be looked at" and has no agency, but can only hide "behind the shoulders of. . . [their] dates."

Williams' account allows no possibility for women to engage in horror fan $(\mathrm{g})$ dom without their (male) "dates" present. Her generalization rules out many women's experiences with horror films, including my own first encounter with A Nightmare on Elm Street (1984) during an all-female sleepover where I cowered, not behind the shoulders of a date, but behind a heap of entangled pajama-clad legs attached to giggling, squealing female friends who pelted each other with junk food during Freddy Krueger's rampages. Brigid Cherry has conducted research of female horror fans who "refuse to refuse to look" that also critically interrogates such sweeping assumptions. Perhaps these stereotypes of women's relationship to horror fictions drive female horror fans into the "closet," as Berenstein puts it, where they can only emerge within a habitus such as the Horror in Film and Literature listserv elsewhere described by Laity. Hills notes the importance of fan autobiographical accounts of encounters with horror, such as the one I have just provided. For Hills, again, this "selfaccount" is simply a performative bid for subcultural capital, or a description of how knowledge of horror has been accumulated, a "position-taking" on the part of an ungendered or otherwise differentiated fan which serves to distance the knowledgeable adult 
fan from "the culturally feminizing spectre of horror as fear provoking" (77-78). For a woman, particularly a feminist, and even more so if she is racialized or otherwise marginalized within a culture, horror fan $(\mathrm{g})$ dom is not always a comfortable fit, no matter how much theory one applies.

A sense of squirming discomfort with horror is very clear in Williams. Following a lengthy argument that makes ample use of Susan Lurie's writing on pornography, Williams suggests "that the monster in the horror film is feared by the 'normal' males of such films in ways very similar to Lurie's notion of the male child's fear of this mother's power-indifference" (23). She grudgingly admits that in "a sense," her monolithic woman may find visual pleasure in her recognition of the monster's "similar status as potent threats to a vulnerable male power" (23). But, despite the interesting questions about "tear jerkers" (melodrama) and "fear jerkers" that are raised in her other essay on horror film, "Film Bodies: Gender, Genre and Excess," Williams's pronounced (and performed) distaste for the genre is always agonistic, being "jerked" around by the film's narrative and imagery which remain mired in the inevitability of the psychoanalytic gaze.

Pinedo has criticized the heterosexist and over-generalizing assumptions that inform Williams's opening statement about audience's and women's behaviour at horror movies, arguing that "Williams fails to recognize the pleasure of not-seeing" and, I would add, the alternating pleasure of peeking from behind shoulders or pillows at the crucial moments. ${ }^{35}$ She goes on to accuse both Williams and Tania Modleski, who also equates horror with

${ }^{35}$ Dennis Giles writes at length about this phenomenon in his essay in Planks of Reason, rather tellingly describing the reactions of his ex-girlfriend to horror film. I will discuss this essay in greater detail in Chapter Four. 
pornography, of wrongly assuming "that the female viewer derives no comparable pleasure from the contemporary horror film since female mutilation and murder figure so prominendy in the genre" (70). However Pinedo herself resurrects Williams' pornography comparison in her use of the term "carnography" and her assertion that "if pornography is the genre of the wet dream, then horror is the genre of die wet death" (61). The word "carnography," which she attributes to Richard Gehr, is intended to highlight "this very carnality which relegates hard core and gore to the status of disreputable genres . . both are disreputable genres because they engage the viewer's body . . . elicit physical responses such as fear, disgust and arousal in indeterminate combinations, and thereby privilege the degraded half of the mind-body split." While this point is well taken, echoing arguments advanced by Joan Hawkins, and putting the (g) back in fan $(\mathrm{g})$ dom, I will argue that fear is not necessarily always a "physical" response and cannot be so simply equated with pornography (which, I will hazard to remark, may also not be so obviously "split" between mind and body). In any case, fear (physical or otherwise) is not usually the subject of pornography and the two cannot be equated without missing the point of what horror does and how it does it.

Carol Clover also follows Mulvey, citing both Poe's "famous formulation" that the most "poetical topic in the world" is the death of a beautiful woman and Hitchcock's comment during the filming of The Birds (1963) that he believed in "following the advice of the playwright Sardou. He said, 'Torture the women!'" (42). The abundance of tortured women in horror does not mean that horror can always be reductively viewed as a particularly loathsome example of the male gaze which feminists must shun. Critics such as Clover, Pinedo and Halberstam do allow for horror fan(g)dom for women: that is, they 
defend the ability of women to enjoy "recreational terror" which may or may not take the form of "gore" or "splatter." ${ }^{36}$ However, their theories ensure that questions linger and remain about the morality of such pleasures.

I do not mean to imply that gender concerns are irrelevant to the analysis of horror fiction. Some of the most celebrated and thought-provoking critical thought on horror has centred upon such concerns, as we have just seen, and feminist theoretical contributions such as Clover's are central to the field. However, the theories of identification that have informed so much feminist criticism on horror need to be themselves informed by a greater respect for the texts themselves and a greater concern for horror's status as fiction. For example, to return to Pinedo's claim diat the pleasures of horror fan(g)dom for women are derived from a woman exercising both rational and emotional faculties, I would argue that it is not so much diis balancing act that produces pleasure (although the implication does recall Samuel Johnson's notorious analogy of the dog walking upon its hind legs in all its offensive reductio ad absurdum). Many compelling horror fictions, which have, let us not forget, also been created and produced by women, bypass the Cartesian binary altogether. Horror achieves this defiance by providing abundant examples of what Barbara Creed has called "the monstrous feminine," as well as the harried and hunted heroine. In this sense, the focus

${ }^{36}$ In fact, all kinds of potentially (potent) feminist horror archetypes, such as the "vengeful goddess" or "the madwoman in the attic" surface in horror if one is not simply looking at slasher films. This colourful array is considerably enriched by recent work on international horror film (Tombs, Schneider) that adds such figures as the Japanese whitefaced vengeful ghost to the pantheon of fascinating and powerful monstrous feminines. Poppy Z. Brite's "Calcutta: Lord of Nerves," for example, appropriates Hindu mythology to makes such a figure out of the already rather horrific Hindu goddess Kali. The postmodern, pubescent lycanthropes of Ginger Snaps and the Salvadoran siguanaba (discussed at the conclusion of this section) are only two of the possible additions to their numbers. 
by feminists upon women not as active fans of the horror text but as passive consumers who merely "identify" with slashed victims rather than participating boisterously in fan(g)dom and producing (slashed) horror fictions of their own, serves to efface some of the most important strategies of horror texts.

This reductive focus is probably due to the concentration of feminist critics and their audiences upon a particular type of horror fiction, the slasher or serial killer film, now somewhat dated, strait] acketed in its "low" cultural asylum, and thus an easy target for what Hawkins has criticized as overly "literalist" feminist readings. Hawkins convincingly underlines the similarity between low-brow slasher film and 'high' art's "metaphorical" violence against female bodies, arguing that the high-brow gets away with murder while all eyes are upon the low, which she calls "para-cinema" (Cutting Edge 195). The temptation to stop at gendered readings of what Halberstam has called "bodies that splatter" (punning of course on Judith Butler's Bodies that Matter [1993]) is difficult to resist, particularly as horror's plays upon gender are so obvious and so entertaining. Although Carol Clover includes sections on the occult film and also on the rape-revenge narrative in Men, Women and Chainsaws, the popularity of her "Final Girl" theory of slasher films eclipsed her work in other areas and established the slasher film as (North American) horror to the exclusion of many other, potentially more interesting sub-genres. ${ }^{37}$ For example, one noteworthy genderbased study of horror film reception by researchers Justin M. Nolan and Gery W. Ryan has yielded interesting results about what plot elements of horror resonate most with male and

Written horror, which contains its own slasher narratives, is doubly excluded by the "Final Girl" theory. 
female audience members. Their study concluded that "rural terror," "a concept tied to fear of strangers and rural landscapes," tended to leave lasting impressions on male viewers, whereas "females display a greater fear of family terror, which includes themes of betrayed intimacy, stalkings and spiritual possession" (39).

Despite an intriguing result indicating that the female subjects of their study reported a higher fear response and the concluding connection of this result with power-control theory, Nolan and Ryan ultimately "screen out" anything about the texts under discussion other than that they are a collection of gendered "themes." Thus, they quote Carol Clover's definition of the slasher film as one in which a psycho killer "slashes to death a string of mostly female victims, one by one until he is subdued or killed, usually by the one girl who has survived" as if that is all one needs to know about slasher films. In such a study, horror texts become not only homogeneous, but homo-generic. Their individual features do not much matter as they are called upon to perform a gendered and genre-d show. Clover's synopsis is therefore presented as the essential metanarrative of the slasher film. One does not even have to view the distasteful thing for oneself before moving on to the study's findings. While Clover's work on gender and the slasher film is justly acclaimed as pioneering, this brief synopsis cannot be good enough to establish and accurately measure responses to horror texts - gendered or not - without incorporating other aspects of the texts under consideration and without acknowledging that there is more to horror fiction than gender performance.

The important point that it is impossible to effectively sum up the horror genre has been made by Stephen King in his fairy-tale encapsulations of "some of the scariest movies 
ever made" (Danse Macabre 179), for example, in the summary of Night of the Uving Dead (1968) which follows:

Once upon a time a lady and her brother went to put flowers on their mother's grave and the brother, who liked to play mean tricks, scared her by saying "They're coming to get you, Barbara." Except that it turned out they really were coming to get her . . . but they got him first. (177)

As King implies by this simplification, such synopses of theme and plot cannot produce sufficient understanding of why and how these movies evoke the responses that they do. Returning to my example, I note that Nolan and Ryan focus their research upon differentiation in gendered responses, and a certain amount of "screening out" of each text's individual elements becomes necessary. But considerations get lost here that ought to be vital to their study. For example, how do the particular (re)presentations of these tropes of "rural" and "family" terror contribute to their respective impacts upon males and females? Does the presence of a stranger or stalker guarantee the responses they describe? Are there gendered aspects to the experience of being frightened itself? Thus, the ability of a horror text to engender multiple, diverse and often pleasurably contradictory reactions among fans, readers and audiences by virtue of its affective and contextual elements, becomes either neutralized by scholarly distance or simply "screened out" by the critic who refuses to give these elements any "play." As Hantke aptly puts it, "[i]t is not the horror text that silences the critic, it is the critic who silences the horror text" (n.pag.).

In this process of disciplining and silencing horror fictions, horror written by women, such as, for example, the terrifying short stories of Joyce Carol Oates and Patricia Highsmith, goes unremarked and unacknowledged, with the possible exception of Anne 
Rice whose bestselling novels have become distanced from die horror genre (Rice's own gender is less remarked on dian die queerness of her vampires). So too do the more obviously horrific narratives of Shirley Jackson, Elizabeth Bowen, Patricia Highsmith, Suzy Mckee Charnas, Tanith Lee, Kathe Koja, Jane Yolen, Lisa Tuttle, Chelsea Quinn Yarbro, Nina Kiriki Hoffman, Melanie Tern, Canadian writers Nancy Kilpatrick and Nalo Hopkinson, as well as the Gen-X Goth splatterpunk trilogy of Poppy Z. Brite, Caitlin Kiernan and Christa Faust, to name only a few women in the field. Written horror has, as Gelder notes (2000) been completely subordinated to film in even very recent critical accounts and this is perhaps why so much horror produced by women does not get any scholarly attention ("play") as a heavier emphasis is directed toward the film industry where women are in a drastic minority on the other side of the camera. While this dissertation does not focus upon gendered readings of horror fictions, I do wish to redirect some attention to the women who write horror fiction against the grain of much scholarship which seems to worry endlessly and solely about the portrayal of women as texts within horror. The $(\mathrm{g})$ in my fan $(\mathrm{g}) \mathrm{dom}$, then, also invokes gender.

In her cinematic study Cuffing Edge: Art-Horror and the Horrific Avant-Garde, Joan Hawkins takes up Williams's intriguing theory that the "emphasis on affect" is what "characterizes ... a low cinematic culture" (4). For Hawkins, horror effectively destabilizes the boundaries between detached "high" art and affective "low" culture, deploying a politics of aesthetic reception that reveals again, the critics silencing the texts, a pitfall of assigning "literary" value which I will strive at all times to avoid. Critics such as Jeremy Dyson are guilty of this practice by associating certain strategies of horror with a more "classic" sensibility of horror as art-form, and thereby nostalgically attempting to construct a Maginot 
line of demarcation between the subtleties of "classic" horror film and the excesses of today. Dyson argues that the horror film in the good old days, before it fell victim to its own success and became exploited as a B-grade venture, used to occupy a far more dignified position in the ranks of studio production. Yet Dyson's selection of films, which revolves around one particular cultural moment (that of Universal Studios during the nineteen-thirties and forties) is somewhat arbitrary and, when it comes to assessing the text's ability to evoke fear, overly subjective.

Furthermore, adopting Dyson's perspective entails that only those works of horror graced with expensive production budgets, canonized actors, and extensive marketing procedures, not to mention being located firmly in a "golden age," should be considered as worthy of critical attention. It is far more interesting and plausible to see merit, in terms of horror, as that engendered in the reader's or audience's response. In so doing, I will be paying attention to what is really at stake: the ability of texts and their intertexts to evoke fear through narrative and rhetorical strategies, and the reader's / audience's interpellation of that fear. As noted previously, Stephen King writes that horror, much like the zombie in the graveyard which opens Night of the Living Dead, "wants to get you" (176). The means by which horror "gets" its readers may well establish it as low, non-literary culture. For the purposes of this dissertation, such strategies deserve analysis, not simply generic designation.

Asserting that "the literary genres, indeed, are nothing but. .. choices among discursive possibilities, choices that a given society has made conventional" ("Notion of Literature" 10), Todorov theorizes a "typology of discourses" rather than an opposition between literature and non-literature: "in place of literature alone we now have numerous types of discourse that deserve our attention on an equivalent basis" (11). As such, he 
follows Northrop Frye in opening up the possibility for studying non-conventional, nonliterary genres such as horror that can fruitfully be compared with other texts obeying other discursive conventions. I join other scholars in asserting that horror fiction and horror art in general constitutes a viable field of serious study by literary scholars. Unlike many other scholars, however; including the growing numbers of those who take a "friendly attitude towards popular art," as Tarda Modleski puts it (164), I shall not, as I stated in my introduction, attempt to "rescue" horror fiction by employing the privileged discourse of the fantastic.

Designating horror fiction as dark fantasy tends to obscure the unsettling link between horror and cultural anxiety, made apparent earlier in my discussion of Henry, Portrait of a Serial Killer in which a fictional film blurs the boundaries between horror fictions and the cultural politics of representation. Defining horror as only the "dark side" of fantasy, a nightmare rather than a sweet dream, is to retreat yet again before the very stuff of which horror's subject is constituted. Furthermore, however dark it may be, the word "fantasy" retains a relatively benign sense, which can equally be used to describe an escapist fiction that is not meant to be taken seriously. Fantastic worlds are imagined as a long and venerable tradition in many cultures, but how do we account for the proliferation of "dark fantasy" in a world which is itself depressingly and often horrifically absurd, as contemporary forms of grimly futuristic realism, from A Clockwork Orange (1962, film 1971) to Trainspotting (1993, film 1996) endlessly seem to claim? Stephen King writes that he is frequentiy asked: "Why do you want to make up horrible things when there is so much real horror in the world?" (26). He wryly remarks that, indeed, 
with such neatokeeno things to deal with as Dachau, Hiroshima, the Children's Crusade, mass starvation in Cambodia, and what happened in Jonestown, Guyana, it becomes evident that "the human consciousness can deal with almost anything. . . which leaves the writer or director of the horror tale with a problem which is the psychological equivalent of inventing a faster-than-light space drive in the face of $\mathrm{E}=\mathrm{MC}^{2}$. (115)

Another way of putting it paraphrases Theodor Adorno: what can horror be "after Auschwitz"? Our headlines are full of the material that Jonathan Lake Crane called "the terror of everyday life" (1994) so how do we distinguish between fictional horror and reallife horror? What does fictional horror become in such a world and what cultural work does it do? Characterizing horror as but one form of the fantastic evades this problem, drawing clear and timeless lines of demarcation between the text and the world. Other critics such as Crane and writers such as King have very deliberately mapped the text onto the world, arguing, for example, that horrific fiction is a way of coping or catharsis practiced upon the horrors of real life in order to render bearable what Jonathan Lake Crane, quoting J. G. Ballard, calls "the terrifying void of a patently meaningless universe" (Crane 5). In such a universe, death and dying lose their sacred meaning and become frightening, senseless events. William Peter Blatty's novel The Exorcist (1971) invokes this terror of random senselessness and meaninglessness by juxtaposing, as Nick Cull observes, "a succession of quotations showing contemporary evil at work":

These include an extract from a FBI wire tap in which a gangster jokes about torture and murder; a graphic account of Communist atrocities against priests, teachers and children from the writings of Dr. Tom Dooley, an 
American doctor who worked in Vietnam in the 1950s; names that evoked the Nazi extermination of European Jews: Dachau, Auschwitz and Buchenwald. (46-51)

Such horrors have become part of the world's collective awareness with the rise of the contemporary mass media. As Paul Virilio has theorized, mass media and telecommunications entail that we now inhabit a speeded-up "real time" where the possibility of a "general accident," the sudden catastrophic event that is the flipside of new technologies, has lost all connection with perceptions of past, present and future, and, unlike Auschwitz, serves not as a historic marker of past atrocities that must never be forgotten, but instead ushers in what he calls the "global accident":

[n]o technical object can be developed without in turn generating "its" specific accident: ship=ship wreck, train-train wreck, plane=plane crash. The accident is thus the hidden face of technical progress .... With the current world-wide revolution in communication and telematics, acceleration has reached its physical limit, the speed of electromagnetic waves. So there is a risk not of a local accident in a particular location, but rather of a global accident that would affect if not the entire planet, then at least the majority of people concerned by these technologies ... It is apparent that this new notion of the accident has nothing to do with the Apocalypse, but rather with the imperious necessity to anticipate in a rational way this kind of catastrophe by which the interactivity of telecommunications would reproduce the devastating effects of a poorly managed radioactivity - think about Chernobyl. (92-3) 
Virilio specifically mentions $9 / 11$ as an instance of the "global accident" that he has theorized: die aftershock of $9 / 11$ created many cultural reflections of that accident, reviving disaster and war film genres, subverting the image of America as an invincible and infallible superpower, and Americans as "the good guys," particularly in the American horror films that are not remakes of Other-cultured texts. In my next chapter, I relate the notion of the "global accident" to apocalyptic horror fictions depicting outbreak and zombie hordes overrunning humanity. ${ }^{38}$

The tendency to conflate reality with horror fiction has most recently cropped up in the label of "torture porn" applied to gory films such as the Saw series (2004-9) and the Hostel films (2005, 2007). "Torture porn" was a term originally coined by New York Magazine film critic and self-confessed "horror maven" David Edelstein in 2006 to describe Hostel, Wolf Creek, The Devil's Rejects (all appeared in 2005) and other recent films in which "explicit scenes of torture and mutilation" occur (n.pag.). Tellingly, Edelstein implies that torture porn is a foreign import: these scenes "were once confined to the old 42nd Street, the Deuce, in gutbucket Italian cannibal pictures like [CannibalFerox] Make Them Die Slowly [1981], whereas now they have terrific production values and a place of honor in your local multiplex." The

38 "Depending on the time and the latitude, the multitude of bodies with no soul, living dead, zombies, possessed, etc., is imposed all throughout history: a slow-motion destruction of the opponent, the adversary, the prisoner, the slave; an economy of military violence likening the human cattle to the ancient stolen herd of the hunter-raiders, and by extension, in modernized and militarized European societies, to the soulless bodies of children, women, men of color and proletarians" (Paul Virilio, Speed and Politics, <http://www.newmappings.net/archives/category/books $>, 76)$. 
implication is that "gutbucket Italian cannibal pictures" may be acceptable to "Others," but why, Edelstein puzzles, would average Americans want to wallow in this deviant stuff instead of just depraved horror fans who are by implication equated with Others / foreigners.

"Torture porn" has arisen, Edelstein suggests, as a cultural reaction to the debate sparked by photographic evidence of Americans torturing Iraqi prisoners at Abu Ghraib:

Post-9/11, we've engaged in a national debate about the morality of torture, fueled by horrifying pictures of manifestly decent men and women (some of them, anyway) enacting brutal scenarios of domination at Abu Ghraib. And a large segment of the population evidendy has no problem with this. Our righteousness is buoyed by propaganda like the TV series 24 , which devoted an entire season to justifying torture in the name of an imminent threat: a nuclear missile en route to a major city. (n.pag.)

Hills mentions Stephen King's designation of "real horror" as "the six-o-clock news" on television (Danse Macabre 212), asking us to consider that many horror texts blur the boundaries between "real" (factual) and "unreal" (Active) events. He makes the important point that "fictional horror's tropes, devices and discursively assumed affects play a material and cultural role beyond their usually perceived parameters" (130). For Hills, the news may operate as a horror "para-site" in that news stories, such as those covering the events of September $11^{\text {th }}, 2001$, can assume the "aesthetic structures of fictional horror" while texts 
such as Dahmer (2002), Ed Gein (2000) and, as I have argued, Henry, blur the boundaries between the "cultural categories" of factual biopic and fictional slasher film. ${ }^{39}$

In addition to Hills' account of "true horror," we might also recall Cathy Caruth's theory of "trauma" in Unclaimed Experience: Trauma, Narrative and History. Trauma as a concept bears some relation to horror in that it affords insight into "the story of a wound that cries out, that addresses us in the attempt to tell us of a reality or truth that is not otherwise available" (Caruth 4). By linking trauma to "what is known, but also to what remains unknown in our very actions and our language," Caruth opens up the possibility of studying horror's evasive and yet revelatory style as not only a "para-site," but as a language of the traumatized representation of horrific realities. Part of the cultural work of horror, then, is to brutally and repetitively expose trauma's wound, insisting upon nightmarish realities in the face of all attempts to suppress them. This theory allows us to identify elements of horror in the fictions that reflect such nightmarish realities. I will illustrate this claim by comparing two fictional versions of historical horrors that are not conventionally read as horror fiction, beginning with D. M. Thomas's The White Hotel (1981). This novel incorporates the story of

In my next chapter, however, I will argue that fictional narratives of serial killers often stylistically expand the serial killer's powers to near-supernatural and omniscient proportions hitherto only enjoyed by more conventional horror monsters. This is a move which may fuel a fan $(\mathrm{g})$ dom characterized by fascination with "true crime" narratives that Hills examines as another neglected aspect of pleasure in horrific serial killer narratives. The exceptionally graphic violence perpetuated by titular narrator Patrick Bateman in Bret Easton Ellis' American Psycho is read as a metaphor for the sociopathic predations of capitalist Ubermenschen on Wall Street in Ronald Reagan's America. However, Bateman's ability to carry out his horrific deeds with perfect impunity is not only an ironic nod to the elevated status of Wall Street super-predators, it also situates the text, as I argue in Chapter Two, within a related context of the supernatural slasher-killer who can appear magically and survive every imaginable attempt to defeat him. 
Dina Pronicheva, survivor of the Babi Yar atrocity in Kiev on September $29^{\text {th }}$ and $30^{\text {th }}, 1941$, one of the largest mass murders of the Holocaust. Thomas's narration of the atrocity is a retelling of the story that Pronicheva related to Anatoly Kuznetsov, the Russian writer who subsequently documented it in his book Babi Yar a document in the form of a novel (1970) which was heavily censored by the Soviet regime before being published in the United States. Kuznetsov, who writes at the beginning of his documentary novel that he has been compelled to constantly write and rewrite, in keeping with Caruth's theory of trauma, the story of Babi Yar "knocking at my heart":

The word 'document' which appears in the subtide of this novel means that I have included in it only actual facts and documents, and that it contains not the slightest element of literary invention — of what 'might have been' or what 'ought to have been.' (17)

The White Hotel'as a pastiche of Kuznetsov's document, Pronicheva's story and Freud's case histories, creates a haunting juxtaposition between the narrations that circle the clairvoyance of the main character Frau Lisa Erdman / "Anna G." (diagnosed by Freud as suffering hysteria), the mysterious pains in her left breast and ovary, and her murder at Babi Yar at the hands of the Nazis who brutalize her body in precisely those places. The horrific passages recounting this fate are taken almost verbatim from Pronicheva's story, as if Thomas were surrendering control of the narrative at this point, in order to convey that this historic horror, this trauma could only be recounted again and again in the words of its witness. Following the novel's publication, Thomas was castigated for exceeding the "resources of his own imaginative recreation" by using Pronicheva's testimony almost verbatim (Kenrick). Since then, he has been celebrated for producing what Linda Hutcheon 
calls a "historiographic metafiction" (1989 3). Thomas's appropriation of Pronicheva's testimony increases the horrific affect of his character's situation, in keeping with the uncanny events of his novel, in order to impress more forcefully on the reader what happened at Babi Yar, evoking Kuznetsov's relegation to literature of "what might have been." While Alvin Rosenfeld condemns the cruelty of Lisa Erdman's rape and murder as evidence that Thomas is mining "the documentary literature of the Holocaust" for "morbid sexual phantasies" (raising the spectre of torture porn), I suggest that, if we recall the cultural work that horror can perform, directing the gaze towards atrocity with the expectation of a certain response, it becomes easier to appreciate Thomas's reasons for such painful elaborations. $^{40}$

Another example of using horror to convey real-life atrocity is the Salvadoran Manlio Argueta's One Day of Life (JJn Dia en la Vida 1980, translated 1983). Argueta's novel reverses Thomas's technique of using documented testimony by underscoring the unspeakability of the state-sponsored atrocities that occurred during the twelve years of civil war between die popular FMLN-led guerrilla movement and the U.S.-backed oligarchy whose National Guard and paramilitary forces murdered, tortured and disappeared thousands of Salvadorans with complete impunity. One Day ofUfe is a complex series of narratives which center mainly around Guadalupe Fuentes, an inhabitant of the besieged rural area of Chalatenango, a stronghold of the resistance. The day culminates with the capture and torture of her

${ }^{40}$ Rosenfeld includes a table comparing Pronicheva's testimony with Thomas's fiction in "Perspectives on the Holocaust in Current Literature" at the Simon Wiesenthal Centre's Museum of Tolerance Online at http://motlc.wiesenthal.com/ site/pp.asp?c=gvKVLcMVIuG\&b=394989. Accessed December 2, 2009 
husband, Jose (Chepe) Guardado, who appears finally in a mutilated and barely recognizable state, dragged out by the death squad and displayed to Lupe and her grand-daughter, fifteenyear-old Adolfina, who must deny knowing him in order to not be murdered themselves (the Guard is also interested in Adolfina's activities). Lupe's narrative is interspersed with the narratives of others: Maria Romelia Ramirez, a twelve-year old girl who participates in a demonstration which turns into a massacre; Adolfina, who is raped by the guardsmen; and Maria Pia Hernandez, Lupe's daughter and Adolfina's mother, whose husband Helio is savagely beaten and 'disappeared' by the death squad. The last we hear of him is a horrific account of his torture, sadistically told to Maria Pia by William, a boy who "likes to accompany the Guard .... like a mascot" (69).

In counterpoint to the stories of these women, an(0)ther voice appears, which is described variously as "The Authorities" and "Them," and which may or may not come from "Ticha's son," a local boy who becomes a guardsman and who is turned against his own people by the "gringo" who trains him to "defend the country against its enemies even at the expense of our own brothers .... The trainer shouts, 'Who is our worst enemy?' And we shout, 'The people!'" (92) ..$^{41}$ This chilling monologue, which describes the guardsman's training in a military camp (possibly the infamous School of the Americas in Fort Benning, Georgia), is the only other male narrative apart from Chepe's account of his terrifying

The guns that the Guards carry, courtesy of the millions of U.S. dollars in military aid that went to the authorities during the Reagan years, are described by Lupe as "monsters" (195): "The worst are those monsters they carry on their shoulders. These are the famous automatics they talk about.... These people are very serious. They're studying to be President. And how can they fail, with monsters that 'shoot a ton of lead a minute,' as Jose says" (81). 
encounter with the Siguanaba. The legend of the Siguanaba is that a beautiful but conceited woman named Cihuehet was punished by the rain-god Tlaloc for neglecting her son. She is cursed to lurk by rivers and on lonely roads, washing her garments, and she lies in wait especially for solitary men who have been drinking or cheating on their wives. ${ }^{42}$ She appears to them in the shape of a lovely woman, which is how Chepe at first sees her: "Her hips, a clay pot filled with fresh water. Her dimples were deep enough to hold marbles. Her eyes shone brightly, like velvet or the eyes of a snake" (182). The Siguanaba pretends to be lost and lures the man away to the river's edge, where she suddenly changes into a horrible monster who has the power to induce madness. As Chepe narrates it, this encounter is genuinely frightening, unfolding gradually to a moment of pure shock:

And then, while I put my hand there where she keeps her two turdedoves, she speaks to me in a different voice, almost like another person: 'You see, I am the daughter of darkness.' .... Then I noticed a light shining through her hair, like light from the eyes of a cat... I, believing in my imagination or in the beauty of her eyes, ask her: 'Why do your eyes shine so much?' 'You should see how they look in the dark,' she tells me .... 'Well, let's go where it's dark to admire them,' I tell her .... And as she walks calmly toward the cliff, she says: 'That's nothing, look at my litde fingernails.' I suddenly saw the longest fingernails I had ever seen .... And then she tilted her head back,

${ }^{42}$ The Siguanaba can be compared to the monstrous maternal ghosts or "bad mothers" of many other cultures who appear in their horror fictions, including the Malaysian pontianak and penanggalan, the Indian churel, the Scottish bean-nighe, the German Lorelei and the Irish banshee, as well as the Mexican 1M Llorona. Like most of these creatures, the legend recounts that she haunts watery places such as coasts and the edges of rivers. 
uncovering her face which had been covered by her hair: there were no beautiful dimples, she was as pale as death. Immediately I let her go because I felt her suddenly become icy cold. At last she says: 'And that's nothing, look at my teeth.' I suddenly saw the biggest teeth I'd ever seen in my life. No sooner had I heard her laugh than I shit in my pants right there. She ripped open her blouse and screamed at me: 'Here are your tits, here are your tits!' I don't know how I didn't turn into stone .... (187-88) ${ }^{43}$

The unmistakable jolt this tale of the Siguanaba gives the reader is amplified in the next chapter, when the National Guard arrive with Chepe's battered body:

Four guardsmen got out dragging the man, pulling him as if he were a sick animal. He was so disfigured, you couldn't even see what he looked like, because of all the blood covering his face and drenching his shirt and pants . ... It wasn't until I got close that I realized it was you, that you had your face covered with blood, and I could see that one of your eyes was tattered, one eye that had observed the life around here, because the eye was showing, it was hanging out. (190)

${ }^{43}$ For online versions of the story of the Siguanaba in Spanish, see www.cipotes.com/rincon_guanaco/leyendas/sigauanaba.asp orwww.angelfire.com/ md3/kafan/leyendas.htm. These stories are very similar to Argueta's version. Significantly, the legend of the Siguanaba is doubly repressed in that she is a Native American/Mayan legend, appearing not only in El Salvador but also in Guatemala. It is possible that, for a Salvadorean, this aspect of the Siguanaba doubles her meaning as the "voice of conscience," like the Cadejos, another Salvadoran legend who appears to Lupe at the beginning of the novel. The Cadejos (a good one) appears to Lupe in the first chapter as a salvation figure, a "voice of conscience" which warns her away from a rattlesnake: "Well, it was the Good Cadejos because instead of scaring people he gives them a kind of confidence. They say that when the Bad Cadejos comes out, he makes you feel like pissing, by just looking at you (17). 
In her anguish, Lupe invokes the imagery of horror once again:

My body turns to ice as I see you transformed into a piece of meat bitten by dogs, because I could see your body through the rips in your clothes, looking as if they had grabbed you and growled at you, pulling off chunks of flesh, sucking your blood. These vampires, sons of a hundred thousand whores, killers of the dirtiest stripe. (191)

Adolfina, faced with this sight, defiandy tells the guardsmen: "If you don't have anything else to do, if you have enjoyed giving all of this abuse, you may go eat the gendeman you have hanging there" (194). After the "vampires" have taken Chepe away, Lupe's grief takes the form of remembering the stories that her husband used to tell, recalling,"my favourite is the one about the Siguanaba. And you should hear it at night." Lupe informs us that Chepe's oftrecounted encounter with the Siguanaba "was the story of his life" (189). Here, horror is situated within a tradition, "the world we know," and becomes, as I argue in Chapter Three, a tale signifying the importance of oral narrative to horror that can be incorporated into a community of belonging. Lupe recounts "how happy Jose gets at die center of a circle of people listening to him. More than anything" (207). But the encounter with the Sigunaba is also die story of Jose/ Chepe's death, as we have seen.

The mythical tale of meeting the monster, therefore, mingled with the other, more realist narratives from men and women, functions as a horror story that at once magnifies and masks the pain of speaking of atrocity, the sign of the trauma that, as Noam Chomsky and Edward S. Herman noted, was a politically "inexpressible" truth (59). Thus, the real-life horror of the death squads is juxtaposed with the apparition of $\sim$ La Siguanaba, in a tale that is ultimately far from pleasurable. Lupe in recalling her childhood memories of being afraid of 
La Siguanaba muses on this seeming contradiction, "I don't know why we have to live off such fears. The little light of hope that lives in you, maybe. The unknown always prompts us to seek the truth .... [tjhose mysteries facilitate life, but so do real things" (144). Lupe's final awakening to the fact that the "real things" may be as terrible, if not more so, than the "mysteries" comes when she beholds her mutilated husband. Horror in this text is pervasive, arising from the border between the narration and the understanding of a traumatic event, invoking what defies knowledge; what those who have not been subjected to such atrocities cannot possibly understand but struggle to, nonetheless.

If, as Robin Wood argues, "[w]hat escapes $r<$ ?pression has to be dealt with by oppression" (8), perhaps it is time to rethink horror as something that lurks at a particular border, which can only be crossed by experiencing some measure of fear. While it is important to be mindful of making claims that horror can be "universal," it is also important to hold out the possibility for cross-cultural understandings of fictions that employ such "real-life horror" even though it is risky to attempt such border-crossings. For example, Charles Larson writes of Sembene Ousmane's short story of slavery and oppression "Black Girl" that it would "horrify" Africans but probably not register as such with "our society [that] has worked so hard to neutralize the shock of death." Larson opines that "[w]hat we really mean when we talk about universal experiences in literature are cultural responses that have been shaped by our own Western tradition .... For better or for worse, each of us was born into an ethnocentrically sealed world" (64-5). Against this rather pessimistic view, I will set the idea that horror, as it is employed in texts such as The White Hotel And One Day ofUfe, actively works through its affect to galvanize "the shock of death" into a response that remains neither distant nor complacent. From a comparative perspective, then, it becomes 
more important to study horror fiction as horror, not as an outpost of the Gothic tradition. For this reason, and others, I take issue with the Gothic consensus in the pages that follow.

\section{3: Overview, Part Two: The Gothic Consensus}

Within the academy, horror's relationship to horrific realities is commonly discussed using the language of the Gothic as, for example, in Victor Sage and Allen Lloyd Smith's introduction to what they call The Modem Gothic, in which they claim that the literary declension of terror is an inevitable response to the atrocity exhibition of the twentieth century, just as it was for the writers of the late eighteenth and early nineteenth centuries as they confronted the social, economic, and political instabilities of a new order, and the mayhem of a revolutionary period .... It is the horror now that is real, and the resolution that is fanciful. Hence the peculiar effect we sometimes find, akin to the dropping of a stone through a spider's web, when the actuality of realisation of the horrors of contemporary life strikes through the web of highlighted representation. (5)

I argue here that the rather beautiful metaphor of the spider's web can also become a trap in that, seeking to find the world in the text, the equally fascinating problem of horror's affects becomes obscured by the encroachment of what Lovecraft, echoed by Hills, called the "intent... to teach or produce a social effect, or one in which the horrors are finally explained away by natural means" ("Supernatural Horror" 368). Stephen King uses a different insect metaphor in decrying the temptation to read every horror fiction as an allegory, likening horror fictions to specimens which are captured and dissected by "college 
and university professors, those lepidopterists of literature who, when they see a lovely butterfly, feel that they should immediately run into the field with a net, catch it, kill it with a drop of chloroform, and mount it on a white board and put it in a glass case" (Danse Macabre 255). ${ }^{44}$ The "incredible shrinking man" of Richard Matheson's classic 1956 novel of that tide, who eventually must battle the black widow spider that assumes fearsome proportions in relation to his steadily diminishing form, might warn us that establishing the species of the spider or what it represents through the kind of analysis which calls for scientific classification will not make it go away.

Thinking of horror as merely an allegorical representation of society also brings up the question of the frequent and vociferous hostility that critics have demonstrated towards horror. Far from presenting any kind of "resolution" to social problems, horror is often resolutely tragic. It often presents the worst possible conclusion to a narrative, far worse than one could have imagined, which has created both a fan $(\mathrm{g})$ dom that embraces horror's relendess pessimism as a radical overthrow of the established order and an opposition that

Although King loves to take swipes at the academy, elsewhere describing how "a great number of the people who are sitting at the long and groaning table of Graduate Studies in English are cutting a lot of invisible steaks and roasts .... not to mention trading the Emperor's new clothes briskly back and forth" (292), he does confess to using at least one "pompously academic metaphor" in his own analysis of horror as a "Dionysian" disruption into an "Apollonian" situation (368), which Nietzschean approach bears remarkable similarities to the myth criticism of Northrop Frye or Joseph Campbell. While much of King's resentment of "the more exalted circles of literary criticism" might be justified, given that horror had indeed been treated like a "pariah dog" (164), it should be said that, since the publication of Danse Macabre, many thoughtful articles and, more recently, collections and books on horror have been published. The fact that most of these are in the field of film studies, and that few of them have actually paid any attention to what King had to say on the matter, perhaps supports his and other writers' contention with respect to the institution of academic criticism itself. This dissertation is in part an attempt to remedy that problem. 
blames horror fictions for every social ill. Theories of horror abound which seek either to claim for it some subversive quality or to roundly condemn it as ultimately oppressive. In this section, I will examine some of these theories, in addition to those I have already mentioned, in light of the most prevalent critical discourse regarding horror's origins, its "subversive" or "oppressive" powers and qualities and the cultural work it is thought to perform. I call this discourse the Gothic Consensus.

Most Anglo-American literary studies of contemporary horror situate it within and subordinate it to the Gothic tradition: thus, contemporary horror becomes, as we have seen with Sage and Smith, the "New Gothic" or "Modern Gothic." ${ }^{45}$ Such a position, I argue, has a flattening effect upon the field, falsely attempting to legitimate horror in the name of a master narrative of literary value. In film, as I stated from the outset, the "H-word" is used far more frequently and with far less embarrassment. Despite the scant attention paid to certain aspects of horror, the fields of Gothic studies in literature and of horror studies in film are vast and both are enjoying surges in popularity, which may, as we shall see, have something to do with the context of a saturated awareness of horrific realities that I mentioned at the conclusion of my previous section. I will confine myself here to mentioning some of the broader underlying assumptions of that field as well as some of the texts and theories which have been central to creating important varying perspectives.

${ }^{4}$ Hills identifies two main approaches, cognitive and psychoanalytic, to academic studies of horror. In fact, taking the Gothic consensus into consideration, textual interpretations may also fall under one or more of the following categories: historical, feminist and literary. Yvonne Leffler's interesting survey of scholarship in the field divides it into how formal vs. thematic elements are stressed: e.g. Punter and Aguirre focus on thematic elements, as do psychoanalytic critics (16). 
There is a general historicist consensus existing among most scholars who study Anglo-American horror fiction and film that horror originates in the late eighteenth century, with the appearance of what David Punter calls the "classic" English Gothic novels such as Horace Walpole's The Castle ofOtranto (1764), Ann Radcliffe's The Mysteries ofUdolpho (1794) and Matthew Lewis's The Monk (1796). (Punter 61-98) Lewis' gory and complicated narrative of intrigue, lust, and demonic seduction that scandalized his contemporaries, is frequently cited by those who define horror as being primarily characterized by elements of the supernatural, such as Noel Carroll, who writes in The Philosophy of Horror "Of greatest importance for the horror genre proper was the supernatural gothic, in which the existence and cruel operation of unnatural forces are asserted graphically" (4). Similarly, Punter writes that "almost all the Gothic writers used the fear of the supernatural for one purpose or another" (11). Punter also draws our attention to material factors such as "the eighteenthcentury change in English social structure and the associated development of the reading public." According to Punter, "the appearance of a trading middle class and the growth of urban centres combined to produce other potential readers," meaning readers $(0)$ ther than the nobility, although he cautions that the high cost of books at that time entails that "Gothic fiction should not be characterized as a popular literature in the sense which we would now recognize" (23-25).

Both Carroll and Punter list various artistic influences that contributed to the emergence of the Gothic novel, including the sentimental novel, graveyard poetry, the German Schauer-Roman (terror-novel), the French roman noir, and English medieval poetry. These novels have sometimes been described as a challenge to the emphasis that the Enlightenment placed upon reason and rationality, which accounts for their aesthetic 
counter-emphasis upon the supernatural, and emotion. Laura Mulvey links the Gothic to the Freudian concept of repression, arguing: "The Enlightenment, illuminating the dark relics of religious belief with science and reason, banished ghosts and other terrifying manifestations only to have them crowd back through the culture of the Gothic" (51). The Gothic "cultural emphasis" on the supernatural, whether "explained supernatural" or "accepted supernatural," as it has been classified by some scholars, is thus a challenge to realism, the dominant discursive and aesthetic mode of the Enlightenment (Punter 22).

Horror, then, insofar as it is seen to originate as a genre in the Gothic, might be viewed as literally a modern counter-culture that presented, above all, a challenge to a certain dominant Western worldview privileging the masculine rationality and Cartesian dualism that the Enlightenment established. This view is what I call the "Gothic consensus," which holds firstly that horror art is best described as "modern Gothic," and secondly, that horror art retains its dominant characteristic of "unreason" in confrontation with hegemonic "reason" (which is what makes it so popular and political). To cite Mulvey again: "[ujnreason, silenced through the Enlightenment period, erupts into the fantastic art of Sade, Goya and horror fiction" ("The Pre-Oedipal Father" 47). In other words, the Gothic, to paraphrase Carroll (58) is the return of the Enlightenment's repressed.

Because of these eruptive and disruptive powers, the study of the Gothic and, more recently, horror fiction, insofar as it is classified as Gothic fiction, has been important to

${ }^{46}$ See, for example, Rosemary Jackson, Cynthia Freeland, Noel Carroll, Victor Sage and Allan Lloyd Smith, Joan Copjec, Terry Casde and Jose B. Monleon in The Horror Reader (2000), and Valdine Clemens in The Return of the Repressed (SUNY, 1999). Carol Clover also has a variation of the repressed hypothesis in her one-sex, two-sex model (see below). 
feminist-deconstructionist projects which seek to criticize and undermine "phallologocentric" Enlightenment narratives, the subversion of which has become a popular and privileged discourse in postmodernist theory. Cynthia Freeland, for example, discusses the appeal of Gothic horror as a counter-discourse to "eighteenth-century concepts of the natural and the unnatural" which "evolved within new paradigms of humans' roles in the cosmos ... [scientific rationality required a masculine disciplining of wild rebellious Nature - often through the exploitation of new technologies" (27). This understanding of the Gothic as a historical form which can be traced through the characteristic conventions of its anti-Enlightenment stance has led some critics to distinguish more recent horror fictions from the Gothic altogether.

Peter Hutchings argues in "Tearing Your Soul Apart: Horror's New Monsters" that "it is more useful... to consider Gothic as a distinctive mode which influences a wide range of cultural forms while horror ... is best seen as a genre, a much more narrowly circumscribed area of cultural activity" (Modern Gothic 89). Hutchings claims that the new horror movie monster (Freddy Krueger from the Nightmare on Elm Street series or Pinhead from Clive Barker's Hellraiser series) partakes of the Gothic mode while simultaneously representing a more "paranoid" and less "secure" form of horror. Freddy Krueger, unlike Gothic monsters who represent the haunting recurrence of the past, is characterized by an absence of desire and feeling (although his apparent indestructability does involve a blurring of boundaries between the human and the supernatural. . . In this respect [he] is more like the zombie, another movie monster which lacks any notable precursors in eighteenth- and nineteenth-century Gothic fiction. (94) 
Hutchings comments that the seriality of the Nightmare on Elm Street franchise permits a constant and open-ended play between more "traditional" Gothic elements and newer "paranoid" horrors where Freddy continues his inexorable return at the close of every Nightmare, signalling yet another sequel in the works:

In the context of this open-endedness, what the references to Freddy as a vampire or Wanderer permit is the projection of the monster into a world of 'secure' horror where he becomes manageable, this in turn enabling the narratives in which he appears to be brought to satisfactory conclusions. Because on a very fundamental level Freddy is not actually a vampire or a Wanderer but instead much more a creature of paranoid horror, this ostensible solution to the threat he poses can never be totally effective. (96) A significant variation on the Gothic consensus comes from Judith Halberstam, who like Hutchings, focuses on monsters but who argues that Gothic monsters as opposed to "mad monks, haunted castles, and wicked foreigners" only begin to appear in the nineteenth century and that therefore "the emergence of the monster within Gothic fiction marks a peculiarly modern emphasis upon the horror of particular kinds of bodies"(3). Employing the term Gothic in an innovative and highly specified way as "a technology of subjectivity," Halberstam contends that, "from the late eighteenth century to the nineteenth century, the terrain of Gothic horror shifted from the fear of corrupted aristocracy or clergy, represented by the haunted castle or abbey, to the fear embodied by monstrous bodies" (16). Halberstam's "monstrous bodies" result from a re-location of modern discipline from the body to the soul: "in the Gothic, crime is embodied within a specifically deviant form — the monster - that announces itself (de-monstrates) as the place of corruption" (2). However, 
Halberstam's texts, which include the "usual suspects" or what Stephen King in Danse Macabre refers to as "the Tarot hand" (61) of horror (Dracula, Frankenstein, Dr. Jekyll and Mr. Hyde) do not offer much to clarify how her "technology of subjectivity" might work for other monstrous bodies, skin shows and places of corruption in non-canonical horror literature.

Noel Carroll also finds it "difficult to confirm . . . that the horror novel represents something like the underside of the Enlightenment." While Carroll allows that the emergence of the horror genre "overlaps with the period that cultural historians call the 'Enlightenment' or 'The Age of Reason'," he observes that, "if the relation of the horror novel to the Enlightenment is initially one of conflict, one wonders about whom the subjects who suffer this conflict are" (56). In accordance with his influential cognitivist theory of horror, Carroll proposes instead that perhaps the Enlightenment "supplied the horror novel with the norm of nature needed to produce the right kind of monster." For Carroll, the skeptical, scientific standards created by the Enlightenment forces fantastic creatures to inhabit the pages of fictions rather than superstitious reality: "[wjhere a reader operates with a cosmology in which witches, demons, werewolves and spectral forces are part of reality . . the sense of natural violation that attends art-horror is unavailable." (57)

Such a shift towards fictional monsters also lies, implicitly, at the heart of Todorov's structural formulation of the fantastic, which occurs "in a world which is indeed our world, the one we know [my emphasis], a world without devils, sylphides, or vampires" as "an event which cannot be explained by the laws of this same familiar world" (Todorov The Fantastic 25). Carroll's paradigm of a shifting "norm of nature" locates the affect of horror, envisioned as the reader's encounters with monstrous beings, within the familiar Aristotelian concept of 
catharsis. Carroll's version of catharsis is "art-horror," and he explicitly states that he will "try to do for the horror genre what Aristode did for tragedy." The issues surrounding horror's appeal are described by Carroll as "paradoxes of the heart":

With respect to horror, these paradoxes can be summed up in the following two questions: 1) how can anyone be frightened by what they know does not exist, and 2) why would anyone ever be interested in horror, since being horrified is so unpleasant? (Carroll 8)

Carroll's term art-horror "names the emotion that the creators of the genre have perennially sought to instil in their audiences" (24). The framework of art-horror, painstakingly sketched out, is designed to address both paradoxes and is valuable in that it draws attention back to the construction of the text itself and away from psychoanalytic or historical determinants. However, Carroll substitutes cognitive determinants for the former and follows the common tendency to lump all horror fiction into a formulaic genre, even to the point where he claims that he has concocted a "recipe" for making monsters, a la Victor Frankenstein. This tendency infuses his theory with a particular kind of hubris that distances the real subject of his investigation - the paradoxical horror fans, readers or audience members - from their experiences of the text qua text. In remarking jovially that "any old monster X can be plugged into the formula," Carroll ignores the far more interesting implication contained in his assertion that when these monsters "cease to be threatening, they cease to be horrifying" (Carroll 28). ${ }^{47}$ As a result, the appeal of horror, Carroll's paradox, is fatally undermined and no pleasure is left for the reader within the text itself. An

${ }^{47}$ Carroll's hypothetical monster, "The Green Slime," is far from frightening, if only because Carroll persists in repeatedly underscoring its absurdity. 
important critique of Carroll's cognitivist theory appeared in Gilberto Perez' The Material Ghost: Films and their Medium (1998) in which Perez argues that such an account of horror suffers, if not from empiricism, from what may be called 'commonsensism,' an unchallenged rule of the commonsensical that would have kept Galileo from ever discovering that all bodies . . . fall to earth at the same rate ... I tend to be skeptical of psychoanalysis . . . but I am more skeptical of commonsensical explanations that would lay claim to everything. (20) Matt Hills offers an excellent overview of the many critiques of Carroll's theory in The Pleasures of Horror (2005). While Hills praises Carroll's approach" as "economical [because] it works across media, explaining horror novels as well as it explains horror films," he also mentions the many theorists who, like me, find Carroll's monster-centric "account" too narrow, insisting that "serial killers and 'realistic' monsters must be admitted" as well as Mark Jancovich's contention that the "victim" position is more central to the horror text than the monster (Hills 15). Hills's own critique of Carroll is similar to mine in that he observes that fan pleasure as well as "audience 'fascination' with monsters" is notably absent because "vampires, ghosts, zombies and werewolves are, far from violating cultural categories, exactly what we expect to encounter within the cultural category of the horror genre" (16). Further, Hills points out, Carroll ignores the intertextual and genre-saturated nature of horror fans' responses to texts:

For example, horror film audiences may take pleasure in the appearances of certain, well-known genre actors such as Peter Cushing and Christopher Lee in Hammer films . . . where cognitive processes would not be entirely narrative based, nor indeed fear and disgust based. Instead, pleasures taken in 
relation to horror texts could be based on appreciation of a star's performance and / or charisma (and this need not imply that the audience member is necessarily a fan, academic, critic or connoisseur of horror). (17) However, Hills argues that this missed "aspect of horror film" is due to the fact that "Carroll's theory aims to account for horror across different media" and, in so doing, misses the intertextual possibilities and "specialized responses" that can also exist for horror novels and short stories. Hills also notes Carroll's dismissive stance towards his subject, making horror into "a type of failed philosophy or metaphysics": this dismissiveness, Hills argues, leads the concept of "affects" "significantly astray" (19).

Another philosophical analysis of horror, Cynthia Freeland's The Naked and the Undead (2000) is concerned with the relationship of horror films to "our reflections on evil and its allure," employing a cognitivist-feminist framework which defines horror's affective function as a combination of emotions (fear) and intellect (our understanding of what is evil). Such an approach does have the merit of taking into consideration, at least implicitly, the rhetorical strategies of horror beyond Carroll's "recipe" for monsters. Although she diverges from his situating of the monster at the centre of horror fiction and also from his concept of art-horror, Freeland similarly situates her definition of horror firmly within the "Western aesthetic tradition," arguing that, like ancient Greek tragedies, horror films are works that involve disturbing an audience. They are 'difficult' works with a kind of negative aesthetic aim. Tragedy, according to the classical account of Aristotle, aims at evoking pity and fear, whereas horror aims to evoke fear, terror, disgust, and other associated emotions. (5) 
Freeland argues for the perspective that horror can "often question the traditional values and gender roles associated with patriarchal institutions such as religion, science, the law and the nuclear family" even though she warns that "the feminist message seems qualified" by horror's overt victimization of women. However, she shares my concern about the reductive pressures that certain kinds of feminisms exert upon texts: "I seek to avoid universalizing assumptions about gender as I ask how a given film depicts gender in relation to its larger themes about good and evil... I consider psychoanalytic feminisms to be theoretically illgrounded and too reductive" (Freeland 4).

Freeland thus criticizes Julia Kristeva's influential concept of abjection, which has been taken up by Barbara Creed in The Monstrous-Feminine: Film, Feminism, Psychoanalysis (1993), as well as Mulvey's concept of the male gaze which, as we have previously seen, was taken up by Linda Williams to analyze horror film. Freeland usefully avoids psychoanalytic determinism in that she elevates the "individuality of critical reaction from the audience" over the generalized "viewer's allegedly primal motives" emphasized by Williams and Creed. Sources of horror, she argues, are not necessarily always synonymous with the "castration anxiety" invoked by being the possessor of "the gaze," just as they are not necessarily synonymous with the gooey, pre-Oedipal stage of Kristeva's abject:

Psychoanalytic feminist film interpretations are significantly constrained by the theoretical vocabulary and framework of psychoanalysis. Psychoanalysis is not only very internally divisive but it is far from achieving anything like general acceptance as a psychological theory . . . typically in film studies, psychoanalytic interpretations are advanced a priori rather than in an openminded spirit of testing how well they actually work .... The notion of 
abjection in Creed's interpretations expands to become almost vacuous. It is simplistic and reductive to understand in advance that all the varieties of horrific monstrousness we can think of or witness on film are really just "illustrations" of the "work" of abjection .... In what sense is a psychological theory of abjection 'explanatory' when it becomes so broad?

Like Pinedo, Kermode and Hills, Freeland takes the audience and the fan into consideration, citing Ed S. Tan's work on "cinephilia" and film as an "emotion machine" to argue for the distinctiveness of horror fans as an audience and a particular group as "participatory. We may clap, laugh uproariously, or otherwise respond in surprising ways to things that we recognize as allusions, in-jokes, or sight gags, while our more weak-stomached friends . . . find the movie frightening or simply disgusting" (7). Freeland, along with many others in the field, cites Carol Clover's gender-bending and ground-breaking Men, Women and Chain Saws: Gender in the Modern Horror Film (1992). She regards Clover's theory of the "Final Girl" in slasher movies as an example of a deep, Irigarayan "disruptive reading" of horror that resists such determinism (14-15) and attempts the same approach, as does Halberstam, with Silence of the Lambs (1991), a canonical text for feminist psychoanalytic horror theories.

With varying degrees of appreciation, as I have demonstrated above, feminist scholars have examined what Freeland calls the "gendered concepts" of earlier 1960s and 1970s slasher and rape-revenge films such as Halloween (1978), The Texas Chainsaw Massacre (1974) and I Spit On Your Grave (1978). Clover's book has been particularly influential in the re-visioning of these sub-genres by making room in psychoanalytic criticism for "crossgender identification" in the viewer's gaze at the figure of the "Final Girl," or slasher 
survivor. In order to explain this gender opposition, Clover resurrects Thomas Laqueur's interesting concept of a "one-sex model": "sexual difference as we officially know it — the 'two-sex' or 'two-flesh' model. . . has not existed from time immemorial but is a relatively modern construction that sits, in fact, rather lightly on large sectors of the culture." This "slippage and fungibility, in which maleness and femaleness are always tentative and hence only apparent" was "displaced" in the late eighteenth century, according to Clover, with the strict division of male and female categories (13-14). Yet the retention of the one-sex model in "the popular mind" has resulted in the popular genres of horror and science fiction:

Horror may in fact be the premier repository of one-sex reasoning in our time (science fiction running a very close second) .... The one-sex model is echoed not only in horror's bodily constructions ... it is also echoed in its representation of gender as the definitive category from which sex proceeds as an effect. (15)

In essence, Men, Women and Chainsaws is a powerful argument that modern horror cannot simply be reduced to female victimization since, in many cases, the slasher film concludes with a "boyish" kicking, screaming, fighting woman who triumphs over her pursuers, the occult film features men "opening up" to feminine forces of "Black Magic" as opposed to 'White Science," and the rape-revenge film explores the most graphic instances of 'getting even.' In Clover's version, however, the horror film viewer is still always gendered male, vicariously enjoying a temporary masochistic position as a slasher victim who is still always gendered female because of 'her' crying and cowering. Clover cautions:

[tjo applaud the Final Girl as a feminist development... is, in light of her figurative meaning, a particularly grotesque expression of wishful thinking. 
She is simply an agreed-upon fiction and the male viewer's use of her as a vehicle for his own sadomasochistic fantasies an act of perhaps timeless dishonesty. (53)

My horror fan(g)dom questions why Clover would open up this wonderful territory for female horror fans by insisting that a horrified subjectivity may be fluid, only to cede it yet again to the ubiquitous, sadomasochistic male fantasy? Still, Clover's emphasis upon horror's dynamic effects and how its consumption may construct varying positions of identification, not to mention her exuberant, detailed and insightful readings of given films, greatly expands the range of available interpretations to feminist scholars such as Pinedo, and joins the more celebratory readings of horror that take up the threads we have explored so far that employ the dynamism of horror - what it does, rather than what it merely symboli2es - to claim that it is a direct attack upon the more frightening structures that govern everyday life.

Wood and Lippe's collection American Nightmare (1979) still remains the most ambitious and interesting articulation of this hypothesis, although, since the authors build a theory of the American horror film on "the increasing confluence of Marx and Freud" in the "recognition that social revolution and sexual revolution are inseparably linked," it does not break with certain psychoanalytic premises of horror. Rather, it is an unabashed polemic against Lacanian psychoanalytic film theory of the kind that has appeared in the journal Screen. In the introduction, Wood writes:

I want to indicate briefly a possible alternative model [to Lacan], developed out of Freud by Marcuse and given definitive formulation in a recent book by Gad Horowitz [....] It is the crucial distinction between basic and surplus repression that is so useful in relation to direct political militancy and so 
suggestive in relation to the reading of our cultural artifacts (among them our horror films), and through them, our culture itself. (7)

This distinction between basic repression and surplus repression echoes that of LeviStrauss's 1969 distinction between the "raw" and the "cooked" as well as Marcuse's distinction between the restricted and general economy. ${ }^{48}$ Basic repression is "what makes possible our development from an uncoordinated animal capable of litde beyond screaming and convulsions into a human being; it is bound up with the ability to accept the postponement of gratification," while surplus repression is what is "specific to a particular culture and is the process whereby people are conditioned from earliest infancy to take on predetermined roles within that culture" (7). Wood produces a long list of surplus repressions, all based on the repression of sexual energy (where he does not deviate significantly from Freud), and argues that what is repressed "must inevitably return" in the form of the Other /the monster (10). ${ }^{49}$

Wood and his co-authors, Andrew Britton, Richard Lippe, and Tony Williams, focus on specific texts, such as The Exorcist (1973) and George Romero's Night of the Uving Dead

4 Horror's "excess" may be related to George Bataille's idea of "the accursed share" (La Part Maudite, 1949). For example, Stephen King insists it is difficult to frighten people whose bellies are full. See also Jean Baudrillard's The Transparency of Evil: essays on extreme phenomena (1993) for his theorem of the accursed share.

49 The monster / Other, Wood argues, can variously be seen as: other people; women; the proletariat; other cultures; ethnic groups; alternative ideologies or political systems; deviations from sexual norms and children. Horror might be said also to function at the level of basic repression since it also postpones gratification and invokes primal punishments. This is a factor that Wood et al. do not consider because their definition of horror functions strictly at the surplus level, serving to differentiate their more materialist theory as intended from other psychoanalytic theories of horror. 
(1968) as well as its sequel, Dawn of the Dead (1985).$^{50}$ While they may disagree on the merits of individual texts, the authors share several tenets in common. They agree that horror is based upon repression, that what is horrific is "the return of the repressed" and that horror can be evaluated ideologically in terms of what is repressed. This evaluation is accomplished by looking at what has been rendered monstrous, because "what escapes ri?pression has to be dealt with by oppression" (8). Finally, the authors agree that horror since the 1970s has moved historically from a "classic" phase to an "apocalyptic" phase that renders it "the most important of all American genres and perhaps the most progressive, even in its overt nihilism" (17).

Against the "progressive" horror film, then, the authors of American Nightmare pit the "reactionary" horror film, which is defined as upholding the norm and reaffirming the dominant discourse of patriarchal and capitalist values. The Omen (1976), for example, is classified as "reactionary" according to several traits: the "designation of the monster as simply evil"; "the presence of Christianity"; the inhumanity of the monster, and the "confusion ... of repressed sexuality with sexuality itself." On the other hand, the grotesque, cannibalistic family members in Tobe Hooper's cult film The Texas Chainsaw Massacre (1974) "only carry to its logical conclusion the basic (though unstated) tenet of capitalism, that people have the right to live off other people" (22).

The designation of some horror fictions as essentially "reactionary" in their concerns echoes Stephen King's assertion that "the writer of horror fiction is neither more nor less

${ }^{50}$ There is also a comparison by Wood of "Der Er/konig" (both Goethe's poem and Schubert's music) with contemporary horror, which emphasizes the "continuities within the development of Western patriarchal civilization" (Wood 29). 
than an agent of the status quo" (Danse Macabre 51) and that horror serves as an outlet for "Dionysian" outbreaks of the abnormal that can be contained by the monster's defeat. ${ }^{51}$ The authors of American Nightmare welcome the increasing "nihilism" and absurdity expressed in the "horrality" of horror films from the 1960s and 1970s, such as George Romero's zombie films and Tobe Hooper's deranged Texan monsters, as a reflection of "ideological disintegration," presenting in their gleeful portrayals of death and destruction the possibility of a real "social revolution" (Wood 28), even if reactionary horror continues to dominate the field. It would be interesting to test this theory against the more recent 1970's-hommage films directed by Rob Zombie such as House of 1000 Corpses (2003) and The Devil's Rejects (2005)to see whether they would qualify as "reactionary" or "progressive."

Making such a claim for some horror fictions is very plausible and has, arguably, inspired the most intriguing scholarship in the field, but when it comes to isolating "reactionary" elements in a horror text, as with feminist theory and slasher films, there is a risk of dogmatic blindness in simply applying formulaic theories to formal content. This obliviousness can be seen in Wood's attack on the filmmaker David Cronenberg. The possible ways in which a Canadian culture and nationality might have influenced Cronenberg's American nightmares seems to have eluded Wood, who labels such powerful and unsettling films such as The Brood (1979) and Shivers (1975) as terminally "reactionary" in that they appear to treat sex "with unmitigated horror" (24). Perhaps Cronenberg's

In The Alphabet Versus the Goddess (New York: Viking Penguin, 1998), Leonard Shlain writes: "We associate Dionysian revelry with a carnival atmosphere, but men, too, had reason to fear Dionysus; carnival and carnivore derive from the same Latin root - to eat flesh" (141). 
technological monsters were too avant-garde at the time that Wood et al. were formulating their theory, but it should be obvious to anybody who has seen Videodrome (1982) that it is not just "sex"perse in the film that is displayed as horrifying; rather, it is the cyborg monstrosity of technology-infested bodies coupled with all-too-human yearnings for intimacy that is most horrific. This example serves to show that, while the surplus repression theory appears to integrate some of the most useful insights of the Gothic consensus, psychoanalytic, feminist and social theories of horror, it can also be used sweepingly to level cultural differences and label texts in an overly blunt fashion.

Such a sweeping perspective, moreover, has tended to fall from favour, as theorists and critics of horror have more recently located particular manifestations of horror within specific national categories other than the Anglo-American and therefore other than those constructed within a Gothic consensus. In The Horror Reader, for example, one may find essays on "New Regional Horror," "Vampires in Greece" (Ken Gelder), the Italian horror film (Leon Hunt) and "Preposterous Hong Kong Horror" (Audrey Yue), while Stephen Jay Schneider's Fear Without Frontiers (2003) opens up further interesting territory for comparativists, always, however, with the focus still firmly upon film. The deconstruction of horror along the fault-lines of ethnic representation and normative ideology has also been attempted by Pinedo in her final chapter on what she calls "race horror," entitled "Recreational Pleasures." However, she only discusses a few examples taken from American film, such as Candy man (1992) and Tales from the Hood (1995).

The difficulties of a purely nationalist approach to horror, such as that taken by Schneider et. al. in the somewhat mistitled Fear Without Frontiers (as frontiers are clearly drawn around national cinemas) can be briefly outlined here. The dangers of too-easily 
assigning national markers have been investigated by post-colonial theorists such as Aijaz Ahmad, who criticizes the tendency of western critics to theorize Other literatures, particularly "Third World literatures" as "national allegory." Ahmad points out that "First" and "Second World" cultures are defined in terms of their production systems and economies (capitalism, socialism) whereas Third World cultures have often been defined in terms of "an 'experience' of externally inserted phenomena" (here Ahmad is quoting "Jameson's Rhetoric of Otherness" 78). Nationalism fills in this gap and so all Third World texts are thought to adopt the national allegory as "the primary, even exclusive form of narrativity." Ahmad suggests instead thinking in terms of "collectivity" (82). In "Signs Taken for Wonders," Homi Bhabha emphasizes the centrality of English literature to colonial discourse, (32) remarking in another essay, "Cultural Diversity and Cultural Differences," that "the problem of the cultural emerges only at the significatory boundaries of cultures, where meanings and values are (mis)read and signs are (mis)appropriated" (206). Bhabha suggests that there are different ways of imagining "nation," either through the historical novel or through liminality, creating a much more uncertain and performative (rather than constative) narrative which, as I propose in Chapters Three and Four, well describes horror fiction.

We might ask, given these critical discourses: where and how does horror figure into post-colonial writings? Is it not better to see horror as a matter of border-crossings rather than being located in specific cultures? Given the prevalence of the Hollywood horror film in critical theory, we should question whether this way of looking at horror fictions, in the context of the western Gothic consensus, constitutes a type of colonization. Are horror texts 
produced by Others merely evidence of cultural assimilation by the darker side of western tradition $?^{52}$ Or is horror generated at the borders themselves?

In order to illustrate this point, I will refer here to the classic colonial horror tale, Rudyard Kipling's "Mark of the Beast," which was castigated by several reviewers when it first appeared as having passed "the bounds of decorum" (105). Indeed, "The Mark of the Beast" nowadays gains a new and disturbing relevance with its scenes of colonial violence and retaliatory torture against the leprous and uncanny "Silver Man" with no face, mewing "like an otter," who punishes the gruff and brutish Englishman Fleete for his drunken desecration of a statue of Hanuman in a Hindu temple. Even without this post-colonial context, Fleete's transformation into a beast remains as uncanny now as it was for Frederick L. Knowles over a century ago, who wrote that "for pure horror, this tale is perhaps unmatched in English literature" (144). Following Fleete's violation, the narrator describes the Silver Man, who appearing from behind the statue that Fleete has desecrated, "caught Fleete around the body and dropped his head on Fleete's breast before we could wrench him away." (72). This contact with the native Other leaves a mark like a rosette on Fleete's chest which soon causes frightening changes to occur:

Fleete came, and when the lamps were brought, we saw that he was literally plastered with dirt from head to foot. He must have been rolling in the garden. He shrank from the light and went to his room. His eyes were

In his introduction to Varney the Vampyre (1970), Devendra Varma advances the interesting idea that vampires migrated from the Indus valley over the Great Silk Route to Greece in the first century A.D. Varma finds numerous similarities between Indian and Tibetan "Wrathful Deities" and the vampire legends of Europe. 
horrible to look at. There was a green light behind them, not in them, if you understand, and the man's lower lip hung down. (75)

Clearly "rolling in the garden" transgresses the "bounds of decorum" for an English colonial gentieman, as do Fleete's table manners and his treatment of the cook, whom he is "abusing for not supplying him widi an underdone chop" (72). This abusive behaviour is a harbinger of his transformation from a "big, heavy, genial, and unoffensive man" with a "limited" "knowledge of natives" into a werewolf (Carroll, doubtless thinking of the rosette shape of Fleete's mark, pronounces that he is turning into a leopard [46] although the story clearly describes the "long drawn-out howl of a wolf coming from Fleete's room after his transformation $\mathrm{p} 6])$ :

Here the chops came in, all red and juicy, and Fleete bolted three in a most offensive manner. He ate on his right grinders only, and threw his head over his right shoulder as he snapped the meat. When he had finished, it struck him that he had been behaving strangely, for he said apologetically, "I don't think I ever felt so hungry in my life. I've bolted like an ostrich." (47) The monstrous thing that Fleete becomes is pitiable and yet abject, as he is subdued and overpowered by his colleagues, who see that he is dying with every "mew" emitted by the leper nearby. The two Englishmen, Strickland and the narrator, then proceed to capture and torture the Silver Man in order to force him to release "die beast" :

Strickland wrapped a towel round his hand and took the gun barrels out of the fire. I put the half of the broken walking stick through the loop of fishing-line and buckled the leper comfortably to Strickland's bedstead. I understood then how men and women and little children can endure to see a 
witch burnt alive; for the beast was moaning on the floor, and though the Silver Man had no face, you could see horrible feelings passing through the slab that took its place, exactly as waves of heat play across red-hot iron gun barrels for instance.

Strickland shaded his eyes with his hands for a moment and we got to work. This part is not to be printed.

[ellipses in original] (78)

Was it this horrific part "not to be printed," corresponding to the "unspeakable" I discuss in Chapter Four, which prompted the outrage of Kipling's critics? It was equally beyond the pale for English gentlemen to openly admit to torturing their colonial subjects as it was for them to roll on the ground, bolt their food in polite company, and accord respectful treatment to their subjects' beliefs. The ambiguity of the narrator's conclusion that "we had fought for Fleete's soul with the Silver Man in that room and disgraced ourselves as Englishmen forever" makes this point very clearly (54). Even though Fleete is restored to humanity following the torture of the leper, the inference, particularly if one reads with a post-colonial sensibility, is that the mark of the beast has been set upon all the agents of the Raj, whose sense of futility and being-out-of-place runs like an undercurrent through Kipling's jovial opening describing the gathering in the club prior to the incident at the temple: a club which Kipling locates across the border, beyond the pale, "East of Suez" where "the power of the Gods and Devils of Asia" holds sway:

Everybody was there, and there was a general closing up of ranks and taking stock of our losses in dead or disabled that had fallen during the past year. It was a very wet night, and I remember that we sang "Auld Lang Syne" with 
our feet in the Polo Championship Cup, and our heads among the stars, and swore that we were all dear friends. Then some of us went away and annexed Burma, and some tried to open up the Soudan and were opened up by Fuzzies in that cruel scrub outside Suakim, and some found stars and medals, and some were married, which was bad, and some did other things which were worse, and die others of us stayed in our chains and tried to make money on insufficient experiences. (70-71)

This is no imperialist celebration, it leads only from "bad" to "worse." As Joshi notes in his introduction to Kipling's horror tales, "the loneliness and homesickness that Kipling must have felt, and which were certainly felt by many of the English civil servants in India . . . are constandy in evidence" (xi). On the one hand, we are reminded of Abdul R. JanMohamed's "economy of the manichaean allegory" where the colonialist constructs the Other as an evil with whom it is necessary to have a "confrontation" (18). On the other, Kipling clearly situates the Other within the Englishmen themselves, in a part "not to be printed" but which is horrifying to the narrator and reader alike. Terrie Goldie remarks "[tjhe importance of the alien within cannot be overstated." "Indigenization," according to Goldie, is a process whereby writing about indigenous people (in Goldie's argument, in Canada, New Zealand and Australia) meets the colonist's own need to "become indigenous" (235). A horror fiction of indigenization (such as the non-Native horror stories of the Native American Wendigo ${ }^{53}$ ) is a different "beast" from horror fictions that may be said to be indigenous and originate in

Dr. Gurli Woods has drawn my attention to Ojibway poet Armand Garnet Ruffo's film A Windigo Tale (2009) which juxtaposes the frightening legend of the Wendigo with the horrors of abuse experienced by Aboriginal people within the residential school system. 
specific national cultures. The difficulty, as my example illustrates, is to identify where and when (and how) the indigenes and their imitators meet. Work on horror continues to proliferate and as more remakes and adaptations of horror narratives from other cultures than the British and American appear, I eagerly anticipate that more transnational and transcultural readings of horror will be produced.

\section{Conclusion - Chapter One}

It is clear from my overview of scholarly contributions to the horror field that simply continuing to elaborate the generic status of horror fiction is far too reductive, given what Cynthia Freeland has called the "slippery" nature of horror's boundaries and contemporary artistic productions' tendency to play with generic elements (10). The vexed question of genre should not determine the study of horror fiction. This is not to say that generic conventions are not important, only that they are not the only means of classifying and analyzing our responses to horror fictions. Included in the recognition of generic codes, there should be a concomitant recognition that such codes are subject always to change and reinterpretation in their encoding and decoding. Rather than struggling with the slipperiness of horror fiction as a category, I would prefer to accept that the category is slippery and to turn my attention to the texts themselves. In so doing, I am motivated by my fan(g)dom, an ongoing intense curiosity about horror fictions, as well as the significance of comparing such representations across cultural borders. I will now examine the "monster narratives" of three creatures frequendy found in horror, the vampire, the serial killer and the zombie with the intention of destabilizing easy assumptions about horror's generic figures. 


\section{Chapter Two: Genre Mutations in Horror s "Monster Narratives"}

As we saw in Chapter One of this dissertation, fear as a fictional product has long been associated with die Gothic tradition in European literature, a tradition which has been exhaustively mapped in both scholarly and popular works. The Godiic consensus has overwhelmingly regarded Godiic as die source of contemporary horror and, indeed, as horror's master narrative to which all discourses of horror fiction must be related and subordinated. However, if "the primary impulse of Gothic tales is the arousal of fear," as Valdine Clemens puts it (1), then why should it be necessary to distinguish between Godiic and horror at all? For die most part, the terms are used interchangeably, with the Godiic privileged over horror in literature, as I stated in Chapter One. The first part of tiiis chapter expands Chapter One's brief discussion of die distinctions made by critics between Gothic and horror in order to argue that such distinctions function less as objective or accurate literary classifications than as examples of how a dominant discourse works to enforce distinctions between taste cultures. Divisions between Gothic and horror thus measure and enforce social and (sub)cultural distances between scholars and fans, whether or not there are any substantive differences in the texts under discussion.

Tracing die Godiic claims staked out on horror fiction, I will argue that die monstrous figure of the vampire, associated widi feudal Europe, became somewhat displaced by the gradual gothicization of the serial killer in industrial, capitalist America as a mythical figure, Mark Seltzer's "mass in person" (2). In turn, die serial killer in contemporary horror narrative has moved over to make way for the post-industrial, late capitalist, globalized zombie, the impersonal mass, as the "monster narrative," to play upon Lyotard's theory, of contemporary horror fiction. 


\subsection{Claims Staked on Horror}

The reading public's appetite for both the Gothic fiction of yesteryear and the horror fiction of today has largely determined the consignment of both Gothic then and horror now to the label of low-status genre fiction. Fan $(\mathrm{g})$ dom, therefore, has had an enormous influence on the field of horror fiction, but scholars have staked the Gothic permanendy onto the permutations of the field. The consensus is correct in identifying the historical literary Gothic as a designation of a clear sense of social and national boundaries, creating a kind of habitus constructed upon the classification of and distaste for exotic, villainous alterities. I see "Gothic" primarily as a sensibility derived from a certain historical and cultural Anglo-European period during the eighteenth and nineteenth centuries, predominantly concerned with the signification of a particular kind of monstrosity related to spatial and temporal tropes. At the same time that the Gothic has been designated in academic circles as a generative myth of horror's origins, beginning with Montague Summers's The Gothic Quest (1938), safeguarded by Devendra Varma's The Gothic Flame. (1957) and continued through David Punter's The Uterature of Terror (1980), Vijay Mishra's The Gothic Sublime (1994) to a veritable explosion of work on the Gothic with ambitiously allencompassing titles, including Nightmare on Main Street: Angels, Sadomasochism, and the Culture of the Gothic (Edmundson, 1999) and Gothic: Tour Hundred Years of Excess, Horror, Evil and Ruin (Davenport-Hines 1998). With all that has been said and written about the Gothic, I argue that the Gothic has drifted further and further away from contemporary horror fiction's evocation of fear, although key elements of Gothic continue to linger. In this chapter, I argue that the horrific monstrosity of the dashing European vampire as a horror fiction has, 
as it has become "gothicized," gradually been replaced as a central figure in horror by the monstrosity of the serial killer. More recently, as the fictional serial killer in turn becomes less horrific and more recognizably stylized, stylish and Romantic rather than merely monstrous, the figure of the zombie as imagined by George Romero and his many imitators has lurched towards a more central signifying position as it mirrors the anxieties of a contemporary globalized Zeitgeist waiting for apocalypse.

In Contesting the Gothic: Fiction, Genre and Cultural Conflict, 1764-1832 (2006), James Watts challenges the Gothic consensus, claiming that the Gothic should be more precisely located within a historical moment, rather than regarded as a stable, continuous tradition. Watts sees the consensus, as do I, as a professional attempt to tidy up horror's messy profusions, creating a "seamless narrative of a far from stable genre" (12). Interestingly, Watts describes the origin of this seamless narrative, Horace Walpole's Castle ofOtranto (1764), which is described by Mishra as "the Gothic precursor text" (2) as a bid for an "aristocratic identity" on Walpole's part (Watts 13). Walpole thus constructed the realm of the Gothic as a privileged place of play for himself as a "licensed risk-taker" who was able to "indulge in bad taste" (16). Walpole thus may have also been the first Goth horror fan. However, The Castle ofOtranto, like the other Gothic novels, including Ann Radcliffe's The Mysteries ofUdolpho (1794) and The Italian (1797), which were read so feverishly by Catherine Moreland and other fans during the eighteendi century, suffers now from a decline in horrific affect thanks to its outmoded language. One could say that its "G-factor" has diminished and that the "G" now signifies historical Gothic alone. As such, Otranto retains a feeble grip on its status as horror literature although it is a canonical Gothic novel. 
The highly theorized figure of the nineteenth- and twentieth-century vampire so long associated with Gothic and, more recently, with Goth subcultural style serves as an important example of a "monster narrative" drifting away from horrific affect. Even as Goth subcultural style has incorporated vampire style, vampire narratives have gradually strayed away from horror and towards the realms of romance, camp, parodies and cereal commercials. As fan(g)doms have upheld, poached and produced vampire fictions, die wellworn conventions have been continually refashioned, re-imagined and re-versioned. How the vampire has been re-versioned in North America speaks volumes. ${ }^{54}$ The "Buffyverse" and its official offshoots, created by horror fan Joss Whedon, as well as die more unofficial offshoots created by Bujfy fans, are an example of this movement of die vampire away from horrific affect, taking on die stature of a romantic antihero. In Bujfy, which its creator envisioned as a reversal of die classic horror plot where die blonde girl is victimized, thus reinventing Buffy as an iiber-Final Girl, the emphasis lies more upon die characters' relationships with each other dian the fearsomeness of the monstrosities diat they embody. Such monstrous features in these narratives seemingly exist as (disabilities to be heroically struggled with, redeemed or overcome by the "human" attributes of the monstrous character, as with Buffy's vampiric lover, Angel. The cult and fan(g) status of Bujfy is unquestionable, but Buffy itself as a fiction is not horror, although it is spun off from horror tropes and elements of horror fictions, and contains many horrific moments and scenes.

Not only in North America, as the recent Swedish film Let The Right One In (2008) attests. 
Similarly, the recent popular vampire romance fiction series Twilight (2005) and the popular "Southern Gothic" HBO television series True Blood (premiered 2008) are not horror fictions. They feature vampires, monsters that have been traditionally associated with horror fictions, but unlike the Masters of Horror series (2005-2007), these television shows do not situate themselves in the fan $(\mathrm{g}) \mathrm{dom}$, nor do they strive for primarily a horrific affect. Rather, following the success oi Buffi (which was unmistakably situated in fan(g)dom), these shows similarly play with standard conventional tropes of horror, spicing their soap opera with the occasional scare. Such prime-time "mainstreaming" of horror may indicate a new direction and new challenges for horror fan(g)dom. Does horror fiction, as a practice of fan $(\mathrm{g}) \mathrm{dom}$, become diluted by merging with other popular forms? Some horror fans, for example, have embraced Buffi as "authentic" horror; others grudgingly accept Buffi as a well-meaning reinvention of certain worn monsters (but draw the line at the recent vampire romances of Twilight and others). ${ }^{55}$ Buffis somewhat tamer vampires, as well as the sultry True Blood vampires and the glittery waifs of Twilight have come a long way from the ravening monsters in Richard Matheson's novel I Am Legend (1954) or those featured in Stephen King's Salem's Tot (1975) or in many short stories, such as Canadian writer Nancy Kilpatrick's vampire tale "Farm Wife" ${ }^{55}$ or even the more appealing (but still monstrous) monsters of Anne Rice's

${ }^{55}$ One very entertaining example of "textual poaching" has a fan, Jonathan Mcintosh in his own words "re-imagining the narrative," pitting Buffy against Edward Cullen who Mcintosh calls a "creepy stalker guy" through a clever juxtaposition of scenes from the series with the film of Twilight. See an article in the LA Times online about "Buffy vs. Edward: Twilight Remixed" at <http://latimesblogs.latimes.com/showtracker/2009/07/buffy-vedward.html $>$ Accessed September 2009 2000 .

${ }^{56}$ In Northern Frights (1992), 95-99. See also The Vampire Stories of Nancy Kilpatrick, 
Interview with the Vampire (1976), which may be accused of definitely romancing the vampire and setting the benchmark for what followed. To paraphrase the Goth band Bauhaus, in their soundtrack contribution to The Hunger (1983), itself a cultural marker for the domesticated vampire: Bela Lugosi and the nosferatu, more purely monstrous monsters, are dead. Vampires, the European monsters of an undead feudal, aristocratic past, are now Gothic only in the sense that they are not horrifying.

Critics such as Judith Halberstam and Nina Auerbach have pointed out the implications of the historical Gothic as a condemnation not only of feudalistic tyrannies, and perverse and antisocial conduct, but also as a useful category of difference. At the same time, an ongoing case can be and often is made for the subversive potential of Gothicized monsters such as the vampire in the fascination with which they are received and often reimagined and celebrated by readers and fans. Widi the subsequent growth in the late nineteenth and early-twentieth centuries of such genres as the ghost story and the "weird tale," followed by horror films, pulp comics, and increasingly graphic and violent representation, the Gothic tradition has by comparison with these forms become respectable as the socially acceptable way to discuss horror fiction. The propensity to distinguish between "literary" and tasteless "trash" exploitation horror is at least as old as the Victorian "penny dreadful" which lifted its plots directly from Gothic novels and true crime narratives. What has been constant is the enduring popularity of the "trash" and its more or less warm reception among its fans who may embrace deliberately flagrant violations of taste and a low-budget subcultural aesthetic or alternately condemn a given text as hopelessly derivative 
and untalented, often in relation to its "original." ${ }^{57}$ The postmodern project of reclaiming marginalized and "low" genres has bestowed cultural capital on both the Gothic and trash aesthetics as more traditional master narratives are questioned and the class implications of such classifications are exposed. Again, more than a superficial study of horror will reveal that this reclamation and pressuring of low texts is not necessarily a new idea. The penny dreadfuls found an earlier, impassioned defence by such a respectable literary figure as G.K. Chesterton who saw popular fiction as the "centre of a million flaming imaginations." Chesterton argued that it is "petty" to blame penny dreadfuls for iniquities committed by the "lower orders" for "[i]t is the modern literature of the educated, not of the uneducated, which is avowedly and aggressively criminal." In addition, Chesterton distinguished between the "literature" of the former as a "luxury" and the "fiction" of the latter as a "necessity" while deftly skewering the "class privilege" of those who sneer at popular culture. More recently, graphic novels such as Alan Moore and Eddie Campbell's From Hell (1999) and the "steampunk" series The league of Extraordinary Gentlemen (beginning 1999) have paid loving intertextual tribute to such popular forms.

Whether or not horror can be constructed as high or low culture, which in Chapter One was described as a futile exercise, many self-appointed guardians from among its legions of fans monitor its quality in what Hills terms "performative" acts of agency and connoisseurship (Pleasures of Horror, 82). A familiar lament, endlessly repeated, for example, holds that much of what is now produced and marketed as horror is trivial schlock, evoking

For example, the "trash" label is often applied to low-budget movies made by what Stephen King calls "morons with cameras" (132) who seek to capitalize upon the perceived success of a particular text or texts, such as the spate of "teenie-kill pic" slasher films that appeared following the success of Halloween (1978) and Friday the Thirteenth (1980). 
a nostalgic vision of a "golden age" of horror that can be, for example, associated with Romero's and Hooper's heyday in the 1970s, prior to a string of derivative, exploitative texts and "remakes" riding the coattails of the originals. Similarly, a "Golden Age" of horror writing spanning the period between 1880 and 1940 has been postulated by S. T. Joshi in The Evolution of the Weird Tale (2004). Joshi finds it far more difficult to commend the work of "post-Lovecraftian weird fiction," writing that "we have entered a definite 'Silver Age' that reveals a marked falling-off of quality and richness from the 'Golden Age'. . . . aside from such lamentably unprolific writers as T. E. D. Klein and Thomas Ligotti, the modern age seems to boast few figures who can rival the 'modern masters,' or even some of the more interesting lesser writers of the earlier period" (8).

Joshi's attempts to construct and define a horror canon as opposed to a Gothic canon are laudable but misguided. In a scholarly context dominated by the Gothic consensus, as we have seen, where a Golden Age of pulp horror is barely visible, all mass horror fiction is constructed as Gothic's low-status Other, and when it is analyzed by scholars, it is therefore "gothicized" or theorized in some relation to the Gothic or interchangeably with the Gothic. Gothic might therefore be a type of fan $(\mathrm{g})$ dom performed by scholars (whereas Goth is performed by fans). In focusing on horror exclusively through the lens of Gothic, I argue, an irrevocable departure from horror fiction and its crucial "affect-function" (Hills) occurs because what I have previously called the G-factor is overlooked and a Gothic canon emerges. For example, Yvonne Leffler talks about the "living canon of the horror genre" as the gothicized "classics" (such as Frankenstein and Dracula (24) whereas I prefer to see the horror classics as "Undead" rather than living texts because living horror is what is currently being produced and read by fans. It is convenient 
for scholars who do not read living horror to relate all horror to the Gothic because the Gothic already arrives with a pre-digested set of claims and connotations that one simply applies (stakes on) to the text or social phenomenon in question. If, for example, one associates the Gothic with castles, ruins and claustrophobic spaces, then the horror that such settings can convey is taken for granted even if it has become banal and conventional.

I argue that "New Gothic" fictions are often selected and labelled as such because they align with scholarly projects of expansion of the privileged discourses of high literature. The contemporary production of fear that these fictions may or may not highlight becomes irrelevant to such projects. The gothicization of these fictions, furthermore, does not tell us very much about comparative cultures or regional horrors other than slapping a regional or national prefix onto the label; thus, we have "American Gothic," "British Gothic," "Southern Gothic" and so on. The "Female Gothic" (Fleenor et. al.), for example, is another interpretive category that subordinates Anglo-American women's fan(g)dom of horror fictions and their affects to the overall symbolization of womblike confinement within patriarchal culture.

Following Halberstam's important work on Gothic technologies of producing monstrosity and Mark Seltzer's equally important work on serial killers and "wound culture" (1998), I examine here the emergence of the serial killer as an archetypal monster who has displaced the figure of the Byronic vampire in contemporary horror. ${ }^{58}$ In this way, I hope to

I am indebted to my colleague Sean Moreland for pointing out the enormous difference between Byronic vampires and horrific vampires such as nosferatu in a guest lecture in May 2009. Dr. Moreland traces contemporary vampire romances back to the Byronic vampire, arguing that the nosferatu is more properly the subject of horror. 
preserve the sense of Gothic as a specific cultural sensibility which can be said to distinguish certain historical fictions and even to linger within others without, however, subordinating horror fiction to Gothic's literary privilege or subordinating popular fan(g)doms to scholarship. Prior to shifting decisively away from the Gothic consensus in this dissertation, it is necessary to review its principal themes and ideas.

Changes in the status of the Gothic can be mapped if we stake out as a focal point the emphasis placed by scholars of the Gothic upon the notion of the repressed past coming back to haunt the present, and upon topography, landscape and place. The grounds of the Gothic have shifted and changed over the years since it was first recognized as a genre and named for medieval architecture because so many of its texts are set in crumbling castles and desolate abbeys (Grunenberg, 195-4). ${ }^{59}$ Of the connection between Gothic architecture and Gothic novels, Grunenberg writes:

The fascination with castles and other medieval. .. buildings in early Gothic novels ... gave the genre its name. The lonely, disintegrating and abandoned house in a bleak landscape with its haunted and dark interior filled with an abundance of heavy furniture and decoration, pregnant with history and memories, makes its appearance later in the development of the genre and

This is not a typographical error; rather, the pages are numbered backwards in a clever, meta-textual reference to the strong presence of the past in Gothic. This handsome volume is the accompaniment to the 1997 exhibition entitled Gothic at the Institute of Contemporary Art in Boston, which featured art that "displays a strong pre-millennial fascination with the dark and uncanny side of the human psyche and attempts to locate it within the context of a revival of a Gothic sensibility in many cultures today" (217). 
constitutes the most popular Gothic topos of the nineteenth and twentieth centuries. (176)

According to the Gothic consensus, architectural ruins, castles and haunted houses signify the barbarousness of the doomed and unenlightened, but lingering past: feudalism, superstition and cruelty. Their presence in Gothic tales invites the reader to explore within, like the vulnerable ingenues who are menaced in Radcliffe's novels, to visit the warped interiorities of characters who mirror these edifices, either inhabiting them or lurking nearby. The villains of the Gothic tale are constantly looking over their shoulders because they have committed some dreadful act in the past which will invariably return to haunt them. Like the ruins and castles with which they are associated, Gothic villains and monsters, and the dreadful deeds they commit, are emblematic of feudalism, superstition and cruelty, but also potentially signify, as Valdine Clemens argues, all that is "repressed" and strives to return, which, for Clemens in a familiar recitation of the Gothic consensus, is "a fundamental dynamism of Gothic narratives":

Something — some entity, knowledge, emotion or feeling — which has been submerged or held at bay because it threatens the established order of things, develops a cumulative energy that demands its release and forces it to the realm of visibility where it must be acknowledged. (4)

In his introduction to The Oxford Book of Gothic Tales, Chris Baldick muses that "the most troublesome aspect of the term "Gothic" is, indeed, that in the sense it depicts the return of the repressed or a just punishment for evil deeds, "literary Gothic is really antiGothic" (xiii). The most recognizable villains of the Gothic tradition are those who seek to impress upon vulnerable heroines and naive heroes the tyranny of cruel, antiquated practices, 
such as forced marriage, or those who gleefully wield instruments of torture from the Spanish Inquisition, wall up people alive like Poe's Montresor in "The Cask of Amontillado" (1846), bury them prematurely as Roderick Usher did with his sister Madeline in "The Fall of the House of Usher" (1839), or imprison them like the patriarchal husband of the hapless protagonist in Charlotte Perkins Gilman's "The Yellow Wallpaper" (1892). Gothic villains, possessed of seemingly unlimited wealth and leisure to carry out their torturous plots, employ nasty subterfuges and bi2arre devices to achieve their ends such as Nathaniel Hawthorne's evil Rappaccini, inventor of poisonous plants (and people). They create monsters and petition demons and other supernatural beings to wreak vengeance on their enemies. Gothic villains are often wholly "Other," bizarrely-named, nobly-tided, and often hailing from or exiled to exotic foreign places. Their grandly exaggerated Otherness, easily caricatured, leads readily to parody, camp and endless reinvention. They receive welldeserved comeuppances when they fall prey to their own creations or when their machinations are exposed and their power is stripped from them. Nonetheless, they are compelling because they retain a feudalistic grandeur which will hold different appeals for different fan(g)doms. Seltzer, for example, draws our attention to the "bundle of bank-notes and a stream of gold" that falls out of the rent in Count Dracula's cloak, signifying that the parasitic bloodsucker's veins flow with capital (70). In the twentieth century, as Nina Auerbach argues, Stoker's haughty creation, a "suggestively amorphous" monster, is recreated over and over again, usurping the more sensual vampire legends that preceded him. (83)

The literary Gothic, Baldick argues, remains counter-cultural because it originates in the weighty disapproval of the Enlightenment directed towards the perceived "darkness" of 
the preceding ages, depicted as backwards and barbaric, and epitomized by the Gothic villain. The "fearful name" of the Germanic Goths

was taken and used to prop up one side of that set of cultural oppositions by which the Renaissance and its heirs defined and claimed possession of European civilization . . . Northern versus Southern, Gothic versus GraecoRoman, Dark Ages versus the Age of Enlightenment, medieval versus modern, barbarity versus civility, superstition versus Reason. (Baldick xii) Victor Sage and Allen Lloyd Smith, the editors of Modem Gothic, thus theorize that "the Old Gothic . . . doesn't stand still as a point of reference: even in the eighteenth century, it was itself an anarchic, popular, and indeed 'camp' recycling of the past." The Germanic Goths and all the collection of elements encoded in Gothic narratives were deployed to perform the past as barbaric, uncivilized and even ludicrous, thereby emphasizing the distance between those benighted Others and the heirs of the Enlightenment. At the same time, Gothic provided a "camp" outlet for rehearsals of compelling Othernesses, and provided a ready-made style in its depictions of architecture and spatial trappings: Gothic is, in this view, "an anti-historicising language, which provides writers with the critical means of transferring an idea of the otherness of the past into the present" (1).

The Gothic, therefore, in addition to possessing cultural capital as a counter-culture, is also a (dis)taste culture, reflecting "estrangement from the dominant cultural values of every age" (Davenport-Hines 3). Insofar as the Gothic takes as its subject matter the distasteful plots of its villains, set among those brooding, crumbling ruins, it is not difficult to see how the consensus has come about that the Gothic is indeed the master narrative of horror fiction, signifying "400 years of excess, horror, evil and ruin," as the subtitle of one 
work on the Gothic sweepingly announces (Davenport-Hines 1998). According to the Gothic consensus, the Gothic thus becomes the "scapegoat" of the Enlightenment: the underside of the idea that people are intrinsically good and rational, transforming a brightlylit perspective, a la the frightening opening credit sequence of the horror television series Tales from the Darkside, which begins by rolling a camera along a pleasant, sunny vista of country road lined with trees. "But. . .," the narrative voice drops and lowers menacingly, "there is ... a DARK SIDE . . . ." and suddenly the peaceful landscape is transformed into a stark, black-and-white negative image that freezes on the screen. This negative image reflects a gothicized sensibility which is taken up by Goth subcultural styles. In Goth subculture, which I shall discuss further in the following chapter, such a sensibility is flaunted. To paraphrase the band Ministry, in Goth subculture, "every day is Halloween"; transgressions of the dominant culture and its dominant tastes are celebrated, including the "excess, evil and ruin" of horror fictions and their villains.

The sweet and naive protagonists of many a Gothic tale pale in the memory compared to the fearful grandeur of the perverse villains described therein. If Milton in Paradise Lost was "of the Devil's party without knowing it," as William Blake quipped, the Gothic fictions were unabashedly of their villains' parties, despite their scandalized tones, devoting pages of description to their ghastly interiorities and dwelling lovingly upon the scenes of their downfalls. It is this fascinating quality of the tradition that led "many anxious readers of the eighteenth century" to envision Gothic fiction "as some sort of irresponsible relapse into the old delusions of a benighted age, nostalgically glamorizing the worst features of a past from which we have thankfully escaped" (Baldick xiii). The seductiveness of Gothic fictions and their creators were thought to corrupt and delude fans, beckoning them towards 
regressive and antisocial ideas and behaviour; they were the Marilyn Mansons of their day, with groupies including Catherine Morland of Austen's Norfhanger Abbey.

I keep returning to this text because it is such an important commentary upon fan $(\mathrm{g}) \mathrm{dom}$. Austen gentiy ridicules the irresponsible delusions of her amiable heroine, Catherine Morland, who eagerly anticipates that she will uncover the secret of Northanger for which the long succession of "horrid" Gothic novels she has read has prepared her: "Its long, damp passages, its narrow cells and ruined chapel, were to be within her daily reach, and she could not entirely subdue the hope of some traditional legends, some awful memorials of an injured and ill-fated nun" (110). Catherine, the avid and knowledgeable fan, tends to gothicize everything she experiences, in a fatal transfer of fantasy to reality, as when she solemnly tells Miss Tilney, "I have heard that something very shocking indeed will soon come out, in London .... I have only heard that it is to be more horrible than any thing we have met widi yet.... I shall expect murder and everything of the kind" (87). The starded Miss Tilney believes that Cadierine is talking about a riot whereas she is in fact, as her brodier Henry laughingly explains, looking forward to "a new publication ... in three duodecimo volumes . . . with a frontispiece to the first, of two tombstones and a lantern" (88). Catherine's fan(g)dom, her appetite for "horrid" narratives, must be tamed and her overwrought Gothic sensibility must be overcome if she is to make the satisfying match with the sensible Henry that concludes the novel. In order to accomplish the taming of this fan $(\mathrm{g}) \mathrm{dom}$, Catherine's attraction to Gothic villainy and her proclivity not only to read horror but, as a fan, to perform it must be exorcised dirough her encounter with Colonel Tilney, whose villainy is far from sublime, but of a decidedly ridiculous sort. Aside from Catherine's own faulty judgment — "Dearest Miss Morland, what have you been judging 
from!" as Henry reproaches her at the denouement (159) — the wickedness that does menace Catherine's happiness is satirically watered down to an ordinary and manageable comedy of manners. It has been pointed out, most notably by Sandra Gilbert and Susan Gubar, that Tilney's father embodies an antiquated patriarchal snobbery that resonates with the Gothic convention of a wicked, scheming nobility set against an intrepid middle-class heroine (64); Austen was remaking the Gothic even as she mocked it.

Still, General Tilney, stubborn patriarch though he might be, is a poor substitute indeed for the Faustian Rappaccini or Walpole's Manfred in The Castle ofOtranto. Once Catherine realizes her mistake, her only fear is that she has become distasteful by her own behaviour, causing Henry to "despise" her. Her return to sense is depicted as a return to her own country, England, where her imagination had previously dwelt in romantic and exotic foreign parts:

Charming as were all Mrs. Radcliffe's works, and charming even as were the works of all her imitators, it was not in them perhaps that human nature, at least in the midland counties of England, was to be looked for. Of the Alps and Pyrenees, with their pine forests and their vices, they might give a faithful delineation; and Italy, Switzerland and the South of France, might be as fruitful in horrors as they were there represented. . . . But in the central part of England there was surely some security. . . Murder was not tolerated, servants were not slaves, and neither poison nor sleeping potions to be procured, like rhubarb, from every druggist. Among the Alps and the Pyrenees, perhaps, there were no mixed characters. There, such as were not spodess as an angel, might have the dispositions of a fiend. But in England it 
was not so; among the English, she believed, in their hearts and habits, there was a general, though unequal mixture of good and bad. (160-161)

Critics writing about the Gothic tradition in literature have concentrated upon this tyranny of the aristocratic past, often located in old Europe and exotic places, whence a dead hand reaches into the present to wreak havoc, primarily expressed through the architectural imagery of the crumbling castles where the villains dwell. Poe's "The Fall of the House of Usher" (1839) is die quintessential example of such a locus horribilis in all its explicitly symbolic glory, condensed within the story by Roderick Usher's poem "The Conqueror Worm," the allegory of "the tottering of [Usher's] reason upon its lofty throne" (176). Usher's body, once a "fair and stately palace" with floating yellow banners, "luminous windows" and "wit and wisdom" "flowing, flowing, flowing" through the door of "pearl and ruby glowing" has become a terrifying, haunted house, where "red-litten windows" disclose: Vast forms that move fantastically

To a discordant melody;

While, like a rapid ghastly river,

Through the pale door,

A hideous dirong rush out forever, And laugh — but smile no more.

"The Bad Place," as Stephen King calls it, or the "closed space," in Manuel Aguirre's book of the same title, has long been associated with the Gothic. Guilt and the long-buried secrets of a family, an individual or a community amplify the Gothic atmospherics, expressed by Poe as the "dull, dark, and soundless day in the autumn of die year" which 
ushers in the "sense of insufferable gloom" (171) pervading the narrative. The title, of course, implies a triple fall of the house of Usher, both in the genealogical and the literal sense, as well as being allegorically duplicated as Usher himself in the poem. The narrator, paying a visit to his friend Roderick, who, he tells us, suffers from "nervous agitation," recounts the mounting evidence of Roderick's madness and the climactic revelation of Roderick's premature burial of his sister, Madeline Usher, who returns from her tomb to claim her brother. In her "violent and now final death-agonies," she cannot be separated from him. Together with the disintegrating house, they are the final "fragments of the House of Usher" (182-3). This tragedy is condensed and foreshadowed in the first glimpse of the "black and lurid tarn," reflecting the "remodelled and inverted images of the gray sedge, and the ghastly tree-stems, and the vacant and eye-like windows" (171). It is into the tarn that the degenerate house of Usher topples and collapses at the conclusion of the tale, mirroring on another level the "black and lurid" mystery of Roderick's morbid and possibly incestuous relationship with his sister.

The mirroring, mutually constitutive effect of topographic, spatial and mental imagery seen in "The Fall of the House of Usher" reflects the "secrets best left untold and things best left unsaid" (J)anse Macabre 60-61) that are at the heart of the evocation of Gothic fear, the guilty past haunting the anxious present. With successive texts and their appeal to successive audiences, the signifiers of the Gothic villain, haunted house, or both become laden with additional meanings in a process of what Henry Jenkins calls "textual poaching," borrowing the term from Michel de Certeau to describe audiences reshaping and rewriting texts (22). Text after text, version after version, copy after copy, and remake after remake inherit, echo and quote their predecessors, creating a dialogical realm steeped in meanings. 
At the same time, the monstrous interiorities of the characters in Gothic texts echo and reflect the symbolism of architectural settings. The Gothic lingers not upon the tragedy of the "fair palace" that Roderick Usher once was, but upon the "red-litten" eyes and maniacal laughter of his fallen self. Thus the Gothic oscillates between the external imagery of sublime landscapes and the internal imagery of obsessive psyches. These are timeless tropes; the past is continually retreating, and the enduring popularity of the Gothic has ensured its continual renewal as a particular sensibility of setting and psyche against the backdrop of an everreceding but hauntingly present past.

Critics locate a "New Gothic," however, firmly in the present. Grunenberg echoes Victor Sage when he sees as a peculiarly American "Gothic sensibility" in ascendency, corresponding to the "particularly dire times" of "latter-day America":

'Gothic' has become the quid pro quo for somber and disturbing moods, sites, events and cultural by-products of latter-day America .... A predilection for the Gothic has deeply affected all areas of contemporary life — from 'high' literature to 'schlock' science fiction, mystery and romance novels .... (210) The dense and all-pervasive proliferation of "Gothic" cultural production that Grunenberg lists, "embracing everything from daytime TV talkshows to O. J. Simpson, Satanic ritual murders, Timothy McVeigh's New York state hometown and the television series of the same name," reminds us that the Gothic has always been prone to classification according to taste, even as "our present apprehension of the term is usually an uneasy concatenation . . . in which there is a complicated interplay of direct historical connexions and ever-variable metaphor" (Punter 5). "Gothic tales" may describe horror fictions or they may describe romances. Categories such as "explained Gothic", "supernatural Gothic", "terror-Gothic", 
"horror-Gothic", and "Sentimental Gothic" give rise to a "dizzying disarray" (Punter 19), while Goth subcultural style and its reception and performance only adds to the confusion.

What, then, actually distinguishes the Gothic from horror? The uneasy relationship between the two terms has either been formally delineated or altogether evaded (see Chapter One), and appears generally, I argue, to be more a question of defining canonical literariness and acceptable areas of scholarship than of any concrete or clear demarcation. In short, the label "Gothic," once a historical category to describe certain works of fiction originating in the eighteenth century in conjunction with a growing audience and featuring certain conventions, is now largely a matter of taste. If we take, for example, the absence of gore or graphic violence as an indication of a "Gothic" text rather than a horror text, we soon see that it will not do. The Hammer House of Horror film studio in Britain, for example, famously featured Gothic conventions such as ruins, castles, dungeons, and secret passageways in a succession of films that adapted Edgar Allan Poe's short stories, while steeping these productions in lurid Technicolor displays of gore which were, for the 1950s and 60s, excessive for "neo-gothic" (McDonald 154). Matthew G. Lewis's The Monk (1796), one of the primary texts of the Gothic canon, concludes with the lingering description of Ambrosio, the fallen monk of the title, undergoing his punishment at the claws of none other than Lucifer himself, who plunges the aforementioned talons "into the monk's shaven crown" and drops him from "a dreadful height":

Headlong fell the monk through the airy waste; the sharp point of a rock received him; and he rolled from precipice to precipice, till, bruised and mangled, he rested on the river's banks. Life still existed in his miserable frame: he attempted in vain to raise himself; his broken and dislocated limbs 
refused to perform their office, nor was he able to quit the spot where he had first fallen. The sun now rose above the horizon; its scorching beams darted full upon the head of the expiring sinner. Myriads of insects were called forth by the warmth; they drank the blood which trickled from Ambrosio's wounds; he had no power to drive them from him, and they fastened upon his sores, darted their stings into his body, covered him with their multitudes, and inflicted on him tortures the most exquisite and insupportable. The eagles of the rock tore his flesh piecemeal, and dug out his eye-balls with their crooked beaks. (420)

This is a strong example of the difficulty of upholding categories between "Gothic" and "horror" when the gore factor of this passage seems to place it firmly in the latter camp. However, The Monk is one of the few canonical Gothic novels with such overt graphic detail (King Danse Macabre 50). The scandalous monk Ambrosio as well as the other Gothic villains who raged at and defied all the proprieties of their time became somewhat eclipsed in the nineteenth century in England, by the more genteel area of ghost stories and tales of the supernatural that left such bodily desecrations implied, although, as we shall see, the Romantic hero and the vampire step in to take Ambrosio's place.

Historical considerations aside, the preciousness of making an overt distinction between today's Gothic and horror fictions, I argue with Mark Jancovich (2002), is but a means of controlling the representation and consumption of horror in texts by classifying them either as high-cultural or low-cultural (generic) forms. This regulation is often quite blatant. As Ellen Datlow observes of The New Gothic (1991), a collection of short stories edited by Bradford Morrow and Patrick McGrath, it "tries to separate itself from the horror 
held by a heroic attempt at obfuscation in the introduction . . . yet another marketing attempt to separate literary writing from popular writing. No go, guys" (xliii). Datlow's blunt comment is a warning that such divisions may be purely arbitrary, determined more by whatever audience publishers and marketers are aiming at than by any innate feature of the work itself or in its reception by readers.

Most literature and film critics, as I have described in my overview of the Gothic consensus in Chapter One, tend to simply accept horror as a natural offshoot of the Gothic tradition and write of "Gothic horror." ${ }^{60}$ Gothic has conversely been regarded as a "subgenre" of horror, as Cynthia Freeland calls it, although, again, it is not clear where the boundaries lie. Peter Hutchings is one of the few to attempt a firm distinction, arguing that it is more useful... to consider Gothic as a distinctive mode which influences a wide range of cultural forms while horror ... is best seen as a genre, a much more narrowly circumscribed area of cultural activity. ${ }^{61}$ (89)

One might ask for whom it is "more useful" to do such a thing. In other words, is the Gothic, then, an arena of privilege to which only the knowledgeable elite have access, while hoi-polloi fans languish amidst the "narrowly circumscribed" formulae of their horror fictions, setting off moral panics and rattling the bars of their tasteless) fan(g)doms? In Hutchings's readings of a narrow selection of contemporary horror films, the distinction serves no more "useful" purpose than to point out what characteristics slasher texts are

\footnotetext{
${ }^{60}$ See, for example, Punter (1980), Russ (1983), Sage and Smith (1996), Grunenberg (1997), Clemens (1999).

${ }^{61}$ The comments of Ellen Datlow (see above) on this text reinforce my discussion of Hutchings' point.
} 
allowed to share with the "old-fashioned" or traditional Gothic texts. Hutchings himself admits that there are "complicated and tortuous relations between mode and genre" (90). The "broad terms" of his formula (93) lead to the vague conclusion that, in horror, "a number of traditional Gothic characteristics . . . are presented as, and to a certain extent transformed into spatial deformations of contemporary reality which impinge upon and disrupt the psyche of the characters caught up in this process" (103). If "Gothic" is a mode and "horror" a genre, Hutchings's tidy distinction then appears to collapse like the House of Usher itself, reverting to the Gothic consensus definition of horror as a part of the Gothic tradition. Both Hills (2005) and Jancovich (2002) have drawn attention to this "Othering" of horror in the delineation of the Gothic and "terror" as culturally distinct from the "gore and low culture" of horror. Hills sums it up succinctly in his discussion of "Gothic TV" in which classic Victorian horror tales from Charles Dickens and M.R. James are adapted and showcased:

Ur-texts of gothic literature thus occupy privileged places in relation to TV horror, as they can work intertextually to separate out such TV from the generic classification of horror-as-low-cultural-threat. 'Gothic tradition' . . . hence re-genrifies and exnominates horror, transforming it discursively from an alleged 'body genre' focused on intense emotion/affect and recontextualizing it within a more genteel paradigm of period drama. By showing less gore and being diegetically cast back in time, 'Gothic TV not only takes on a literariness or worthy wordiness, it also overwrites the culturally dangerous category of "TV horror.' (120) 
While I agree with Hills and Jancovich's readings of Gothic, as a literary critic rather than a cultural critic, I continue to insist that horror literature itself is still regarded as a "culturally dangerous category," as infectious, if not as widespread and available, as TV horror. When Charles Dickens and M. R. James, furthermore, are collapsed into a "Gothic" category of "period drama," it becomes important to try to make at least some distinctions. Demarcating the Gothic as a separate generic entity, even critically, as do Hills and Jancovich, will inevitably flatten such a rich and varied field as horror. Instead, this demarcation reveals more about its classifiers than what it is intended to classify, hinting perhaps that what we think of as genres are often the material effects of production and consumption practices, of the shifts in taste, the "gentrification" of low areas of culture and the segregation of fan(g)dom from the habitus of scholars.

The gate that has been kept between the Gothic tradition and popular horror fiction by such critics as Morrow, McGrath and Hutchings may well be another example of the habitus at work. ${ }^{62}$ In Genres in Discourse (1990), Todorov argues that "the literary genres, indeed, are nothing but. . . choices among discursive possibilities, choices that a given society has made conventional" (10). The "gentrification" of the Gothic and its acceptance as a literary genre by mainstream scholars paves the way for the increasing acceptance of horror fiction as less unsettling and more worth studying once its conventions have gained

${ }^{6}$ The popular appeal of horror has led to many considerations of its 'decline' (see Chapter One) or, conversely, its ability to reflect mass anxieties as a genre. See Tania Modleski's discussion of horror as mass culture in "The Terror of Pleasure" For a gendered analysis of the mass and changing appeal of the "body genres" - pornography, horror and the melodrama - see my discussion of Williams's "Gender, Genre, Excess" in the previous chapter. 
familiarity among a more widespread audience. This happened to some extent with the slasher film parodies that began to appear in die 1990s which provoked some discussion on the "postmodern" aspects of horror fictions. Scream (1996) and Scary Movie (2000), for example, which both explicitly mock and yet pay tribute to the slasher films of the 1980s, are the Northanger Abbeys of our time. Here I am not rejecting the idea of genre so much as suggesting that genre is a conversation between different voices and discourses of horror, similar to Bakhtin's theory of dialogism. In Chapter Three, I will discuss the debate between "quiet horror" and "splatterpunk" as another example of this conversation at work. The Gothic is another site of endless conversation about horror, but it is not the only site, as the consensus would seem to indicate. In my next chapter, I will focus on the short story and Poe's "unity of effect" as an alternative genealogy of horror fiction.

Given the proliferation of its available meanings, some prefer to examine the Gothic simply as "a way of relating to the real, to historical and psychological facts, which will clearly contain a moment of variation as other aspects of cultural life vary, but which nonetheless has forms of continuity which we can trace right through from the eighteenthcentury writers to the contemporary world" (Punter 15). Victor Sage and Allen Lloyd Smith define the Gothic as a "tradition of representation, evidently still in the making," which doubles back through the figure of "reiteration . . . the modern form of haunting" expressed through "narrative manoeuvres and motifs." Ken Russell's film Gothic (1986) foregrounds these manoeuvres by mingling supernatural elements of old Gothic narratives (the ghostly knight, the demonic woman) with the modern sexual permissiveness of the gathering, in June 1816, of Lord Byron (Gabriel Byrne), Dr. John Polidori (Timothy Spall), Claire Clairmont (Miriam Cyr) and the Shelleys (Natasha Richardson and Julian Sands) at the Villa 
Deodati on Lake Geneva. This gathering was the maddest British tea party of all time," as Stephen King calls it, with its challenge, inspired by German ghost stories, to write a tale of terror. The session engendered not only Frankenstein, but also Polidori's Varney the Vampire (1819). The latter, which achieved notoriety as a "penny dreadful," is regarded as a literary antecedent of Bram Stoker's Dracu/a. ${ }^{63}$

Gothic dwells upon such strange instances as the documented episode whereby Percy Bysshe Shelley hallucinates a woman with eyes instead of nipples in her breasts, and the entire party seems to tumble into a kind of surrealistic Sadeian fantasy where Byron and his guests are cast as the libertines possessed of a wild space that brooks no meek-and-mild conformity. The virginal Mary Shelley (Natasha Richardson) is depicted as the last vestige of conformity, her husband is portrayed as weak and paranoid, and Polidori acts as a kind of Renfield to Byron's Dracula, while Byron himself seduces Clairmont, his half-sister, in exaggerated displays that render her "fey" and possessed. In what is one of the most visually disturbing sequences of the film, she descends a staircase backwards with an uncanny rapidity in the middle of a flashing lightning storm, similarly to the recently released "spider walk" sequence from The Exorcist: The Version You've Never Seen (2000). These are horrific bodily performances, like the creepy stop-motion gait of the somnambulist Cesare in The Cabinet of Dr. Caligari (1920), creating an affect of uncanniness that I term "The Appalling" in Chapter Four. The eroticized horrors that befall the Shelleys are related to the documented

${ }^{63}$ King argues that this "would make Byron the literary grandfather of the legendary Count, who boasts early on to Jonathan Harker that he drove the Turks from Transylvania ... and Byron himself died while aiding the Greek insurgents against the Turks in 1824 ... It was a death of which the Count himself would have greatly approved" (Danse Macabre 70- 
episodes of their lives, Mary's tragic losses of her children and her husband by drowning and, as such, signify the intrusion, not of the past but of the future of Gothic canonicity into the historical present of the film. Through metafictional mixing, stirring Henry Fuseli's famous The Nightmare into the text in a sequence portraying the demonic goblin figure of Fuseli's painting crouched upon a sleeping Mary Shelley, and through other such grotesque tableaux and set-pieces, Gothic is an erotic horror film about the myths that would be woven around the generative fable of Frankenstein, a break with the Gothic past.

The supernatural libertinism of Hollywood's production of Gothic reveals what had been becoming a torrential motif in the production of the Gothic itself: the taking up of the older formulas only to abandon them halfway as insufficient in the face of changing social and moral regulation. This means, as Sage and Smith observe of the novels of Don DeLillo and Thomas Pynchon, that the Gothic can appear "as one element among many: as a particular setting, an epiphanic moment, a distorted and threatening environment, subdued supernaturalism, a sudden and grotesque violence" (Modem Gothic 13)., ${ }^{64}$ Revenants in the shape of vampires, ghosts and reincarnations populate the landscape of the Gothic, as do ruins, monuments, burial-grounds, haunted places and other signifiers of the "locus horribilis" (Grunenberg 195). The Gothic "sensibility" that Grunenberg identifies, which I have taken up here to describe a movement between the axes of symbolic place, from exterior (setting) to interior (psyche), is also therefore the awareness that a mirror is being held up to the self,

${ }^{64}$ In Michael Enright's conversation with Don DeLillo, "Seeing the World with Black-Tinted Glasses" recorded on the CBC's Ideas program, Monday June 9th 2003, DeLillo observes that a particularly Gothic discourse emerges in opposition to what he calls the Hollywood film version of America, "a different, darker point of view" reflecting a "conspiratorial sense of reality," "a world filled with the inexplicable, the harsh, the magical." 
distorting and yet revealing, and an awareness of the space that makes such a distorted revelation possible. Both the past and the concomitant topoi have shifted for the contemporary Gothic sensibility and it has become an underlying sensibility for not only horror texts but for mass culture.

The frightening and suspenseful enigmas that beset the heroine of Radcliffe's The Mysteries ofUdolpho serve to provide a comforting didactic conclusion in which it is "shewn," as Radcliffe's final "peroration" trumpets, "that though the vicious can sometimes pour affliction upon the good, their power is transient and their punishment certain" (IJdolpho 672). This is also an apt description for the conclusion of Austen's parody in which reason reigns triumphant and the vicious, or at least the frivolous, are discomfited if not punished. In "New Gothic," the "didactic convention" that Anne Williams finds such endings to embody (145) has yielded to a destabilized narrative which proffers only more enigmas at the conclusion. These enigmas are more effective for their move away from conventionalized exotic sites, now haunting the urban landscapes of contemporary society. Familiar sidewalks, alleys, apartment buildings and offices become haunted, displacing the exotic context of the European landscapes which used to form the settings for the historical English Gothic novels.

For Judith Halberstam, monstrosity according to Gothic convention will always be located in "someone else," a foreign Other that "condenses various racial and sexual threats to nation, capitalism and the bourgeoisie in one body" (3). To support this contention, Halberstam discusses the quintessential Gothic villain, the vampire, reminding us, for example, that the American Civil Liberties Union placed a lawsuit against Universal Studios because of Count Dracula's gold medal, which bears a strong resemblance to the Star of 
David, marking the vampire as Jewish. The technique of the Gothic, Halberstam writes, produces national "identity" in particular ways, according to what she calls, citing Benedict Anderson, "imagined communities which are 'conceived in language not in blood'" (14). For example, "the racism that seems to inhere to the nineteenth-century Gothic monster . . . may be drawn from imperialistic or colonialist fantasies of other lands and peoples, but it concentrates its imaginative force upon the other peoples in 'our' lands, the monsters at home" (15). Thus, Dracula becomes a real threat only when he leaves his castle and establishes a stake on English soil. Bram Stoker's novel concludes with a lengthy chase, pushing the vampire away from England and back towards his ancestral land. Part of the power of the nineteenth-century Gothic, Halberstam writes, was drawn from British colonial expansion: "As the English empire stretched over oceans and continents, the need to define an essential English character became more and more pressing" (16). Following Halberstam's argument, we might attempt to define an American Gothic sensibility as die twentieth-century mirror of an inverted (and ultimately imperialist) American consumer society expansion. ${ }^{65}$

The "place of corruption" demonstrates the persistent relocation of horror from "haunted castles and abbeys" to "monstrous bodies" and souls (Skin Shows 16), although

${ }^{5}$ Halberstam's complex attempt to bring race, nation and class into the discussion is certainly long overdue but she selects only certain national identities for discussion and comparison, interpreting the classic English Gothic novels by Mary Shelley, Bram Stoker, Robert Louis Stevenson and Oscar Wilde on the one hand, and postmodern American slasher movies such as The Texas Chainsaw Massacre II and The Silence of the Lambs on the other. This ignores the possibility of other "imagined communities" that might partake of similar Gothic constructs through the movement of colonialism. Where, for example, might Canadian fiction fit into this topography? 
Valdine Clemens points out that "the originating image of the ancient castle as bastion of personal or cultural identity under assault" by revenants lives on in texts from "King's burning Overlook Hotel in The Shining, to Ridley Scott's exploding spaceship in Alien" (7). As Grunenberg puts it, die contemporary Gothic

is no longer exclusively at home in medieval casdes . . . the uncanny today surfaces in strange and bizarre American landscapes, in dark urban nightscapes, abandoned parking lots, factories, warehouses, and other remnants of postindustrial culture as well as in the suburban sprawl of apparent normality and peace. (176)

As the ruined casdes and abbeys of the first Gothic fictions invoked the barbarity of feudalism and religious superstition erupting into the present, so do the shabby streets, deserted factories "and other remnants of postindustrial culture" signify the lingering presence of feudalism's descendants, the capitalist tycoons and robber barons whom Marx described in horrific terms as bloodthirsty monsters. For example, Tania Modleski analyses Marx's use of the shape-shifter as "an enthusiastic endorsement of that creature's activities": ${ }^{66}$

Marx tells us that the capitalist's 'werewolf hunger,' which drives him continually to replace 'living labour' with 'dead labour' . . . will lead to a mode of production in which 'labour time is no longer the sole measure and source of wealth'. ("The Terror of Pleasure" 155)

${ }^{66}$ Matt Hills (2005) has used the term "theory-horror" to describe this overt use of horror language in philosophy and social science. 
Connotations of fabulous wealth as well as the accrued and romantically burdensome capital of immortality linger particularly in die eroticization of the darkly handsome, aristocratic vampire figure, Lord Byron's poetic descendant (by way of Polidori's Lord Ruthven) in stark contrast to his more horrific, bald-pated, glaring and taloned counterpart, the nosferatu. See for example F.W. Murnau's Nosferatu, which the 1979 television mini-series version of King's Salem's lj)t consciously resurrected. The Romantic vampire, far more sensual and eligible, is the character that has been most beloved of fans and feminists writing in Gothic discourses, such as Nina Auerbach, who dwell upon the patriarchal and sexual oppressions that this monster embodies (Our Vampires, Ourselves 1997).

The Gothic tradition was constructed around the quivering heroine's ordeal-filled quest for a financially well-endowed husband, thereby serving to denaturalize that quest. A Gothic sensibility still tinges those narratives that circulate and multiply around such similarly haunted loci of sexuality as homo-eroticism and adolescent love-games. The romantic figure of the literary vampire, originally drawn by Bram Stoker as the decayed aristocrat of a bloodthirsty old Europe, is ideal for this sort of narrative. By "literary vampire," I am describing a different phenomenon from the vampire folklore that runs through many of the world's cultures. Vampires are not attractive creatures in many of their mythologies, but are variously described as deformed, hairy, bestial and loathsome corpses. The ghoulish monster in Nosferatu is far closer to the folklore vampire of legend. With the success of Anne Rice's bestselling Vampire series, beginning with the massively popular Interview with the Vampire, a host of fans and followers, as previously observed, have taken up the romantic possibilities of vampire love, including in such popular depictions as Bujfy the Vampire Slayer, the recent television series True Blood that depicts the politics of vampire 
segregation, and now notoriously in the runaway success of Stephanie Meyer's Twilight series with its sulky, sparkling Undead teenagers. "Gothic TV," as Matt Hills calls it, reflects the sensibility that horror is Gothic's other in privileging vampire romance and period drama.

Matt Hills traces the publicized process of becoming a horror fan, analyzing the selfconscious descriptions of academics such as Mark Kermode and Charles E. Weigl, for example, in which Hills discerns a "before" and "after" micro-narrative that is not restricted to academic discourse but also "crop[s] up across a number of horror fan online message boards":

What such micro-narratives achieve is the discursive production of a contemporary valued self, aligned with cultural norms of rationality and literacy, while aporias in this self-account (how to explain becoming a fan?) are dealt with via performative citation of Romantic intensities, attributed to the past / child self. The fact that this micro-narrative so economically works to position the (masculine) horror fan as beyond cultural reproach may account for its widespread circulation across horror fan cultures. \{Pleasures 78) I want to suggest, following Hills, that the Gothic sensibility that lingers within horror fiction, as well as being tied up with connotations of eroticized feudal and industrial economic predation, also corresponds with the "Romantic intensities" that Hills identifies as being part of the enjoyment expressed during the "before" process of becoming a horror fan. This somewhat explains the romancing of the vampire in contemporary mainstream culture. Romantic intensities, as Hills rightly points out, are gendered because they are culturally acceptable in women and children, not men. Twilight and other vampire romances have resurrected such gendered readings of vampire fiction as Gothic at a time when Goth 
subcultural style, the former custodian of vampire fan(g)dom, has itself drifted, becoming far less anti-capitalist punk and far more consumerist romantic ("emo"). Hills claims that such manifestations of "Romantic-intensity-turned-to-cool-knowledgeability" avoid the taint of "'pathologized' horror fandom" and "challenge the dominant, hegemonic, cultural representation of the 'weird' horror fan." At the same time, such "micro-narratives" work to construct a privileged discourse of "'non-effeminate' affective responses" to horror and "work in the service of fan / non-fan cultural distinctions" (78).

The designation of Gothic shifts the field of horror towards a self-conscious and ambivalent response, avoiding the pathological taint of horror fan $(\mathrm{g})$ dom while retaining the powerful elements and themes of guilt, past sins coming to light, compelling monsters and hints of supernatural force which enabled the Gothic to define horror for so long, and for so many. The label "Gothic" is therefore a rather weak and ineffective way to characterize horror unless we regard it very specifically, as a responsive sensibility originating from a set of culturally particular historical discourses of nation and Other, sex and class.

\subsection{The Gothicization of Serial Killers}

In this chapter, I have so far examined the popular rewriting of the Gothic tradition as a Romantic sensibility that can on the one hand generate horror and on the other venerate romance, as the figure of the vampire demonstrates. I will now pursue the idea of changing monstrosities and changing fears in order to examine one of the most potent symbols of horror in the contemporary industrialized West: the serial killer. Here too, scholars have accorded a Gothic designation to the serial killer, notably Judith Halberstam, who writes that "our current preoccupation with individualizing by use of the term evil, with creating 
monsters and ignoring monstrosity, indicates our nostalgia for the premodern, for the comfort that those old monsters offered us" (39). This, she argues, makes the serial killer a "naturally" Gothic creature:

The Gothic, that place where we play with the fear of the text's extratextuality, of its unspeakability, is where we find it natural to place the serial killer, he about whom we can't stop talking and he who leaves us speechless. It is in the Gothic novel where ideas central to the way we perceive ourselves and our society seem particularly threatened, and where language itself seems vulnerable to an impending silence. \{Skin Shows 49) ${ }^{67}$ Halberstam's flexible definition of the Gothic, as I showed in Chapter One, in stretching itself to incorporate the serial killer and all other forms of horror, indeed supplanting horror's affective representation of "unspeakability" altogether, ignores the fact that serial killer narratives are a far more recent mode of horror fiction, whereas the Gothic implicates the "old flame" from the past. The patterns that are therefore discerned in serial killer representations are those which organize and group the killer's motives around some discernible aspect of the world upon which he preys, while Gothicized fictions tend to dwell upon the world from which the monster emerges. Where the serial killer narrative belongs to the field of horror is in the response to many of these narratives by that world: at once outraged, morally panicked, and yet desirous of more. Tithecott's suggestion that "perhaps

${ }^{67}$ The serial killer, though, has lent his face to more of the covers that are "embossed with dripping blood" (Tithecott) than Gothic novels. Halberstam's idea of the Gothic as a "technology of subjectivity" can be applied to the serial killer only insofar as we speak of him endlessly, and with fascination. 
we need to examine the relation of dreams of violence, of racial or sexual purity, of closure, of death, to our dominant culture and its dreams" echoes this reception. Like Tithecott, I believe in the instability of the "common ground" that the serial killer's Other gives "us." And like Tithecott, I am interested not so much in the dichotomy of "monster vs. human" (a dichotomy that Carroll, Halberstam and others seem to perpetuate even as they deconstruct it), but in the "dynamic continuum" of "normality" and "perversion" and the story of "a slow progress from nonviolence to violence" (7).

Tithecott argues that, by "removing nature from the equation," we can access the pure constructedness of the serial killer and defy the "inevitability" of mass murder (8). While I applaud the sentiment, I am not so sure that we can, in fact, "remove nature" from the fact of construction itself. The serial killer and the Gothic both share a tinge of the abnormal lurking beneath the surface and the sense of a ruin where the resurgent past is ceaselessly relived. The psyche of the psychopath corresponds to historically Gothic anxieties about the feudal past and the industrial present. I argue that fictional representations of serial killers as they are read in horror (as opposed to the serial killers we read about in the newspapers), can be interpreted as a continuation, a reinvention and a displacement of the older, formerly fearful but now romantic, archetype of the feudal, aristocratic vampire. The fictional serial killer, (vampirically) sustained by fan $(\mathrm{g})$ dom, gradually takes on more and more power and omniscience, becoming, not inhuman, but superhuman.

If fear, as Brian Massumi defines it, is "the objectivity of the subjective under late capitalism . . . the direct perception of the contemporary condition of possibility of beinghuman" (12), then what does the fear engendered by the ubiquity of serial killers, who are 
defined as at once more than and less than human, tell us? It will be seen that the very excess of the serial killer in fictional guises is an ironic device that works to ruffle the surface of the "low-level fear" Massumi describes. It is the injunction of "unspeakability": to not speak, show or tell of these acts which is the truer indication of fear. Intimacy with the monster, horror fictions repeatedly tell us, is the only way to survive.

The prime example of such a monster is Dr. Hannibal Lecter, the cannibalistic psychiatrist from the hugely popular Thomas Harris novels Red Dragon (1981), The Silence of the Lambs (1988), Hannibal(1999) and Hannibal Rising (2006). Witty, elegant, discerning, educated and cultivated, a genius, a Renaissance man brimming over with cultural capital (in Hannibal, he assumes with no difficulty whatsoever an academic position in art history in Florence, although his field is psychiatry), Lecter is figured as vampiric in a number of ways beyond the obvious penchant for feasting on others, enjoyably imbued with his cultural capital as a gourmet. Anthony Hopkins's famous line from the film version of Silence of the Lambs (1991) in which he plays Lecter, "I ate his liver with some fava beans and a nice Chianti," followed by a shockingly sudden preverbal utterance - "ftftfftftft" - of crude, yet gourmet appreciation, has become a popular meme as well, if not better known and appreciated as the Bela Lugosi line from Dracula, "I never drink .. . wine." Also vampiric is Lecter's peculiar insistence, like other god-like serial killers, on manners and morality as he punishes those who violate these codes. Character such as the smarmy, opportunistic Dr. Chilton in Silence of the Lambs or the misogynistic Paul Krendler in Hannibal, signify a connection with the feudal, aristocratic vampire, who must be invited in and conform to certain restrictive rules. At the same time, like the vampire, Lecter is monstrous, radiating menace, with his strange maroon-coloured eyes that "reflect the light in pinpoints of red" 
\{Silence of the Lambs, 16). Descriptions of Lector's weird eyes, like Lugosi's burning, hypnotic vampire gaze, are featured in each Harris novel. Lecter's horrific affect is shown in both novels and films as his veneer of urbanity and charm vanishes quickly and ferociously, revealing a hungry predator beneath. In the film Silence of the Lambs, he is shown listening rapturously to Bach's Goldberg Variations prior to brutally murdering, flaying and crucifying two policemen. Prior to disembowelling the hapless detective Pazzi and pushing him out of a high window at the Italian academy, Lecter delivers an eloquent lecture on art history to a learned audience at the Academy in Florence. To his victim, he reveals his knowledge of the Pazzi family history during the Italian Renaissance and metes out the same fate to the detective as that suffered by one of his treacherous forebears.

Like the vampire, Lecter over a series of increasingly popular narratives throughout the years has become more sympathetic and highly eroticized, particularly in the novel Hannibal, where he and Clarice Starling, the ingenue FBI agent who establishes a special rapport with him, eventually fall in love and disappear together. In the final pages of Hannibal, Starling, the "well-scrubbed, hustling rube with a litde taste," as Lecter sneers at her in Silence of the Lambs (22), is spotted emerging from a Mercedes Maybach at the opera in Buenos Aires, wearing exquisitely tasteful clothes and jewellery, while the throng around them gape with appreciation:

A man, slender and elegant in white tie, got out and handed out a woman. The sight of her raised an admiring murmur in the crowd around the entrance. Her hair was a shapely platinum helmet and she wore a soft sheath of coral frosted with an overlayer of tulle. Emeralds flashed green at her 
throat... His head was as sleek as an otter and his nose had an imperious arch like that of Peron. His carriage made him seem taller than he was (539). By becoming consort to the vampiric serial killer, literally, in the novel, and sharing his cannibalistic meal of Krendler's brains (becoming herself vampiric or cannibalistic, as Lucy and Mina do in Dracula), Starling the "rube" acquires his taste, distinction, and cultural capital. She becomes, like Lecter (lecteur), both reader of Others and text to be read by her devoted cannibal and the hypocritical crowds who worship them. The horror of such a pairing, however, becomes diluted by the romantic elopement of Lecter and Starling, which is why, perhaps, the film version emphasizes Starling wearing the gown, rather than eating the brains, and remaining firm in her role as agent of order in her resolve to capture and restrain Lecter. In the film, she is Mina, in the novel, she is a latter-day Lucy, a bloofer lady clad in brand names. ${ }^{68}$

The acts of serial killers and the mass murders performed by an individual, specifically a white, male, powerful individual, have become a staple of contemporary AngloAmerican horror fictions. Serial killer narratives are acknowledged as a subgenre in popular culture. In his foreword to Richard Tithecott's Of Men and Monsters: Jeffrey Dahmer and the Construction of the Serial Killer, James R. Kincaid points out the increasing prevalence of "general knowledge" about figures such as Dahmer, writing that, like Clarice Starling, "we

${ }^{68}$ In the film Hannibal (2001), Starling (Julianne Moore) does in fact wear a black spaghetti strap evening gown during the infamous dinner with Krendler scene, but unlike the poised and elegant woman in control of herself and her surroundings, drawing admiring eyes at the conclusion of the novel, she is shown desperately attempting to shake herself free of her drugged state, lurching and stumbling, with straps falling down over her shoulders and slurring her words, while Lecter calmly and paternalistically orchestrates the dinner and its aftermath. 
have a not very clandestine affair going with these monster-hunks, these white male superhero fiends, these Hannibal Lecters. We build them up as Others so we can fear and despise them, while we long for them and admire them" (ix). This movement towards the romanticization of the serial killer echoes that already discussed in the figure of the vampire. Popular fascination with serial killers resembles a full-fledged commodity fetish imbued with trendy menace: from the daily fare of tabloids and television specials, the latest bestselling documentary film, or the flourishing trade in red-and-black "true crime" paperbacks that promise the details of Jeffrey Dahmer's or John Wayne Gacy's awful deeds, to websites and the notorious serial killer trading cards. ${ }^{69}$ This cultural phenomenon has stimulated moral panics and courtroom dramas, media saturation and controversial fan(g)doms. It has also given rise to a particularly influential and controversial type of horror fiction under the rubric of "serial killer narratives," which may widely range from the expert analysis to the purely imaginative portrayal, or, as in Thomas Harris' bestselling novels, mingle the lurid imaginary with realistically "gritty" detection and "true crime."

What is missing from this discourse of serial killer fascination is the particular ways in which, fictions about serial killers are horror fictions in that they work through the deliberate evocation of fear and the designation of imaginative abnormality in the culture at large. The role of the reader or fan in these consuming obsessions about serial killers and the

${ }^{69}$ The moral repugnance that greeted these cards, however, seems to have been considerably muted in the wake of the recent American invasion of Iraq and the overthrow of Saddam Hussein's regime. The galaxy of 'villains' represented by the serial killer cards, which could be simply a new form of the Newgate Calendar, became a deck dealt out to military personnel that featured Baathist party members: the 'Most Wanted' writ anew. 
acts of reading or fan $(\mathrm{g})$ dom are largely overlooked in these "accounts. ${ }^{170}$ Mark Seltzer, for example, examines serial killing in relation to the spectacle in Serial Killers: Death and Life in America's Wound Culture (1998). However, he is more content to speculate at great and complex length about the phenomenon of the serial killer as an archetype of machine culture rather than examine his cultural manifestations as fiction, although he acknowledges that "fact and fiction have a way of changing places here" in an "identification without reserve" (16). Preferring to discuss the alcoholic memoirs of Jack London (1913) and the pulp noiroi Jim Thompson's The Killer Inside Me (1952), with scant attention paid to such horror texts as Bret Easton Ellis's American Psycho (1990) or the Hannibal Lecter series, Seltzer dismisses horror as simplistic "genre-fiction," in the process making some rather sweeping generalizations about what he calls "lurid redescription" and "evil kitsch" (108). The result of Seltzer's own redescription is lurid in an entirely different way:

The popular representation of serial violence tends to turn on a fundamental disavowal. . . of the radical link between technologies of writing and the work process ... also then on a disavowal of the mechanisms of simulation and reduplication - the primary mediations - that everywhere traverse cases of serial violence. (40)

The notion of "primary mediation" central to Seltzer's theoretical framework remains murky, defined as "lifelikeness" rather than "the imperfection and threat of living life itself (20).

${ }^{70}$ As previously mentioned in Chapter One, I again here use the word "account" guarded by quotes to describe my suspicion of the businesslike organization of a fluid and changing field into neat, theoretical formulations while sidestepping issues of affect and fan discourses. 
Here, Seltzer conflates a great deal in theorizing the "popular representation" of the serial killer, including fictions, but he ignores the issue of audience altogether. Are readers and fans necessarily the passive dupes of this "version of collective experience" which Seltzer describes as "the crowd gathered around the fallen body" (22)? What does it mean to consume serial killer horror fiction beyond rubbernecking at the wound culture? Seltzer maintains that "popular and professional accounts of serial killing instance again and again the absolute proximities between bodies and representations, implicitly understanding serial murder as a kind of machine work and even a pathologized work ethic" (40). For Seltzer, the serial killer becomes "the mass in person" (2) or "the species of person proper to a massmediated public culture" (7).

Seltzer's point is valid, but I would add that the "lifelikeness" of the serial killer is also closely related to Freud's simulacral uncanny ( "automatic, mechanical processes at work behind the ordinary appearance of mental activity" [226]), and thus to a horror which explicitly rather than implicitly depicts serial murder as "a kind of machine work," thereby laying the connection bare, raw and bloodied. This may hold true for "popular," rather than "professional" or criminological texts such as Elliott Leyton's, while the mechanism of reproduction between these differentiated narratives goes unremarked. While Seltzer mentions Freud's idea that our attraction to violence is an "aesthetic issue" (66), he ignores or derides what he calls the "mixture of moral and feral intentions" underlying serial killer representations in other than "professional" discourses. This mixture is one way to describe horror fan(g)dom which is certainly "feral" and arguably (im)moral in its embrace of nihilistic violence and gore. Here, Seltzer is missing the possibility of horror fan $(\mathrm{g})$ dom altogether. The drawbacks of such a stance become apparent in his critique of Joyce Carol Oates's 
article on serial killers in The New York Review of Books (March 24,1999). Seltzer calls her article

typical on several counts: in its almost ritual relaying of standard conceptions and misconceptions; in its coupling of lurid redescription and moralizing cliche; and in its gravitation toward nonexplanation and non-comprehension as a way of conserving the mystery of evil (conserving it by aestheticizing it). Hence the acts of the serial killer are like 'nightmare art-works' and 'suggest a kinship, however distorted, with the artist' . . . and the serial killer's pleasure in killing ... is simply repeated. (120)

Seltzer neglects to mention Oates's own serial killer novel, Zombie (1995), which is based upon the case of the notorious Jeffrey Dahmer and features a first-person narrator who, like Dahmer, sought to create human zombies by the drilling of holes in the skulls of his victims. His condemnation of Oates's "conserving of the mystery of evil (conserving it by aestheticizing it)" could equally be said to extend to horror fiction itself which, after all, aestheticizes noncomprehension, uncertainty, and the surreality of the spectacle of the fallen body, in Seltzer's own terms. However, Seltzer, eschewing fan $(\mathrm{g})$ dom, completely misses the Oates connection with horror narratives or "nightmare art-works."

This downright dismissal of the horror novel which has, since Frankenstein, shadowed the discourses of scientific expertise and technological mastery of bodies and wounds, is a constant feature of Seltzer's work. One might well ask what Seltzer is doing when he evokes William Gibson in his characterization of FBI "mindhunter" John Douglas as "of course . . . Johnny Mnemonic" (17). Is this display of intertextuality any more appropriate (or less fanlike) to the study of the serial killer than Oates's "aestheticization"? Does it reflect "moral" or 
"feral" intentions on his part? Is it any less pleasurable to certain privileged and "of course" knowledgeable scholars and fan(g)s? The culminating effect of Serial Killers, despite its many valuable insights, is that, as with the Gothic staking its claim on horror, an abstracted and privileged theoretical jargon of "gothicization" takes the place of "evil kitsch": "what is imaged as the 'nightmare artwork' of the serial killer is more exactly the primary mediation of serial violence" which brings up the "failure of distance" (121). More importantly, only one reading position is applauded by Seltzer, only one form of potentially dangerous prurience is identified. By collapsing the serial killer into the "species of person proper to a massmediated public culture: the mass in person" (7 his italics), Seltzer implies that only one reading position is available without considering that some positions may be more "prurient" than others and, a related question: how should we judge them?

Here again, lingering anxieties about the danger of horrific representation and its effect upon the gullible masses are invoked. I stated in Chapter One that horror is partially about measuring distances between the self and Others, but not in the sense in which Seltzer intends. Here, the knowledgeable academic steps in to join the expert "professional" or "mindhunter" as part of the privileged circle equipped with the suitable epistemological "distance" to understand the serial killer phenomenon, and, Sherlock-Holmes-like, "detects . . . a series of promiscuous substitutions between bodies and representations" (45). This echoes the familiar portrayal of horror as sensational, promiscuous, gratuitous and low-class, at least until it reveals its G(othic)-factor, which allows it to "pass" for a low form of literature. It is telling that, of all horror fictions, those involving serial killers have often generated the most controversy, sparking the censorship and branding of horror fiction in the 1940s as a dangerous genre, productive perhaps of the behaviour it depicts. One 
justifiably asks: who or what is promiscuous? The lingering scent of a penny dreadful haunts the Victorian alleyways of such designations as we rip through the layers of meaning. Tainted tabloids and yellowing and sinful journalism rather than professionals inform a horror fiction that rips and slashes the reader in an assault of blood-soaked imagery.

And yet, as a general repudiation of such theories, "gende readers" of horror fictions, including serial killer fictions, remain. Arguably, this reader is fascinated by something more than the "renovated version of motiveless malignity" which Seltzer argues, following Karen Haltunnen, lies at the heart of the "modern horror experience" (134). The problem with such an approach is illustrated by Seltzer's discussion of John Carpenter's homage to Lovecraft, In the Mouth of Madness (1994) as "a burgeoning contagion of senseless violence and mass murder":

On this reductive account of representation, the primary mediation of the subject is doubly quarantined. On the one side, it is projected onto a general indictment of media-borne violence — that is, violence as media-born; mediation impinges on the subject only 'from the outside,' in a failure of correct distance with respect to representation. On the other side, the primary mediation of the subject is exoticized, identified with the unreal genre-fiction of the horror story. At once making visible and derealizing the primary mediation of the subject, such genre-fictions screen (in both senses) the manner in which identity or the face ("the face-system,' in Deleuze and Guattari's sense), is a horror story. (177)

By leaving the audience and their supernatural horror fan(g)dom altogether out of the picture as "unreal," Seltzer unnecessarily confuses the issue of "distance" with the 
potential of aesthetic enquiry and the relevance of Kincaid's "general knowledge" on the part of readers, which folds older supernatural meanings into newer social nightmares. The abstraction of Seltzer's discourse, too, tends to evade the rhetorical and visual devices by which "distance" can be experienced. To take a previously cited example from recent serial killer representation, John McNaughton's chilling pseudo-documentary Henry: Portrait of a Serial Killer (1986), the titular character Henry goes about his grisly work with grim detachment, distanced through acoustic flashbacks and graphic tableaux. We are only allowed to view his acts of murder mediated through the technology of video camera recording, the implications of which have already been discussed. Only once do we glimpse Henry in action, when he suddenly smashes a television over a man's head, which is indeed "media-borne violence" in the most literal way. Even when he is engaged in such violence, he remains silent, dispassionate. Henry's detachment is contrasted with the unsavoury compulsions of Henry's accomplice, Otis, a slavering pervert who cannot refrain from fondling the body of a female victim until he is angrily stopped by Henry. Henry also saves Otis's sister, Becky, from being raped by Otis, although this is shown to mean less later on. Such representation blurs conventional distinctions between motiveless and motivated malignity, disrupting comforting sociological and historical notions of madness and destabilizing the understanding of murderous violence without, as Seltzer argues, "eroticizing" and "conserving the mystery of evil."

The popular fascination with horrific representations of serial killers has been placed under scrutiny as, variously, a (gendered) "affair" with the horrific; a growing addiction to violence; and an important indication of the breakdown of social boundaries between the real and the represented. I would like to take up the first two aspects with reference to the 
latter, as exhibited by certain fictions of the 1980s and 1990s that explicidy make forays into the real their subject matter and the site of their investigation; where, in other words, "textual poaching" becomes an art of the fictional projected upon the real, throwing it into stark and gruesome relief. Borrowing Michel de Certeau's idea in The Practice of Everyday Ufe (1988) that "readers are travellers; they move across lands belonging to someone else, like nomads poaching their way across the fields they did not write ..." (174), Henry Jenkins argues that fans "construct their cultural and social identity through borrowing and inflecting mass culture images, articulating concerns which often go unvoiced within the dominant media" and becoming "active participants in the construction and circulation of textual meanings" $(23-4)$.

In other words, the possibility of fan $(\mathrm{g})$ dom of serial killer narratives creates a slashed intertext, spilling meaning onto both high and low cultures. From isolated and marginalized figures of the 'beyond,' serial killers have moved into discursive prominence. Further, they are inevitably linked, as Seltzer has pointed out, to the question of the mass individual, to difference and to monstrosity, which we should do well to keep in mind, under normative regimes that would turn us into a mass of undifferentiated and apathetic readers. I argue for a more nuanced understanding of serial killer horror fiction as a disturbing reading experience that goads a reader into response and, thus, into a more self-reflexive examination of his or her position within the mass of individuals through the display and demonstration of different layers of historical, cultural and fictional knowledge.

The history of serial killers is lengthy and well-documented, including a couple of vampiric feudal figures, such as Countess Erzebet Bathory of Hungary in the seventeenth century and the French nobleman Gilles de Rai's. Katherine M. Ramsland has recendy argued 
that the first known serial killer was a female poisoner named Locusta who poisoned the Emperor Claudius and put Nero on the throne (1). Generally, the designation of such infamous historical criminals as serial killers is aligned with the description of bloody murders, skyrocketing body counts and sadism. Perpetrators of mass murder, whether or not they are given the contemporary designation of serial killers, for example, are widely referred to by the sort of synecdochal and metaphoric nicknames that serial killers routinely receive in the popular press: "Jack the Ripper," "The Bloody Countess," "The Beauty Queen Killer," "The Butcher of Buchenwald," "The Angel of Death," "The Boston Strangler," "Son of Sam," "The Night Stalker," "The Monster of Dusseldorf," and "Chemical Ali," to name only a few. Richard Tithecott points out that it is the gendered male, heterosexual killers who mostly acquire this "sobriquet" (73). Despite the atrocities of history, the evidence weighs towards the notion that serial killing as we know it is more a contemporary construction shaped by cultural brooding upon recendy multiplying atrocities with anxious eyes. The term itself, as Seltzer notes, is derived from cultural production, coined by an FBI detective after the "cliffhangers" in cinema serials (64).

Serial killing is conceived as a particularly American phenomenon, but there have been many serial killers hailing from other national cultures. To name only a few recent serial killers, along with their media monikers, gives some idea: in Russia, there have been Nikolai Dhzurmongaliev and the pedophiliac murderer Andrei Chikatilo, popularly known as the "Rostov Ripper"; in the Ukraine, Anatoly Onoprienko; in Central America, Pedro Lopez, or "The Monster of the Andes"; and in Mexico, Adolfo Constanzo, a cultist who reveled in torture and human sacrifice. Australia has been terrorized by the "Night Caller," Eric Edgar Cooke, and William "the Mutilator" MacDonald. In Pakistan, Javed Iqbal and three young 
accomplices preyed off the streets of Lahore, raping and slaughtering at least a hundred children; Iqbal was sentenced to the same kind of horrific death he had meted out to his victims - to be publicly strangled with a chain, dismembered and dissolved in acid, a judgment which drew protest from the United Nations. France and especially Germany have also had their share of serial killer atrocities, and Japan made the self-confessed cannibal, art student and scion of a wealthy family Issei Sagawa a notorious celebrity and film star.

The bare facts of serial killer stories, such as those found through online and crimegenre galleries of infamy are presented as a confrontation with monsters. Perhaps the most shocking aspect of the contemporary serial killer narrative is that the evil we always have suspected to lurk in human hearts is now amplified in chatrooms all over the World Wide Web, a huge online version of the labyrinths of Whitechapel, complete with their own versions of penny dreadfuls, as the Michael Marshall Smith story "More Tomorrow" makes abundandy clear. Real-life atrocities, particularly those committed by the people we know popularly as serial killers, epitomize a certain unspeakability that is endlessly discussed. The discourse around such atrocities mirrors Michel Foucault's theory of sexuality as that which is endlessly talked about but which is popularly perceived to be repressed (History of Sexuality 1977). Hence the journalistic truism, "If it bleeds, it leads." In place of a scientia sexualis, or more accurately, operating as a concurrent discursive practice, with its emphasis upon twisted or perverted sexuality in the killer's "profile," we have a science of popular homicide, generating not only psychopathologies and forensic studies, but myths and fictions about those rites and practices. Celebrity and literary authority accrues to serial killer adversaries such as John Douglas, the FBI's serial killer profiler or "mindhunter," who was the inspiration for the fatherly figure of Jack Crawford in Silence of the Lambs; Robert Hare, the 
author of Without Conscience (1999), a study of psychopathy; and Elliot Leyton, the author of Hunting Humans (2005).$^{71}$ This science is not simply a disclosure of the perverted perpetrator, a hunting of the humans, but also a hermeneutics of the monster, a disclosure of primal causes of abnormality that provides fertile ground for satiric and subversive impulses. My intention here is not to denigrate attempts to prevent serial murder, but rather to call attention to the proliferation of auras, symbolizations, technologies and authority vested in the figure of the expert on serial killers: St. George versus the Red Dragon. It is unsurprising therefore that Thomas Harris's novels are perceived as the quintessence of serial killer narratives with their Byronic, vampiric (anti)hero. In keeping with the ancient stories and with more recent horror fictions, the monster is wise beyond measure. The mindhunter must match wits with him and even come to love the monster before he or she can triumph.

Commensurately with this glowing pedigree of the Nietzchean, abyss-gazing hero, society goes to great lengths to display the unspeakability of the killer's acts in the form of censorship and publication bans, which, ironically, lends a prurient air to even the sanctioned discourses surrounding serial killing as the media play a real-life horror game of looking and not-looking with the masses. ${ }^{72}$ The recent trial of Robert Pickton, murderer of several of the

${ }^{71}$ The IMDB page for Silence of the LMmbs includes a disturbing bit of "trivia": the actor Scott Glenn who played Crawford was given audio tapes by John Douglas of serial killers Lawrence Bittaker and Roy Norris torturing, raping and murdering two teenage girls. "Glenn listened to less than one minute of the tape, and has since said that he feels he lost a sense of innocence in doing so and that he has never been able to forget what he heard. To this day, he says that the tapes still cause him anxiety and bad dreams" < http://www.imdb.com/title/tt0102926/trivia > Accessed December 3, 2009.

72 The debate over whether or not to show the execution of deposed Iraqi dictator Saddam Hussein in 2006 is an instructive case in real-life horror and the media. David Olive, noted "the continued resistance of Western media consumers to depictions of real-life 
Vancouver Downtown Eastside's missing women, for example, has raised the issue of the publication ban once again, as with the notorious Paul Bernardo and Karla Homolka case. ${ }^{73}$ In both of these instances, the Canadian media was placed under a publication ban, while international media both publicized and reveled in the grisly evidence. The rise of the World Wide Web here too has complicated matters. In an online community, details of the Pickton case can be sought outside national borders and laws, rendering morality bans upon the dissemination of knowledge about horrific acts both problematic and unfeasible.

In the proliferation of discourses surrounding the serial killer - medical, legal, ethical - the deeds themselves retain a horrific affect of unspeakability in the face of discovery and broadcast, and that unspeakability persists in the representations and imagery that are evoked by such acts. It is here where the work of horror is performed, both drawing upon explanatory discourses and refusing to attribute final authority to anything short of the mythic, which is what makes the link between the represented and the real particularly fruitful in a study of serial killer fictions. Rather than a wound culture "conserving the mystery of evil," in Seltzer's terms, horror fictions about serial killers such as Alan Moore and Eddie Campbell's graphic novel From Hell (1993), which details one version of the Jack the Ripper murders but includes all the "Ripperologies," laid out and illustrated in

horror. . . . [r] eaders who don't give a second thought to planning an evening around a DVD rental of Pulp Fiction often have an unforgiving regard for horror verite" ("To Show or Not to Show," Toronto Star, Sunday January 7, 2007).

${ }^{73}$ See "Untangling Karla's Web: Post-National Arguments, Cross-Border Crimes, and the Investigation of Canadian Culture" by Michael Dorland and Priscilla Walton in the American Review of Canadian Studies, Vol. 26, 1996 for a discussion of the publication ban around the Bernardo/Homolka case. 
painstaking footnotes, ceaselessly probe and explore that which was hidden and forbidden to disclose, forcing the reader to examine and balance their own constructions of the many signifiers of horror, both real and fictional.

Serial killers in fiction, often composites of "real life" (natural born) killers, tend to present a cracked chain of intertextual signification from the real to the entirely fictional. The gruesome mutilations and murders committed by Ed Gein, for example, in Plainfield, Wisconsin, were the inspiration for Robert Bloch's Psycho (1959), Deranged (1960), and The Texas Chainsaw Massacre (1974), albeit in an oblique fashion. Bloch, claiming to have known "very little of the details concerning the case," based his novel on "the situation rather than on any person, living or dead, involved in the Gein affair .... It was only some years later that I discovered how closely the imaginary character I'd created resembled the real Ed Gein both in overt act and apparent motivation" (Clive Barker's A-Z of Horror 2\%). Tobe Hooper, the director of Texas Chainsaw Massacre, heard about Gein from his relatives, who "told me these terrible stories ... I grew up with that like a horror story you tell around a camp-fire. I didn't even know about Ed Gein .... But the image really stuck" (32). As the original becomes the stuff of legend, so does the copy. What become "stuck" in the recounting are the horrors of the "overt act" and "apparent motivation" committed by the killers, turning unspeakable acts into the stuff of mythology. Gein's mummified corpses and his mother fixation became, through slippage and transmutation, Norman Bates's experiments in taxidermy and the Sawyer family's bizarre skeletal furniture. For the purposes of horror, it is no longer the specific "details" of Gein's case that matter, but the acts and images of the fictions that, in their turn, "stick" in the imaginations of readers and audiences. However, it is the very realism with which those acts and images are portrayed that originally provided the glue, 
figuratively speaking, to bind myth, the real and the fiction together in a seamless and terrifyingly contemporaneous whole.

More recently, it has been the unraveling of those seams that has mattered in horror's treatment of the serial killer. The figure of the killer is at once clearly "real" and yet fantastically murky. In fiction, the serial killer becomes a reductio omne cides. The Henry of Henry: Portrait of A. Serial Killer is neither "Freddy" nor "Jason" but, although "real" in the film's lexicon, he is not quite Henry Lee Lucas either. Both Leatherface in Texas Chainsaw Massacre and Norman Bates in Psycho are derived from, but not identical with, Ed Gein. Poppy Z. Brite's unlikely pair of serial killer lovers in Exquisite Corpse (1996) mirrors Jeffrey Dahmer and Dennis Nilsen, but the similarity ends very quickly when they discover their HIV-positive status and their love for each other in a type of serial killer "slash" fiction. Reality is here itself stalked, slashed and mutilated: the truncated result inhabits a disturbing borderland where the position becomes something different from gendered sadism. ${ }^{74}$ It is a struggle, quite literally, with the issue of the representation of the reality of violence and fear. As Hills notes, the interpenetration of categories of "fact" and "fiction" in films such as Dahmerwhich. purport to be biopics "violate[s] cultural categories of fact/fiction, thus violating their supposedly 'separable' communities of understanding by throwing up category confusions, errors or hybrids" (132). In this way, the film Ed Gein (2001), a biopic of a "real" killer, was marketed very similarly to the fictional Henry: Portrait of a Serial Killer, capitalizing

It is important to note that gendered readings of serial killer narratives continue to be dominant, and excellent work has been done by Clover, Pinedo and others on the subject. For that reason, I concentrate here upon the implications of audience fan $(\mathrm{g}) \mathrm{dom}$, while acknowledging that gendered experiences of serial killer fiction retain their relevance. 
upon the serial knowledge of audiences, however distant, by which Gein is the 'prequel' to the "stuck" Norman Bates and Leatherface: "Before .. . there was Ed."

The implicit realism of all serial killer narratives, then, explicidy encourages the contemplation of the acts of seeing and reading in relation to one's knowledge and one's fan(g)dom. The pathology of the act of seeing/reading itself as "sick" or "addictive" performs the discursive function of exposing the limits of acceptability according to community standards or other categories, and also has been constituted as an element of a particular subcultural style, to use Dick Hebdige's terminology (1979). Not surprisingly, the goth/punk subculture in particular has adopted slasher motifs and textually poached numerous serial killer and slasher narratives, situating them within Goth discourses of postindustrial alienation. For example, the Toronto industrial metal band Malhavoc's track "S.C.E.X." is a pastiche that samples indiscriminately from the 1973 documentary Manson the indignant voice of a cellmate of Manson Family member "Squeaky" Fromme ("I think that's sick,") from The Texas Chainsaw Massacre 2 (1986), source of the song's title and a grimly funny moment when the elder Sawyer admonishes his boy Leatherface to choose between "sex or the saw," and also from the Goth cult film Heathers (1988) ("Fuck me gently with a chainsaw"). ${ }^{75}$

Sick is a familiar word in the serial killer lexicon that connotes both illness and disgust. The act of representing what such atrocities must look and feel like is particularly associated with that epithet. Horror films about serial killers represent a nightmarish

${ }^{75}$ From Malhavoc's album The Release (1990), which features tracks full of horror references, including "William Wilson" (Poe), "The Dunwich Horror," "Reanimator" and "From Beyond" (Lovecraft) as well as "Dread" and "Attack from the Sepulcher." 
empathy, a stretching-beyond the limits of permissible discourse. The designation of "addictive" is reserved for such representations and their consumers, who are caught up, it is implied, in the perpetual hesitation of the fantastic and, therefore, are themselves suspect of "sick" pathologies. Seltzer gives a partial indication of this "psychopathology," referring frequently to literature and film in order to make the point that this kind of "addictive violence has become not merely a collective spectacle but one of the crucial sites where private desire and public fantasy cross" (Seltzer 1). But who, precisely, is addicted? And what do we mean when we speak of "addictive violence"?

The relationship between reality and representation might not be so much a matter of "public fantasy" and "private desire" as of private desires which then become synonymous with publican'. This relationship is not necessarily celebratory. As Pinedo has commented, graphic imagery of the "ruined body" has laid open the problem of the individual in capitalist and, more specifically, American society:

Given the dominance of the individual within American culture, the intimate apocalypse is the most effective way to stage the experience of helplessness .... What fictional and real-life violence have in common is their location within a capitalist production context that commodifies everything, including death. (108)

I would take Pinedo's insight further to argue that the serial killer narrative as a realistic spectacle (in Guy Debord's sense) also implicates other social situations than "the experience of helplessness": namely, the experiences of mastery, intertextuality, pleasure and disgust which might, all at once or in varying measures, characterize a horror fiction reader's responses. As Hills observes, critiquing Seltzer's, Annalee Newitz's and Mark Pizarro's 
theories of seriality and addiction: "Once more the serial killer functions less as an object of study, and more as a metaphor that can be used to cast moral disapprobation across an anonymous 'mass' of consumers construed, rather bizarrely, as setial-kiilers-manque" (142). Hills's point that "academic practices and discourses ... work on texts to produce them as meaningful within ethical/moral frameworks" (143, his italics) can also be applied to horror fan(g)dom as a text. Hence Robin Wood has observed that, for him, the most frightening aspect of Texas Chainsaw Massacre was viewing it with a raucous group of teenagers who cheered on every flourish of Leadierface's chainsaw.

This perceived inclusion or identification of horror fans with the omnipotent and omniscient slasher killer as texts to be read and understood may be one strategy for negotiating the "helplessness" that horror engenders as threatening affect. The teenagers are displaying the negative, nihilistic aspect of desire or repression, in Wood's terms, which explodes in fury towards permissible fictional subjects, allowing them to cheer on the monster. At the same time, such performances of fan $(\mathrm{g})$ dom render the youths threateningly textual, monstrously subcultural and politically volatile. The chain of signification between reality and representation is particularly tense here, however, resulting in real-life repression of serial killer narratives with fan(g)ed appeal such as Bret Easton Ellis's American Psycho (1991), the ultimate satire on our fascination with the omniscience of the serial killer. It has been argued by moralists and proponents of the "video nasties" debate, as discussed in my first chapter, that private desire and public fantasy not only cross, but continue upon a disturbing trajectory into areas where spectacle becomes enactment.

This argument, accusing literature and film of motivating and informing further atrocities, is fiercely contested. Stephen King discusses the ramifications of depicting graphic 
violence in his final chapter, "The Last Waltz - Horror and Morality, Horror and Magic" (Danse Macabre), recalling the Werewolf as archetype in order to playfully suggest that, despite horror's normative concerns which are masked by the theatrical costumes and gestures of playful signification, the writer might be "under his/her fright wig and plastic fangs" a "capering, gleeful, red-eyed agent of chaos" (369). ${ }^{76}$ King recalls being accused by a young reporter of "feeding off people's worst fears" (361).

As we saw in Chapter One, exploitation and immorality have always been felt to taint horror fictions and their fans by virtue of their status as infectious commodities, the consuming of which displaces proper processes of mimesis and catharsis, giving way to mimicry and simulation. In this view, serial killing is an addictive form of post-industrial consumer capitalism. To the vapid, indifferent model sitting like an expensive doll with Patrick Bateman in yet another expensive restaurant rife with the ennui of the privileged, Bateman may as well be engaged in "murders and executions" as the "mergers and acquisitions" she hears him say (he has in fact said the former) (206). Despite his increasingly frantic efforts to reveal himself to his jaded peers, Bateman's class status confers impunity on the serial killer's murders and executions. In the world of American Psycho, it is implied, all are complicit, all are guilty in keeping Bateman in his elevated place. This complicity is underscored by Bateman and his peers frequently being mistaken for each other, which provides him with a constant alibi. As an indistinguishable simulation of every Wall Street

${ }^{76}$ The cover art of my edition of Danse Macabre indeed echoes such a view of the creator of horror, consisting of a drawing of King's face lit from below with glowing red Hannibal-Lecter or vampiric eyes: the author taking on a resemblance to the texts and the publishers capitalizing upon it. 
yuppie around him, Bateman the torturer, cannibal and monster, is no more or less frightening than his peers.

It is for this reason that Phil Hardy identifies a film such as John McNaughton's Henry as "resolutely unexploitative" in its creation of a Brechtian Verfremdungseffekt through the sequence with Otis and the video footage. In fact, this film, like American Psycho, foregrounds such affects to specifically and politically demystify and decriminalize horror fan $(\mathrm{g}) \mathrm{dom}$ through the exposure rather than the "conservation" of the mystery and the breach of the fourth wall, breaking down the boundaries between the real and the represented. Ernst Bloch, explaining the political aesthetics of the Verfremdungseffekt, reminds us that its purpose is to challenge alienation (Entfremdung) "at home in our own world, where our lives have been sold, turned into commodities, reified" (121). The Verfremdungseffekt $" h$ directed against that very alienation which has doubled in strength as people have grown accustomed to it." Bloch describes the "Tableau!" or "Aha!" moment as a "recognition" where "insight into what is closest to the beholder grows out of his amazement at being confronted with what is farthest away" (124). Thus the Verfremdungseffekt is the "provision of a shocking and distancing mirror above the only too familiar reality; the purpose of the mirroring is to arouse both amazement and concern" (125). The moments of "Tableau!" in serial killer narratives such as Henry and American Psycho are such mirrors.

In American Psycho, the narrator, Patrick Bateman, is not only a serial killer but also a horror fan who emits random bits of knowledge about other serial killers, such as Ed Gein, and obsessively rents horror movies such as Body Double (1984). This fan(g)dom on the part of the serial killer protagonist performs the satiric function of making the reader question his or her own fan(g)dom concerning serial killer fictions, but also throws into stark contrast the 
isolation of Bateman from his Yuppie peers as they discuss women. Bateman's horrific caricature of misogyny, quoting Gein, mirrors and exposes his peers' misogyny, bringing it into sharp relief and they do not know how to respond, except with the banalities that make up the fabric of their lives:

After a deliberate pause I say, "Do you know what Ed Gein said about women?

"Ed Gein?' one of them asks. "Maitre d' at Canal Bar?"

"No," I say. "Serial killer. Wisconsin in the fifties. He was an interesting guy." "You've always been interested in stuff like that, Bateman," Reeves says, and then to Hamlin, "Bateman reads these biographies all the time: Ted Bundy and Son of Sam and Fatal Vision and Charlie Manson. All of them." "So what did Ed say?" Hamlin asks, interested.

"He said," I begin, '"When I see a pretty girl walking down the street I think two things. One part of me wants to take her out and talk to her and be real nice and sweet and treat her right." I stop, finish my J\&B in one long swallow.

"What does the other part of him think?" Hamlin asks tentatively. "What her head would look like on a stick," I say. (92)

Bateman's connoisseurship of serial killers, which clearly makes even his amoral yuppie peers uneasy, caught up as they are in the relentless glitzy cheer of high-end brands and luxury living, is juxtaposed with his stature as an ultimate authority upon elegant men's and women's clothes, which marks him as a sought-after authority. Indeed, his understanding of how to dress and his connoisseurship of brands is the only knowledge that matters, more so 
than literary or popular erudition, in his elite world summed up by "surface, surface, surface, a Rolls is a Rolls is a Rolls" (342). His obsessive attention to the details of tailoring and coordinating vests, socks, pants, and labels is coupled with his knowledge of serial killers, as somebody who can tell Ed Gein from the maitre d' at Canal Bar. Ellis's satiric emphasis on Patrick's horror fan(g)dom sets him apart from his boorish friends, who take pleasure in torturing homeless people on the streets of New York by holding out money to them and pulling it back, an activity in which Patrick does not engage as his tortures are more prolonged and more private.

In this context, his horror fan(g)dom marking him as different from the others becomes doubly ironic. Thus, he is "recognized" as dangerous by the clerk at the video store, who notices that he has rented the Brian de Palma film Body Double thirty-seven times: "I pretend to ignore his horrified reaction as he recognizes me after he looks at the Body Double box" (113). However, when Bateman follows this up with a drooling, predictable psycho act, the other video store clerk pointedly ignores him. The grim joke, of course, is that, because of Patrick's Wall Street status, all his "true" confessions are doomed to go unheeded by friends and strangers alike:

"I like the part in Body Double where the woman . . . gets drilled by the . . . power driller in the movie . . . the best," I say, almost gasping. It seems very hot in the video store right now all of a sudden and after murmuring "oh my god" under my breath I place a gloved hand on the counter to settle it from shaking. "And the blood starts pouring out of the ceiling." (113)

Brian Massumi has described the pervasiveness of the commodity in contemporary American culture as the "hinge" which holds the individual and his or her identity together 
(8), and this process of commodity-recognition, taken to amusing excess in American Psycho, is, in an equally satiric move, offered as the antidote to Bateman's fan(g)dom. After almost losing control in this scene, Patrick tells us,

I take a deep breath and while I'm saying this my head starts nodding of its own accord and I keep swallowing, thinking $\mathrm{J}$ have to see her shoes, and so as inconspicuously as possible I try to peer over the counter to check out what kind of shoes she's wearing, but maddeningly they're only sneakers - not KSwiss, not Tretorn, not Adidas, not Reebok, just cheap ones. (113)

Both the horror film and the cheap sneakers launch the breakdown of Patrick's carefullyconstructed persona and reveal the disturbed monster beneath the surface in a wryly absurd comment upon "improper" reading practices. Renting Body Double thirty-seven times is something only a fan would do. Describing a gory scene in such an appreciative way is something a horror fan would certainly do. However, the sheer excessiveness, the G-factor of Patrick Bateman's acts (he is literally a "baitman" for moralists) gives the satire away. The fact that the sight of a brand-name shoe has the power to prevent Patrick's veneer from cracking, however, destabilizes the convention of reading horror fan $(\mathrm{g}) \mathrm{dom}$ as dangerous. Bateman's fan(g)dom is not as bizarre as his commodity addiction taken to a ludicrous extreme. His fan(g)dom marks him rather as an alienated Other grotesquely conforming to his predatory Wall Street reality.

Critics have taken up the obvious class aspects of serial killing: Leyton notes that "the pre-industrial multiple killer was an aristocrat who preyed on peasants." The industrial era "produced a new kind of killer, most commonly a new bourgeois who preyed upon prostitutes, homeless boys, and housemaids" whereas "in the mature industrial era, he is 
most often a failed bourgeois who stalks university women and other middle-class figures" (269). Tithecott disagrees with Leyton, however, presenting evidence that the serial killer is instead "an archetype of bourgeois success .... the serial killer, like Jekyll, is representative of a society which seems prone to conceal secrets behind respectability: the brothel-visiting banker, the transvestite clergyman, the broker whose interest in stocks is as much sadomasochistic as financial" (54). Bateman the fictional serial killer certainly fits Tithecott's profile rather than Leyton's but his fan $(\mathrm{g})$ dom is marked as sad and desperate, not heroic. The fact that Patrick Bateman's breakdowns and slippages occur during his fan(g)ed discussions of horror fictions indicate that the real "body double" is not the horror fan, but the hyper-consumer who is busily discerning brand names everywhere, including on die bodies of his victims.

The act of killing is itself a kind of purchase in the serial killer narrative. Carol Clover has detailed the 'shopping list' of weapons that a slasher might employ, noting that guns have no place in slasher films .... In some basic sense, the emotional terrain of the slasher film is pretechnological. The preferred weapons of the killer are knives, hammers, axes, ice picks, hypodermic needles, red hot pokers, pitchforks and the like. Such implements serve well a plot predicated on stealdi and the unawareness of later victims that the bodies of their friends are accumulating yards away. (Clover 31)

Insofar as the slasher is a kind of fictional representation of the serial killer, albeit faceless, stripped of personality and reduced to machine-like, compulsive and fantastic repetition, Clover's point is valid; as she says, the slasher film is virtually defined by its emphasis upon the weapons and the bodies rather than upon the psychological and social construction of 
the killer. The same is not true, however, for serial killer narratives, which often perform generic crossovers into the realm of horror's relative, the detective story, where "mindhunters" stalk their dangerous prey. In this sense, serial killers are indeed Gothic. As Seltzer notes, there is an emphasis upon the ruined places of their workings, where they take their victims, rather than the weapons that they employ.

In Chapter One, I touched upon the moral panic associated with horror fictions and with horror fan(g)dom, using Columbine as an example. Serial and spree killers have been the favoured site where moral panics can interrogate and castigate horror fan $(\mathrm{g}) \mathrm{dom}$. The examples discussed by King in Danse Macabre (361-7) constitute only some of the evidence that has been amassed to claim that the creators of horror films such as The Exorcist (1973), Psycho (1960), and Carrie (1976) bear responsibility for horrific acts. More recently, William Wheeler Dixon has joined the host of fingers pointed at violent and horrific video games, in particular Doom, citing particularly the use of simulated 'video-game' style training programs in army operations: "Not everyone who plays Doom IJI will become a mass murderer, but even a casual glance at the social landscape of contemporary America reveals that it has become a nation marked by outbursts of senseless violence .... The culture of guns, of death, of'kill or be killed' must inevitably lead to violence" (Visions of the Apocalypse 124129). ${ }^{77}$

The extent to which we embrace this notion of causation reveals the simultaneous need for explanatory fictions and enjoyable fear of horrific representations that characterizes

${ }^{77}$ Dr. Brian Greenspan notes, however, that "games are procedural, performative and interactive in ways that books and films aren't" and are therefore more susceptible to charges of contamination. 
serial killer fan(g)dom. It is with no great surprise, indeed with a certain relish, that we learn that Richard Ramirez took his serial killer nickname from an AC/DC song "Night Prowler." Such unsavoury trivia accumulates around the figure of the serial killer, lending to the narratives that circulate around these figures an aspect of subcultural connoisseurship that must be factored into their reception as both cult and popular fiction. The tendency to play with gimmickry and to revel in the peril of consuming the fictions was notoriously capitalized on by director William Castle, who installed ambulances in the lobbies of movie theatres and issued "at your own risk" warnings. Even if we are not as literal as Castle, Richard Tithecott points out that this is a particular kind of "product liability" (10), one which is mirrored in the classification of serial killer films.

According to Seltzer, such warning labels signify "the popular understanding of trauma" as cause, which lumps together "two coupled but different versions of the violence of representation ... the notion that representations of violence cause acts of violence fmonkey see, monkey do*] is conflated with something else: with the violence intrinsic to the penetration of representation into real life" (262). "The danger," as Seltzer puts it, "that one might be devoured by representations" is synonymous with the fear engendered by horror. The fascination which has been labeled "addictive" might consist simply, therefore, of exploring the extent to which representations can affect readers. When the knife strikes, we flinch, regardless of what attitude we have adopted towards the text. The characterization of the horror reader or viewer as masochistic, potentially vulnerable to the transmission of violence, misses both the affects and the ideological messages of horror generated through narrative. For example, the indignation and outrage inspired by American Psycho that Linda Kauffmann describes in Bad Girls and Sick Boys: Fantasies in Contemporary Art and Culture (1998) 
badly missed the point, as Kauffman writes, that the book was "a death letter for the consumptive greed and entitlement of the 1980s" (249).

Unfortunately, the 1980s did not "get" this letter, and the book's dizzying array of consumer references are still relevant in the 2000 s, even post-financial crisis. The giants of Wall Street still get away with murder. Patrick Bateman's gleaming stainless-steel world still conceals heads in his Viking refrigerator. Imagining danger through consuming fictions about serial killers might, as the protesters of NOW might see it, be a means of masochistically subjecting oneself to the identifications of psychoanalytic criticism - or it may be a pleasurable way of rehearsing death and mutilation in a culture where such things are kept out of sight and rehearsing them, as knowledge, in the violent effects produced upon the reader/viewer's body. This is the work of the G-factor in all its excess where the shudder and the scream, as I suggested in Chapter One, become the litmus test of knowledge. I think that Hills, Kermode and others who theorize horror's pleasures overlook this type of fan $(\mathrm{g}) \mathrm{dom}$, and this is an important reason why horror fans and non-fans seek out and rehearse not only their connoisseurship, but their fears.

Seltzer invokes the compulsive repetition, inspired by trauma, which traverses the boundary of real-life and fantasy. "Wound culture," as "the torn bodies and torn persons about which the crowd gathers," is the proliferation of these representations in the "information society," a fusion of the individual with what he calls the "mass in person." The wound becomes no longer a marker of the sacred, but the "icon, or stigma, of the everyday openness of every body" (2). Seltzer traces this to a shift in our understanding of individuality during the course of die nineteenth and twentieth centuries, which has coincided with the discovery, in horror fiction, that monstrosity or deviance can be an 
inward secret or disease. Robert Bloch's Psycho is, in a sense, the culmination of dragging this knowledge into the light. Seltzer's penultimate chapter is devoted to "cleaning up": cars and bodies are pulled from swamps, and Lila hears a logical exposition of Norman (Normal) Bates's Oedipal nightmares from Sam, who keeps referring to what "Dr. Steiner" says: A lot of the things he said, about fugue and cathexis and trauma, are way over my head. But as near as he can make out, this all started way back in Bate's childhood, long before his mother's death. He and his mother were very close, of course, and apparendy she dominated him. Whether there was ever anything more to their relationship, Dr. Steiner doesn't know. But he does suspect that Norman was a secret transvestite long before Mrs. Bates died. You know what a transvestite is, don't you? (Psycho 212)

Lila, listening to Sam's lengthy summary of Steiner's diagnosis, muses, "then the horror wasn't in the house ... it was in his head." After Psycho, everybody "knows" what a transvestite is, and "knows," moreover, that a transvestite is "abnormal." This fear is taken up by Brian De Palma in Dressed to iO7/(1980), his tribute to Hitchcock. The novel Psycho reserves yet another conclusion, however, one that is not so conducive to the wrapping-up of ends, being a brief, uncanny epilogue by Norma(n) Bates, the "ventriloquist and his dummy" (217):

The real end came quiedy.

It came in the small, barred room where the voices had muttered and mingled for so long a time - the man's voice, the woman's voice, the child's. The voices had exploded when triggered into fission, but now, almost miraculously, a fusion took place. (221) 
This nuclear discourse, the "real end," is deceptive in that the fusion retains the gendered attributes of Norman's mother, who retreats into illusion and silence: "She was the only one left and she was real. . . but just to be on the safe side, maybe it was best to keep pretending that one was a stuffed figure" (223). Fission and fusion, in Carroll's terms, create the ultimate nuclear family. Several hundred Psychos later, the emphasis has today shifted from the toxicity of the family to the toxicity of the killer himself against an insane world where his stabs speak for the masses, and the wounds multiply exponentially. In the serial killer film SeTen (1995), for example, the killer "John Doe" (Kevin Spacey) acts as a self-identified moral purgative, punishing in frighteningly novel ways the seven deadly sins embodied in his victims. The allegory culminates with Doe's final victory over his pursuers, particularly the young detective played by Brad Pitt, who is provoked by Doe into unleashing his own violent impulses and killing the killer, who is demonstrated to have been in control all along.

Such a depressing conclusion relates to what I described earlier as a Gothic sensibility: the serial killer, rather than embodying the horrors of the inner psyche, becomes a mythical, almost god-like figure embodying the horrified imaginations of a post-industrial culture enmeshed in a permanent state of low-level fear. The reader or audience of the serial killer narrative in "wound culture" thus becomes a knowledgeable fan $(\mathrm{g})$, hyper-aware of the dangerous contagion of worshipful spectatorship, continually mediating (propitiating?) the god with intertextual representations that both distance and bring the reader closer to the horror as we rehearse our ability to be affected. Tithecott draws attention to this condition when he argues that we "watch the exorcism of Dahmer's apartment and don't flinch when we hear his attorney telling the jury that Dahmer's favourite movie was The Exorcist and that he showed it to some of his victims before drugging them" (20). If we don't flinch or 
experience horror at such a conflation, it is implied, we are all complicit, all potentially toxic, serial killer fictions tend to suggest, in a promiscuous interpenetration of the real and the representation.

Tithecott writes that the serial killer allows us to "exist in a kind of horror movie which we write and perform for ourselves daily" (9). As such, he indicates fan(g)dom's production of knowledge around its fictions. In many ways, this interpellation, this performance underscores Seltzer's point: if the site where "private desire and public fantasy cross" can be represented simultaneously in woven braids of real life and fictions, then horror becomes very much a matter of the present and not the Gothic past. In this synchronous moment, fan(g)dom, the fictional serial killer, and a "most wanted" poster produce a horror story written by fan $(\mathrm{g}) \mathrm{s}$ that is more like a pool of shared memories, memes and discursive practices than a romantic and distant Gothic space.

Fictional serial killer narratives across media often evoke the same rough-edged, tense and action-driven tone that characterizes the shady urban industrial settings of the mid-twentieth century noir writers Raymond Chandler and Dashiell Hammett. Above all, they are close to the feral intensity of the later Mickey Spillane, whose ultra-violent books take the premises of noir to explicit conclusions. Spillane's hyper-macho creation Mike Hammer crosses the border of the psychopathic: he savours his slaying with a coldness and calculation that are horrifying. Shulamith Firestone once wrote that the "male sexual sickness, the confusion of sexuality with power, hurts others" and, in the noir cycle, 
duplicitous women routinely enacted confessions and were punished. The extent to which the "hurt" was represented only increased with the popularity of noir authors, up to Spillane's depiction of Hammer's femmefata/e fiancee, Charlotte Manning, in I, The Jury (1947). In the film version (1953), Charlotte's character (Peggie Castle), shot by Hammer, gasps "How could you?" before slumping to the floor. Hammer calmly replies, "It was easy." In the moments before he fires the gun, Hammer forces Charlotte to perform a strip-tease.

In his later novel Vengeance Is Mine (1950,), Spillane rewrote the Charlotte Manning character; only this time, Juno's final strip-tease is more brutally handled by Hammer, who discovers that she is, in fact, a man. The serial killer is often similarly depicted as a "jury," and, of course, an executioner, only with the difference that the punishments are not carried out by a gun but by ingenious and diverse implements and methods: chainsaws, ice picks, cannibalism, and ritualistic arrangement of the bodies. The most obvious example of this "nightmare artwork" as Oates called it, is in Se7en (1995), where the trail of the slain, dispatched and mutilated in a gruesome and mysterious pattern turns out to embody (literally) the killer's (Kevin Spacey) conception of the biblical Seven Deadly Sins. The film, like Thomas Harris's Hannibal Lecter series, blurs the boundaries between the professional "mindhunter" and the killer in its twist ending, where the young detective (Brad Pitt) who has stalked and captured the killer is presented with the evidence of his final two "sins" which become the crowning act of horror. Finding his wife's head in a box, he shoots the kneeling Spacey, unwittingly becoming himself the final sin: Anger. The theme of theatrical

${ }^{78}$ Mike Hammer notwithstanding, the fantasy of male power that horror presents can also be quite deftly transformed into a fantasy oi female power, as several critics have shown. 
staging that underlies the clever and startling plot twist reinforces the emphasis upon the ritualistic enactment of guilt and terrible punishment that pervades serial killer narratives.

In Seltzer's analysis of the construction of the serial killer, the blurring of particular fantasies of power (especially male power) with reality (or in other words, the realization of those fantasies) is contextualized by his quoting of Margaret Morse who sees a "cultural shift away from the forms of realism, literacy, and objectivity which have been dominant in Western culture since the Renaissance and the age of industrialization" (Seltzer, 10). This shift corresponds with the Gothic sensibility of cleaving to a haunted space. The mind of the killer itself becomes the haunted house upon which our attempts to imagine monstrosity are projected. He is Roderick Usher, yet more fantastic still because we witness his breakdown, endlessly repeated. A spate of recent serial killer horror films since Henry has echoed this Gothic romancing of the figure of the monstrous killer, rendering him either fantastic or fascinating, worthy of fan $(\mathrm{g}) \mathrm{dom}$.

One such film, The Cel/(2000), portrays the literal imprisonment of a "mindhunter" (Jennifer Lopez) in the killer's mind through her gift of telepathy. ${ }^{79}$ In such a context, the context of horror fiction, the serial killer can take on omniscient and almost supernatural powers. Rather than being merely a miserable wretch, a murderer or a madman, the "sane and evil killer" becomes the "jury" of social conditions and the "judge" of individuals. A line is crossed when he becomes the executioner but, increasingly, that line is blurred, as the film Se7en demonstrates. More recently, the Saw franchise has taken up this concept of the

The empathetic woman versus the fascinating man-monster. In both Silence of the Lambs and The Cell, empathy is heavily gendered female. 
omnipotent and fiendishly clever killer, setting traps and twists for his victims at every turn. The killer rigs up a series of different traps for his victims, which they must attempt to spring in torturous and agonizing ways. In Saw II (2005), for example, a recovering heroin addict (Shawnee Smith) is forced into a pit filled with thousands of dirty syringes in order to find an antidote to the sarin gas that is being pumped into the house she and others are imprisoned in. As we saw with the romantic vampire, increasing familiarity tends to create more representations of the serial killer as satirical tricksters, which gradually dilutes the horror that they can elicit and, thus, their potency as critical representations of consumer capitalism. The inevitable traps in the Saw series become as hackneyed a convention as the brooding castle glimpsed by moonlight to the sound of baying wolves.

Furthermore, as Tithecott has noted, "[fjhe acceptable face of cannibalism and serial killing is white ... [of Hannibal Lecter] ... This is no transgressive monster. This is your arrogant, middle-aged, white guy with all the power in the world" (85). Tithecott goes on to insist that, "[i]n portraying the serial killer in superhuman terms while objectifying his victims, we construct our own dehumanizing, pornographic fantasy" (107). This is a far cry from the horror in American Psycho, which knowingly draws on the intertexts of serial killer narratives and positions fan(g)dom as an anti-capitalist intervention in order to assert that the "arrogant. . . white guy" is indeed no transgressive monster but an American gothic antihero, holding a mirror darkly to readers' practices of consumption and fan(g)dom.

\subsection{Romancing the Zombie}

The apocalyptic film 28 Days Later (2002) holds a similar mirror up to the audience's consumption of and obsession with violent imagery. It begins with a montage featuring an 
array of horrific and very realistic-looking violent scenes, including what looks like news footage of executions, lynchings, desecration of dead bodies, street rioting and police brutality. According to director Danny Boyle's DVD commentary and the Internet Movie Database page for the film, he and screenwriter Alex Garland based some of this footage on events in Rwanda and Sierra Leone as filmed by the journalist Sorious Samura. Although the footage of dead bodies was faked, the street riots and other footage interspersed were real. The camera then pans back to reveal a chimpanzee hooked up to electrodes, strapped to a gurney and forced to watch this violence unfolding on a bank of monitors, reminiscent of Clockwork Orange (1971). This experimental screening at the Cambridge Research Centre, we are told, is combined with their exposure to a mysterious, possibly man-made virus known as "rage." When animal rights activists break into the lab to free the infected chimps, it is not clear which exposure — the virus or the violence or a combination of both — has triggered the chimpanzees' murderous behaviour as they turn on the activists, biting and infecting one woman with the rage virus.

The symptoms of the rage virus resemble both ebola and demonic possession. The infected woman's eyes glow red and she vomits blood before turning on her comrades to infect them in turn. 28 Days Later uses this frightening "monkey-see, monkey-do" premise to launch an outbreak which precipitates an apocalyptic transformation of London, in which a man we know only as Jim (Cillian Murphy) wakes up to find himself alone in an echoing wasteland, adrift with garbage and bits of newspaper recording the panic, attempts at evacuation and apocalypse, recalling Seltzer's fragmentary signs of the machine culture. Wandering through London, the bemused Jim comes across a heartbreakingly massive column of scraps of paper posted in Piccadilly Square by people caught up in the sudden 
outbreak and desperately seeking their loved ones. This is Virilio's "general accident," a frighteningly swift and catastrophic collapse figured in some way whether through viral outbreak or space radiation in every apocalyptic zombie narrative.

Such a scenario is familiar to zombie horror fans, and numerous comparisons have been made by reviewers of 28 Days Later to George Romero's Dead films, including Night of the Uving Dead (1968), Dawn of the Dead (1979), Day of the Dead (1985), Land of the Dead (2005) and Diary of the Dead (2007). Other intertexts include the John Wyndham classic sciencefiction horror novel Day of the Triffids (1951), in which the narrator, like Jim in 28 Days Later, wakes up in a hospital not knowing mat he has slept through the collapse of a civilization, and the Richard Matheson novel I Am Legend (1954), filmed as The Omega Man (1971) and I Am Legend (2007). Matheson's frightening vampires are, it is revealed, the results of an infection to which the protagonist Neville is somehow immune. He, as the exception to the rule, is the legend, rather than the vampires. As the "last of the old race" of humans, a "scourge" on the vampires, who are terrified of him, Neville is doomed to extinction. In $I$ Am Legend, all the zombie apocalypses, Romero's as well as the "fast zombies" of 28 Days Later and the earlier remake oiDawn of the Dead (2004), are prefigured, as well as the discourses of outbreak and the collapse of civilization. What Carol Clover calls "White Science" (instead of "Black Magic") has transformed the older conventions of the zombie narrative based upon overtly racist notions of voodoo practices and enslaved, exoticized, Othered cultures, to reflect the more contemporary (coverdy racist) realities reflected in the clockwork chimpanzee's monitors.

The zombie narrative as the lowest of the low horror texts has been the site where gore affects could be experimented widi most freely, thus making a "splatterpunk" aesthetic 
viable and particularly effective combined with the social satire of the masses. Romero's Night of the Uving Dead (1968), for example, has been justly acclaimed for its early portrayal of a sympathetic black protagonist who with dignity and courage survives the marauding zombie hordes only to be suddenly, shockingly shot by a posse of "good ol' boys" led by a redneck sheriff. The heroic protagonist's body, undifferentiated in death from the zombies he has batded all night, is then thrown on a pile of burning corpses while the film's credits roll. In the Romero tradition, the zombie narrative with its unflinching splatterpunk style has become a cultural framework on which to hang troubling social and political issues, and to express the dread of cataclysmic events that is becoming all too common in these times. In Regarding the Vain of Others (2003), a meditation on the photography of war atrocities that foreshadows what emerged from Abu Ghraib into public consciousness in 2004, Sontag describes the zombies that arise at the climax of J'Accuse (1938), French director Abel Gance's antiwar film:

"Morts de Verdun, levez-vous!" (Rise, dead of Verdun!"), cries the deranged veteran who is the protagonist of the film, and he repeats his summons in German and in English: "Your sacrifices were in vain!" And the vast mortuary plain disgorges its multitudes, an army of shambling ghosts in rotted uniforms with mutilated faces, who rise from their graves and set out in all directions, causing mass panic among the populace already mobilized for a new pan-European war. "Fill your eyes with this horror! It is the only thing that can stop you!" the madman cries to the fleeing multitudes of the living, who reward him with a martyr's death, after which he joins his dead comrades: a sea of impassive ghosts overrunning the cowering future 
combatants and victims of la guerre de domain. War beaten back by apocalypse. (Sontag 16-17)

Sontag nowhere describes this sequence as a zombie narrative, yet a zombie narrative it is: one that will be very familiar to viewers of Showtime's Masters of Horror cable network television anthology series that showcases one-hour short films directed by individual horror auteurs. Joe Dante's "Homecoming" (2005), based on Dale Bailey's short story "Death and Suffrage" (2000), also depicts the gruesome theme of dead veterans rising from their graves, only these zombies are arising to vote out the president who sent them to war. When their mission is fulfilled, the zombies turn away from the ballot box and go gendy back to death, in contrast to other, more apocalyptic zombie narratives such as Romero's Dead series. In the zombie film, horror is presented as the obvious response to a steady "diet of horrors" that threatens to corrupt us with apathy unless we heed the madman's cry to "Fill your eyes with this horror! It is the only thing that can stop you!" (106).$^{80}$ As one commentator wrote on the Internet Movie Database page for 28 Days Later, "every generation gets the zombies it deserves." 81

The horror we deserve, it seems, is placing less emphasis on the "mass in person" of the post-industrial serial killer, who is becoming increasingly familiar. For example, the popular television series Dexter presents us with a charmingly tamed monster who uses his

This cry echoes the point about the sanitization of disturbing realities made by a journalist quoted by David Olive in "To Show or Not to Show" about the execution of Saddam Hussein that "sometimes news is very, very troubling. People should be troubled by it."

<http://www.imdb.com/title/tt0289043/trivia), accessed September 2009. 
powers for good. From the white magician Hannibal the Cannibal whose cannibalism represents, as Robin Wood reminds us, "the ultimate in possessiveness, hence the logical end of human relations under capitalism" (22), we move to the spectacle of thousands of cannibals, overwhelming in sheer numbers, zombie masses of depersonalized post-humans who are single-mindedly mindless, bent on consumption and devastation, abject in the singular and overwhelmingly powerful in the plural. Raymond Williams reminds us in Culture and Society that "[fjhere are in fact no masses; there are only ways of seeing people as masses" (300). In keeping with Virilio's theory of the general accident that causes such monsters to be, I argue that zombies function as a horrific signifier drawing attention to a certain way of looking at people: what Naomi Klein calls "disaster capitalism" or "orchestrated raids on the public sphere in the wake of catastrophic events, combined with the treatment of disasters as exciting market opportunities" (6). Disaster capitalism writ small after the general accident is what we find in the plots of virtually all contemporary zombie apocalypse fictions, as the microcosmic bands of survivors struggle to re-create devastated communities and stay one step ahead of the zombies, finding in the process that some of the complicated living are far more evil than the simple, mindless dead, described by Louis Gross as "the proletarian" to the living's bourgeoisie (86).$^{82}$

Academics are just now turning their attention to the proliferation of zombie narratives, once considered the lowest of the low of horror genres and un-Gothic in every respect. In the 1970s, however, Robin Wood noted the satiric implications of using the

For another reading linking serial killers, zombies and capitalism, see Annalee Newitz's Pretend We're Dead: Capitalist Monsters in American Pop Culture (2006). 
Monroeville Mall in Pittsburgh as the setting for Dawn of the Dead (1979). In comparing the first two Romero films, noting that "the metaphor of America-as-graveyard is central to Romero's work" (93), Wood also notes the importance of the communal relationships among the band of survivors whose survival and resistance to the teeming zombie hordes depends upon a gritty professionalism devoid of personal emotions. The irony and tension of the zombie narrative is that, in the survivors' ongoing struggle to find shelter from the zombies, they become as depersonalized and ruthless as the zombies. As Selena (Naomie Harris) tells Jim in 28 Days Later, you have to be prepared to kill your loved ones "in a heartbeat," a horrific possibility which recurs throughout the film. Wood hails the radical possibilities of the disruption of bourgeois institutions that the zombie apocalypse or outbreak creates: as he observes, "[tjhe zombies of Night have their meaning defined fairly consistently in relation to the Family and the Couple" (91). While all of the survivor bands of zombie narratives struggle with the idea of community post-apocalypse, the presence of the shopping mall and a marauding biker gang in Dawn reminds us that "disaster capitalism" is still present. ${ }^{83}$ Woods writes:

In place of Night's dissection of the family, Dawn explores . . . the two dominant couple-relationships of our culture and its cinema: the heterosexual [white] couple ... and the male 'buddy' relationship with its evasive denial of sexuality. . . Through the realization of the ultimate consumer-society dream.

${ }^{3}$ In the context of the financial crisis at the time of this writing, the discourse of "zombie banks" as a mark of disaster capitalism's opportunism is particularly apt. 
. . the anomalies and imbalances of human relationships under capitalism are exposed. (96)

Less attention has been paid to Romero's Day of the Dead (1985), which more closely resembles more recent zombie narratives as they work out the problems of survival postapocalypse. In Day, the zombies are defined in relation to the vestiges of the military and scientific institutions that are hiding in a bunker underground. The ragtag soldiers, similarly to the ones encountered by Jim and Selena in 28 Days Later, are led by a megalomaniacal and hyper-patriarchal captain named Rhodes (Joe Pilato), while, in 28 Days Major Henry West (Christopher Eccleston) envisions controlling the future as he pacifies his men with the kidnap and rape of female survivors. Rhodes bullies both the civilians who have taken shelter in the bunker and the scientists who are feverishly working on a solution to the zombie plague, led by an eccentric scientist Dr. Logan (Richard Liberty), nicknamed by the soldiers "Dr. Frankenstein," who turns out to be trying to domesticate the zombies in a ghoulish manner, by feeding his captured specimens body parts harvested from Rhodes's soldiers. "White Science," in the person of Dr. Frankenstein in his blood-stained lab coat, is therefore as unstable, bankrupt and horrifying as the other institutions such as the government and the military. However, the scientists are not as violent. Rhodes's special hatred is reserved for the female protagonist Dr. Sarah Bowman (Lori Cardille), who represents the increasing strength of Romero's female characters throughout the zombie series. Sarah's lover Miguel (Anthony Dileo) is the butt of Rhodes's racist vitriol. After being wounded in a skirmish with the zombies that the soldiers are trying to capture for the scientists' experiments, Miguel breaks down and offers himself up to the zombies as he presses the button to let them into the underground bunker. I interpret this as Romero's 
satiric quip on the "domino theory" espoused by the American government as an excuse for its meddling in Central America.

Both films end (including the three alternative endings of 28 Days Later) with the ultimate restoration of a fragile family that defies the white patriarchal nuclear family model under capitalism. In his next zombie film, twenty years later, however, Romero pessimistically portrays disaster capitalism entrenched at the top of the social hierarchy in the wake of the apocalypse. In Land of the Dead (2005), the despotic and feudal Paul Kaufman (Dennis Hopper) lives in Fiddler's Green, a luxury high-rise apartment building at the centre of a city which has been fortified against the zombies. The poorer survivors who build their encampments within the city's walls aspire to get into Fiddler's Green, where a tiny elite indulge in consumer luxuries that are surreal and absurd in the context of the destruction around them. The zombies are kept in check by the display of fireworks (bread and circuses), while the poor organize a secretive resistance against the elite. In every Romero film, the fortifications, no matter how clever or how secure, are eventually overcome, and it is the breakdown of community that leads to their breach.

Wood observed in the 1970s that "[t]he characters of Night were still locked in their responsibility to the value-structure of the past," while "the characters oiDawn are at the outset absolved from that responsibility, they ate potentially free people, with new responsibilities of choice and self-determination" (95). In recent zombie narratives, however, such as the films I have been discussing, freedom means defeating the disaster capitalists and the old order that is struggling as much as the new for a place in the apocalypse. Woods commented that "Dawn is perhaps the first horror film to suggest - albeit very tentatively the possibility of moving beyond apocalypse" (97), but since then, there have been many 
narratives that gesture towards such possibilities, including stories such as those in Max Brooks's bestselling World WarZ: an oral history of the ^ombie war (2006) ${ }^{84}$ In World WarZ, the reader is offered not just the story of one band of survivors, as with Romero's zombie films, but many stories, ranging across the globe and told from many different points of view: a horror narrative well-suited to our globalized times, an antidote to the "manichaean allegory," emphasizing rather the plurality of oral storytelling.

Again, the pursuit of all such narratives is far beyond the scope of this dissertation, but in concluding this section, it would be remiss not to mention the proliferation of short zombie fiction in such anthologies as John Skipp and Craig Spector's Book of the Dead (1989), which, in the Romero tradition, set zombies against the shibboleths of consumer capitalist culture, notably the merger of television entertainment with religion in the heyday of the socalled "Moral Majority" under Reagan. In stories such as David Schow's "Jerry's Kids Meet Wormboy," Nina Kiriki Hoffmann's "Zombies for Jesus" and Joe Lansdale's "On the Far Side of the Cadillac Desert with Dead Folks," what I will describe in the next chapter as splatterpunk, zombie fiction uses gross-out horrality to challenge the mad monks of today's sacred institutions. The classic example of such horrality is Peter Jackson's Braindead (also known as DeadA.live 1992) where the Great White Explorer at the beginning of the film discovers a Sumatran rat-monkey that has the power to infect people with a zombie virus (deliberately rendering the border between Black Magic and White Science absurd). He is bitten by the rat-monkey and swiftly dispatched by his native crew but the creature is taken

${ }^{84}$ Brooks is also the author of The Zombie Survival Guide (2003) a tongue-in-cheek survival manual offering advice on how to cope with the zombie apocalypse in painstaking detail. 
to a zoo where it bites and infects the protagonist's overbearing mother who soon begins to eat dogs and drip pus and body parts, while continuing to exert an unhealthy Oedipal control over her son. ${ }^{85}$ Bodies are exploded and reconstructed as malignant, zombified wreckage, including tops of heads sheared off but whose eyes still blink and a walking, gurgling digestive system, complete with gas-emitting lower intestine.

This gross-out humour pervades written zombie horror as well. In "Dead Giveaway," for example, Brian Hodge imagines the aftermath of a zombie apocalypse where an audience of zombies who "still want to be entertained" fill a television studio where a harried, enslaved character named "Monty Olson" hosts a game show similar to Monty Hall's Let's Make a Deal where his fellow-survivors are captured, caged and then offered up as prizes for the zombies behind Doors Number One, Two and Three:

They sat politely, somewhere around a thousand of them, somewhere around two thousand unblinking eyes staring back at him. Some of them clapped, or tried their best, clumsy hands slapping together like pairs of gutted fish. Others cheered, sounding like contented cattle lowing gently into the night. A sea of gray faces, agate eyes. (348)

The grimly humorous parallels between the blissed-out consumer "cattle" sitting slack-jawed in front of their entertainments and the zombie are quite obvious. In the other stories mentioned above, religion, rather than game shows, functions as the opiate of the zombie

${ }^{85}$ Earlier I referred to the intertextuality of the Norwegian Nazi zombie film Dod Sno which depicted one of the besieged group wearing a Braindead $\mathrm{t}$-shirt. Seth Grahame-Smith's best-selling pastiche Pride and Prejudice and Zombies also pays tribute to Braindeads gross-out by having Charlotte Lucas slowly degenerate into a zombie much like the evil mother in the Peter Jackson film, mindlessly consuming the pus that drips from her zombifying body. 
masses. The inference to be drawn in all of these stories is that the zombie narrative is more about us than it is about the zombies. Humans are tried and tested in apocalyptic zombie fictions, and the majority of them fail dismally at preserving a shred of decency and compassion towards one another. In fact, the zombies become more sympathetic, the further one proceeds along Romero's apocalyptic trajectory. Bub, for example, the zombie that is the likeliest candidate for Dr. Frankenstein's taming procedure, approaches likeability, especially when he becomes the instrument of vengeance on Rhodes, while the zombies in Romero's Fand of the Dead, increasingly aware and organized, and led by "Big Daddy" (Eugene Clark), a black gas station attendant, more closely resemble Fanon's "wretched of the earth" organizing against their oppressors than fearsome flesh-eating monsters.

Indeed, we may be heading back towards the provenance of the gothic even with the zombie narrative as it ascends the ladder of respectability. The recent rise of a cross-cultural "Zomedy" subgenre and even "zom-rom-com" (zombie romantic comedy) with the British Shaun of the Dead (2004), the Canadian Fido (2006) and the American Dead and Breakfast (2004) may indicate a "gothicization" of the zombie in the sense that the zombie narrative is becoming more presentable, more popular, more mainstream and more obviously a social satire intended for broader consumption beyond fan $(\mathrm{g}) \mathrm{dom}$, even though this entails the stripping-away of some of the "G-factor." In Fido, for example, while all the elements of the Romeroesque narrative are present, including a fortified zone, zombies wandering the perimeters, disaster capitalists and intimate conflicts raging within, the titular zombie, played by Scottish comedian Billy Connolly, is as lovable as Sean's friend ends up being in Shaun of the Dead. Fido's horror is even more muted. The role of the evil corporation ZomCon that keeps the weirdly regressed community safe from the zombies at the gate is downplayed: it is 
up to the viewer to surmise that perhaps the practice of expelling dissidents to the zombie zone has purged the town of all but the white middle class. All of the zomedies are affectionately intertextual even if they are not as horrific. In Dead and Breakfast, for example, the zombies suddenly break into die famous zombie dance sequence from Michael Jackson's Thriller music video released in 1983. In Pride and Prejudice and Zombies (2009), Seth GrahameSmith felicitously combines an increasingly universally acknowledged zombie lore in a horrlarious manner with Elizabeth Bennett's transformation into a warrior woman. It is to be hoped that the zombies will invade Northanger Abbey next.

\section{Conclusion - Chapter Two}

In this chapter, I have explored the "genre mutations" of horror as it has developed and proliferated in various texts and through various monsters, notably die vampire and die serial killer with some discussion of the zombie. Criticism of horror has focused almost exclusively on the monster, treating die vampire, die serial killer and the zombie as fixed elements of the horror text. By showing how these dominant figures, these "monster narratives" of horror are not static but rather interact with texts, fans and socio-cultural factors, as well as with each other as monstrous figures, at times overlapping in characteristics, at odier times occupying central positions, I hope to have contributed some more nuanced readings of vampire, serial killer and zombie narratives to the field. I will now turn to a closer analysis of how horror fictions create their memorable affects in readers and audiences, turning from the gothic to other "G-factors." 


\section{Chapter Three: Towards a Poetics of Literary Horror}

Here, we were the modern equivalent of the people at Villa Diodati. We were the modern equivalent of the Algonquin Round Table. Just people telling stories out loud to each other. People looking for one idea that would echo for the rest of time .... The babe who wrote Frankenstein, she was the kid of two writers: professors famous for think-tank books called Political Justice and A Vindication of the Rights of Women .... We were no summerhouse party of brainy bookworms. No, the best story we'd bring out of this building would be just how we survived .... Still, that story would have to be good enough. Exciting enough. Scary and dangerous enough. We'd have to make sure it was. (Chuck Palahniuk Haunted 82-100)

\subsection{An Art of Darkness}

The previous chapter discussed generic horror figures such as the vampire, the serial killer and the zombie, defining horror as a mutable reader and audience response that can shift and transform the figures themselves. Such generic mutations in horror's affects draw upon, amplify and reflect the fears and anxieties that multiply and circulate within particular social, economic and cultural contexts. The task of this dissertation now becomes to clarify how these affects arise. How exactly are horror and fear invoked and implied as specific affect-responses on the part of readers and fans to these texts? Yvonne Leffler points out that horror defies the "affective fallacy": "It is hard to draw a distinction between the emotions depicted within the fiction and the emotions the work arouses in the audience, between what the work is and what it does to the presumed reader or viewer" (22). To this I would add, what does the reader or viewer do with the work? What is it about language that 
evokes fear, in contrast to visual representations of frightening images? Can such language be quantitatively or qualitatively analysed?

I argue in this dissertation that written horror's language of fear certainly can and ought to be analysed. My definition of the horror text, as elaborated in my introduction, is a text where this language of fear, inspiring the specific responses associated with horror in its readers and audiences, can be discerned. Without this language and its responses of horror, terror, feat, frisson, disgust, whether the response can be described as "gross-out" or "horrality" or whether the effort is more or less successful, without these affects, a horror fiction has not taken place. ${ }^{86}$ These terms show that we recognize such a response to be part of the experience of horror fiction. Yet the issue of how those responses may be generated within the text has been largely passed over by critics on their way to staking out the terrain of horror theory. This claim may seem overly sweeping on the face of it. For example, Yvonne Leffier makes a distinction between those who study the formal elements of horror fictions and those who focus on more "thematic elements" (16) while Matt Hills contrasts "a study of the details of specific horror texts ... as aesthetic objects" with those studies that concentrate upon "framing theoretical assumptions" (5). My research and reading in the field has shown, however, that even those studies that purport to read texts as formal or aesthetic objects soon abandon the texts for the allure of approaches that provide a more comprehensive framework for theorizing. The field is once again left to the fans and the

${ }^{86}$ Following Hills, I do try to avoid the trap of prescribing an "authentic" horror that stays within boundaries - his point that horror resides in intertextual cues and spills over generic boundaries, existing in "para-sites" as a Derridean "principle of contamination" is well-taken (6). I also agree with Hills that, even if a horror text is "nonscary," "bad" or "failed" horror, "audiences (and critics) will evaluate it as horror nonetheless" (34). 
writers to articulate horror's formal and aesthetic pleasures. For example, Elizabeth Bowen, author of "The Demon Lover," remarks: "Fear has its own aesthetic . . . and also its own propriety. A story dealing in fear ought, ideally, to be kept at a certain pitch" (Hartwell 2). ${ }^{87}$ The venerable British horror writer Ramsey Campbell also supports a particular aesthetic for horror, arguing that

[fjinding [terror] worthwhile in itself often gets horror buffs looked at askance, but I don't know why this should be the case, any more than I see anything odd about admiring a comedy for provoking mirth or a tragedy for moving its audience to tears (so much, by the way, for the specious argument which links pornography and horror fiction on the basis that both, and only both, seek to achieve a physical response). (Cut! 69)

General "wholesale" theories of horror fiction now abound, but not enough attention has been paid to examining that "certain pitch" of horror; to horror's own aesthetic "in itself," and to the specific devices that generate horror and fear in specific texts. Such particulars tend to be quickly glossed over or assumed to be understood, often for example, in the work of Joshi who, despite a masterful knowledge of the tradition of written horror, confines himself to vague descriptions of how one story or another is "gripping." In most recent criticism of horror fiction, I contend, this crucial aspect of horror has either been ignored altogether or taken as given, in keeping with my argument in the two previous

${ }^{87}$ Bourdieu identifies a "popular aesthetic" in Distinctions which emphasizes the continuity between art and life (4). Function is thereby prized over form. While "any object can be perceived aesthetically" (39) through an aesthetic disposition (taste), reactions to a horrifying photo show a definite classificatory system at work (45). 
chapters that what I call the "G-factor" of horror as a way of describing what horror does to its readers and audiences, has been largely neglected.

The lack of attention to textual detail may, as I explained in my introduction, be related to the temptation to advance some sort of unified general theory in the context of an emerging field of horror studies rather than focusing on specific elements of the texts themselves. Hills describes this problem as follows:

At worst, dieoretical answers seem to be determined in advance of critics' encounters with horror texts, while at best scholarly theories continue to be accorded discursive primacy (that is, academic texts routinely offer popcultural examples that somehow mirror, 'prove' or allegorize the writer's chosen/favoured theory). (Pleasures of Horror 7)

As a remedy, Hills suggests that if "we treat horror as an aesthetic, fictional exercise from the start — rather than arriving at this as a conclusion — then the genre's pleasures do not need to be explained (away)" (5). In this chapter, I too will attempt to avoid explaining (away) the pleasures of horror while maintaining that horror's affects do merit closer analysis and in fact that this can be one of the pleasures of horror. I am thereby heading in the direction that Hills identifies as "study of the details of specific horror texts" beginning with "books themselves as aesthetic objects"(5). ${ }^{88}$

${ }^{8}$ Hills mentions Freeland and Steven Jay Schneider as other scholars engaged in this work. I will take up Freeland's work further on and acknowledge the fine work of Schneider also, which remains, however, located in film and international film studies. The only critic who concentrates upon horror fiction and who mentions the short story is Swedish comparative literature scholar Yvonne Leffler in her monograph Horror As Pleasure: The Aesthetics of Horror Fiction (2000). 
The primacy of theory over textual analysis in scholarly discourse may also be related to contemporary trends in literary and cultural criticism. From the perspective of contemporary poststructuralist criticism, a focus on poetics and the machinery of the text, what Matt Hills valiantly attempts to update in his "discourses of affect" (6), seems rather obvious, if not a bit pedantic and quaint. Formal literary features such as narrative structure, style, plot devices, phrasing, tropes and figures have received short shrift of late in the general turn towards meta-linguistic, postmodernist considerations. Instead of regarding texts as discrete, "centripetal" signifying systems, critics have recently favoured theories of discourse where horror becomes just one of many forms of cultural production and is a convenient way to decode and trace the machinations of certain discourses. ${ }^{89}$ As Hills observes above, the text then becomes a site of the contrivance of a particular theory and anything unique to the text itself is subordinated to the theory that is being advanced. For example, even an aesthetic approach will "still tend to fall back on cognitive (Freeland 2001) or psychoanalytic frames (Schneider 2001)" (Hills 5). Such generalizing tendencies recall Bourdieu's critique of "cultural consecration" (27) where the consignment and confinement of horror by legitimate culture to a certain set of notions about what horror "really is" results in its subordination to "higher" purposes. In The Umits of Theory (1989), Michael Kavanagh points out that

The contemporary preoccupation with theory has had as one of its effects the displacing of interest away from what is specific to any individual work

${ }^{89}$ 1.A. Richards' distinction between the "scientific" and "emotive" uses of language mirrors Frye on "centrifugal" and "centripetal" (Lodge Language of Fiction 7). 
and toward die presuppositions and systemic cogency of the theoretical constructs that allow us to carry out our analyses. According to this position, the elaboration of an adequate theory of literature must become the central preoccupation of all critical discourse aiming at a significance beyond that of the belle-lettristic curiosity shop. (3)

The strange little "curiosity shop," for example as it appears in Stephen King's Needful Things (1991) is a familiar setting of horror. Kavanagh's point that an "adequate theory" is what confers significance upon a text, however, is a central position for many of the theories that I have covered in this dissertation and, I argue, a false position. Exploring the operations of such theoretical entities as abjection, oppression and alienation is undoubtedly a fascinating and challenging aspect of horror studies. Much research in the area has, as we have seen, taken up issues of gender in horror texts and has also involved examining the relationship of the monster in horror to Other(ed) subjectivities. It is unfortunate that this often results, as we have seen, in a subjection of the text to prefabricated and one-dimensional explanations. The implications of such reductions become more sinister and totalizing when we consider Barbara Christian's argument in "The Race for Theory" that "high" theory constitutes a "takeover" on the part of elite Western philosophers colonizing literatures (457). Christian points out that "people of color have always theorized" in the form of storytelling as a way of understanding culture, a different model than that of the "abstract logic" privileged by the West where literature is part of everyday life, "not an occasion for discourse among critics." Christian passionately rejects the pressure to come up with a "wholesale theory," insisting that this pressure silences critics who do not necessarily feel at home within a Western philosophical tradition: 
The race for theory, with its linguistic jargon, its emphasis on quoting its prophets, its tendency towards "Biblical" exegesis, its refusal even to mention specific works of creative writers, far less contemporary ones, its preoccupations with mechanical analyses of language, graphs, algebraic equations, its gross generalizations about culture, has silenced many of us to the extent that some of us feel we can no longer discuss our own literature, while others have developed intense writing blocks and are puzzled by the incomprehensibility of the language set adrift in literary circles. (458)

My contention here is that the horror text minus its G-factor invariably becomes diminished by the overarching theories, whether psychoanalytic, cognitive, feminist or reception-oriented to which it is subjected. I do not argue that we should eschew theory altogether, but advocate rather for more theories that respect texts as works, not merely as functional illustrations. Following Wlad Godzich, Kavanagh reminds us that the etymological roots of "theory" refer to the establishment of a theoria in ancient Greece as a "particular kind of seeing or beholding," an officially authorized version of events based upon the testimony of a collective of theoros or formal witnesses. As such, Kavanagh argues, theory is "the definitional opposite of aesthesis (or feeling)" (8), which might account for the sense of struggle that characterizes much of the scholarly work on horror which attempts to come up with an "adequate" theory of horror. In order to accomplish such a thing, I argue, it becomes necessary to witness what is occurring in the text, not only on the screen, but on the page.

This chapter therefore concerns itself with what I will call the poetics of literary horror, implying strategies that may perhaps best be envisioned as branding irons whereby 
written horror fictions stamp their most interesting and powerful effects upon the bodies

and the minds of their readers and audiences. With the possible exception of S. T. Joshi, whose approach is highly idiosyncratic and who recognizes few contemporary texts that, in his opinion, merit consideration, no other scholars have, to my knowledge, provided much close or detailed analysis of written horror texts beyond the canonical work of Frankenstein or the Gothic novels (and even then, not much about the horror in the text). ${ }^{90}$ In film, D.L. White's 1971 article on the poetics of horror is one of the only critical enquiries into horror fiction that my research has uncovered that specifically tackles how the form of a horror film may work towards an "expressive" function. ${ }^{91}$ Invoking Poe's "unity of effect" principle in his insistence that a "unity of a certain kind of action" (5) or "pervading sense of horror" (6) is a narrative engine that characterizes the horror film, White argues that "something within the identities of the pieces from which the film is constructed and within the nature of the

Joshi, a renowned Lovecraft scholar, judges all contemporary horror writers by Lovecraft's principles and finds most of them wanting. For example, he writes disparagingly of Poppy Z. Brite, the only woman writer to appear in his Evolution of the Weird Tale (2004): "Child prodigies are tolerably common in horror fiction . . B Brite can write, but in many cases she has nothing to write about" (203). His statements about Brite's "owlish schoolgirl philosophy" reveal an "old boy" sexism quite typical of the regressive and aggressive elitism of his writing in general: see, for example, his introduction to the Kipling collection The Mark of the Beast and Other Horror Tales (2000) where he sneers at the "mundanity" of the "common man's prose" pioneered by Kipling but taken up by other horror writers such as Stephen King and Richard Matheson (xiii). Joshi has recently published a two-volume encyclopedia Icons of the Supernatural (2006) that talks about some of the stories I mention here, but he frames his essays around the "icons" (monsters and themes) of horror such as witches, zombies etc., rather than the narrative affects I am focusing on. In so doing, he is adopting an approach very similar to Carroll's monster-centrism.

${ }^{91}$ Brigid Cherry's 2009 book on Horror (Routledge) has a chapter on the aesthetics and affect of horror films. Again, however, the all-encompassing "horror" of the title does not cover any horror literature. 
ways in which they are combined" (2) works to produce horror in ways that a "superficial or specious" analysis will not capture:

[t]here seem to be no particular camera angles or movements, editing techniques, acting styles, make-up methods, or set designs common to all horror films or essential to the production of horror. However, there is a technique, as distinct from theme, that is found to some degree in all works of horror. It can result from the way a writer describes a shot or a cut, from the way a cameraman frames a shot or lights a scene, from the way an editor assembles that scene or from the way the sound mixer manipulates its sound, or it can result from the way a director places and moves his actors and props. We all dream and as a result can see elements or scenes in films as having the quality of a dream, of psychological aberrations or hallucinations. The horror of Polanski's Repulsion, for example, does not come just from the theme of the girl's fear of sex. Instead it results from film's ability to make her real life and her fantasy life look and sound the same, and to manipulate the physical appearance of both to capture her increasing isolation and madness by literally making the ceilings increasingly nearer, the corridors longer, the rooms larger, the lighting darker, and the sounds more distant.

This outline of a poetics of horror, an examination of the elements and techniques that produce an "art of darkness" (Winter), badly needs to be expanded and applied to 
printed forms. Calls for more attention to this aspect of horror have recently arisen from other critics; notably, the prolific horror film scholar Steven Jay Schneider calls for a "close comparative analysis" of horror's "timeless effects" in "Towards an Aesthetics of Horror Cinema" (Prince 2004). Outside film studies circles, however, the idea of "effects" (which I have, following Hills, been calling "affects") retains a vulgar association with the type of sensationalism that automatically assigns a work inferior status. In short, literary horror has received scant aesthetic attention because it has not been considered to possess aesthetic qualities by literary critics, with the exception of S. T. Joshi and one or two others operating at the borders of respectability and within quite narrowly circumscribed limits. ${ }^{93}$ This is

${ }^{92}$ White observes:

The only way to reveal. . . the implications of the events and techniques in such films as The Boston Strangler, A Walk with Love and Death, or Seconds is through the use of horror. As a critical tool, horror should not be restricted to films employing the same devices, plots or actors as the classics of the genre. Anyone not willing to apply the concepts of horror to all films that employ the themes and forces of horror has litde chance of appraising the total value of many, perhaps most, works (17).

${ }^{93}$ Joshi traces the stigmatization of the "weird tale" to the rise of the pulp magazines in the 1920s (Mark of the Beast and other horror tales, $\mathrm{x}$ ). In keeping with his project of authorizing some horror as "literary," however, Joshi insists that craftsmanship is not enough to redeem a story without a "philosophical basis" and deplores the reduction of horror to its purpose "to frighten":

If weird fiction is to be a legitimate literary mode, it must touch depths of human significance in a way that other literary modes do not; and its principal means of doing so is the utilization of the supernatural as a metaphor for various conceptions regarding the universe and human life. Hence the need for a world view that structures and defines the use of the weird in literature. Mere shudder-mongering has no literary value, however artfully accomplished. 
unfortunate for, as White reminds us, "[tjhe linking of horror and art, in fact, goes back to Greek tragedy":

The word "horror" itself is found in Aristotle's Poetics: "fear and pity may be aroused by spectacular means; but they may also result from the structure of a piece . . . even without the aid of the eye, he who hears the tale told will thrill with horror and melt to pity at what takes place. (White 1)

Critics such as Bruce Kawin have sought to establish an aesthetics of cinematic horror, defending the artistic value of set pieces and death scenes in certain horror films that "cannot be called disgusting; what they have instead is a horrible beauty that has always been one of the central attractions of the genre and the core of its claim to art" (111). Thus horror possesses its own macabre beauty, thereby constituting a form of art in the classical sense. Critical discussion of avant-garde art has concerned itself with the value of shock and negative beauty, and horror apologists who look for "redeeming features" in horror have made similar claims for horror as a kind of avant-garde art connected to Surrealism. An example can be found in Guardian critic Jonathan Jones's contention that

[wjithout surrealist cinema, we wouldn't have the concept of weirdness as an aesthetic; that inexplicable vein of cinema in which the physical world is violent, erotic and so shocking that you don't need a coherent story. Lynch is Dali's heir. But you also see this thickening of texture, this ripeness of things, in the trashiest horror, with its putrefying zombies and baths full of flesh soup. (18) 
Jones's claim that "weirdness as an aesthetic" belongs to Salvador Dali, Louis Bufiuel and Surrealism completely ignores the enormous influence on horror fiction of their muchmarginalized contemporary, H. P. Lovecraft and the pulp magazine Weird Tales which frequently published his stories. Again, the pitfalls of a high-brow approach that seeks to "elevate" popular culture become obvious as certain horror fictions are chosen at the expense of others that cannot be overlooked. Unfortunately, the neglect of horror as a viable field has often resulted in the widespread and uncritical acceptance of such claims.

An aesthetic concept of "terrible beauty" is in keeping with the contention made by several critics that horror shares many defining characteristics with that category of aesthetic appreciation that Edmund Burke, then Immanuel Kant, originally designated as "the sublime." ${ }^{94}$ The connection is perhaps best drawn by Tarda Modleski, who insists that:

The type of mass art I have been discussing ... is as apocalyptic and nihilistic, as hostile to meaning, form, pleasure and the specious good as many types of high art. . . Since Jean-Francois Lyotard insists that postmodernism is an 'aesthetic of the sublime,' as Immanuel Kant theorized the concept, it is interesting to note that Kant saw an intimate connection between the literature of the sublime and the literature of terror, and moreover saw the difference as in part a matter of audience education [my italics]. (162)

${ }^{94}$ See Vijay Mishra, The Gothic Sublime; Antonin Artaud, "The Theatre and Its Double," David Skal, The Monster Show, Pam Keesey in Tear Without Trontiers, Matei Calinescu, Joan Hawkins, Roger Salomon and Yvonne Leffier, among others. 
Insofar as "art" is intended to signify a consecrated high culture according to certain conventions such as, for example, literary renown, obviously horror, with its connotations of commercial exploitation and "grindhouse" rather than "arthouse" qualities, will not be art. As I shall argue in this chapter, however, the aesthetics of horror do merit attention on their own terms, which do not necessarily uphold "art" as a privileged aesthetic category of the beautiful or, for that matter, the sublime as it has been conventionally understood. An aesthetic study of literary horror is needed that critically and thoroughly examines the specific qualities, characteristics and values of horror texts in much the same way that Burke defined the sublime, beautiful and picturesque.

Writers and fans of horror have kept the idea of a poetics of horror in the forefront, serving in numerous anthologies as the curators of horror 's artistries. Often the scholars who venture into the field to test their distinctions are scornfully dismissed on the grounds that their theories do not do justice to horror texts. ${ }^{95}$ Ellen Datlow, for example, skewers Walter Kendrick's The Thrill of Fear: 250 Years of Scary Entertainment (1991) for dismissing horror 's affects and for claiming that short horror stories are "one note compositions, reducible to a gimmick apiece." Datlow asks dramatically: "Where has Kendrick been the last twenty years?" (Year 's Best Fantasy and Horror 5 lxii). Similarly, Datlow offers a scathing critique of Mark Edmundson's Nightmare on Main Street: Angels, Sadomasochism and the Culture of

${ }^{95}$ There is a lengthy list of horror authors who are themselves academics, although they do not publish scholarly work in the field. Obviously M. R. James and the Bensons come immediately to mind when one thinks of scholarly storytellers of horror, but a perusal of more contemporary writer bios, in the pages of the Year's Best Fantasy and Horror series, for example, reveals a strong presence of academics. 
Gothic (1997) as exactly the kind of academic hogwash that readers of horror fear. Datlow pointedly accuses Edmundson of "ignorance of the field he 's condemning to carry some very heavy baggage" (Year's Best Fantasy and Horror 11 lxxii). This is an accusation that could easily be leveled at many other academics writing in the field. ${ }^{96}$

Such "position-takings," as Hills calls them, mirror an artificial divide where scholars are supposed to generalize about culture and horror in pursuit of theory whereas writers, fans and curators of horror such as Ellen Dadow are die authorities upon matters of technique and artistry. For example, Dadow describes the reclusive American horror writer Thomas Ligotti as a gothic writer with a "baroque style" (Year's Best Fantasy and Horror 5 xlvi). Similarly, Joe Lansdale vigorously defends horror's tradition from the narrow parameters that have been placed around it by such an exclusive concentration on film:

When people learn that I sometimes write horror or dark fantasy or suspense, they immediately assume I spend my time writing the twenty-sixth version of Friday the 13 th, and that's more than a litde tragic .... To have [horror's tradition] bogarted by a small backwater subgenre of pinheaded chop-'em-up flicks is to demean the art of scaring - and being scared. (Cut! 169)

Given the long-standing hostility expressed here by writers pointing out that the field of horror is vast, it is indeed rather tragic to find a common myopic approach among scholars who stubbornly persist in chipping out more meaning from a small lode of well-

${ }^{96} 1$ will offer another example here (they are numerous): the writing team of John Skipp and Craig Spector call the roller-coaster-ride theory of catharsis "bogus" because it does not pay enough attention to quality (Cut! 252). 
mined examples, mostly taken from film and often from Lansdale's "chop-'em-up flicks," without spending time on the actual techniques whereby the affect of fear in the text is produced. Even those who mention the aesthetic and rhetorical possibilities of horror are not exempt from this tendency to extrapolate and generalize from an overly narrow approach. Cynthia Freeland for example, who is held up by Hills as an example of a textbased approach to horror, adopts a cognitivist framework in her study of horror films as essentially a meditation upon the nature of evil:

In reviewing the many ways horror films present evil, I will regard these films as artifacts structured so as to stimulate both our emotional and our intellectual responses. I draw on recent cognitivist film theory and maintain that horror films are designed to prompt emotions of fear, sympathy, revulsion, dread, anxiety, or disgust. And in doing so, they also stimulate thoughts about evil in its many varieties and degrees .... (The Naked and the

\section{Undead 3)}

Freeland, who clearly identifies herself as a fan, explores a wide array of films, including The Silence oftheTambs (1991), Peeping Tom (1960), and Repulsion (1965). Arguing strongly that "[w]e must look at both the aesthetic features of representations and the audience's cognitive and emotional responses to them" (16), Freeland, citing Carroll, mentions the "rhetorical strategies" and "effects" whereby horror films elicit and provoke fear reactions (13). She also writes intriguingly about subversive audience responses, describing a screening of Cat People (1982) she attended where "the audience hooted loudly and derisively at [bondage] scenes" that had been denounced as sexist (17). However, the "participatory" aspect of horror response is quickly dropped by Freeland, who concentrates 
upon narrative as "the most important element, because in most cases, it is what provides the background or structure of a film" (13).

Thus, while Freeland is right to criticize die work of psychoanalytic feminists such as Barbara Creed, who takes up Kristeva's notion of abjection, for failing to attend to what she calls the more "cinematic aspects" of horror texts (20), her own study concentrates mainly upon narrative sequences, subsuming other elements of style such as affective violence, which Freeland calls "spectacle" versus "plot," following Aristode's Poetics (21). The promised details of these cinematic aspects never quite materialize because Freeland's cognitivist psychological framework emphasizes the work of plot and narrative structures.

Concerned with the representation of evil in various forms, Freeland focuses on the hunt, in Frankenstein, for "where evil really resides in the novel" (27), arguing that "the concerns of Mary Shelley in Frankenstein are more general than just to narrate an entertaining or scary tale" (30). The search for an "Irigarayan deep reading" of "concerns" such as, for example, the mad scientist as monster theme thus takes Freeland far away from "just" the "scary" elements of the novel. However, something important is obscured here in Freeland's ready dismissal $o £$ Frankenstein's scariness. The very idea of horrific monstrousness needs to be scary if Freeland's notion of evil is to be effectively conveyed. Evil in horror can be likened to Kipling's tale of the "Mark of the Beast," in that it is highly apparent, like the rosette marking that appears on Fleete's body where the Silver Man touches him in Kipling's story, like the subsequent changes to his body that occur. Horror's signification of evil requires mat attention be paid to its frightening affects, whether those be visible, such as the demoniac facial contortions of a possessed Regan McNeil in The Exorcist (1973) or Emily Rose in The Exorcism of Emily Rose (2005), audible, such as the thunderous, jarring sounds of 
the invisible menace in Robert Wise's The Haunting (1963) or conjured in the imagination through print, such as the intense and terrifying final confrontation scene between the governess and the "beast" in Henry James's "The Turn of the Screw" (1898). Freeland does observe some of these narrative affects in her reading of the various versions of Frankenstein. For example, discussing the Kenneth Branagh version (1994), she notes:

[t]he monster's existence is previewed, and his violence is hinted at when the sled dogs who go chasing after him are violendy tossed back like rag dolls.

But the appearance of the monster is forestalled; we only get sounds of harsh breathing and point-of-view shots of him running across the ice. (39)

Freeland claims that "Branagh here invokes more modern horror movie conventions used to depict villains since Halloween. Such delays make the monster a curious object of the audience's ambivalent desire" which is presumably a desire to see the monster and yet to be spared the frightening spectacle (39). This is all true and well-stated. Yet, the hint of supernatural violence and the delays in revealing the figure also serve a narrative function: to simultaneously compel the audience's attention and escalate the frightening impact of the text. The tantalizing and suspenseful affect of this device is why the "killer cam" (which, before 1978 and Halloween, was used very effectively by the 1974 Canadian film Black Christmas) has become such a staple of the slasher film and indeed of any sequence aiming to connote a sense of lurking menace.

Anna Powell's Deleuzian approach marks a significant turn towards these questions of affect. If we merely looked at horror as a vivid collection of macabre images presented for a suitably distanced spectator, we would not be able to approach what horror does and how it. does it. Applying Burke's concept of the sublime to horror is not enough to describe the fear 
that horror fiction evokes because affect is not always conveyed by a vision of grandeur or overwhelming force. Often horror is experienced as a sly "creeping" sensation that is gradually escalated throughout the text until some "tableau" is revealed that presents a stark horror which gains its full force from the careful preparation and "grooming" of the reader beforehand. This has been described, from Ann Radcliffe to Stephen King as "terror" rather than "horror"; however, the question remains: how was it accomplished? I have been arguing that the aesthetic values of horror, the G-factor, shadowy and fantastical images, violence, mutilation and splatter should be examined as strategies that persuade the reader/audience to experience fear. As Hills justly comments, this "affective" aspect of horror has been trivialized in preceding theories of horror, from cognitive to psychoanalytical accounts. Without that experience happening "between the shoulderblades" (64), to borrow Vladimir Nabokov's phrase, a horror narrative cannot be said to have really taken place. ${ }^{97}$ Thus, we are again compelled to face what the text does to the embodied reader.

In this chapter, focusing upon what I call the poetics of horror, I will demonstrate with reference to written horror that such devices, far from being new techniques, are in fact far older and more pervasive than Halloween and other films of its ilk. The killer cam should be understood as an updated, cinematic version of a time-honoured means of heightening what Freeland characterizes as the "tension" between plot and spectacle in the service of

${ }^{97}$ Nabokov, in Lectures on Literature, insisted that "[ajlthough we read with our minds, the seat of artistic delight is between the shoulder blades. That little shiver behind is quite certainly the highest form of emotion that humanity has attained when evolving pure art and pure science. Let us worship the spine and its tingle." The reference to spines tingling allows us to appropriate this famous quote for the purposes of artistic delight in horror fiction. 
creating horrific affect. As such, I am proposing an alternative genealogy of horror to the Gothic consensus, situating it in the atmospherics outlined by Poe in his "Philosophy of Composition." Poe advanced the principle of the "unity of effect" which needed for its maximum realization a work that could be absorbed in one sitting. In meticulously describing the step-by-step composition of his poem "The Raven," Poe argued that the form of the poem's final draft was dictated by the requirement to create a certain mood in his reader. Lovecraft, following Poe, took this to mean that atmosphere trumped plot and other narrative elements. The creation of horror's affects is therefore contingent on the devices employed to create atmosphere.

The term "affect" is being used here to connote not only the particular narrative feature or device but the obvious response it is designed to evoke in the reader. Clearly, not every response will be the same and different readers will react according to cultural value and belief systems influenced by a wide array of factors. The features themselves may be more or less successfully accomplished within the texts in that they may be considered effective or ineffective by the reader, whose response will vary accordingly (particularly ineffective or "lame" affects may create either "horrality" or boredom). What is commonly discernible, however, is the texts' use of recurring and similar features. Such features have been associated with the "rhetorics" of horror. For example, Ken Gelder introduces The Horror Reader, which purposefully sets out to define the arrival of horror studies as a viable field in the academy, by offering a tantalizing concept of the "deployment" of the "rhetorics of horror" located not only in fiction but in everyday life:

Horror is one of many forms of cultural production, represented in this Reader primarily through film and fiction - horror texts - but also through 
the everyday deployment of what might be called the rhetorics of horror. . . [Rhetorics of horror] provide ways of defining, for example, what is evil (and what is good) in societies, what is monstrous (and what is 'normal ${ }^{1}$ ), what should be seen (and what should remain hidden), and so on. These rhetorics are put to use routinely not just in horror texts themselves, but in the very same socio-political system that can find itself worrying about their proliferation. (1)

What Gelder calls the "rhetorics of horror," however, remains very loosely defined and left up to each contributor to the Reader to elaborate. These contributions partake mostly, as Gelder presents them, of "semiotic" approaches to horror (6). Taking horror as a "signifying system," the Reader contains multiple examples of projects of excavation, decoding, for example, what may be represented by monsters or monstrous practices. These projects then produce academic "deep" readings that, as Gelder observes, can be contrasted or compared to the shallower, more "horizontal" (thus, it is not so subtly implied, more trivial) readings of "horror fanzines and genre guides" (5).

The field that is laid out for us therefore already contains striations of taste that have little to do with rhetorical considerations; similarly, Gelder writes about the "high and low cultural components" of horror, where "texts at the bottom end of the market, for example, can send the more discerning member of the audience scuttling off to other, more accommodating points in the field" (4). ${ }^{98}$ Again, it is implied that the profound, scholarly

${ }^{98}$ Skipp and Spector insist that "[ijndeed, the distance between [John Waters's 1972 cult film] Pink Flamingos and Peter Greenaway's The Cook, the Thief, His Wife and Her Loper is simply a matter of breeding and income bracket" (Cut! 244). From "seedy" to "sumptuous," 
readings will only be generated by those few worthy (more accommodating) texts that are recognizably "high end" in terms of their cultural capital. For example, such texts may be produced by well-known and bestselling authors, written in more "sincere" and less "meretricious" language (Joshi 7), employ more "literary" forms and feature more tasteful and subtle images, whereas the unworthy, low texts will wickedly resist all interpretation and exist merely to be abandoned to all save the undiscerning, vulgar Lumpen fan(g)dom who are slaves to horror's spectacle. However, this is a failure of what Gelder sees as discernment. Franco Moretti reminds us that "history" moves from "dime store novels" to Henry James, "not the other way around" (New Left Review 112).

Somewhere between the excavation of meaning and the surface fanning-out of networks, genealogies and details about horror, the defining stratagems of horror fiction 's monstrous representations continue to slip and elude our attempts to pin them down. Here it will be seen that, although I accept and appreciate Gelder's broader use of the term "rhetoric," I insist that it should also be considered in its more traditional sense as part of the narrative affects of the horror texts themselves. In so doing, it is not necessary to abandon all other considerations. Terry Eagleton has called for a rebirth of rhetoric as "the received form of critical analysis all the way from ancient society to the eighteenth century" (205). Eagleton defines rhetoric as an examination of

they suggest that both films are "vile." In keeping with their fan(g)dom, they take a mockingly appreciative stance to lowbrow "movies ... so utterly clueless, that intellectuals are forced to hallucinate deeper meaning in them" (250). An interesting point is made here, that the act of trying to read meaning into these films staves off the fear of stupidity that consuming low-status culture might generate in the audience. 
the way discourses are constructed in order to achieve certain effects ... its horizon was nothing less than the field of discursive practices in the society as a whole, and its particular interest lay in grasping such practices as forms of power and performance .... It saw speaking and writing not merely as textual objects, to be aesthetically contemplated or endlessly deconstructed, but as forms of activity inseparable from the wider social relations between writers and readers, orators and audiences, and as largely unintelligible outside the social conditions in which they were imbedded. (205)

Informed by such a broad definition of rhetoric, I will examine and identify affectfunctions of horror in short stories as part of my exploration of horror texts as, not only cultural yardsticks that establish responses of horror as measurements of distance between selves and Others, but as valuable and interesting works in themselves. This approach significantly differs from other critics in that I believe it crucial to spend time upon an adequate consideration of the production of horror by horror texts. To argue that this is a novel approach may seem peculiar in light of the fact that horror is frequently identified by the presence of generic conventions, which are related to the strategies of written texts that I am going to discuss. For example, Noel Carroll's Philosophy of Horror (1990), as we saw in Chapter One, takes the presence of the horror convention of the monster as its startingpoint for Carroll's definition of horror since, for Carroll, the presence of the monstrous is always that which creates the horrific affect. Carroll thus upholds the original meaning of a monster; it is there to de-monstr-ate something.

Carroll's overly fussy definitions, however, have a narrowing effect upon the field and tend to obscure some of the more interesting and subtle features of horrific texts. 
Unacceptably, he excludes some texts altogether, including many short horror stories, which he classifies as "tales of dread" rather than horror, noting without further elaboration that these "seem to prosper best in short form" (42). There are many such horror fictions without monsters as Hills points out, rather working to horrify through the creation of "atmospheres and ambiences." The aforementioned Thomas Ligotti comes to mind as a good example of this atmospheric horror, as does the British writer Ramsey Campbell: scarcely in their stories does the reader find anything resembling a monster, only a vague, unsettling sense approaching panic that something is terribly wrong. Therefore, Carroll has, in Hills's view and in mine, "discursively restricted" horror. As Carroll himself admits, his theory of "art-horror" will entail that "some of the works . . . will have to be reclassified. Several of the works mentioned above will drop out of the genre when it is subjected to theoretical regimentation" (7). It is unthinkable to any serious student of horror that Ramsey Campbell, for example, would have to "drop out of the genre" in order not to disturb Carroll's project of "solving" the paradox of horror (x).

Rather than subject horror to the Procrustean and totalizing discipline of "regimentation," I have been arguing in this thesis for readings of horror that can, on the contrary, expand their borders in order to engage more horror fiction as it is read across cultures while at the same time attempting to respect what Dean Koontz calls the "legerdemain of language" which "cannot succeed if the author accompanies his story with analysis ... Good magic requires secrecy" (301). My discussion therefore goes against the grain of the rather jaunty and dismissive tone of critics such as Carroll and Hills, who are obviously having a good time with the subject, but who are working from authoritative positions that imply they are doing horror fiction a favour by paying any attention to it at all. 
Although Hills takes a strong and convincing position vis-a-vis horror fans and their pleasures; he still performs a vanishing act with the horror texts themselves, causing horror fiction to diffuse into broader areas: discourses of pleasure, mass media, "real life horror," "theory-horror," and of course, Hills's own "account" of the pleasure of horror as a performative function of fan and intertextual knowledge. In this sense, I am sceptical of Hills's observation that Carroll's theory "works across media, explaining horror novels as well as it explains horror films" (15). Firstly, the language of "explaining" invokes that perilous theoretical compulsion to explain (away). Secondly, horror media is not restricted solely to novels and to films. In practice, "media" has usually meant an almost exclusive focus on the visual iconography of film.

To be fair to Hills, he is one of the only scholars in the field, as previously mentioned, to devote time to a contemporary horror writer. However, his is a classic approach of literally putting theory before horror. Hills discusses the British horror writer Kim Newman, author of the metafictional Anno Dracula series (1992) as well as numerous other novels and short stories, as an example of the complexity of applying the term "postmodern" to "empirical instances of culture" as a "manically iterated master narrative": Such an approach ultimately installs sameness across instances of popular culture. Contra such a theoretical discourse .... I am concerned here not with reading horror's 'intertextuality' as an automatic signifier of the 'postmodern', but rather with considering a range oftextually and sociologically distinctive types of intertextuality [Hills's emphases]. (165)

Newman's intertextualities, which Hills calls '"scare quotes'" (168), invite "positiontakings" and "bids" for symbolic cultural capital along "possible socio-cultural trajectories". 
Thus, according to Hills,' fans may prefer reference-spotting over 'being scared' while more casual genre followers may reverse this discursively structured knowledge-affect response" (170). Earlier in The Pleasures of Horror, Hills rightly criticizes Mark Kermode's assumption that knowledgeable horror fans are not scared by horror texts (74) so it is disappointing to see the same assumption being resurrected here, even framed in the language of preference and framed as a "continuum" rather than a rigid divide. Even so, Hills places "fans and scholars" on the side of knowledge rather than affect in a "cultural reproduction" where "horror becomes a matter of performed cultural value - a 'mind genre' rather than a 'body genre' - for sections of its readership / audience possessing higher level of cultural and/or subcultural capital" (171). For Hills's fans, it may indeed be a question of showing off their cultural and/or subcultural capital: however, I maintain that even the most knowledgeable horror fans may yet seek out the "body experience" of being pleasurably scared by texts as much as they may enjoy the "mind game" of "reference-spotting." ${ }^{99}$ Note that we have left Kim Newman and his books in the meantime cooling their figurative heels in the chapter's antechamber while Hills lays out his theoretical framework for several pages. When Hills invites them in to undergo analysis, it proceeds as both a demonstration of the alternative fan "canon" and as a display of both intertextual cultural and subcultural capital (175):

For it is a distinctive positioning, a claim to culturally-politically surpass 'classic' texts nevertheless linked to a claim to continue in their tradition of cultural value, that characterizes the gothic rereadings / rewritings of

${ }^{99}$ A weariness with mere "reference-spotting" may be why fans in North America have embraced the Japanese horror of directors such as Takashi Miike who has not refrained from delivering intense G-factor affects but who is not as easily "spotted" intertextually. 
Newman's horror. Newman's 'alternative story stories' locate themselves in relation to what are insecurely canonical texts, actively bidding for neocanonical status. (178)

This interpretation yields a fascinating theory of the cultural economy of Kim Newman's writing. However, we are at the "knowledge" end of the spectrum and very far from horror's affects here. The "dark power" that Newman himself praises in another author's work (179) is nowhere acknowledged in Hills's analysis of Newman's work. At the conclusion, Hills briefly mentions other writers, including Joyce Carol Oates and Stephen King, as other instances of these deployments of sub- and cultural capital (180). Horror fiction, one surmises, is ultimately reducible to an endless game of cultural "positiontakings." I argue that horror and its fan(g)doms deserve better.

A study of the elements of horrific style in fact broadens the possibilities of intertextual, comparative and cross-(sub)-cultural readings by elucidating patterns of language, phrasing and textual devices that may or may not be present across cultures and traditions. There is plenty of evidence that such comparative readings can enrich both film and literature as horror is read and, in the case of film, often collaboratively produced transnationally. Hills notes the frequent presence in Newman's horror fictions of intertextual allusions to other horror texts but this is not confined to Newman nor is it restricted to one culture. For example, a zombie film such as Shaun of the Dead (2004) is an affectionate British parody of Romero's American zombie films (Romero's now-classic 1979 Dawn of the Dead was produced with the assistance of Italian director Dario Argento). The Canadian zombie film Fido (2006) echoes Shaun of the Deads, "zom-rom-com" (zombie romantic comedy) parodic elements while retaining the subversive social commentary of both the Romero 
"originals" and the British parody. On the other hand, Pontypool (2008) returns to the more serious real-life-horror scenario of the uncontrollable, apocalyptic outbreak depicted in die British film 28 Days Later (2002) or the Spanish film REC (2007) while adding a uniquely Canadian element (not found in the 1998 Tony Burgess book from which the film is adapted): as the besieged host of a radio show soon learns, speaking French is die only way to short-circuit the zombie infection which manifests itself as a litany of babble, a killer language.

As these examples show, horror broadcasts a transcultural call to comparison whereby the authority of previous texts is intertextually invoked, not only to display fan knowledge but to contemplate and induce fear. To provide an example from written fiction, M. R. James sets the stage for the revelation of his horror show by using a verse from Coleridge's "The Ancient Mariner" (1798) in "Casting the Runes" and a quote from The Pilgrim's Progress (1678) in "Oh Whistle and I'll Come to You, My Lad." Both allusions are affective in their own right, but the Coleridge verse is particularly haunting, as it is received in the mail by a former victim of the vindictive Mr. Karswell who casts his occult runes upon the protagonist as vengeance for a poor review. The victim's brother describes the increasing sense of doom that finally overtakes his brother, as he receives one day a woodcut of Bewick's, roughly torn out of the page: one which shows a moonlit road and a man walking along it, followed by an awful demon creature. Under it were written the lines out of the "Ancient Mariner" (which I suppose the cut illustrates) about one, who once having looked round walks on,

And turns no more his head, 
Because he knows a frightful fiend

Doth close behind him tread. (142)

This cut-and-paste intertextual paraphrase, "roughly torn out," echoing the "unnaturally rough and hot" hand that thrusts a leaflet into the protagonist's hand prior to this story, invokes the sense of pursuit by an "awful demon creature" that is so central to creating the menacing affect of James's narrative. In "Oh Whisde and I'll Come to You, My Lad," Parkins the protagonist inadvertendy sums up a terrifying creature by excavating a whisde he finds buried in the sand at the site of an old Templar church near a beach. He recalls the scene from Bunyan's A Pilgrim's Progress while walking back along the beach, the whisde in his pocket, and glimpsing "a rather indistinct personage, who seemed to be making great efforts to catch up with him":

In his unenlightened days he had read of meetings in such places which even now would hardly bear thinking of. He went on thinking of them, however, until he reached home, and particularly of one which catches most people's fancy at some time of their childhood. "Now I saw in my dream that Christian had gone but a very litde way when he saw a foul fiend coming over the field to meet him. 'What should I do now,' he thought, if I looked back and caught sight of a black figure sharply defined against the yellow sky, and saw that it had horns and wings?" (70)

Again, this intertextual reference to the fear evoked by the "foul fiend" of The Pilgrim's Progress then gradually creeps into its intertext as the thing's approach becomes more and more sinister over the course of the story until the memorable and conclusive scene 
where the unknown monster suddenly sits up in Parkins' bedroom in the bed next to him and, under the sheets, rushes at him with a "face of crumpled linen" (80).

James is acclaimed as a master of "quiet horror" as opposed to "splatterpunk" and in my ensuing discussion of this debate within the field, I will refer to his techniques and that of others as demonstrating recurring patterns of certain affects that are discernible in horror writing, no matter which style or school it is said to uphold. That said, I take to heart Douglas Winter's lamentation of the fact that horror gets "pigeonholed" too easily into recognizable cliches (Prime EvilW). For Winter, horror is an "emotion" that can be found in "all literature" (12). While I agree with the importance of avoiding cliches as much as possible, I believe that it is a byproduct of the types of irreverent and theory-bound approaches that I have exhaustively critiqued. It is possible to examine horror's affects, including emotion, without resorting to cliches as my subsequent analysis shows.

An important question of response to the affects of horror films versus the affects of writing is raised by the advances in technology and computer-generated imagery (CGI) that have rendered horror 's filmic effects much more dramatic and "realistic." This is not an issue that this dissertation can thoroughly address but it should certainly be kept in mind. We must also keep in mind that, in adapting from literature to film, not all that can be shown by advances in technology will be shown. The emphasis on filmed visual and graphic displays of what Mark Seltzer calls "wound culture," the public fascination with "torn and opened bodies" (1) has resulted in the vilification of films that are seen to embody horror's more shocking excesses. In fact, a look at certain adaptations shows that the print form is often far more disturbing. One example is the 2000 adaptation of Bret Easton Ellis's novel American Psycho (1991). The film version's director Mary Harron wisely steered clear of the ultra- 
violent "unfilmable" scenes of torture, rape and mutilation in the book, which would have rendered the movie version too "hardcore" for a wider audience. Ramsey Campbell brings up another good example from an earlier period when he discusses the difference between Cornell Woolrich's Black Alibi (1942) and its film adaptation The Leopard Man (1943):

Whereas the film shows us only a trickle of blood beneath a door, however, Woolrich flings the door open. ("It was as though clots of red mud had been pelted at the outside of the door, until, adhering, they formed a sort of spattered mound up against it. There were rags mixed in with it, and snarls of hair...") (Cut!70)

A related issue arises from what I described in Chapter Two as the loss of scare power on the part of Gothic monsters that become genetically coded and recognizable. ${ }^{100}$ This is an issue that cognitive and psychoanalytic theories often fail to take into consideration. As an illustration of this point, an Ottawa arthouse cinema often screens a double billing of the classic Universal horror films, Tod Browning 's Dracula (1931) and James Whale 's Frankenstein (1931). From my observation in the theatre, it became obvious that members of the audience, well-versed in these particular monsters as cultural memes,

${ }^{100}$ For instance, John Farris's comment that vampires are a "weakening market" in horror (although, as more recent events show, vampires became strongly marketable for romance) (Cut! 84). Stephen Jones writes somewhat bemusedly in the eighteenth edition of The Mammoth Book of Best New Horror Stories:

Reminiscent of the boom-and-bust horror cycle of the 1980s, vampire romances and - even more bizarrely - vampire/werewolf romances swamped the market in 2006. Not only were these volumes mostly aimed at people who read outside the horror genre, but the majority were written by authors (often under multiple pseudonyms) who had no other interest in horror. However, there was no denying that there was a huge audience for these types of books. (9) 
were less interested in being horrified by these texts than they were engaged in the ironic appreciation of films which were originally horrifying to their audiences but which now bear iconic status as "originals" to a lengthy string of successors. Chuckles greeted Bela Lugosi's Dracula, particularly at the close-ups of his burning eyes, and the same knowing sounds of appreciative derision were echoed upon the screening of Boris Karloff s Frankenstein monster's famous scenes, such as the shot where the monster cocks his head inquisitively at the little girl playing with flowers by the river. The audience was signaling its fan $(\mathrm{g})$ dom of this film, its intimate familiarity with what follows: the knowledge that the monster will then toss the little girl into the water, inadvertently drowning her, imitating what she has done with her flowers.

Compare this reaction, this indulgent familiarity with the responses of an audience watching Dario Argento's short film "Jenifer" [sic] (2005), made for the Showtime cable network 's auteurist Masters of Horror series and based upon a 1974 comic by Bruce Jones and Bernie Wrightson. ${ }^{101}$ Argento knowingly refers to this famous sequence from Frankenstein, showing his grotesquely deformed, albeit repulsively sympathetic female monster similarly cocking her head inquisitively at a small girl with flowers beside a paddling pool who greets her in a friendly fashion. However, Argento, drawing upon state-of-the-art special effects, goes much further than the classic Frankenstein 's director James Whale in depicting what follows, as the audience then witnesses, along with Jenifer's protagonist, the monster crouching over the child's disemboweled corpse at the bottom of the basement stair, feasting

101 The comic from the Creepy series can be viewed here: $\langle$ http://davidz.blogspot.com/2006/11/jenifer-by-jones-and-wrightson-just-say.html > 
upon the child's entrails. This is strong stuff and very difficult to watch; as Argento observes in the featured interview on Jenifer's DVD version, "So Hideous, My Love," showing the "spectacle of the ruined body" of a child remains taboo and crossing this line creates a powerful impact. In another graphic scene that was deleted from the airing of the film, the monster also is shown devouring a victim 's very realistic-looking penis; as Argento acknowledges here also, the phallus is too sacred an object to be thus violated. ${ }^{102}$ Such scenes would have been unthinkable in James Whale 's time; however, the intertextual reference to Frankenstein persists, adding a broader dimension to the horror of the scene. As previously mentioned, I will devote some pages later to the "quiet horror" versus "splatterpunk" debate that has dominated the horror field since the 1980s. The allusion to Frankenstein in Jenifer vividly illustrates the idea that this distinction between different types of horror based upon their "G-factor" may be more reflective of changing technologies and changing cultural tastes (what is unacceptable to show) than a superior efficacy or artistry in producing horrific affects.

Another taming — this time of the ghost - is dramatized in M. Night Shyamalan 's The Sixth Sense (2002), in which the fearsome apparitions become an extension of the special empathic gift of the charming little boy who suffers only from the ability to perceive them. Although the onset of ghostly visitations are presented as frightening throughout the film, the narrative ultimately reverts to a comforting explanatory mode a la Radcliffe, and thus is a

Of course, it is interesting to consider that Showtime's censors cut the penis eating scene but not the child-eating scene. 
story of the marvelous in Tzvetan Todorov's sense. The marvelous, defined by Todorov as the "supernatural accepted," belongs more to the uncanny realm in which horror thrives: The fantastic .. . seems to be located on the frontier of two genres, the marvelous and the uncanny, rather than to be an autonomous genre. One of the great periods of supernatural literature, that of the Gothic novel, seems to confirm this observation. Indeed, we generally associate, within the literary Gothic, two tendencies: that of the supernatural explained (the "uncanny"), as it appears in the novels of Clara Reeves and Ann Radcliffe; and that of the supernatural accepted (the "marvelous"), which is characteristic of the works of Horace Walpole, M. G. Lewis and Maturin. (The Fantastic 41-2)

Todorov 's definition of the fantastic has proven fruitful for many students of horror but also shows the flaws in a merely plot-driven approach. If we accept that a text is either fantastic or marvelous, what does that actually tell us? The concentration upon the plot of The Sixth Sense obscures the fact that it is also a very effective horror film in its deployment of the elements of horrific style. In what follows, I will draw upon Todorov 's work to elucidate certain passages of horrific texts, but I argue that merely establishing the events of a narrative as one category or another is not enough to account for its "affect-function." As Hills puts it, the "epistemological" resolution of knowing what world we find ourselves in, thereby settling the question of the fantastic, is not always provided by horror. Instead, Hills argues, the horror text often presents an "ontological shock" in which the world we think we are in suddenly shifts and changes (34). If we are to find concrete examples of Todorov 's fantastic hesitation, we must look more closely at the text itself. 
Technique in fiction, the "art of language" is, as David Lodge points out, "far from obvious" even if it is taken for granted (5). It is unfortunate that this realization has not been more widespread in the recent "discovery" of the field of horror by cultural critics. The predominance and recent proliferation of film studies of horror has possibly contributed to this taking for granted of written horror. Written horror, of course, uses different affects from film although, as my examples above illustrate and as more will show, there are many useful equivalencies between cinema and print in the horror text. Still, critics have shockingly neglected the stories and novels that constitute a significant part of the field. As Gelder notes, this is a real gap (The Horror Reader 6), one that this dissertation seeks in part to fill. ${ }^{103}$ The analysis of an art of darkness has been similarly neglected; what Edith Wharton called a tale's "thermometrical quality; if it sends a cold shiver down one's spine, it has done its job and done it well." ${ }^{104}$ Here, I will side with Wharton and eschew other considerations of what may or may not make horror valid art, bearing Theodore Sturgeon's famous claim in defence

Hills takes issue with Gelder's "exaggerated" claim that there have been no academic studies of horror writers, citing a few titles to prove his point. I have already mentioned the problems with S. T. Joshi's approach to all writers outside the Lovecraft circle, but Hills also cites Bloom (ed. 1993); Talbot 1995 and Reynolds et. al, 2001. Clive Bloom's uneven collection of excerpts does contain a couple of original and interesting pieces on African-American and Caribbean women's horror (G. Wisker) and one article on horror narrative by Laurence Talairach-Vielmas. Mary Talbot's Fictions at Work: language and social practice in fiction (1995) is not exclusively focused on horror, using it as one example among others. The Reynolds book on Frightening Fiction cited by Hills concerns recent children's horror literature - a fascinating topic but a bit misleading in this context.

${ }^{104}$ Cited by Alberto Manguel in Black Water: the anthology offantastic literature, 62. Manguel was introducing the Wharton story "Pomegranate Seed" (1931), a horror story for second wives where the first wife writes her husband letters from beyond the grave, a wonderful Jamesian exercise in inducing "thermometrical" suspense. 
of science fiction that ninety percent of everything is "crud." What I am interested in here is examining a specific type of artistry which has gone unheeded under broader conceptions of culture.

Even in film studies, I would argue, the techniques that create horror's special "affects" and "thermometrical quality" have yet to be fully explored. The dominance of psychoanalytic film theory in horror criticism is underscored by the amount of scholarly work that confines its analysis to horror film narratives and ignores written horror. Outside the discussion of the Gothic, when literature other than the privileged examples of Frankenstein or Dracula is mentioned, it is usually in order to demonstrate a theory or a historical transformation in its adaptation to the screen. ${ }^{106}$ Film and cultural studies scholars frequendy ignore the fact that many horror films are taken and adapted from horror literature, novels and even more often, short stories. The enormous field of cultural production that is written horror is neither as well-known nor as established as its filmic

This principle, which can be found in the Oxford English Dictionary, was first expounded as "Sturgeon's Revelation" in Venture magazine 66/2 March 1958: "I repeat Sturgeon's Revelation, which was wrung out of me after twenty years of wearying defense of science fiction against attacks of people who used the worst examples of the field for ammunition, and whose conclusion was that ninety percent of sf is crud.

"The Revelation: Ninety percent of everything is crud.

"Corollary 1: The existence of immense quantities of trash in science fiction is admitted and it is regrettable; but it is no more unnatural than the existence of trash anywhere."

"Corollary 2: The best science fiction is as good as the best fiction in any field."

${ }^{106}$ An interesting variation on adaptation theory is the comparison of remakes, such as the versions of Dracula, King Kong, Night of the Living Dead and The Thing, which either blatantly or subdy reflect changes in the cultural contexts that re-produce them. 
counterpart, and certainly cannot be "taken as read" by anybody who is serious about studying the field. For this reason, I believe that certain key features of the horror text deserve at least some formal examination.

\subsection{The Told Tale at the Heart of Horror}

The first problem that arises in a formal approach to textual features is that of what Carroll calls "artforms." In other words, since horror may be found in literature, film, graphic novels, the plastic arts, video games and even, now in descriptions of "zombie" banks following the economic crisis, how may such heterogeneous texts be compared or interpreted together as horror? ${ }^{107}$ One rudimentary comparison is advanced by Judith Halberstam, who begins Skin Shows (1995) with an intriguing distinction between literature and film, arguing that "the production of fear in a literary text (as opposed to a cinematic text) emanates from a vertiginous excess of meaning." She goes on to write that "the shift from the literary Gothic to the visual Gothic was accompanied by a narrowing rather than a broadening of the scope of horror" (2). Halberstam compares literature with horror film by asserting that the spectacle of film creates different types of horrific images: ${ }^{108}$

One might expect to find that cinema multiplies the possibilities for monstrosity but in fact the visual register quickly reaches a limit of visibility.

${ }^{107}$ See Chris Meyers's and Sara Waller's "Disenstorted Horror: Art Horror without Narrative" for a discussion of visual horror art such as painting (in Film and Philosophy Special Edition on Horror, 2000, edited by Daniel Shaw).

${ }^{108}$ See the quote by Stephen King paraphrasing William Nolan's dictum that the sight of a monster is never as frightening as what is behind the "closed door" mentioned later on page 300 of this dissertation. 
In Frankenstein the reader can only imagine the dreadful spectacle of the monster and so its monstrosity is limited only by the reader's imagination; in the horror film, the monster must always fail to be monstrous enough and horror therefore depends on the explicit violation of female bodies as opposed to simply the sight of the monster. (3)

Unfortunately, Halberstam goes on to examine only films in the latter part of her book and this interesting argument finds no further purchase. The shortcomings of the monster-centric approach are again apparent. For example, my earlier discussion of the adaptation of American Psycho shows that a horror text can work in the opposite direction as the "violation of female bodies" is more explicit in the book and more implicit in the film. If horror films fail to be "monstrous enough" and demonstrate horror in specific ways, an interpretation which compares those techniques with the ways in which horror can be demonstrated in literature, graphic novels, radio drama, television drama, theatre and the plastic arts will surely yield a better understanding of how horror can function as a mode of representation for fear. Formulating a poetics of horror is therefore useful for comparisons across media, even though a discussion of the full range of horror media is currently beyond the scope of this dissertation.

Most scholars do not discuss the abundance of horror literature that is being produced in the form of short fiction. Many horror films are adapted from short fiction; yet, critics examine only the adaptation without looking at the original source. In the collection Classics of the Supernatural (1998) collected and introduced by Peter Haining, the short stories behind films such as Haunted (1995) (James Herbert's "Hallowe 'en 's Child"), the omnibus film Dead of Night (1945) (Gerald Kersh 's "The Extraordinarily Horrible Dummy" among 
others), and Night of the Demon (1958) (M.R. James "Casting the Runes") are presented. The film Candyman (1992) was based on a Clive Barker short story, "The Forbidden" (Books of Blood, Volume V); a fact which Isabel Cristina Pinedo never mentions in her analysis. While Swedish scholar Yvonne Leffler discusses the importance of the horror "story," what she means by story is narrative and her contribution Horror as Pleasure (2000) publication makes no references to any short stories, only novels and films. Martin Tropp's Images of Fear: how horror stories helped shape modern culture (1999) is another welcome discussion of literature but one that only discusses fiction written between 1819 and 1918.

The neglected significance of the short horror story or what S. T. Joshi in the Lovecraft tradition calls "the weird tale" is demonstrated by the appearance in 1995 of The Supernatural Index: A lasting of Fantasy, Occult, Weird and Horror Anthologies. Since horror fiction in the nineteenth and twentieth centuries in the U.K. and U.S. is predominandy published in short story form, the Index set out to make the listings of such anthologies more complete. Both the short story anthology and also the pulp magazine as a forum for short fiction, I argue, following Stephen King and other writers who have looked at horror 's history, play enormously important roles in the dissemination of horror fiction (1995). Franco Moretti writes of the novel that it is long because novels recount "adventures": "The text has an orientation, it leans forwards" (New Left Review 112-116). Leffler has similarly noted this tendency in horror's "forward-pointing narrative" (97). However, we will see that this question of orientation is even more vital for the short horror story. We have become accustomed to placing die novel at the centre of the literary universe, regarding the short story as somehow a lesser form, a sneeze to the novel's discursive tissue. However, in horror, the short story form is at least as important and, I would argue, more important than the 
horror novel because of the short story s kinship with the oral narrative and its ability, not only to achieve Poe's "unity of effect." but to create a plausible basis for shared fictional worlds such as the Lovecraft Mythos. Arguably novels can create shared worlds too as intertexts (for example, Stephen King's Maine towns as settings and his characters that pop up in other novels), but neither as easily nor as openly to the participation of writers, fans and fans who become writers and filmmakers.

Until the massive popularity of Stephen King in die $1980 \mathrm{~s}^{109}$ which created an enormous market for horror novels, as David Hartwell observes in The Dark Descent, there was no such thing as a horror novel. Rather, there has been what Hartwell calls an "evolution" of horror from a short form to a "novel genre" in more recent times. ${ }^{110}$ One might object to this idea by casting back to the Gothic novels and the classics of the horror genre, but there, too, one finds a plethora of story forms even within the novels themselves. Dracula is an epistolatory novel, narrated by several different characters. Frankenstein is a packet of letters sent from aboard a ship that finds a stranded passenger who recounts a tale in turn which includes the Monster's tale. The omnibus films and the "novel in stories" Haunted by Chuck Palahniuk all pay tribute to the centrality of the story to horror. The

${ }^{109}$ John Farris describes Stephen King as a "whole genre": "There is a Stephen King type of book. I mean, that's pretty well established. Like Summer of Night - Dan Simmons wrote it, but it's a Stephen King book. That's a whole genre that King actually perfected" \{Cut! 88). Al Sarrantonio also talks about the horror boom of the 1980s in 999.

${ }^{110}$ In response to which development The Dark Descent (1987) was conceived as a "definitive" anthology of horror short fiction (Hartwell 2). Hartwell's anthology is excellent and includes many important stories. It is one among many others, however, and thus not "definitive." That said, it is a good reference for people working in the field of short horror fiction, along with Kirby McCauley's Dark Forces (1980). 
horror novel, in fact, is best seen as intra-diegetic, cogs ticking and gears spinning to form a maze of stories within stories, enmeshed intertextual labyrinths haunted by fragments, found objects, forbidden texts and hybrid monsters.

In my analysis, which seeks to address the glaring oversight of the short story 's neglect among horror scholars, I place the short story at the centre and other forms at the margins. I consider the short story to be the essential form of horror and the horror novel and films that have received so much critical attention as peripheral "spinoffs" (and "spinouts") of that form. With S. T. Joshi, I believe that "the weird tale as an art form generally works better in small compass" (Evolution of the Weird Tale 4). The only explanation that Joshi gives for this assertion, however, is another rather cryptic assertion that "weird fiction should not be about ordinary people." Joshi hints that perhaps this is why horror novels such as Ramsey Campbell's are not as compelling as his short stories (7); he also quotes Thomas Ligotti on the difficulty of writing a horror novel. Novels, it is implied, are concerned with realistic portrayals of "ordinary people" and situations whereas, as Joshi points out, realism "is not a goal but a function in Lovecraft; it facilitates the perception that 'something which could not possibly happen' is actually happening" (8).

The intertextual tendency of horror, as well as its repetitive, serial quality, could itself be considered a narrative strategy, used frequently to make allusions, hommages and selfconscious references to other horror texts. Both horror proper and horror parodies make liberal use of intertextuality, as we have seen, and readers since Catherine Moreland have responded to it. George Sieg describes horror as "self-referential," always returning to itself in an "infinite regress" \{Collapse TV32). This becomes very obvious when one compares horror short story plots to observe how many are recycled and re-versioned. In one striking 
example, Robert Bloch's story about fembots, "Wheel and Deal" (Atoms and Evil), for example, predates both Ira Levin's novel The Stepford Wives and the film version by a decade. Pastiches of Lovecraft require a dissertation of their own, while those stories traceable to the influence of M. R. James include, for example, Adam L. G. Nevill's story "Where Angels Come In" (2006) or the compelling story "The Ragthorn" (1992) by Robert Holdstock and Gary Kilworth. Sometimes the "textual poaching" is clumsy. Mary Danby's story "Party Pieces" and John Burke's "Party Games" \{Stories That Scared Even Me 71), for example, are both clumsier versions of Ray Bradbury's "The October Game" $\left\{6^{\text {th }}\right.$ Fontana book of Great Horror Stories $\backslash 91 \backslash$.

Reading widely in the field of short horror fiction, one everywhere notices this looping characteristic; it is what leads some to dismiss horror as derivative, unoriginal and therefore unworthy of aesthetic consideration. However, this tendency of horror fiction to self-cannibalize could also be regarded as the source of its scary strength. Indeed, David Hartwell observes of Stephen King that one of his "most salient influences on the horror story is the extent to which he is synthesizing and mutating" his fan $(\mathrm{g})$ dom into "a wholesale regeneration of horror traditions" (The Dark Descent 382). One example is the striking similarity between King's earlier short story "The Ledge" \{Night Shift), Jack Finney's "Contents of a Dead Man's Pockets" and Henry Slesar's "A Cry From the Penthouse" \{Stories for Late at Night). In the latter, especially, the narrative events are almost identical. A sympathetic character is forced by an unsympathetic character onto the balcony of his highrise apartment and must battle the winds outside, only to turn the tables on his adversary. One of Nathaniel Hawthorne's recorded fragments or notes for a story which he never wrote out in full also sounds very much like King's short story "The Mangier" \{Night Shift): 
"A steam engine in a factory to be supposed to possess a malignant spirit; it catches one man's arm and pulls it off; seizes another by the coat-tails, and almost grapples him bodily; catches a girl by the hair and scalps her; and finally draws a man, and crushes him to death" (Black Waters 951). J. B. Priestly's disturbing story "The Grey Ones" and King's "The Boogeyman" are also very similar. L.P. Hartley's tale "W.S." (Terrors, Torments and Traumas) is almost identical to the plot of The Dark Half. "The biter bit" is a recurring theme in horror stories, supplying much of die plot twist in a twist ending. David Schow's nasty litde tale "Pick Me Up" and "Him Her Them" by William F. Nolan, both concerning chance encounters between serial killers, are two more examples of this repetitive quality of the horror story, which is not a matter of shameful impoverishment but rather of storytelling wealth. ${ }^{111}$ Again, the possibility of a shared world that many horror stories open up is a gesture against the primacy of originality and uniqueness as a marker of literary worth.

It is a conceit of consciously "higher" forms that originality is the sole determinant of art. The horror story pretends to no such thing. In fact, horror stories often refashion and reshape the canonical texts of western literature as well as less-canonical texts within the horror tradition. To Hills's discussion of Kim Newman's intertextuality, I will add some other examples, such as Brian Keene's story '"The King', in: Yellow" which updates the classic 1895 Robert W. Chambers weird tale "The King in Yellow" with some gory additions. ${ }^{112}$ Barry Malzberg and Bill Pronzini's story "Clocks" remakes Poe's "The Tell-Tale

${ }^{111}$ Both stories are in 'Psycho-paths (1991). "Pick Me Up" also appears in Dark Voices 4, and was also made into a Masters of Horror episode.

${ }^{112}$ In Mammoth Book of Best New Horror, 2005 
Heart" with a twist. ${ }^{113}$ Brian Lumley's 1988 story "Uzzi" remakes Hortense Calisher's tale "Heartburn." ${ }^{114}$ Simon Clark's "The Extraordinary Limits of Darkness" is a horror intertext of Joseph Conrad's Heart of Darkness, similarly reflecting colonial brutality in less circumspect ways. Dante's Inferno also furnishes material for Dan Simmons's "Vanni Fucci is Alive and Well and Living in Hell,"115 in which the titular character returns to a televangelist's show to discuss his torment of seven centuries in the Inferno created by a "dirty litde Florentine," "that neurotic litde whimshit." Fucci asks the dumbstruck television audience he has commandeered during his brief escape from the Inferno, "who has bothered to redefine Hell?" since Dante's vision: "The Germans came close in this century, but their visionaries were snuffed out before the new concept could take root in the mass mind" (156).

The field in particular teems with horrific re-versionings of myth and folklore, as well as that rich repository of horror, children's literature. For example Gahan Wilson's story "The Sea Was Wet as Wet Can Be" explores the gory potential of the predations of the titular characters upon the ill-fated oysters in Lewis Carroll's "The Walrus and the Carpenter" poem from Alice in Wonderland ${ }^{\wedge}{ }^{6}$ Lewis Carroll himself appears as a character and quotes from Alice in Wonderlandare employed in Stephen Dedman's haunting vampire tale about a strange little girl who becomes an agent of vengeance against pedophiles, "Never

"ui In Shadows 2, 1979

${ }^{114}$ The Calisher story appears in Best Horror Stories (ed. John Keir Cross). "Uzzi" is in Dark Terrors: the Gollanc ${ }^{\wedge}$ Book of Horror Stories (1995).

${ }^{115}$ Skin Trade, 153-55

${ }^{116}$ In The Playboy Book of Horror and the Supernatural, 1967 
Seen by Waking Eyes (YBFH10). Another example of a fabricated Hell (and a deliberately imagined escape) is in "The Boatman's Holiday" by Jeffrey Ford, using more conventional Greek mythology. Charon seeks out the island of Oondeshai, constructed by a cleric who foresaw he would commit murder and so deliberately contrives to imagine an escape hatch from hell. ${ }^{117}$

While the recent, seemingly endless spate of Hollywood remakes of now-canonical horror films exasperates some critics and audiences who insist upon "fidelity criticism" (Hutcheon) and decry the mimicry and exploitation of the "originals," I choose to see it as a sign that the recycling principles of the short horror story remain central to horror fiction in general. To Brophy's coinage of "horrality — horror, textuality, morality, hilarity," I would also insist upon the "orality" of the horror story, derived from popular performances and "campfire tales" (Leffler), where a tale might be recounted many different times, in many different ways, by different tellers. ${ }^{118}$ The relationship to "urban legend" here is clear (what Stephen King calls "Tales of the Hook" in Danse Macabre), and in fact many horror tales, as Pinedo notes in her discussion of Candyman (Recreational Terrors), trade as popular texts upon the urban legend breaking down the borders of the story and erupting into reality. Glen

${ }^{117}$ Again, the number of horror stories based upon versions of the Christian devil and of Hell, such as John Collier's "The Devil, George and Rosie" requires a separate dissertation.

${ }^{118}$ The humorous (horrlarious?) remake is also a kind of story telling, as Brad Linaweaver's tongue-in-cheek recounting of the "Universal curse" in "Close Shave" illustrates (Ultimate Werewolf) 
Hirshberg's story "Mr. Dark's Carnival" is a good example (YBFH14). The postmodern Scream franchise trades upon the concept that popular horror fictions themselves sink into the cultural sediment of urban legendism, while stories such as Harlan Ellison's "The Whimper of Whipped Dogs" (Deathbird Stories), Fritz Leiber's "Smoke Ghost" (The Dark Descent) and Poppy Z. Brite's "The Ash of Memory, the Dust of Desire" (Wormwood) indicate that the process of creating new legends to fit with contemporary industrial urban settings and situations is ongoing.

In my discussion of two M. R. James stories that employ "cut and paste" allusions to other texts and in the above discussion of remaking horror stories, I have significandy expanded the idea of intertextuality that Hills cites as a pleasure of horror. The found document, fragment or myth-creating forbidden work is the signifier of this insistent (inter)textuality. Arthur Conan Doyle's "The Horror of the Heights" describes a found scrap, entided the "Joyce-Armstrong" statement, of the journal of an enterprising pilot who ventures into the "jungles of the air": "Forty-three thousand feet. I shall never see earth again. They are beneath me, three of them. God help me; it is a dreadful death to die!"120 Another frequently recurring short horror story narrative stratagem that foregrounds the urban legend is the overly literal or the argument-taken-to-logical-conclusions in, for

${ }^{119}$ Obviously, the film franchise Urban Legend is an example. As an aside, it is interesting to note how many of the "postmodern" fright movies literalize common horror plots in their tides; Wrong Turn, for example. Many horror stories hinge upon a "wrong turn" with the main characters getting lost (of course The Rocky Horror Picture Show parodies this, alluding to J. B. Priestley's classic "The Old Dark House"). Stephen King's "Children of the Corn" and "You Know They've Got a Hell of a Band"are two well-known examples as well as his Lovecraftian "Crouch End."

In The $7^{\text {th }}$ Fontana Book of Great Horror Stories, 86 
example, Stephen King's early short story "Quitters, Inc"121 (Night Shift) which shows a clear influence on "The Monkey Treatment" by George R. R. Martin (Masters oj"Darkness II). Both these stories feature smoking cessation and weight loss regimens that become horrific.

The short horror story therefore demonstrably does not share the novel, the theatre and, arguably, film's concerns with what Lionel Trilling calls "sincerity" or the discovery and proclamation of an individual's unique and inner self, the "salient, perhaps a definitive characteristic of Western society for some four hundred years" (Sincerity and Authenticity 6). Rather, the short story impresses upon its reader what Trilling described as "authenticity" or the organic, "in-flowing" impressions of "the mental processes of others" (61). For a traditional understanding of the novel, Catherine Belsey's idea of "expressive realism" has been the determining mode: the expression of a "unique world-view" and a "more or less truthful representation of reality" (Lodge 12). In contrast to this view, Californian horror writer Dennis Etchison avers, "I think the novel is an outdated form .... In our time, the novel is a curiosity" (quoted in Joshi, Evolution of the Weird Tale 185). I would argue that the horror short story is so enduring and effective precisely because it recognizes the impossibility of establishing Belsey's "more or less truthful representation of reality" in a world beset by a multitude of nightmarish uncertainties. George Lukacs writes that the short story is "the narrative form which pin-points the strangeness and ambiguity of life," where "lyricism must entirely conceal itself behind the hard outlines of the event": "The short story

${ }^{121}$ This story has been transculturated and adapted into a 2007 Bollywood film entitled No Smoking <http://nosmoking.erosentertainment.com/> 
is the most purely artistic form; it expresses the ultimate meaning of all artistic creation as mood, as the very sense and content of the creative process ..." (The Theory of the Novel'51).

In the place of the novel's "expressive realism," the short horror story's particular authenticity might be seen as signified by its intertextuality rather than a claim to originality, its invocation of a tradition of the tale told and its ability to not only create a mood, Poe's principle of the "unity of effect," but to replicate that mood in its audience. The prevalence of the forbidden tome or "found document" in a horror story as a gateway to its frightening events is a signifier of the story's placement in a textual reality, as well as its location among listeners and readers. Skipp and Spector declare that "Your whole grip upon consensual reality inescapably mutates upon exposure to art like this" (Cut! 245). The key word here is "consensual": a textual community means that it does not lessen the text under discussion to note, for example, the debt to the Lovecraft mythos in Michael Chabon's "The Black Mill" $(\mathrm{YBFH} 11) .{ }^{122}$

Rather than the genius scribbling away at his epic in a lonely attic, the iconic image of the short horror story is the circle of people seated around the campfire or the hearth, telling each other tales. Theorists of the short story such as Dominic Head, Susan Lohafer, Allan Pasco and notably Sarah Hardy confirm this idea. Hardy finds that "(t)he short story, while undeniably a product of a literate culture, demands a similar kind of knowledge from its

${ }^{122}$ To map thematic similarities among stories is part of the gratification of working in this field. Charles Beaumont's gender-queering "Miss Gentilbelle" (in Stories for the Dead of Night, 1957, also anthologized in The $6^{\text {th }}$ Fontana Book of Horror Stories, 1971) recalls the earlier and very disturbing "Raspberry Jam" by Angus Wilson (in Best Horror Stories, ed. John Keir Cross, Faber 1962). The relationship between the imagination of a child and the madness of an adult (or two adults in "Raspberry Jam") is similarly explored and both stories graphically feature the mutilation of animals as a way to abuse the child. 
audience and demands it at once. This quality suggests that die act of reading a short story could be different from that of reading other kinds of fiction" ("A Poetics of Immediacy: Oral Narrative and the Short Story"). Hardy goes on to speculate that "[tjhe dynamic of the oral theme carried forward into the study of written narratives brings out interesting possibilities for a reader aesthetic that takes into account issues of community."

Hardy claims that a short story ending "frequently asks us to reinterpret all that has come before it, an act of listening (or re-listening) that in its most radical interpretation approaches the process of authoring an utterance" (11). This idea of re-listening and reexamining "all that has come before it" also fits with Hills's concept of "ontological shock" where the world of the horror story is suddenly altered. David Hartwell noticed the prevalence of the short story form in moderating a panel discussion of horror novelists: "the good stuff is pretty much all short fiction" (The Dark Descent!) $\}^{23}$ Hartwell attributes to Stephen King's massive popularity the rise of a type of horror novel that became predominant in the 1970s and 1980s as "an avant-garde and experimental literary form which attempts to translate the horrific effects previously thought to be the nearly exclusive domain of the short forms into newly conceived long forms that maintain the proper atmosphere and effects" (3). Clive Barker, Hartwell writes, is rare among contemporary

${ }^{123}$ Gary Raisor in Cemetery Dance concurs with Hartwell's assertion, arguing "it has become increasingly, and appallingly, obvious that most of the interesting writing in the horror field is being done in the form of the short story. By people you've probably never heard of. Published by houses you've probably never heard of, either" in "In Defense of the Horror Short Story," <http://www.cemeterydance.com/ page/CDP/WritersColumnGaryRaisor>, accessed July 2009. 
horror writers in attaining popularity through his short stones in The Books of Blood (The Dark Descent 339).

I do not agree with Hartwell's implication that the short story is merely a stage in the "evolution" of the novel. Many contemporary horror fictions that are not "Stephen King novels" are, like Chuck Palahniuk 's Haunted or Max Brooks's World War Z, novels only in name, length and marketing. In fact, they are serial stories with a framing narrative, like die writer's retreat that becomes a trap for the storytellers in Haunted or die zombie wars that give rise to Brooks's "oral histories." These are tales that solicit, that indeed require "an act of listening" (Hardy). In order to properly appreciate the important role played by the oral history of the short story, an eclectic variety of stories will be considered in this chapter. ${ }^{124} 1$ offer no apology for ranging so freely among the decades in my selections. While historical factors do weigh upon horror fictions, the affects that I wish to pinpoint are less subject to change while the themes, language and cultural preoccupations may differ from one generation to the next. Yvonne Leffler points out that the "narrative technique and basic themes of the horror story have remained largely unchanged for two centuries" (23). It is quite clear that many contemporary horror stories, including those of Stephen King, are influenced by earlier versions of similar tales, an insight which would not be captured by restricting myself to one particular moment in the production of the horror story. I am conscious, however, of the dominance of Anglo-American short fiction throughout my

${ }^{124}$ In fact, the generic "Stephen King" type of horror novel (as opposed to the parodic or the experimental horror novel) appears at the time of this writing to be decidedly on the decline, while the short story form is still going strong. Note, I am not counting the increasingly romantic vampire novel subgenre as horror. 
dissertation and hope that the categories I identify can and will be applied further afield in the consideration of horror in various cultural contexts.

For the purposes of this dissertation, I need to make a theoretical distinction between my usage of the terms "story" and "tale" in order to begin drawing out some elements of the horror fictions I will be analysing in the second half of this chapter. ${ }^{125}$ This distinction and my subsequent discussion is strongly influenced by structuralist narrative theory, including what Barbara Herrnstein Smith calls "dualist" constructs such as the Russian Formalists' distinction between fabula (the story or raw elements of the narrative) and $s j u^{\wedge}$ et (the manner of telling the tale) (Propp) as well as the roughly correlative French structuralist distinctions between various terms, discours, recit, narration and histoire (Benveniste, 1971; Genette, 1980). Leffler similarly employs Genette's distinction between "story" (events in chronological and causal order) and "narrative" (textual presentation of those events) to discuss horror fiction (100).

At the same time, I am mindful of the criticisms levelled against such torturous mechanisms by Derrida in "Living on - Border Lines" where he insists that "[w]hat is judiciously called the question-of-narrative covers, with a certain modesty, a demand for narrative, a violent putting-to-the-question, an instrument of torture working to wring the narrative out of one as if it were a terrible secret. .." (261). Horror, trading in precisely such "terrible secrets," foregrounds the anguish of its narrative, wrung out of the narrator. Horror, more importantly, displays a connection to oral storytelling that removes it a small

${ }^{125}$ Smith in Bal, 2004, 95. Smith's essay "Narrative Versions, Narrative Theories" as well as Barthes' "The Structural Analysis of Narratives" are in Bal, Mieke. Narrative Theory: major issues in narrative theory. Routledge: 2004. 
distance from the paradigms elaborated by the structuralists. Thomas King reminds us in The Truth about Stories: a Native Narrative (2003) that oral storytelling performs for an audience rather than maintaining "a sense of rhetorical distance and decorum while organizing the story for a knowledgeable gathering" (22) ${ }^{126}$

Here, I will refer to the horror "story" as the material thing that the reader comes across and begins to read, for instance, in a collection of short stories. The tale, on the other hand, is an oral narrative within the story. A tale, often explicitly marked as being recounted and focalised by a narrator-character within the story, is what not only opens and introduces, but sets up the horrific elements of a story and marshals its affects for its audience. Samuel Taylor Coleridge's "willing suspension of disbelief for the moment, which constitutes poetic faith" certainly applies here (157). Stephen King recognizes the importance of this famous principle to horror, writing:

When Coleridge spoke of 'the suspension of disbelief in his essays on imaginative poetry, I believe he knew that disbelief is not like a balloon which may be suspended in air with a minimum of effort; it is like a lead weight, which has to be hoisted . . . and held up by main force. (Danse Macabre 104)

Robert Bloch, comparing written and filmic horror, also highlights the necessity to "suspend our disbelief and the difficulties of making that happen in written horror:

This temporary suspension of disbelief is, of course, a classic and muchreiterated requisite of fiction in the field. Unfortunately, the author can bring

1 Thomas King slyly remarks, "And cranky old Jacques Derrida notwithstanding, we do love our dichotomies" (25). 
few artificial aids to his task. His lines have no musical accompaniment to enhance mood, no sound effects for sudden shock; his words appear upon the printed page in a simple arrangement of black and white, without transformation to Technicolor. (Psycho-paths xvii)

The Tale Told, Coleridge's Ancient Mariner at the wedding feast of the story, is what proleptically draws the reader in, signifying something askew in the otherwise "normal" and sunlit world of the story. The editors of The Postcolonial Studies Reader observe that orality marks an "exchange where those involved are physically present to one another .... the oral only exists and acquires meaning in the possibility of an immediate and modifying response, existing therefore only interactively with its whole speech or movement event" (321). In Bloch's terms, the framing device of the tale told constitutes the "transformation to Technicolor" for written horror. It does the heavy lifting for the suspension of belief that allows the reader to experience affective responses to the story. This function is absolutely crucial for horror, because the entire success of the fiction in achieving Wharton 's "thermometrical quality" lies in its being not necessarily taken seriously, but experienced very seriously, at least for the narrative's duration.

For example, the story "The Inexperienced Ghost" by H. G. Wells explicitly draws attention to and simultaneously defies the suspension of disbelief through being narrated as a tale by the character Clayton, which is then reminisced about by the narrator, possibly at an ensuing gathering of the same kind at a gentlemen's club:

The scene amidst which Clayton told his story comes back very vividly to my mind. There he sat, for the greater part of the time, in the corner of the authentic settle by the spacious open fire, and Sanderson sat beside him 
smoking the Broseley clay that bore his name. There was Evans, and that marvel among actors, Wish, who is also a modest man. We had all come down to the Mermaid Club that Saturday morning, except Clayton, who had slept there overnight — which indeed gave him the opening of his story. (175) Horror fiction abounds with examples of The Tale told at this very old-fashioned venue for storytelling, the Victorian gendemen's club (Kipling's "The Mark of the Beast" is another of these). Here is another example from a story by Paul S. Powers entided "Monsters of the Pit" (131), set in "British East Africa." Power's protagonist will shordy be describing his encounter with giant spiders in the colonies, and the story opens with him direcdy addressing his audience and, implicidy, the reader:

How did I lose my left arm? Well, gentlemen, I have felt that question coming for a long time, and to tell the truth about the matter, I rather dreaded it. For, as well as I have grown to know you during these lonesome nights at the club, I never thought the time would come when I could unburden my mind. I don't expect that you will believe me, either you, Bronson, or Roberts, here. I tried to tell the story once before, to a French doctor at Port Said. He laughed at me at first, and thought me insane afterwards. I won't blame you for doing the same. Sometimes I hardly believe the story myself. It seems more like a nightmare than a reality. But here's the proof, gendemen - this poor stump that was once a fairly serviceable left arm. It looks like a neat surgical operation, doesn't it? But it took my wife three hacks to get it off. \{Monster Book of Monsters 126) 
Obviously, this is a compelling opening that draws us straight into the tale. However, we should not miss the added implications of the device of situating the reader among the charmed circle of listeners, in this case, the gendemen's club. Stephen King is appealing to more than a sexist and classist nostalgia for the gentlemen's club when he resurrects the setting for stories such as "The Breathing Method" (Different Seasons) and "The Man Who Would Not Shake Hands" (Skeleton Crew). King's club, which he invests with Lovecraftian elements such as slithering, ${ }^{127}$ and bumping noises that menace the askers of too many questions about the club, and a mysterious factotum named Stevens who is "much much older" than he appears ("The Breathing Method" 439). As part of the club ritual, the teller of the tale throws a packet of chemical powder into the fire which "turned the flames momentarily parti-colored" (445) (again invoking Bloch's "transition to Technicolor" as setting the tale in motion). The next part of the ritual is the utterance of a toast "[t]o the tale, not he who tells it" (446).

Outside the club, hierarchies are restored, as the narrator of "The Breathing Method" soon finds out when he attempts to praise the storyteller, a senior partner, following his first visit to the club, and is haughtily rebuffed. The community of tale-telling that temporarily lifts restrictions and levels class differences (for white men anyway) exists only as a fantasy. The narrator's wife jokingly calls him a "male chauvinist" and calls "Oink, oink" after him when he leaves for his second visit to the club. By thus acknowledging the sexism and elitism inherent in the classic gentlemen's club setting, King is asking for the reader to

${ }^{127}$ A quantitative stylistic analysis of King's writing would undoubtedly find a high frequency of die word "slithering," of which he seems as fond as Lovecraft does of the word "eldritch." 
consider the appeal of some of the practices instituted by such a gathering and inviting the reader regardless of gender to join the circle and partake of the tale. Similarly, Peter Straub's Ghost Story features an informal type of men's club, the Chowder Society, that gets together to share stories as a rite of male friendship. The horror tfiat slowly rises to the surface in Straub's novel is diat the gentlemen are not so gende; in fact, they have killed a woman, figured as monstrous, who comes between them by seducing them, and secretly buried her body. Straub's novel, with its vengeful spirit figured as a female shapeshifting manitou would likely be described by Barbara Creed as an instance of die "Monstrous Feminine." ${ }^{128}$

Updated versions of the gendemen 's club as a narrative framing device also appear in Bret Lott 's tale "The Train, The Lake, The Bridge" (YBFH14) as well as Ian Rodwell and Steve Duffy 's "The Penny Drops" (YBFH 13). However, this specific framing device is not necessary as long as the tale is told by a character; for example, in Reggie Oliver's singularly creepy possession story, "Among the Tombs" (YBFH 19) to which I shall return. A framing tale is also not restricted to specific cultural settings such as the gendemen's club. Vikram Chandra 's acclaimed story "Dharma" also sets up the tale in this way as Subramaniam the narrator addresses a circle of listeners in a Bombay bar called "The Fisherman's Rest" wiui

${ }^{128}$ The manitou is a Native American creature - it is interesting, given Thomas King's reminder that the oral storytelling tradition is linked to Native identity, to find it cropping up as a monster in this context. Similar use has been made of the Wendigo and other Native mythologies in numerous texts, including Algernon Blackwood's short story (1910), Stephen King's novel Pet Sematary (1983), Muriel Gray's novel The Trickster (199'4) and Ann Tracy's novel Winter Hunger (1990), not to mention the films Wendigo (2001) and Ravenous (1999) as well as Ruffo's Windigo Tale (2009). Unfortunately, there is not enough room here to explore all the implications of the use of Native folklore in non-Native horror stories. Terrie Golding has discussed "indigenization" where the impossibility of becoming indigenous is recounted in fiction and Louis Gross in Redefining American Gothic asserts that "Indian" stands in for European supernatural beings. 
the Ancient Mariner-like injunction to "Listen" to his tale of a general and a ghost (475). ${ }^{129} \mathrm{~A}$ conscious oral tradition that involves setting up a tale for an audience has been, as Thomas King points out, associated with Native and colonialized cultures, and it has similarly been associated with lower- and working-class culture as much as it has been a standard of the upper-class gendemen's club. Jack Cady's story about revenant miners seeking revenge on their scoundrel boss, "The Souls of Drowning Mountain" is a good example here ( $Y B F H$ 19). Michael Chabon's "The Black Mill" is another such tale. Gary Braunbeck's story "Union Dues" also features very consciously class-based horror.

The psychic / supernatural detective theme is common in horror stories and, besides being a literary hybrid of the horror and mystery genres, this narrative structure works as another type of framing device for the tale. Reginald Bretnor 's "The Beasts That Perish" is a memorable story about "The Team" and roadkill revenge. Kim Newman's Richard Jeperson and the Diogenes Club, William Hope Hodgson's Thomas Carnacki and Edward D. Hoch's Simon Ark are all supernatural detectives. Gary McMahon's recent story "Hum Drum" adds a Thomas Usher to the list. In place of the gendeman raconteur at the club hearth or the working-class storyteller in the pub, the supernatural detective describes case files.

No matter who the teller is, the same distance applies in horror between the embedded tale and the story. The story is the package; the tale is what lives to frighten us, the fiction that comes wrapped up in the package. The cinematic equivalent would be the portmanteau horror films made by the Amicus film studios, such as the film that heralded

The Raj has left its mark on Indian culture, so much so that the gendemen's club as an instituion still flourishes among the elites in India and Pakistan. 
Britain's post-WWII return to horror, Dead of Night (1945), Mario Bava's Black Sabbath (Tre volti dellapaura 1963,) or, more recently, George Romero 's Creepshow and the Dario Argento George Romero collaboration Two Evil Eyes (1991). ${ }^{130}$ In television, which obviously lends itself better to short forms, there are numerous examples of horror's proclivities for the short story, including series such as The Twilight Zone, Tales of the Unexpected (based on the short stories of Roald Dahl), The Outer Umits and Masters of Horror. All of these examples are heavily dependent upon short fiction and most employ framing narratives to introduce and connect their tales.

In introducing her theory of adaptation, Linda Hutcheon comments that there are "significant differences between being told a story and being shown a story, and especially between both of these and the physical act of participating in a story's world" (Hutcheon xv). I would expand on Hutcheon's comment which invokes mimesis and diegesis by observing that readers and viewers of horror in particular approach the story with the sense of expectation that they will unwrap the package, be drawn into the tale and physically participate in a story's world because, whether told or shown, the story will scare or disturb them. The narrator of the tale within the story confirms this expectation. F. Marion Crawford's story "The Screaming Skull," for example, repeatedly has the narrator of the weird tale address an implied reader who becomes part of the action of the story. The tale, then, functions as a very effective device to connect readers and audiences to the horror story's world by

\footnotetext{
${ }^{130}$ Craig Shaw Gardner mentions the relationship between Robert Bloch as "house writer" and the macabre humour of the Amicus anthology productions in the 1950s [Cut! 96)
} 
breaking down boundaries between the categories of showing, telling and physically participating. ${ }^{131}$

Another important effect of using the tale as a framing structure is die potent implication, creating dread on die part of the reader, that the horror of die tale may yet be lingering in die present tense of the story once the tale is finished. H. G. Wells's "The Inexperienced Ghost" has its tale-teller Clayton demonstrate to his audience at die club the mysterious passes widi the hands that he learned from the misplaced ghost in his tale, only to drop dead, confirming that the tale was actually true widiin the bounds of the story, diat ghosts do exist and (more frighteningly) retain the same traits in the afterlife tiiat they possessed in life.

Having a narrator describe his or her experience prior to returning to the present of the story where the horror of his or her tale continues padiologically to oppress him or her is another variation upon this theme that we could call Ancient Mariner Syndrome (Propp 1968). Poe's "The Tell-Tale Heart" is a famous example: die narrator begins his tale in a present where, we realize during the course of his tale, he is recounting his descent into madness and murder, perhaps over and over again, to an audience that might be the police or might be die walls of his cell. The Stephen Laws story "The Crawl" is another example, where the narrator describes his current state before proceeding to the explanation of how that state came about, informing the reader that "this tale is about the worst thing that ever happened to me" (440): an apt nutshell for horror more generally. Peter Brooks has

See David Bordwell, Narration in the Fiction Film (1985) for a discussion of how narrative theories apply to visual media. 
connected this compelling contamination from the narrator to the listener to Freud's theory of repetition compulsion (218). For Brooks, "the interlocutionary situation becomes the place of repetition and working through of a past not yet mastered and brought into correct, therapeutic relation with the present" (226). In horror, however, the "therapy" has not worked as the frightening event pervades and overtakes the present. Horror's "transference" negatively infects the present, contrary to Brooks's hopeful claim that "it actualizes the past in symbolic form, so that it can be replayed to a more successful outcome" (235).

A narrator who remains indelibly affected by his or her tale effectively transfers that sense of dread and foreboding to the reader. Here, for example, is E. F. Benson, preparing the tale of the vampiric Mrs. Amworth in mid-story: "Then came that evening when, as I see in the light of subsequent events, began the first twitching of the veil that hid the secret horror from my eyes" (Terrors, Torments and Traumas 72). In one quick twitch, Benson arouses the reader's apprehension, ushering in Barthes's "hermeneutic code": what is the "secret horror" and at what point will it be revealed to the reader? Benson does the same job of careful preparation in another extremely scary story, "The House with the Brick Kiln": "We arrived accordingly from town at about five o' clock on a cloudless afternoon in May, and through the mists of horror that now stand between me and the remembrance of what occurred later, I cannot forget the exquisite loveliness of the impression then conveyed" (327). Like M. R. James, Benson is a master at introducing frighteningly jarring notes into otherwise sunlit scenes, another technique working towards the creation of Hills's "ontological shock" which I shall explore further on. The centrality of the tale and the telling of it to horror fiction is what I wish to focus on here. 
Charles L. Grant writes: "A good horror story is one that implies that the horror isn't over when the story is" (Fears viii). This idea of the monster or horrifying phenomenon rupturing the boundaries between the factual and the fictional, betweenfabu/a and $s j u^{\wedge} e t$, and between narrative time and "real" time is another aspect of how the device of the tale functions very effectively to convey horror's affects across media. ${ }^{132}$ We have already seen that the narrator may remain haunted or maddened by a horror which is not safely confined within the borders of the tale but which lingers and casts doubt over the story. For example, Robert Graves's hallucinatory story "The Shout" is a story within a story that overflows its bounds and plunges the reader into uncertainty about the truth of anything that has occurred. To compare with film, this is also the narrative (and visual) technique used so effectively by Wes Craven in A. Nightmare on Elm Street (1984) when his monster Freddy Krueger violendy ruptures the membrane dividing the dreams of his victims from their waking lives, bursting into the "reality" of the film's story. Literary examples of the horror of breaking down boundaries between tale and story where horror escapes the confinement of the tale and erupts into other dimensions show that this device is not a new phenomenon. ${ }^{133}$

Horror film franchises, including the Nightmare films, as critics have noted, depend upon the serial resurrection of the monster, its refusal to die, go away or to be imprisoned within a single text (Worland, 2007; Hantke 2007; Cherry, 2009). This has been hailed by several working in the field as a "postmodern" characteristic of horror films (Pinedo, Clover)

${ }^{132}$ See the new book by Brigid Cherry, Horror Routledge, 2009, for a discussion of horror's aesthetics, stylistics and affect in cinema.

${ }^{133}$ See Kim Newman's commentary on the hoax, including a discussion of "framing" and "authentication" at <http://mssv.net/realityart/bfinewman.html $>$. 
but, unless we can consider Lovecraft postmodern," this characteristic is, as I have said, nothing new. Nor is it confined to films and literature. For example, the British television special mock-umentary Ghostwatch (1992), presented as a live television episode of paranormal investigation of a poltergeist "Pipes," depicted ghostly events that escalated and then spilled over to the BBC studios, where Pipes "possessed" the well-known British television host Michael Parkinson. Ghostwatch terrified a nation who interpreted the context and perceived the events unfolding on their television screens as "real." Following this success (in horror's terms, it was certainly a success, although there were many complaints from traumatized BBC viewers), ${ }^{134}$ Stephen Volk, author of the original Ghostwatch screenplay, remediated the horror in a story by having the actors revisit the setting of Ghostwatch as a follow-up TV special, only to become victims of the ghosts, again turned suddenly "real" in the story.

Many horror fictions have similarly incorporated references to the ghostly presences of other media within their pages, placing this media in the role of the tale as, for example, a found diary or a letter (what David Morrell in Cut! calls the "James M. Cain technique"), a newspaper article, such as the tabloid stories in Kim Newman's "Where the Bodies are Buried: Black and White and Red all Over" to which Hills refers, a song, a video- or audiotape. Alternately, horror stories blur the borders between media forms, calling into doubt which is the story and which is the tale. Peter Crowther's "Too Short A Death" is a vampire story about poets where the fragments of poetry in the story evoke the appealing

${ }^{134}$ The IMDB page for Ghostwatch reports that it has "the dubious honour of being the first TV programme to be cited in the British Medical Journal as having caused Post Traumatic Stress Disorder in children" 〈http://www.imdb.com/title/tt0200659/trivia > 
monstrousness of the vampiric muse who is portrayed as "Robinson" in the poet's work (YBFH9). Poetry, however, remains in the realm of the literary so the apparition of a poem within a story is not as incongruous as other media forms. Robert Aickman remarks, "The ghost story, like poetry, deals with the experience behind the experience" (Dark Forces xiv).

On the other hand, Dennis Etchison, influenced by his work as a screenwriter, often mixes his media in far starker ways. His story "The Blood Kiss" alternates straightforward narrative with extracts from a script for a television segment entitled "Queen of the Zombies," which lies at the core of a story of a troubled screenwriter who "could no longer be sure which was the delusion and which the reality" (75). ${ }^{135}$ She has "appropriated" (82) the work of an unknown to put together the script that could make her career, but when she discovers that she will be replaced and given no credit as the scriptwriter, she decides to elicit the support of the obscure writer. She arranges to meet him at a cast party where all are wearing masks, but true to the story, the man she assumes is the obscure writer is not who he seems, being a rather frightening obsessive who becomes violent and pursues her until she flees the party. The script itself features a zombie movie being shot as part of its action, opening with zombies ravaging a supermarket and a cynical director who seduces a vulnerable actress at its centre. The exploited actress in the movie-within-a-script confronts the director towards the conclusion of the shooting of the zombie movie and deliberately shoots herself in a way that will incriminate the director. The director, mindful of the old

${ }^{135}$ Compare this mingling of media with George Romero's Martin which presents a mediated monstrosity. As in The Howling, with people watching television as the real werewolf is killed, Martin's closing credits roll against an audio backdrop of listeners on the radio talk show that the lonely titular vampire character has frequented, asking for "The Count." 
saw that the show must go on, devises a solution to this problem by rigging his actress's corpse up to explosives in the final scene; however, the actress returns to life as a zombie and dislodges her explosive gear. In attempting to put the explosive back and conceal his crime, the director is blown up with her reanimated corpse in what turns out to be "the best effect of the film" (97).

Etchison's skilful weaving of illusion and Hollywood ambition plays a game of Mobius strip poker with the reader's comprehension of the narrative, peeling away layers, twisting perceptions and refusing to prioritize one media version over another, returning the reader inevitably to the overarching theme of ambition, exploitation and betrayal. ${ }^{136}$ The selfreferential intertexts of screenplay, story and the subtext of the increasingly delusional "reality" of making horror films in Hollywood jostle and vie with one another dialogically for the tale-teller's position (Bakhtin).

Kim Newman's story "Going to Series" is another example of the transmediated tale with a very similar theme. This grimly amusing expose of television network programming is the story of a new "reality show" that deliberately recruits some of the worst specimens of humanity to be confined together and, it is implied, manipulates them to murder each other for the entertainment of television audiences, while the person responsible for the conception of this vile conceit enjoys more status as the story progresses to its conclusion just prior to the airing of the show. The tale is told through interview transcripts, internal memos and production notes. Newman writes in an afterword: "The real-world precedents

${ }^{136}$ Etchison's "Deathtracks" also features television programming and ratings, incorporating dialogue. In Fears (ed. Charles L. Grant, 1982). 
for the story are horribly obvious and have become more so since I wrote it" (276). Earlier I argued that the novel, rooted in a tradition of authenticity and "truthful" realism, was fundamentally different from the short story form, which remains less certain of its representation of reality in a world where reality itself is increasingly difficult to comprehend without horror. In juxtaposing different types of fictions, the short horror story is not only adhering to the narrative technique of using the framing device to draw the reader into the world of the story but also continually reminding the reader that reality itself is essentially narrative, woven from storytelling and tales. Robert Bloch says, "The greatest horror story of all is history" (Psycho-path, $\mathrm{xx})$.

In contemporary horror's mixing of media, the discourse of history and other truthclaiming discourses such as the travelogue and scientific discourse are also not exempt from this type of reality-shaking juxtaposition. For example, Christopher Fowler's "At Home in the Pubs of Old London" begins as a seemingly prosaic London pub travel guide and turns into the dramatic monologue of a bizarre character, possibly a killer, who meets a steady stream of women (and one man) in one pub after another (Dark Terrors 5). Ramsey Campbell's "A Street was Chosen" presents "scientific results" observed from some unknown and omniscient vantage point — the God's eye view — that, by surreptitiously and ruthlessly manipulating the denizens of the street, causes tragedy on a previously tranquil and friendly community. ${ }^{137}$

${ }^{137}$ This is a very similar story to Stephen King's Needful Things (1991), where the villainous Leland Gaunt enmeshes the citizens of Castle Rock through their consumer cravings in an artful trap where they "prank" each other, resulting in tragedy. 
Another chilling example can be seen in the story 'N0072-JK1" by Adam Corbin Fusco, which presents "notes" from a scientific experiment involving tickle responses — the cumulative effect is absolutely devastating as the reader is invited to imagine the torture between the calm, methodical lines of scientific discourse:

Photograph $\mathrm{H}$ shows a female subject at the four-hour mark of tickle response. Subject presents facial rigor, gritted teeth, and tears of laughter (note Study 10M8/42-2-14 "Spinal Cord Harmonies in Comparison to Violin String"). Response increased over the next three hours, peaking at the sevenhour mark. It remained at this plateau until the fifteenth hour when stimulation was halted due to lack of skin integrity of the foot. (256) $)^{138}$ All these examples serve to show that a kind of realism is in fact invoked by the short horror story. However, rather than the novel's extended foray into a world, I would argue that the short story often presents a condensed or densely compressed realism. This realism is manifested as an intertextual and intermedial space of "para-sites" (Hills), ${ }^{139}$ which

Robin Mackay writes that horror fiction provides "experiences of the conceptual upheavals characteristic of the post-Enlightenment age," "a laboratory for shaping narratives pointedly informed by the conceptual paradoxes produced by modern science and philosophy. And increasingly, philosophy itself, and the high arts which so long looked with disdain upon such pulp fictions, are realizing with what anticipatory clarity these genres have formulated problems which are becoming ever more pressing, not only conceptually and aesthetically, but even politically ...." \{Collapse TV, May 2008, 5).

139 Surely part of Stephen King's success has lain in overtly acknowledging these fearful symmetries. The creature from It, for example, is not one but a multiplicity of monsters, many of them recalled by King from childhood films and television shows, such as The Creature from the Black $I^{\wedge}$ agoon (1954, scheduled for remake in 2011) and The Crawling Eye (1958). In a memorable scene from $I t$, the Creature's victim gropes vainly for the zipper on its back before it bites his head off. The novel itself, as Leffler has noted, is a nostalgic 
requires the reader to assume a radical openness to the "fearful symmetries" of a reality glimpsed not between the lines, but between the texts, an active reading position which is not adequately described by the frequendy proffered designation of masochism or "helplessness" (Mulvey; Linda Williams; Clover; Pinedo).

In an interview with Isaac Bashevis Singer for his anthology Dark Forces (1980), Kirby McCauley asked the Nobel Prize winner why he wrote so often of "demonic and supernatural happenings." Singer replied: "It brings me into contact with reality" (Dark Forces xiv). This idea of the story as a transmitter, as an apparatus that puts one "into contact with reality" reverses the principle that Thomas King refers to when he discusses colonialism and its narratives as starting off with "the wrong story" but similarly acknowledges the power that stories have to condense and "conduct" realities (26). Another (much less lauded than Singer) writer David Morrell writes about the technique of a short story that it was a matter of compression: "Like most novelists, I find the discipline, the compression, of a story enormously difficult" (Masters of Darkness III 82). Morrell discusses the "dramatic monologue" technique used in Robert Browning's poem "My Last Duchess" which is "unbelievable, artificial, yet wonderfully effective." The first-person technique is "direct," "intimate" and "vivid" and "allows a writer to compress. The tormented narrator blurts out his tale of horror" (83).

series of analepses and prolepses, recounting events from the characters' childhoods and adulthoods. 
Clive Barker distinguishes horror with the specific "sensibility" of intending to scare from "nonhorror" films such as Martin Scorsese's Taxi Driver, that nevertheless "blurt out" a certain kind of horrific tale:

Doug Winter said in his horror/antihorror thing that something has to intend to horrify you. But I think there's a further twist on that. There's a kind of horror - the horror of The Killing Yields, for example — where they clearly mean you to be horrified but they don't want you to take pleasure in that. \{Cut! Horror Writers on Horror Film 13)

These references and events are named "true horror" by Hills or "RLH" ("Real Life Horror") by the contributors to the Horror listserv. Atrocities, history's horrors, ${ }^{140}$ are often far too overpowering for a tale that must be blurted out in its compressed intensity. Instead, a kind of metonymy occurs, a process that either juxtaposes or merely features the real life horror, rather than metaphorically or allegorically tackling it head-on. Gerald Kersh's "Comrade Death," for example, is a story about an arms trader who, with each amoral transaction, eventually attains a supreme power which leads him to a supreme ennui. He and a team of scientists manufacture horrible chemical weapons that are eventually unleashed upon themselves. This is no allegory, but a straightforward invocation of real life horror. In a thoughtful meditation on writing horror, co-authored with her husband Steve Rasnic Tern, Melanie Tern follows a discussion of real life horrors such as child abuse with the observation that:

${ }^{140}$ See Lawrence Langer, The Age of Atrocity, for a thoughtful discussion of the depiction of historical atrocities such as the Shoah (the Holocaust) in literature. 
the world also has in it: werewolves, whose unclaimed rage transforms them into something not human but also not inhuman .... Vampires, whose need to experience is so unbridled that they suck other people dry and are still not satisfied. Zombies, the chronically insulated, people who will not feel anything because they will not feel pain. Ghosts .... I write dark fantasy because it helps me see how to live in a world filled with monsters. (225) K.W. Jeter's frightening story of filial responsibility "True Love" (YBFH 5) is allegorical in this sense, depicting the narrator feeding her vampiric father with the blood of kidnapped children. When she is not kidnapping and murdering children, the narrator is attending a support group for sons and daughters caring for their elderly parents. Families are frequently the site of horror, not only in "monstrous feminine" or psychoanalytic categorizations but to convey the leaden sense of obligation or the horrors of abuse by, for or of loved ones. References to real-life atrocities often crop up in short horror stories but they are seldom drawn-out explorations of the topic. The inference is that the reader ought to know about or can fill in what lies between the lines. ${ }^{141}$ David Schow's hitchhiker serial killer in "Pick Me Up" invokes the RLH of the torture training ground in Georgia formerly known as the School of the Americas and the massive prison-industrial complex in the United States: "The killing part I learned from the army and jail. Fort Benning and Folsom. That's some nasty business you don't really need to hear about" (Psycho-paths 283). Another

${ }^{141}$ Another example of a reality-inflected fantasy is Paul di Filippo's "Femaville 29" which is a dark fantasy referring to Hurricane Katrina's destruction of New Orleans in 2005. In di Filippo's story, government bureaucrats are defied by the children of a refugee encampment (YBFH 2007). 
example of this oblique referentiality would be Brian Hodge's horror story about war photographers written a few months after September 11, 2001, "With Acknowledgements to Sun Tzu" (YBFH17) or "Pol Pot's Beautiful Daughter (Fantasy)" by Geoff Ryman, where the titular character, likeable despite her status as "poor little rich girl," is being haunted through her cell phone by the ghosts of the thousands upon thousands of people that her father sent to their deaths in the killing fields of Cambodia. ${ }^{142}$

For the Terns, the reality outside the worlds of their fictions is filled with monsters far scarier than the things in their stories. This is a concept cleverly taken up by John Cheever's story "The Enormous Radio," which invites the reader to imagine that being constantly able to spy on your neighbours and their daily goings-on through the enormous radio of the title would prove Sartre's dictum that "Hell is other people." Horror in the short story is conceived thus, in bits and pieces; the Terns' metaphor for horror, the "man on the ceiling," is a composite creature, reflected in his metonymic description as a changing collection of parts:

Usually he is this shadow I've described, a silhouette clipped out of the dark, a shadow of a shadow. But these are merely the aspects I'm normally willing to face. Sometimes as he glides from darkness into light and back into darkness again, as he steps and drifts through the night rooms and corridors of our house, I glimpse his figure from other angles: a mouth suddenly fleshed out and full of teeth, eyes like the devil's eyes, like my own father's

${ }^{142}$ For a thought-provoking review of this unsettling story, see Matthew Cheney's article "Pol Pot's Fantasized Daughter" online, including a PDF of the story, at <http://www.strangehorizons.com/2007/20070813/cheney-c.shtml >. 
eyes, a hairy fist with coarse fingers, a jawbone with my own beard attached .... And sometimes his changes are more elaborate: he sprouts needle teeth, razor fingers or a mouth like a swirling metal funnel. (222)

Horror short fiction has been interpreted as belonging to a category of the surreal or even the "irreal" (Gardner; Swinford; 1984): in fact, Al Sarrantonio calls Ramsey Campbell one of the "Irrealists" $\{999$ 507). This notion is not far from the idea I have presented above of a "condensed realism" expressed through intertextual and metafictional layers. Horror works on both levels of the irreal; the notion that reality is not fixed but is rather constituted by a series of tales that "offer particular versions of reality rather than actual descriptions of it" (Gardner), and "the irreconcilability between human aspiration and human reality." ${ }^{143}$ For example, in the Robert Bloch short story "You Could Be Wrong," horror is derived from the protagonist Harry Jessup's growing disgust and paranoiac perception that everything is a "fraud" as he realizes, decades before the publication of. Manufacturing Consent (1988), Fight Club (1996) and No Logo (2000) that he is subject to media manipulation, steeped in artifice and completely encircled by simulacra, from television shows, to his wife 's clothing and cosmetics, to his "mock chicken" dinner, to the "ranch house" he lives in that's "not on a ranch," to the cars on the street:

"Ever stop to think about that, Ed? No average cars any more. Everybody's got a Commander, or a Land Cruiser, or a Coup de Ville, or a Roadmaster, or a Champion. Even the poorest slob owns a Super Deluxe Model. Aren't there any plain, old-fashioned automobiles any more? I haven't seen any. Just

See for an example of irrealistic art, Canadian artist Tristan Tondino's Zot (2003) 
millions of Hornets and Ambassadors and Strato-jets, driven by people who have no place to go. ${ }^{144}$ No real place, that is. They drive to a grocery store built like an Italian Doge's palace which calls itself a Supermarket and offers Below Cost Bargains, yet still makes a profit and -"

"Dig this!" Ed Myers chuckled again. "You talk like a Commie."

"How do you know how a Commie talks?" Harry retorted. "You ever hear one? Did you ever see one in the flesh?"

"Why no, but I read the papers; everybody knows about Communists."

"You mean everybody is told about them. You read what's printed, that's all. How do you know any of it ever happened?" (93)

As Jessup grows increasingly frantic, haunted by the simulacra he suddenly notices everywhere, his awareness that "everything is ersatz" (95), the reader's unease deepens with him, following Bardies' proairetic code that anticipates closure. We follow Jessup to his inevitable conclusion that something has happened - in this case, he speculates, "bombs" that destroyed a country and replaced it with "fakes" (96). When Jessup cries "Maybe they've gotten so used to the fakes they can't detect the difference anymore," we are seeing the map replacing the territory (Jorge Luis Borges, "On Exactitude in Science" 1946). ${ }^{145}$ Horror, however, does not stop to contemplate. Jessup takes up a knife and plunges it into the head of his neighbour, screaming "Sawdust and a bunch of cog-wheels" (99). However, his wife

${ }^{144}$ Jessup's tirade is an antecedent to the stream of brand-consciousness in Bret Easton Ellis's American Psycho.

${ }^{145}$ See also Jean Baudrillard, Neil Gaiman and a host of others who have echoed this metaphor. 
insists that what is pouring out of the neighbour's head is blood and Jessup (with die reader) begins to doubt his own perceptions. Finally, Bloch's twist ending removes all doubt, in keeping with the resolutely negative world of horror. Jessup is taken away and "there was nobody left but Marge. She was all alone and there was nothing else to do, so she got out the dustpan and the broom and swept up the litde pile of sawdust from the floor" (100).

This is an example of Hills's "ontological shock" as the Todorovian fantastic hesitation — is Jessup sane or insane, is the world artificial or not? — is resolved by a tale that has its "proof at the end. The twist in the ending toys with the reader's suspension of disbelief in the context of reality. Robert E. Howard's "The Dream Snake" or Basil Copper's "The Janissaries of Emilion" are dream-stories where the surreal dream abruptiy breaks into the reality of the narrative. Similarly, the short stories in Richard Matheson's collection Shock Waves (1970) all turn upon the sudden irreality of an everyday situation: a man cuts himself shaving and discovers he is like one of Bloch's sawdust-oozing replicants, only machine oil oozes from the wound. A woman's husband steps out to use the men's room and does not return. Conversely, the weird turns out to be mundane; a man sets his wife up to be "hit" and returns to find her still alive; a young man dreams of being the fastest gunslinger in the West and ends up getting fatally shot almost immediately on his first foray into a town. Horror's unapologetically paranoid sense that "they really are out to get you" is mirrored, in more or less explicitly politicized ways, in many horror texts, including J. B. Priestly's underacknowledged story "The Gray Ones" and John Carpenter's underappreciated film They Live! (1988), as well as Stephen King's very similar story about grotesque "bat"-headed monsters who have enslaved humanity, masquerading as people occupying positions of power, who can only be discerned in their true forms by the smokers who congregate in huddled groups 
outside their workplaces in the morning ("The Ten O' Clock People"). All these stories suggest that reality is itself irreal.

\subsection{Splatterpunk versus Quiet Horror}

The radical political implications of horror's "condensed realism" are often obscured ironically by the frightening "realism" of its depictions of death, violence, torture and other worst-case scenarios. The fact that horror seems to dwell lovingly upon such fearful matters has underscored a fierce debate between those who defend what has been called "quiet horror" and those who advocate for what has been called "splatterpunk" or "extreme horror." The study of horror seems inevitably to lead to the coining of "po-mo" portmanteau concepts: Brophy's "horrality," Pinedo's "carnography," John McCarty's "splatstick," "gorno," "torture porn" and "zomedy" (zombie-comedy), to name but a few, as well as the use of puns and plays on phrases, such as Halberstam's "bodies that splatter" and my "fan(g)dom." These playful inventions are themselves rhetorical strategies devised to speak to the unspeakable, to serve up the raw and bloody messes of horror as exquisitely cooked formulations that critical audiences will find "more accommodating" to their tastes. However, before any of these categories were conceived, David Schow had coined the term "splatterpunk" at the World Fantasy Convention in 1986, a term that caught on among many writers in the field as a term for what Andrea Hasenbank describes as "emergent horror fiction pushing the limits of gore and sex to excess. It features frequent and graphic descriptions of grisly violence, bloody deaths, and extreme sex, built on the aesthetics of 
slasher movies, punk rock, and video pornography." ${ }^{146}$ While S. T. Joshi connects splatterpunk with urban horror, post-industrial decay and an "in-your-face aesthetic" (607), Hasenbank ties splatterpunk to its roots in the "traditional strategies of horror fiction: heightening tension, disruption of order, and focus on visceral sensation."

An emphasis upon craftsmanship, however, remains central to those curators, as I have called them, of horror fiction in all its forms. Often accusations of declining artistry, crass commercialism and poor taste are made by the opponents of "splatterpunk," who accuse its practitioners of shoddy craftsmanship and an over-emphasis upon the "splatter" side of the equation. The late Karl Edward Wagner lamented in 1990 that the short story has also fallen victim to pure and simple bad writing. Plots, when present, are too often so obvious and trite that one can only wonder as to why the author is bothering to clone a cliche. Characterization is too often lacking, motivation absent, and writing skills laughable. One evidence of this is the shrinking average word length of the horror story. This reflects a growing trend in horror writing simply to introduce a few faceless expendables and rush them to a grisly end — the grislier the better. (14) Similarly, the Monteleones deplore the "steaming organs school of writing" (Borderlands 141) and, while Joe R. Lansdale applies the term "splatterpunk" to the Bible (Cut!

${ }^{146}$ Andrea Hasenbank, "Splatterpunk" from the website "Text in Transit: a guide to genre in popular literature" < http://www.crcstudio.org/textintransit/ viewtext.php?s=browse\&tid=42\&start=12> Accessed May 2009. 
143), he also makes distinctions between exploitative "evisceration extravaganza" films and "good" horror (147): "What gives the good film its power is its bravery, its willingness to let the wind blow it across the line of good taste, into that part of the field that is less mannerly and sometimes downright rude" (148). In so doing, Lansdale argues, a low-budget horror film can become, if not art, "artistic."

Screenwriter John Farris contrasts "suspense" to "splatterpunk":

This little corner of the horror world that Douglas Winter thinks so much of - splatterpunk? - is a dead end if ever there was one. I think you have to scare people . . . but viewers are too sophisticated in all the state-of-the-art gore and there's a limited market for that. (Cut! 87)

Robert Bloch agrees with Farris on this one, predicting in his introduction to Psycho-paths (1991) that "'splatterpunk' will not have much of a metaphysical and / or metamorphic effect on horror fiction" (xix). Bloch castigates the emphasis on the "spectacle of the ruined body":

Despite vivisections made vivid by Technicolor and shrieks of agony enhanced by stereophonic sound, despite on-camera atrocity and cruelty, all that the filmmakers have given us over the years is more ketchup on our people-burgers (xvi).

Ellen Datlow is also critical of splatterpunk, finding that "what is being called 'splatterpunk' is for the most part violent, brutal, ugly fiction treating women as victims"

\footnotetext{
${ }^{\text {U7 }}$ Skipp and Spector claim that the Pythons were the ultimate "splatter comedians"
} (Cut! 243). 
(YBFH 9 xli). ${ }^{148}$ Datlow here, similarly to feminist film critics, does not mention the work of women whom I would describe as "splatter-feminists," particularly the trio of Gen-X Goth writers Christa Faust, CaitHn R. Kiernan and Poppy Z. Brite. Faust's character in "Tighter," whose stage name is Persephone, strips and binds herself like Houdini, only she is eroticized (171) as a bondage fetishist, which does not equate with victimization. Instead, she victimizes a young man with whom she falls in love because he can create ropes for her made from the veins in his arms. This may be a "steaming organs" type of story, but it is also a meditation upon domination, control and gender roles which, in splatter-feminism, refuse to be tied down to a victim position. ${ }^{149}$ Indeed, the story indicates a wry, feminist awareness of how restrictive such positions can be. Persephone is a powerful figure, an escape artist who revels in the "male gaze" of her audience but who yearns to be dominated. When she finally meets the man with a never-ending supply of rope, she is foolish enough to kill the

14 My discussion of splatterpunk invites comparisons between the "realism" of contemporary horror (splatterpunk) and contemporary science fiction (cyberpunk and steampunk). Jeff Nevins's introduction to Steampunk, an anthology, muses that the punk stance of rebellion "against the system it portrays" in both cyberpunk and steampunk is essential. Joe Lansdale's crossover steampunk-horror story in that anthology "Steam Man and the Dark Rider" is a web of intertextuality - H.G. Wells's Time Traveller from The Time Machine becomes a vampiric figure, leading an army of Morlocks around to slaughter whole villages, having his victims impaled like Vlad Tepes. Another interesting idea of Nevins' is that the Victorian era very closely mirrors our own in its "social, economic and political structures" and "cultural dynamics" (8). I find the interrelationships of bodies and technology to be a common factor in all three - steampunk looking whimsically to the past, splatterpunk describing the horror of the present and cyberpunk anxiously anticipating the future.

${ }^{149}$ Faust, like many of her contemporaries, is drawn to an intertextual combination, in her case of horror and urban noir. Her latest novel, Money Shot (2008), features a hardboiled porn star back from the dead and seeking to solve and avenge her own murder mystery. 
goose that laid the golden eggs and is punished for her greed. Again, focusing on the splatter rather than the punk obscures in a wash of bloody imagery the punk Situationist aesthetic of "detournement," as Greil Marcus puts it, "the construction of situations" through "a politics of subversive quotation" where social symbols are "yanked through the looking-glass" and violently exposed in all their contradiction (Lipstick Traces 179).

All the examples of short stories I have been discussing are, in one way or another, metafictional. As Patricia Waugh puts it, "contemporary metafictional writing is both a response and a contribution to an even more thoroughgoing sense that reality or history are provisional: no longer a world of external verities but a series of constructions, artifices, impermanent structures" (Waugh 7). Waugh and other postmodern theorists such as Linda Hutcheon and Brian McHale concentrate almost exclusively on the novel as the former site of realism, now opened up to metafictional possibilities. Like the postmodern novel, the "condensed realism" of the short story and particularly short horror fiction, often "selfconsciously and systematically draws attention to its status as an artifact in order to pose questions about the relationship between fiction and reality" (2). Splatter, as Halberstam and Pinedo have both suggested, is one way to draw this attention to textual surfaces.

In film, the preference for "suggestiveness" rather than what Phil Hardy calls the "graphic technicolor realism of today's 'splatter movies'" (Overlook Encyclopedia xi) is often praised by detractors of the latter such as Jeremy Dyson in Bright Darkness: the lost art of the supernatural horror film (1997). Dyson argues that the production values of earlier horror films such as the Universal Studios classics reflect the artistic seriousness of the genre and that, in this sense, horror has fallen prey to the exploitation of its aesthetic success. Ray Garton echoes Dyson's lament for a generic decline when he opines: 
I think there are way too many people out there making horror movies who, first of all, have no respect for the genre, and who wouldn't know a solid story from a bowl of pudding. Some of them say they love horror, but what they really love are the special effects, the mechanics of making die horrors. Or maybe they just want to make a buck. They don't seem to realize that a horror story, just like any other kind of story, has to make sense. \{Cut! 110) Similarly, Ramsey Campbell denounces "mindless escalation" and "coarsening" from the "legitimately" "appalling" to when "the urge to be terrifying gets out of hand" (73): In general I think that horror films have recendy been at least as guilty of the coarsening which David Aylward (writing in the sadly defunct Canadian journal Borderland) found in too much of today's horror fiction; whether or not they "used to strive for awe and achieve fear," certainly now they "strive for fear and achieve only disgust. \{Cut! 74)

Reverting, briefly, back to film in order to make this point before returning to the much-less-attended-to question of "splatter" in written fiction, I argue that much of the debate about splatter's "coarsening" affects can be framed by comparing the violence in Alfred Hitchcock's film version of Bloch's short novel Psycho (1960) with Tobe Hooper's The Texas Chainsaw Massacre (1974), both of which are based upon the murders committed by serial killer Ed Gein. These films have repeatedly been theorized as the origins of serial killer and slasher narratives and present a significant turning-point in the history of the horror genre (Hardy, Overlook Encyclopedia). Both Psycho and Texas Chainsaw Massacre exhibit a starkness of detail and realistically gruesome violence that shattered (splattered) boundaries in their day. However, Hitchcock leaves the violence to the shadowy processes of the 
audience s imagination, for example, in the famous shower scene, the knife descends repeatedly upon Marion Crane (Janet Leigh) amid shrieking violins, but the camera, moving quickly, simultaneously conceals and reveals the stabbing, leaving the audience to imagine the ruined body, cued by the blood swirling into the drain. ${ }^{150}$ In Seymour Chatman 's words, the "discourse-time" of Marion Crane 's death, the story of her life, has been cut and slashed (122).

Tobe Hooper, on the other hand, stretches violent scenes out painfully and diachronously, according to the "story [histoire) time" of the violence; for example, that of Sally's final ordeal at the hands of the family of dispossessed slaughterhouse workers, who are rehearsing their version of the good old days starring Sally as the animal who must be dispatched by an old-fashioned blow to the head. In an almost unbearably lengthy sequence of chases, captures and escapes, Sally, screaming and sobbing for the duration, is tortured by being repeatedly clubbed by the ancient, hideous patriarch of the family, whose infirmity has weakened his aim. Ramsey Campbell mentions the unbearable tension caused by watching such scenes of stretched-out violence, "scenes prolonged so as to make the audience sweat" \{Cut! 69).

Carol Clover has emphasized this stretching-out of the "Final Girl's" ordeal in a succinct series of verbs and her interest in the Chainsaw series is predominantly vested in the heroine of Chainsaw Two who is, in fact, known as "Stretch," a coincidence which Clover finds significant. The Final Girl is the one who is "chased, cornered, wounded; whom we see

${ }^{150}$ Horror critics, including Andrew Tudor and Carol Clover have exhaustively discussed Psycho, which enjoys canonical status not only as a horror film. I mention it here only to give some grounding to the splatter vs. quiet horror debate. 
scream, stagger, fall, rise, and scream again" (Men, Women and Chainsaws 35). Like Sally in the original Texas Chainsaw Massacre, Stretch undergoes a painful dinner scene with the Sawyer family; like Sally, she screams incessantly as she is repeatedly clubbed by the frail and ghoulish patriarch, who manages to knock her out at one point. Unlike Sally, however, Stretch ultimately comes to grips with the chainsaw itself, facing down her tormentors rather than merely escaping. Stretch's final appearance is one of madness and potential violence as she whirls the weapon in the air above her head, screaming defiance as the credits roll.

The ghastly effect of stretched-out violence lies in its uncomfortable proximity to an unthinkable reality. Death, we suspect, must be something rather like this; no neat bullethole and tidy corpse, or even a sudden, terrifying and beautifully-filmed assault in a shower, but rather a clumsy, messy struggle with an inexorable and absurd inevitability: a futile resistance, a protruding tongue, popping eyeballs, blood and ultimately putrefaction. ${ }^{151}$ At the same time, as much as we cannot believe this will happen to us (but can believe, in spite of ourselves, that it is happening to the character onscreen or in the story), stretched-out violence is irreal. In this sense, however, it is exactly like the unbearable tension that characterizes "quiet horror."

Violence and mounting tension in horror, if depicted realistically and effectively, must be endured somehow for their duration, although various coping practices can be resorted to, such as shutting one's eyes or using a barrier, getting away from the screen,

${ }^{1}$ This is why King refers metaphorically to the experience of horror as being in the same room with a corpse, the "body under the sheet" (Night Shift, xvi). Julia Kristeva comes closest to the "power of horror" here when she describes the abject (which other critics such as Barbara Creed in The Monstrous Feminine have exhaustively discussed). 
shutting the book, writing a critical theory of horror or interacting with the text by means of a cry, shudder or laugh. The expression of one's own horror does not contradict the affect of horror that is produced: indeed, it heightens it for many (just let out a scream during a tense or building moment of a horror movie in a theatre and see how many scream along). What many critics fail to consider in looking (or not looking) at the G-factor is that it is not simply the sight of blood or dismemberment, the spectacle or the monster that produces the horror-affect; it is also the "discourse-time" or the duration of the reader's or audience's exposure to the tension or to the blood and dismemberment. The more closely that comes to the "story-time" of the violence, the more "splatter" there will be (and, as Linda Williams observes, the status of the text will fall accordingly). In the short horror story, the margins for such durations are adjusted and again, the affect is created by condensation. ${ }^{152}$ A short story such as David Schow's "Jerry's Kids Meet Wormboy," which is replete with ultraviolent images of exploding zombies, giving the reader no time to recover from one scene to the next, is indubitably splatter or, in Schow's coinage, "splatterpunk," a term that has been used more frequently to describe written rather than filmic horror.

In S. T. Joshi's chapter on Schow and "splatterpunk" in The Evolution of the Weird Tale (2004), Joshi thoughtfully observes: "It always puzzles me how the splatterpunks — and [Clive] Barker as well - can imagine that the mere harm that can be inflicted upon the

${ }^{152} 1$ Spit on Your Grave (1978), Meir Zarchi's powerful rape-revenge film, is another good example of narrative time working to establish a horrific affect. The rape sequence, in which Camille Keaton is cornered, raped, staggers home, is chased and raped again, then gets to her rental cabin finally, naked, battered and bloodied, only to find her rapists waiting for her, is an exercise in prolonging the agony. The film was banned as a "video nasty" for many years: it is, like the previously discussed Henry: Portrait of a Serial Killer, "unexploitative" in its depiction of the brutality and power dynamics of rape. 
human body is the culmination of horror or weirdness" (191). Joshi castigates "mere sensation," arguing persuasively that "splatterpunk, if it is anything, is not so much a subgenre — much less a world view — as a mode of writing which all sorts of writers can employ when it suits their purposes" (193). Karl Edward Wagner also notes the needless "fragmentation" between advocates of "quiet horror" (dark fantasy) and splatterpunk fan(g)s: "Because a story is dead boring dull, it is not necessarily literary horror. Writing about a Roto-Rooter rapist does not necessarily push back the frontiers of horror's future" (The Year's Best Horror Stories XVIII15). Both these viewpoints are valid and I agree that "splatterpunk" has relied on somewhat of an artificial and arbitrary distinction between styles in the production of horror fiction. For the purposes of a discussion of affect in written horror, however, the debate is not about "splatter" versus "quiet horror" so much as it is between showing and not-showing, telling and not-telling.

If we read, for example, Arthur Conan Doyle's classic story "The Leather Funnel," we will soon come across a dreadful scene of "torture porn": the narrator sleeps at the house of his friend Dacre with the titular object under his pillow for the purpose of inducing a dream about the funnel's origins. Obligingly, he dreams of a room where a young, attractive woman is being tried by three men in black. She is then taken to a torture chamber "not unlike a modern gymnasium" and strapped down while the narrator describes his emotions: My heart sank within me as I saw these ominous preparations, and yet I was held by the fascination of horror, and I could not take my eyes from the strange spectacle. A man had entered the room with a bucket of water in either hand. Another followed with a third bucket... The second man had a wooden dipper - a bowl with a straight handle - in his other hand. This he 
gave to the man in black. At the same moment one of the varlets approached with a dark object in his hand, which even in my dream filled me with a vague feeling of familiarity. It was a leathern filler. With horrible energy he thrust it — but I could stand no more. (159)

Our tale teller simply cannot go on to describe the torture in the dream and struggles awake with a shriek. Like Hitchcock's Psycho, however, enough has been shown to engage the reader's imagination. The horror is not diminished: indeed, the proponents of "quiet horror" would argue, it is actually heightened by being proairetically left up to the reader to imagine where that funnel was thrust and what ensued. The difference between splatterpunk and quiet horror is that splatterpunk more or less successfully goes on to attempt the unspeakable and would describe the torture from which Conan Doyle's narrator awakens, screaming. If "The Leather Funnel" were made by Rob Zombie, Eli Roth or Takashi Miike into a film, the film would show the "ordinary and extraordinary question" in all its agony, not fade into a close-up of the narrator screaming as the funnel is about to be applied "with horrible energy." Such a torture scene, in fact, would fit well into the Technicolor depictions in the Hammer and Corman films of the 1960s, such as Corman's loose adaptation of Poe's The Pit and the Pendulum (1961), featuring bodice-clad beauties pursued by raving inquisitors. Since then, however, the camera, particularly with Miike, does not flinch away from showing the application of torture. ${ }^{153}$ Datlow touches upon this difference between showing and not-

${ }^{153}$ Miike's short film for Masters of Horror, "Imprint," was the only film to be banned from being screened to the cable network's viewers. It features a lengthy scene of excruciating torture of a woman by trussing her upside down, then inserting bamboo slivers under her nails, ripping them away. Miike's other films such as Odishon \{Audition) (1999) and Koroshiya Ichi (Ichi the Killer) (2001) similarly depict hard-to-watch scenes of torture. In Ichi, a 
showing when she argues that "one of the apparent misconceptions of the splatterpunk writers is that describing the infliction of pain or the throes of death makes their stories realistic. All it does, actually, is demonstrate that they've been seeing too many movies" (xviii). The intertextual permeation of the visual horror film sensibility into the short story, with its concomitant sense of time, is what has shaped contemporary horror's "G-factor." In Harlan Ellison's 1967 story "I Have No Mouth and I Must Scream," this cinematic sensibility is apparent. Ellison imagines a world where several abject humans are kept alive and tormented within the labyrinthine complexity of an insane super-computer known only as AM. At times, their bizarre ordeals approach Brophy's "horrality" or "splatstick," a recurring characteristic of splatterpunk:

One day he $[\mathrm{AM}]$ decided to cause an earthquake, at the same time rooting us to the spot with nails through the soft pads of our feet. Ellen and Nimdok were both caught when a fissure shot its lightning-bolt opening across the floorplates. They disappeared and were gone. When the earthquake was over, we continued on our way, Benny, Gorrister and myself. Ellen and Nimdok were returned to us later that night which became a day abrupdy as the heavenly legion bore them to us with a celestial chorus singing "Go Down Moses." The archangels circled several times and then dropped the hideously mangled bodies. We kept walking, and a while later Ellen and Nimdok fell in

rival yakuza boss is trussed up with meathooks through the skin of his back and has boiling tempura grease splashed onto his body. 
behind us. They were no worse for wear. But now Ellen walked with a limp. AM had left her that. $(28)^{154}$

Horrality in contemporary splatterpunk offers what Mikhail Bakhtin calls "the permanent corrective of laughter" (55) as a way of addressing the violence and death that pervade reality. Gross-out horror often serves the purpose of horrality. ${ }^{155}$ For example, in Robert Bloch's story "A Case of the Stubborns," a dead grandfather refuses to be buried and insists upon eating hearty meals with his appalled family, even though he's getting "ripe," flies are buzzing around him and the neighbours are fleeing. Possibly the most unsettling aspect of this story is the grandfather's persistent requests for meals and his enormous appetite, signifying a monstrous interstitiality in Carroll's terms. A wise woman comes up with the solution: giving the zombified curmudgeon a black napkin to wipe his mouth after dinner, which shows up the maggots, convincing him that he should go and lie down decently. Canadian writer Nancy Kilpatrick's "Farm Wife" is another example of a (literal) horrality story where the pragmatic narrator dispatches her husband who has turned vampire with the same trick that she has learned to kill mosquitoes; by waiting patiently and flexing her arm until a vein swells up, exploding the parasite.

${ }^{4}$ The video game based on this story is worth noting as the voice of the computer in the game is narrated by Ellison and the game attempts to remain faithful to the nightmarish spirit of the story.

${ }^{155}$ Joe Lansdale is a master of the horrality gross-out: "A white pustule the size of a thumb tip had taken up residence on the left side of his snout, and it looked like a pearl onion in a turd" ("On the Far Side of the Cadillac Desert with Dead Folks" in Book of the Dead 324). 
Brophy's term can also be extended to irreverent reversionings of formerly frightening texts, such as Neil Gaiman's metafictional Gothic parody "Forbidden Brides of the Faceless Slaves in the Nameless House of the Night of Dread Desire" in which a bored Poe-like writer finds himself slipping into bathos whenever he attempts to write a Gothic passage. Another great example of this comedic tension-reliever in splatterpunk is Dan Simmons's hommage to Dante's Inferno that I have already mentioned as an instance of intertextuality, "Vanni Fucci is Alive and Well and Living in Hell" (Skin Trade). This story presents not so much the gory spectacle of splattered bodies that an over-reliance upon filmic examples will emphasize, but rather again demonstrates the "punk" aspect of "splatterpunk" in its challenge to authority and irreverent use of the canonical text. The furious Fucci, condemned with the others of his Bolgia filled with "shit and sinners" (158) in Hell to endure episodes eight times a day of the nauseatingly hypocritical televangelist Brother Freddy's "Hallelujah Breakfast Club" show, expresses his outrage by giving God "the fig" with immediate and amusing consequences for all the hypocrites in the televangelist's circle, in the television studio and in the audience:

Vanni Fucci had said that all thieves within a hundred yards of his blasphemy traditionally were transformed. Out of 319 audience members present that morning, 226 were unaccounted for the next day. The auditorium was filled with screams as those who stayed human watched their husbands or wives or parents or in-laws or the stranger next to them transform in a flash into snakes, fanged newt-things, legless toads, giant iguanas, four-armed boa constrictors, and die usual assortment of chelidrids,jaculi,phareans, cenchriads and amphisbands. (161) 
The potency of splatterpunk, I argue, is derived from its willingness to give "the fig" to authoritative systems: including the cultural systems of distinction which govern what is acceptable to show and not show; what can be textually poached (television shows) and what cannot (Dante); what is in good taste and what is in poor taste. Horrality and intertextuality are two of the ways in which this is accomplished, as well as the irreverent, cinematic style and a dialogical narrative distinguished by different points of view (focalizations) and voices, including oral storytelling and colloquialisms. Ignoring the "punk" aspect of the "splatterpunk" style, as Joshi, Datlow and others do, only focusing on the "splatter," decontextualizes its co-ascendancy in the 1980s with Reagan and the rise of the religious right in the United States, a reason why its ire is often directed at televangelists, holy rollers and religious hypocrites. Splatterpunk corresponds to what I described in Chapter Two as the ascendancy of a central monster of the apocalyptic millennium and the globalized postcapitalist twenty-first century, the flesh-eating, hollowed-out, abjectly living-dead zombie, the embodiment of the masses with a body that splatters. It is no coincidence that some of the most splatter-filled, gross-out stories in horror such as Schow's "Jerry's Kids Meet Wormboy," Joe Lansdale's "On the Far Side of the Cadillac Desert with Dead Folks," Nina Kiriki Hoffmann's "Zombies for Jesus" and Les Daniels's "The Good Parts" mingle hypocritical televangelists, preachers and other patriarchs encountering hordes of ravening zombies over issues near and dear to the "Moral Majority," such as pornography and abortion. The zombies are likened to the masses, as we saw in Chapter Two, while the real evil resides in those who lead them. Gore and splatter punctuate and underline this point.

These splatterpunk zombie stories feature sickening scenes of rapid-fire, almost cartoonish violence. The following example is from Schow's "Jerry's Kids Meet Wormboy," 
set in a zombie-ravaged post-apocalyptic cemetery where Wormboy, an obese and ghoulish social outcast (a corpse-eating version of Ignatius O'Reilly) ${ }^{156}$ battles an army of "bornagains," tame zombies led by a Reverend Jerry who has managed to suppress their flesheating proclivities by the use of snake venom:

Jerry felt something skin past his ear at two hundred per. Behind him, another of the born-agains came unglued, skull and eyes and brains all cartwheeling off on different trajectories. Jerry stepped blind and his heel skidded through something moist and slick; his feet took to the air and his rump introduced itself to the pavement and much, much more of Deacon Fatty. More colors soaked into his coat of many. The Right Reverend Jerry involuntarily took his Lord's name in vain .... It took no time for the air to clog with the tang of blackened geek beef. One whiff was all it took to make Wormboy ralph long and strenuously into the moat. Steaming puke pasted a geek who lay skewered through the back, facing the sky, mouth agape. It spasmed and twisted on the barbs, trying to lap up as much fresh hot barf as it could collect (372-3). ${ }^{157}$

Literary splatterpunk, as replete with "body horror" (Williams) as its filmic counterpart, thus employs what Brophy calls "horrality" and what Kristeva calls "apocalyptic

${ }^{156}$ In A Confederacy of Dunces by John Kennedy Toole.

${ }^{157}$ Doubtless, Gelder would find this one of the less accommodating points in the field and it is also an example of what Mark Kermode describes as the machismo of horror film fans who, taking pains to master their emotional response through knowledge of the genre, remain "unafraid and triumphant" (Kermode quoted by Hills 75). 
laughter" (204). Splatterpunk signifies a slipperiness, not only of guts but of genre. Through such outrageous displays as the passage quoted above, a Brechtian verfremdungseffekt or awareness of fictional boundaries and distances occurs, forming a break not only with the past but with master narratives of all kinds, including those that determine genres and tastes. To refer back to Halberstam's retooled formulation of the Gothic as a technology of subjectivity, the monstrous - in this case, the zombie - is born-again (or resurrected) into a present filled with the ruins of certainties and master narratives, which does not recognize any privileged form. Another equally stomach-churning example of "apocalyptic laughter" directed at authoritative narratives is the tongue-in-cheek parodic "splatterpunk versus quiet horror" story "Des Saucisses Sans Doute" by Peter Schneider which employs the framing metafictional device of a faux editorial introduction which presents an "author" named "Pamela Jergens" in a highbrow style, preposterously littered with French phrases, as One of our new breed of writers of le horreur [sic], as I like to call it.... "I disdain the recent work of the so-called splatterpunks," says Pamela. "My work is instead the materiel oi the night. . of the dark places that live within us, expressed through only the subdest of metaphors and signals." (362)

The story "Des Saucisses Sans Doute" by the refined advocate of "quiet horror" who cites Rappacrini's Daughter (Nathaniel Hawthorne 1844), "Pamela Jergens," then begins with the following brutally violent descriptive passage which provides a sudden, jolting contrast with the previous passage and would be appallingly offensive had it not been situated in the context of satire: "I brandished the severed left tit of the blond chick in one hand. It had not been a clean cut - Momma never got me braces when I was growing up" (362). The brief story becomes more absurd, hallucinatory and surreal in its violence as it continues - the 
monstrous narrator s tongue turns into a "tempered steel fork" which he or she uses to sever the victim's legs and attach them to his or her own body. Then a passage follows which temporarily relieves the surrealism as the narrator's alarm rings and he or she wakes up to "no blood, no breasts," that is, until the narrator, preparing breakfast, splits an English muffin "open with my stainless steel forked tongue and watched the surface of my coffee as a taupe nipple bobbed insouciantly to the surface" (363)..$^{158}$

Craig Shaw Gardner writes that both humour and horror are derived from the same premise: "Something is wrong with everyday life" \{Cut! 92). Gardner argues that the humour in horror can be regarded as being part "release mechanism" or coping strategy, as I have suggested, part tribute (intertextuality), and pardy a function of the "faster and bloodier" horror film of more recent decades, where the humour was at first "tentative" but is now firmly entrenched (100). All of this play with horrality and humour is still related to what I have been calling horror's "condensed realism." Discussing the werewolf film The Howling, for example, which is situated around media forms such as television journalism and pornography, Gardner remarks that "hyperrealism played against buffoonery continues throughout the film, and gives the proceedings a surreal quality, which, in an odd sort of way, makes the supernatural events that occur later all the more acceptable" (98).

This over-the-top violence recalls the hallucinatory and intense passages from American Psycho which outraged feminist groups such as the National Organization for Women, whose members read the book as a straightforward channel of the mind of its author and vehemendy protested its publication. In Bad Girls and Sick Boys, Linda Kauffman documents this outrage, remarking that Bret Easton Ellis was not allowed into Euro Disney following the book's publication "as if his very presence would taint the atmosphere" (251). 


\section{Conclusion - Chapter Three}

My discussion of "splatterpunk" fiction has touched upon the distinctive inclusions of horrality, an apocalyptic cinematic sensibility in both pacing and intertext, and a political commitment to challenging the more entrenched master narratives of contemporaneity. As I hope to show in the ensuing discussion, the apparent "quiet horror" of many "classic" short stories shares identical narrative techniques and devices with "new" or "splatterpunk" horror fiction. These differing styles, as Joshi suggests, are best located on a continuum, rather than situated in opposition to and in competition with each other. For Gardner (and also for John Keir Cross), horror generally accomplishes a "twist" on the familiar which recalls the uncanny, Freud's Unheimlich, or, as John Keir Cross puts it, "the familiar turned inside out" (Best Horror Stories 9). Gardner argues that we need horror to evoke familiarity in order to frighten us: "Any design based upon the truly unknown would not be horrible. It would only be incomprehensible" (94). The familiar similarities that can be discerned between horror fictions may be attributed to various factors, including the basic strategies that may be deployed in evoking fear. We have already discussed the broader themes and the narrative structure of many horror stories. The next and final chapter of this dissertation will continue to examine and explore yet more closely common narrative elements in the tales which I have identified as the core of horror fiction. 


\section{Chapter Four: The Elements of Horror's Style}

Writers, filmmakers and horror fans have developed their own terms for horror's narrative devices, some of which pass into easily mocked convention. In film, for example, audiences have become familiar with the convention of the startling effect or "jump scare" where characters undergo shocks, as if they are subjected to animated figures in a haunted house jumping out at diem, which turn out to be either false or a preparation for the "real thing." This contrived false menace is known as "the bus" after die celebrated scene in the classic horror film Cat People (1942) where the rival of "the marvellously feline" Simone Simon

is walking alone along a road in Central Park at night. The pool of light becomes an island of safety surrounded by menacing blackness. Her hesitant footsteps seem to be echoed by stealthily padding paws and the rusde of stirring branches. The denouement, in which the anticipated doom finally materializes as a screeching feline hiss — made by the opening pneumatic doors of a bus as it pulls up alongside her — is one of the cinema's most heart-stopping moments. (Hardy 79) ${ }^{159}$

15 Writer Don Miller is quoted as observing the audience's response to the first screening of Cat People: "|T| watched the concerted scream of the packed house when a bus pulls alongside the girl with the hiss of airbrakes. An optical illusion, perhaps, but it seems that die entire theater audience rose and fell in one rippling wave of fear." in Mark A. Vieira Hollywood Horror: From Gothic to Cosmic (New York: Harry Abrams, 2003), reprinted online in Bright Lights Film Journal, Issue 50 <http://www.brightlightsfilm.com/50/lewton.htm>, accessed December 2008. 
The startle tactic as part of a "threat scene" as Robert Baird calls it, is therefore quite well recognized as an affect in horror cinema. ${ }^{160}$ Despite Val Lewton's dictum that, given enough "dark patches," a horror film audience will do all the work in creating and imagining their own fear, ${ }^{161}$ horrible sights are quite unmistakable in visual form. When the camera zooms in on "the ruined body," both the spectacle and the threat are clear and can also be measured as an affect in the reactions of audiences. Similar affects are used in written horror but it is not clear how these affects can be represented in print form through "the mind's eye." This section amasses a large number of concrete examples taken from short fiction and organized under certain recurring patterns I have identified, thus constituting a typology or a poetics of the short horror story's affects. In some cases, as we will see, correspondences between film and written fiction do occur, while other elements of horror's style belong to literature alone. However, we cannot discuss style without discussing horror's affects and it is to those that I now turn.

In The Dark Descent, Hartwell quotes Freud on the uncanny which, as we have already seen, is often raised in conjunction with horror as a twist on the familiar that evokes a fearful response. Hartwell muses that

${ }^{160}$ See Baird's article on "Startle and the Threat Scene" in Images: a journal of film and popular culture, issue 3 , at <http://www.imagesjournal.com/issue03/features/startlel .htm\#top >, accessed October 2009.

161 "If you make the screen dark enough, the mind's eye will read anything into it you want! We're great ones for dark patches." Val Lewton, Life magazine interview, 25th Feb 1946, quoted by J. P. Telotte in '"Dark Patches': Structures of Absence in Lewton's Cat People." PostScript, vol. 2 no. 1. 1982 Fall, pp: 40-57. 
[m]uch as we ask for it, the, frisson of horror, among the many oddities of our emotional life, is one of the oddest. For one thing, it is usually a response to something that is not there . . . unlike terror, which is extreme and sudden fear in the face of a material threat. (4) ${ }^{162}$

Setting aside Hartwell's distinction between horror and terror, the problem of literary horror becomes: how do we frighten the reader with "something that is not there"?

Cinematic and visual effects show grotesque monsters, dead and reanimated bodies, startling occurrences and stretched-out violence. Some audience research has been carried out on the effects of horror films, ${ }^{163}$ while no studies have been conducted on readers' responses. How, then, is horror as a response generated by written fiction?

Such questions bring us inevitably to the consideration of style as a "technique of exposition" derived from the rhetorical tradition in poetics (Lodge, Language of Fiction 53). The analysis of style in considering affective responses makes it possible to determine what can be studied objectively, such as the disposition of words in a passage, the manipulation of imagery, and possible connotative meanings, all of which are crucial to literary horror. While the field of stylistics spans several disciplines — linguistics, literature and cognitive science —

${ }^{162}$ Hartwell concentrates upon narrative: therefore, he divides horror stories into three "streams" of symbolic thematics, "moral allegorical," "psychological metaphor" and "fantastic" (8). He argues that the first stream is for the commercial horror category, embraced by the "style-deaf (regardless of the excellence of some of the works" (9). The second stream includes sci-fi horror hybrids and psychological tales with monsters at their centre, while the "third stream stories lack any explanation that makes sense in everyday reality," blending with "magic realism, the surreal, the absurd, all the fictions that confront reality through paradoxical distance" (10).

${ }^{163}$ See Baird for some examples as well as Nolan and Ryan on gendered responses to slasher films (2000). 
we can draw insights from several of these areas in order to understand how style produces affect in horror. As Michael Riffaterre argues, it may be difficult to discover the author's intentions and impossible to map reader responses, but if we focus on literary style as a process of decoding horrifying meanings, the task becomes much simpler. A number of literary critics have given us concepts of style that are ideal for the study of horror fiction: for example, Riffaterre's idea of the inescapably intertextual "encoding and decoding" of stylistic devices as well as his "superreader"; Genette's "exemplification" versus "denotation" (1991); Roman Jakobson's "poetic function" (350-377); and David Lodge's idea of "realization," or "the art which exploits the uses of language in such a way that words 'become' what in non-literary discourse they merely represent" (66). Such literary theories have seldom been applied to horror fiction, at least not to the contemporary short stories. ${ }^{164}$ As we have seen, most critical writing on horror has been generated by film studies and has therefore been understandably more concerned with decoding visual images and less concerned with decoding language, while the concept of a "horror literature" is still tapping a claw on the shuttered windows of departments of languages and literatures.

Particularly useful for the analysis of horror is David S. Miall and Don Kuiken 's empirical study of "foregrounding" (389-407) as a description of literary affects created through the use of style that slows down reading time in order to create what they call deautomatized perception, thus defamiliarizing the reader's experience enough to experience certain affective responses. This recalls the "stretched-out" violence that I earlier described

${ }^{164}$ Leffler uses reception theory to discuss selected novels, such as Stephen King's It, but ignores the short story. 
as an effect deployed by more contemporary horror, such as splatterpunk. Miall and Kuiken explain "foregrounding" as follows:

The term foregroundinghas its origin with the Czech theorist Jan Mukarovsky: it is how Mukarovsky's original term, aktualisace, was rendered in English by his first translator .... It refers to the range of stylistic effects that occur in literature, whether at the phonetic level (e.g., alliteration, rhyme), the grammatical level (e.g., inversion, ellipsis), or the semantic level (e.g., metaphor, irony). As Mukarovsky pointed out, foregrounding may occur in normal, everyday language, such as spoken discourse or journalistic prose, but it occurs at random with no systematic design. In literary texts, on the other hand, foregrounding is structured: it tends to be both systematic and hierarchical. That is, similar features may recur, such as a pattern of assonance or a related group of metaphors, and one set of features will dominate the others. ... a phenomenon that Jakobson termed "the dominant." (392)

Literary foregrounding thus works against everyday "automatized" communication in a "violation" so that "the primary focus of the reader is upon style." Miall and Kuiken combine this theory with Russian Formalist Viktor Shklovsky's concept of "defamiliarization," or making strange (pstranenie). I noted above the Brechtian verfremdungseffekt $\backslash n$ splatterpunk's cartoonish violence. Echoes are also found here of the uncanny effect noted by Todorov, the "twist" upon the familiar. Shklovsky notes that the use of style creates "a special perception of the object," a "vision" returning us to the realm of the "mind's eye" that Lewton regarded as so important in the creation of the horror affect 
as the viewer strains to fill in dark patches with his or her imagined fear. Miall and Kuiken point out that "Mukarovsky and Shklovsky, although they seem unaware of it, show continuity with earlier work by Coleridge and Shelley . . . ." Interestingly, they do not mention Coleridge's principle of the suspension of disbelief, which I have argued, following Stephen King, is central to the apprehension of horror fiction. Instead, Miall and Kuiken formulate a process of defamiliarizing and subsequent "refamiliarizing" which they then test upon reading subjects with three short stories, including one, "The Trout," that mentions an eerie place called "The Dark Walk":

Briefly stated, we propose that the novelty of an unusual linguistic variation is defamiliarizing, defamiliarization evokes feelings, and feelings guide "refamiliarizing" interpretative efforts. There seems little doubt that foregrounding, by creating complexity of various kinds, requires cognitive work on the part of the reader; but it is our suggestion that this work is initiated and in part directed by feeling .... The process unfolds in three phases. First, these novel linguistic features strike readers as interesting and capture their attention (defamiliarizationperse). Second, defamiliarization obliges the reader to slow down, allowing time for the feelings created by the alliterations and metaphors to emerge. Third, these feelings guide formulation of an enriched perspective on the Dark Walk. Readers whom we have asked to talk about their responses to this segment frequently found this passage striking (e.g., "very beautiful"), mentioned specific feelings (e.g., "foreboding"), and developed novel perspectives on the Dark Walk (e.g., "something that's not of this world"). (393) 
More than once, examples of what Miall and Kuiken term "striking" words or phrases in fact generate reported responses tinged with horror-affect, such as the "foreboding" quoted above. In another passage, they report a response to a poem that mentions the "sinister" affect of the rhetorical device used (synonymy). Their overall findings that there is a significant correlation between foregrounding, reading times and readers' reports of affect open up fascinating ground for the study of horror fiction, including the question: does refamiliarization even occur for horror readers?

Miall and Kuiken explicitly distinguish between their process of foregrounding of literary texts and reading processes in "popular fiction" such as horror, reporting that in their third study, they examined first-year Psychology students: readers who were "lower in literary competence" than the two groups of senior-level English students they had previously tested. The Psychology students "reported that they rarely if ever read a literary text except as required in English courses at school or university, although many read popular fiction such as romances, horror fiction, or fantasy." Not surprisingly, Miall and Kuiken found "less interest and involvement in the reading process" when the Psychology students were subjected to a story that the English graduate students and professors who selected them had found exemplary of foregrounding. It would be highly interesting to try to replicate these results using horror fiction to test the same groups. The authors' insistence upon the literariness of their selections as opposed to "popular fiction" and their resulting failure to discern the possibility of "striking words" and thus defamiliarization in such fiction as well as failing to recognize responses to such fiction as a potential area of "literary competence," ultimately unnecessarily narrows and obscures the role of affect. 
Miall's and Kuiken's insistence upon foregrounding in the text as "an intrinsically literary quality," where "literariness" is narrowly defined to exclude " popular fiction such as romances, horror fiction, or fantasy" sets them at odds with Stanley Fish who, as we have seen, regards reader responses as generated by the reader's position within "interpretive communities" (14) and argues that literature is a "conventional category. What will, at any time, be recognized as literature is a function of a communal decision as to what will count as literature" (10). For Fish, the features of a text cannot trump the interpretive strategies of the reader, which argument is sorely put to the test when we consider some of the features displayed in the splatterpunk texts I have mentioned. The dilemma is, as Antoine Compagnon succincdy puts it, that "interpretation presupposed description, but description presupposed interpretation" (134). Compagnon points out that even "exhaustive" efforts to describe "everything" such as Roman Jakobson and Claude Levi-Strauss's famous 1962 article on "Les Chats" could not establish that the structures they identified hold any meaning for readers. This is a problem that using Fish's theory of interpretive communities can address and, as we have seen, fan $(\mathrm{g}) \mathrm{dom}$ is constituted of such interpretive communities who are gleefully informed of the horrality and intertextuality implied in splatterpunk, for example.

Here, the advantage of working in such a lowly "popular" field as horror becomes apparent: while I certainly argue that "foregrounding" applies equally well (if not more so) to horror fictions, I am not unduly anxious to prove the "literariness" of the texts I have selected. I also do not claim to have exhaustively analyzed the entire opus of horror literature which is impossible in any case, as new horror fictions are constandy being generated. It may one day fall to the computer engaged in what Alan Beye Riddell optimistically calls 
"quantitative stylistics" in order to keep up with Franco Moretti's "prose style from below":

With digital databases, this is now easy to imagine: a few years, and we'll be able to search just about all novels that have ever been published, and look for patterns among billions of sentences. Personally, I am fascinated by this encounter of the formal and the quantitative. Let me give you an example: all literary scholars analyse stylistic structures-free indirect style, the stream of consciousness, melodramatic excess, whatever. But it's striking how little we actually know about the genesis of these forms. Once they're there, we know what to do; but how did they get there in the first place? How does the 'confused thought' (Michel Vovelle) of mentalite, which is the substratum for almost all that happens in a culture — how does messiness crystallize into the elegance of free indirect style? Concretely: what are the steps? No one really knows. By sifting through thousands of variations and permutations and approximations, a quantitative stylistics of the digital archive may find some answers. It will be difficult, no doubt, because one cannot study a large archive in the same way one studies a text: texts are designed to 'speak' to us, and so, provided we know how to listen, they always end up telling us

${ }^{165}$ Alan Beye Riddell notes on his website that he likes "the term "quantitative stylistics"—it seems to bridge in one breath the considerable distance between, say, computational linguistics and comparative literature" <http://allenriddell.org/blog/ 2009/02/quantitative-stylistics/>. Accessed August 2009. 
something; but archives are not messages that were meant to address us, and so they say absolutely nothing until one asks the right question. (114)

My aim, in this chapter, is to ask the right types of questions about horror, questions about narrative, form, structure and affect which have so far yielded some intriguing answers. I have already discussed some important aspects of horror stories, including the framed tale with its connection to oral storytelling. In what follows, I have arranged examples from various stories under ten headings that reflect the most common patterns of defamiliarizing foregrounding that I find in effective horror stories. Unlike Miall and Kuiken, I employ a qualitative, rather than an empirical, methodology. These patterns of affect seem to recur frequently in various combinations, whether the text is well-known or lesser-known; whether it was written in 1909 or 2009; whether the author is a recognized literary figure or known only to horror fans; and whether a high-flown style or colloquialisms dominate.

Not all of these affects occur in the same text: it matters, for example, whether the story tends towards "quiet horror" or is unabashedly "splatterpunk," but even then, the range of affects follows discernible patterns as well. It will be noted that certain of these categories are already in circulation in horror film criticism, for example, "character identification" has been noted (and dismissed) by Carroll, while Giles, Pinedo and Will R. Rockett (1988) have all discussed the pleasure of not-seeing inherent in the affect of the "imperfectly seen" or the glimpse in horror film. Dennis Giles discusses "not-seeing" and the "diffuse anxiety in which dread of the return of full vision is commingled with desire for its return to the screen. It is this anticipatory vision - showing little or nothing of the true object of terror - which interests me here" ("Conditions of Pleasure in Horror Cinema" 42): 
The articulation of imagery from film to film is so flexible, so dependent on context, that I hesitate to speak of set visual codes. Better, perhaps, to call these images figures — devices or patterns of figuration — leaning on arguments advanced by Lyotard. Rather than being a decorative or ornamental "turn" (trope) of the discourse, as classical rhetoric would have it, the figure allows a more primary, preconscious or unconscious fantasy to contaminate and rework the ordered surface of the ostensible text. The figure is a kind of overflow from an invisible scene onto the imagery of the film, so that what Heidegger or the expressionists might call the stimmung — the mood or "attunement" of the image — is bent by fear, desire and anticipation so that it "speaks" something more than it shows. The figure of the delayed, partial or empty vision ambiguates the image; it overlays the explicit significance of the scene with a monstrous presence which belongs to an other scene. (42)

Giles's "incomplete catalog" of figures in film could be compared with the affective elements I find in numerous horror stories where, as in film, "the viewer seems to be invited to look less at whath seen than at how it is seen" (45). Themes and plots have been frequendy discussed in horror - Carroll claims to have boiled horror down, as Vladimir Propp did with folktales, to "fourteen basic plot structures," centred around discovery of and confrontation with the monster (116). Here I de-centralize and de-emphasize the prevailing exclusive focus upon one category or another, as well as on plot, in insisting upon the importance of considering all stylistic and formal affective elements that may be at play and often combined within horror texts. In keeping with the horror novel market's penchant for nominative titles, I list these elements as follows: 
1) The Identification

2) The Glimpse

3) The Unspeakable

4) The Appalling

5) The Monstrous

6) The Uncanny

7) The Sickening

8) The Bad Death

9) The Sudden

10) The Twist

The first three elements — identification, glimpse, unspeakable — fall under conceptions of "terror" as I described them in my section on definitions of horror (Chapter One); while the next three — appalling, monstrous, uncanny — roughly correspond to the sense of horror that Stephen King described as showing us "something" (J)anse Macabre 35). Sickening, of course, is "gross-out" while the remaining three devices are halfway between effect and plot, returning us to the frame of the story. Some of these ideas have been partially advanced by critics. Carroll, for example, speaks of a "mirroring" affect whereby the reader identifies with a character's horrified perspective, similarly to the first proposed category of identification, while Rockett's cinematic study Devouring Whirlwind: Terror and Transcendence in the Cinema of Cruelty proposes a theory of "synaesthesia," a combination of textual (in his case filmic) elements that create shock and novel perceptions of "wonder and astonishment" to create transcendence (Leffler, 78) that seems to match the idea of the sudden as well as indicating the idea of the "imperfectly seen" (the glimpse). Still, not enough 
time, as I argue, has been devoted to examining how these singled-out elements are actually at play in a given text, especially in written horror.

\section{The Identification}

The identification affect is the narration of a fear response within the tale that invites or draws out a similar response on the part of the reader through focalization. Its cinematic equivalent is the close-up of the staring or screaming face of a character who is seeing some menace off-screen not yet available to the audience, an oft-noted iconic visual image of horror that is depicted almost exactly here in print in the 1958 George Langelaan story that became adapted to the cinema as The Flj (1986). Here the ill-fated scientist's wife is recounting her experience upon first seeing her transformed husband, who has been lurking concealed since the accident that mutated him so horribly. The description of her fear prolongs the suspense:

The horror was too much for me, too unexpected. As a matter of fact, I am sure that, even had I known, the horror-impact could hardly have been less powerful. Trying to push both hands into my mouth to stifle my screams and although my fingers were bleeding, I screamed again and again. I could not take my eyes off him. I could not even close them, and yet I knew that if I looked at the horror much longer, I would go on screaming for the rest of my life. (252)

In print, this response can be conveyed through indirect speech, direct speech or interior monologue. Stephen King frequently and successfully employs the latter. Here is a typical description of the onset of a fear without a tangible basis (yet) on the part of his protagonist: 
But there was just the silence, thick and smooth and total, die sort of silence the dead would hear in their coffins if they could still hear, and Tell again became convinced that Sneakers was dead, fuck logic, he was dead and had been dead for who knew how long, he was sitting in there and if you opened the door you would see some slumped mossy thing with its hands dangling in the fork of its crotch, you would see - - ("Sneakers" 38)

In this passage, the character Tell's rising panic is cut short; this time, there is nothing to see behind the door. However, the reader, hailed by the repetitious "you," has been caught up in Tell's flurry of panicked consciousness, envisioning the "slumped mossy thing" (this overlaps with other effects, such as The Glimpse), creating a simultaneous identification with the threat to Tell. The description of panic and fear states often work in conjunction with The Sudden, expressed through a lack of definitive stops in the paragraph and a sense of running wildly until the moment of cutting off the panic:

Hal crawled backward, sweating, hot and cold, all fire and ice, waiting for the cymbals to begin, and when they began, the monkey would leap from its box and scurry beetlelike toward him, clockwork whirring, cymbals clashing madly, and — and none of that happened. He turned off the light and slammed the small down-the-rabbit-hole door and leaned on it, panting. At last he began to feel a little better. (39)

This type of narration bears a strong resemblance to the Conan Doyle story "The Leather Funnel" I mentioned earlier in the context of graphic imagery. Recall that the tale of the narrator's dream in that story ends abrupdy upon another such dash - " [w]ith horrible energy he thrust it -" — inviting the reader to fill in the blank indicated by the dash and imagine the 
worst before yanking them back into a relatively safer scene. Another scene from the same story has the character engaged in a stream-of-consciousness flow about his feelings for his two sons and then, suddenly: "[h]is thoughts froze. The monkey. The monkey was sitting on the windowsill, cymbals poised. Hal felt his heart stop dead in his chest and then suddenly began to gallop" (39)

As characteristic of Stephen King's prose as this intimate identification is, characterized by first hailing and then drawing the reader into a flow of consciousness, it is also a narrative technique that long precedes him, as we can see in this description from E. M. Forster's "The Story of a Panic": "It was not the spiritual fear that one has known at other times, but brutal, overmastering, physical fear, stopping up the ears, and dropping clouds before the eyes, and filling the mouth with foul tastes" (Black Water 924). In "The Brick-Kiln," E. F. Benson employs much the same affect:

At that moment I saw the face of Fear; my mouth went dry, and I heard my heart leaping and cracking in my throat. That face was only turned on me for a moment and then away again, but I knew it to be the genuine thing; not apprehension, not foreboding, not a feeling of being startled, but fear, cold Fear. (335)

In Ray Bradbury's story "The Veldt," 166 two scheming children lure their parents into a technological marvel of a playroom that is all-too-realistic and to which the children become addicted. When the parents try to discipline the children, they get locked in the

${ }^{166}$ This story was adapated and filmed, as Dr. Brian Greenspan points out, as part of the Bradbury anthology filmic Illustrated Man (1969). A remake of this film is scheduled for release in 2010. 
"Africa" version of it, to be devoured by lions that breach the boundary between makebelieve and reality. This horror is set up through identification:

And here were the lions now, fifteen feet away, so real, so feverishly and startlingly real that you could feel the prickling fur on your hand, and your mouth was stuffed with the dusty upholstery smell of their heated pelts, and the yellow of them was in your eyes like the yellow of an exquisite French tapestry, the yellows of lions and summer grass, and the sound of the matted lion lungs exhaling on the silent noontide, and the smell of meat from the panting, dripping mouths. \{American Gothic Tales 266)

The tension of such sequences is heightened by the narrator or protagonist's struggles to resist the overwhelming sense of fear. For example, in Charles Dickens' frequendy-anthologized ghost story "The Signalman," the narrator describes "[fjesisting the slow touch of a frozen finger tracing out my spine" (212). Here is another example from H. Russel Wakefield's starkly terrifying classic "The Red Lodge": "After a time, I became more absorbed and less fidgety, and then I heard a very soft cough just behind me. I felt icy rays pour down and through me, but I would \#<f look around, and I wouldgo on reading" (21). An oscillation or "double vision" is thus created - the reader knows that through the character, the revelation of something horrible is about to be experienced and so struggles against the identification. ${ }^{167}$ The atmospheric effects so admired by proponents of classic

${ }^{167}$ The tension between being "in control" and "out of control" of identification that such narrative segments convey is also played upon in unexpected ways in American Psycho, where only the reader is witness to Patrick Bateman's inner monologues and his sickening rampages. Through the creation of such distinctions and intimacies, a particular type of identification on the part of the reader is explored. Rather than "moral" and "feral" 
"quiet" horror depend upon how long one can prolong the moment of revelation to focus instead upon what Fielden Hughes' narrator in "Dear Ghost" calls watching "the behaviour of my fear": "... I dared not stay in the house alone .... I felt a strange warning; words are such poor servants of meaning: say a queer slight dislocation of inner vision, accompanied by this vague fear, and by my impatient repudiation of its need" (57). Hughes' narrator eventually succumbs to "the secret cold fingers of the [haunted] house" to discover that the ghost is not only benign, but actually welcomed by his landlady as it is the only communication she has with her dead husband. Still, the build-up to this discovery is what creates the horror of the tale.

Edgar Allan Poe also uses the technique of identification in many of his stories, including "The Facts in the Case of M. Valdemar": ${ }^{168}$ "No person present even affected to deny, or attempted to repress, the unutterable, shuddering horror which [M. Valdemar's words] were so well calculated to convey" (Poe 296). Even when the identification is presented in a brusque and factual way, such as by Rudyard Kipling in "My Own True Ghost Story," the effect is unmistakable: "Next minute I heard the double click of a cannon and my hair sat up. It is a mistake to say that hair stands up. The skin of the head tightens, and you

intentions being elicited from the reader, that passive dupe of machine culture (Seltzer, 120), the text comes apart at the seams, as the reader is encouraged to cut and slash through the thickets of consumer kitsch to Bateman's heart of darkness.

${ }^{168}$ Roland Barthes's exhaustive "Textual analysis of a Tale of Poe" (172-86), in noting the play of codes (as with $S / Z$ ) reduces the horror of "Valdemar" to the interstitiality of Death and Life, which frustrates our attempts to classify and produce "meaning" (181). His emphasis upon the narrative propulsion affect of the "appetizers" of Valdemar's mesmerism process is, as Leffler notes, interesting (98). See also Tracy Ware's analysis of Barthes's reading of Poe in "The 'Salutary Discomfort' in the Case of M. Valdemar," Studies in Short Fiction'iX (1994): 471-80. 
can feel a faint, prickly bristling all over the scalp. That is one s hair sitting up" (Thin Air 201). ${ }^{169}$ In this story, the explained supernatural ending, which Hills calls a "Scooby-Doo style narrative" (35), does not detract from this moment of horrere. The identification effect shows that the overall intent is to convey fear, whether it is ultimately explained or not. In "An Apparition," Guy de Maupassant's narrator asks dramatically: "Why did I take that comb with a shudder, why did I take that long black hair that made my skin creep as if I were handling snakes? I don't know" (222). Here is another (far less poetic) example from Gardner Dozois's story "Flash Point": "Jacobs could not explain the chill that hit him then, the horror that seized and shook him until he was almost physically ill" (19).

The identification affect is instantly recognizable in many horror stories by its repeated references to the root of horror, horrere, as we have already seen, describing die physical sensations of creeping, crawling and hair standing or sitting up ("piloerection"). It may also occasionally engage other senses besides touch, such as this example from Harlan Ellison's "The Time of the Eye": "My fist went to my mouth, and the sound of a small animal being crushed underfoot came from me" (243). For the most part, the affect is located in the skin or hair. In Manly Wade Wellman's "Up Under the Roof," the narrator adapts Dickens' "frozen finger" thus: "On my back would sprout and fan and winnow litde

${ }^{169}$ T. H. White's "The Troll" is another such for a matter-of-factual approach that, like Kipling's narrator, solicits identification without trying to suspend disbelief:

I suppose the best way to tell the story is simply to narrate it, without an effort to carry belief. The thing did not require belief. It was not a feeling of horror in one's bones, or a misty outline ... It was eminently solid, about eight feet high, and dressed in brighdy ornamented skins. It had a blue face, with yellow eyes, and on its head there was a woolly sort of nightcap with a red bobble on top \{Black Water'209). 
involuntary wings of chill, that made my spine shrink and quiver as though ice came and mingled with the marrow" \{Masters of Darkness II3). Such a bodily affect is experienced and described across cultures. The Uruguayan writer Horacio Quiroga's "The Feather Pillow" contains the following description as the monstrous bloodsucking parasite inside the pillow that has drained the life of a young woman away is eventually discovered:

The servant raised the pillow, but immediately dropped it and stood staring at it, livid and trembling. Without knowing why, Jordan felt the hair rise on the back of his neck. "What is it?' he murmured in a hoarse voice. 'It's very heavy,' the servant whispered, still trembling. (Black Water819J

Again, note the intersection of Identification with Suddenness as an effect of pacing in both the Quiroga story above and in the passages below from Walter de la Mare's story "Seaton's Aunt" below:

He was looking almost nonchalantly at the ceiling at the moment, when I saw his face change, saw his eyes suddenly drop like shot birds and fix themselves on the cranny of the door he had left just ajar. Even from where I sat, I could see his cheek change colour; it was greenish. He crouched without stirring, like an animal. And I, scarcely daring to breathe, sat with creeping skin, sourly watching him. (Hartwell The Dark Descent 830)

This fear is transmitted to the narrator who has been observing, somewhat cynically, Seaton's fear and thus leaps to the reader: "And suddenly, I can hardly explain it now, a kind of cold and deadly terror swept over me" (832). The identification affect resists explanations, sweeping the reader along. It is a prelude to what most critics focus on - the revelation of or confrontation with the horrible thing — but it is vital to the dramatization of that revelation. 


\section{The Glimpse}

The glimpse is an essential technique of "quiet horror" in literature, perhaps akin in cinematic terms, to peeking through the fingers or the camera registering a shape moving too quickly or too far off to recognize. It is an affect far more achievable in literature, although Charles L. Grant mentions the "black-and-white sensibility" of some horror films that use chiaroscuro and other techniques of light and shadow to create suggestion rather than the show (Cut! 120). Horror films that remain exclusively vested in the glimpse are celebrated, but rare. No matter how many shadows, subliminals and half-seen images, as King says, quoting William F. Nolan, the horror film must eventually show the audience something, thereby allowing the tension to dissipate in a scream and a confirmation: Nothing is as frightening as what's behind the closed door, Nolan said. You approach the door in the old, deserted house, and you hear something scratching at it. The audience holds its breath along with the protagonist as she/he (more often she) approaches that door. The protagonist throws it open, and there is a ten-foot-tall bug. The audience screams, but this particular scream has an oddly relieved sound to it. "A bug ten feet tall is pretty horrible," the audience thinks, "but I can deal with a ten-foot-tall bug. I was afraid it might be a hundred feet tall." (114)

The affect of the glimpse, on the other hand, is to create a perennial confusion akin to Todorov's hesitation as we struggle to make sense of what we have seen. The famous exception, of course, is Robert Wise's The Haunting (1963). Nancy Holder describes the creepiness of The Haunting. "It follows you home . . . but it never quite catches you" \{Cut! 
133). Holder reminds us that the filmic sensibility of the "dark patch" originated with Val Lewton: "[fjrom Lewton, Wise learned to create fear, stretch it out, heighten it again, and build upon it until it's almost unbearable" (133). The Glimpse in literature produces such tension, foregrounded in language by unsettling descriptions of what a thing is not, halfhidden, hinted at, only described in equivalencies and suggestion. The tension between "seeing" and "not-seeing" that Giles and Pinedo hold up as constituting the pleasurable experience of horror belongs in this category. In reading, however, the "not-seeing" becomes part of the narration of the tale.

Some tales are told entirely as a glimpse. In Oliver Onions's "The Beckoning Fair One," the insubstantial thing that haunts the protagonist and ultimately murders his friend is never revealed. In this way, the story is comparable to The Haunting. Kathe Koja's "At Eventide" (122) asks the reader to imagine an artist's experience at the hands of a serial killer. After the narrator narrowly escapes this ordeal, which is never described, she crafts "Rorschach boxes" out of the scraps and fragments of others' lives, like the machine in William Gibson's Count Zero (1986). ${ }^{170}$ More often, however, the Glimpse operates as an affect of the impossibility of comprehending a vision of horror, which links it to the next category, the Unspeakable. It is the simile to the Unspeakable's metaphor. For example, Robert Louis Stevenson describes not the imp in his tale "The Bottle Imp," but its effect upon the two who insist upon seeing it: ". . . the imp looked out of the bottle, and in again,

${ }^{170}$ See Mark Seltzer's Serial Killers (1998), which makes important connections between machines and bodies, technology and the obsessive compiling of fragments which characterizes his "account" of serial killers. Koja's story fits his interpretation of the "wound culture." 
swift as a lizard; and there sat Keawe and Lopaka turned to stone" (68). In "The Red Lodge," after the narrator has vainly battled his initial incredulity and fear, something begins to show itself through a door, the knob of which begins to turn: "And then it began slowly to open, and something which was horridly unlike anything I had seen before began passing through it" (23).

In "The Facts in the Case of M. Valdemar," Poe's narrator devotes some time to describing what Valdemar's living-dead voice is not in order to convey the hideousness of what it is. This effect of negative equivalency, as also seen above in "The Red Lodge," creates uncertainty on the part of the reader. Miall and Kuiken's comforting "refamiliarization" is not allowed here. The slowing-down, in their terms, forces the reader to consider what Barthes calls the "encroachment" of both states, living and dead, and ruptures the boundary between the text and the reader as the reader struggles to make sense of the negative equivalencies that are being so rapidly suggested. This is the affect that Brecht's theatrical Verfremdungseffekt sought to create, the awareness of fictionality that, refusing to comfort and pacify, would engender political awareness on the part of the audience.

The thing that is haunting the house in Robert E. Howard's pulp classic "Pigeons From Hell" is likewise described in a string of negative equivalencies: "It looked like a woman, but no human woman ever walked with that skulking gait, and no human woman ever had that face of horror, that leering yellow blur of lunacy . . ." (48). The narrator stutters and struggles with the impossibility of description. In J.B. Priestly's "The Grey Ones," the narrator remarks, "[fjhey looked - this is the nearest I can get to it - like big semitransparent 
toads" (814). Harlan Ellison's monster in "Lonelyache" is given a description which the narrator then places sous rature, fiercely rejecting possibilities:

Hunkered down in the far corner of the room, near the linen closet, the huge soft-brown furry thing that had come to watch him sat silently, paws folded across its massive chest. Like some great Kodiak bear, yet totally unlike it in shape, the truncated triangle of its bloated form could not be avoided — by glance or thought. The wild, mad golden discs of its eyes never turned, never flickered, while it watched him. (This description. Forget it. The creature was nothing like that. Not a thing like that at all.) (Alone Against Tomorrow 299)

Where equivalency is left to the imagination in this way, through negative descriptions and such hesitations — "this is the nearest I can get to it" —, the reader's anxiety, as Barthes points out, is heightened in striving for something definitive to which the glimpse can be tethered. The glimpse is not solely about interstitial transitions, however, but suggests a definitive thing, albeit difficult to see or describe. The hesitations, qualifications and nearequivalencies that mark the glimpse, thereby resembling Todorov's fantastic, resist comfortable decodings, suggesting instead the monstrous, frightening and, above all, anything but human:

There, pattering up and down the asphalt paths, was something white. I was too much alarmed to see clearly; and in the uncertain light of the stars the thing took all manner of curious shapes. Now it was a great dog, now an enormous white bat, now a mass of quickly travelling cloud. (Forster "The Story of a Panic" 932) 
The hesitant trying-on of descriptions in the examples both above and below creates uneasiness in the reader who is struggling to follow the narrative, but it also gives a sense of presence and speed that is uncanny:

It had been only along the side of his glance that the face, if face it were, had appeared, a kind of sudden white scrawl against the blur, as if it were a mask hung by the window rather than any living person, or as if the glass of the window itself had looked sideways at him. (Charles Williams, "Et in Sempiternum Pereant" 623)

In Fitz-James O'Brien's "What Was It?," the narrator eventually takes a plaster mould of the invisible thing that attacks him in order to see it, but even the final sight of the thing can only be expressed in negatives and equivalencies:

Its face surpassed in hideousness anything I had ever seen. Gustave Dore, or Callot, or Tony Johannot, never conceived anything so horrible. There is a face in one of the latter's illustrations to Un voyage oil il vousplaira which somewhat approaches the countenance of this creature, but does not equal it. It was the physiognomy of what I fancy a ghoul might be. It looked as if it was capable of feeding on human flesh. ${ }^{171}(872)$

${ }^{171}$ Echoes of this earlier story can be discerned in H. P. Lovecraft's "Pickman's Model." An unnamed narrator recounts the tale of Pickman, an artist of the macabre, who is shunned for his talent for frightening art: "Boston never had a greater painter than Richard Upton Pickman. I said it at first and I say it still, and I never swerved an inch, either, when he shewed that 'Ghoul Feeding'. That, you remember, was when Minot cut him . . . only a real artist knows the actual anatomy of the terrible or the physiology of fear - the exact sort of lines and proportions that connect up with latent instincts or hereditary memories of fright, and the proper colour contrasts and lighting effects to stir the dormant sense of strangeness" (The Dunwich Horror and Others 13). 
Brian Lumley's "The Thin People" illustrates another glimpse affect which evokes the uncanniness of everyday artifacts, such as the prosaic lamppost:

Across the road, three lampposts - where there should only be two! The one on the left was okay, and the one to the far right. But the one in the middle? I never had seen that one before. I blinked bleary eyes, gasped, blinked again. Only two lampposts! (270)

Another example of such "urban horror" comes from Fritz Leiber's classic "Smoke Ghost": "There was something unwholesome in the posture of the thing that stuck in his mind - a bulge in the sacking that suggested a misshaped head peering around the ventilator" (632). The doubting perception of the reader, expressed in the hesitant clauses, draws out the affect of the glimpse which, in Leiber's tale, evokes the alienated industrial landscapes of the modern city, a place where the old gods don't fit, so frightening new ones, as with Ellison's "Whimper of Whipped Dogs," must be created and worshipped. In Leiber's story, the glimpse is used to suggest the uncanniness of everyday urban life where all the teeming protrusions surrounding the city dweller are rife with menacing possibilities that are the more menacing for only being glimpsed as one hurries by. Steve Rasnic Tem and Melanie Tem write:

The most disturbing thing about the figures of horror fiction ... is a particular kind of vagueness in their form .... The faces of our real terrors shift and warp the closer they come to us ... The face of horror freezes but briefly, and as quickly as we jot down its details, it is something else again.

("The Man on the Ceiling" 217) 
The concluding passages of William Hope Hodgson's "The Voice in die Night" present anodier example of the glimpse which can no longer recognize anything human. The thing that comes out of the night has been telling its tale to the becalmed sailors, a tale of being stranded with his fiancee on a strange island with sinister lichens growing everywhere that gradually take over the couple's bodies. The tale up until this moment has been wholly pitiful, evoking compassion for the plight of the stranded pair, and all the reader's and the listening sailors' sympathies are directed toward the voice in the night. When it plies its oars away, however, the narrator glimpses the monster that the thing has become: "Indistinctly I saw something nodding between the oars. I thought of a sponge - a great, gray, nodding sponge"172 (138).

The use of equivalencies in the glimpse can create a powerful effect that is often more unsettling than die goriest splatterpunk passage or torture porn film sequence. Here is a fine example of the glimpse-as-metaphor in a description of a corpse in Margo Lanagan's "A Pig's Whisper":

Even as she turned away from the clearing, she saw the heap beyond him, beyond the dead fire. She crawled away fast, but she had seen it. The flies had lifted from it and she saw all the colors. It was a pile of burst mattresses, black mattresses, with their innards forcing out through the skin, purple and yellow and green. (327)

172 Stephen King poached this story for his "Gray Matter" (Night Shift). For this reason, his role in Creepshow as a somewhat simpleminded farmer who becomes infested by lichen that overruns his place, in the aftermath of a meteor that lands in his field, is amusingly apt. 
Avram Davidson's "The Tenant" creates a similar, extremely powerful effect:

At first glance he thought he saw a child ... - a child like one of those in the hideous photographs of famines: all bloated huge belly and sticklike arms and legs — but in just an instant he saw it was no child ... How many joints there might be, he could not afterwards remember, but more than on his own fingers; and he had been put in mind, by those fingers, of the bandy, loathsome legs of some huge bird-eating spider. (32)

Algernon Blackwood's description of the "otter" in "The Willows" similarly adopts a frighteningly roundabout way of describing an unknown creature as a

black tiling, turning over and over in the foaming waves, swept rapidly past. It kept disappearing and coming up to the surface again. It was about twenty feet from the shore, and just as it was opposite to where we stood it lurched around and looked at us. We saw its eyes reflecting the sunset, and gleaming an odd yellow as the body turned over. (915)

In the Blackwood passage, the glimpse is countered by the returned gaze of the glimpsed thing, which signals its uncanniness through the "odd yellow" of its eyes and its corpse-like action of "the body turned over" (later the narrator observes the body of a drowned man, the sacrifice to whatever haunts the willows, doing the same thing). M. R. James, who uses the glimpse to devastating effect, employs it in this way, hinting and hinting, building up the horror's cumulative affect, firstly through repeated use of the glimpse, and then by bringing his grotesque creatures either gradually or suddenly into a fuller view. I have already mentioned James's skilful use of intertextuality to build horror in his tales. The intertexts of "The Ancient Mariner" and The Pilgrim's Progress that I mentioned previously 
also functions as a type of glimpse, describing a horror through an equivalency (the "frightful fiend" of Coleridge's verse and Bunyan's "foul fiend" both suggest and stand in for die unseen horrors that are pursuing the protagonists). There are numerous examples. From "Casting the Runes" (already discussed, but worth returning to as it is, in my opinion, one of the most frightening tales ever written): ${ }^{173}$ a character describes the evil Karswell as, like James himself with his readers, showing the village children a slide-show which depicts "a horrible hopping creature in white, which you saw first dodging about among the trees, and gradually it appeared more and more plainly" (130). The victim of Karswell's runes, Mr. Dunning, is accosted by somebody or something handing out leaflets, who thrusts one into his hand as he passes with an appendage that "seemed unnaturally rough and hot. He looked in passing at the giver, but the impression that he got was so unclear that, however much he tried to reckon it up subsequently, nothing would come" (135). ${ }^{174}$

In "Oh Whistle and I'll Come to You, My Lad," James's narrator sees "a little flicker of something light-coloured moving to and fro widi great swiftness and irregularity. Rapidly growing larger, it, too, declared itself as a figure in pale, fluttering draperies, ill-defined. There was something about its motion which made Parker very unwilling to see it at close quarters" (73). Note how effectively this last sentence engages the glimpse affect. James's frequent relegation of the glimpse affect to the very last sentence of a paragraph increases

${ }^{173}$ M. R. James's "Casting the Runes" was adapted for the screen as the classic Night of the Demon (1957), which generated a good deal of controversy over its decision to show the demon at the conclusion. It is also very cleverly pastiched in James Hyne's Publish and Perish: Three Tales of Tenure and Terror (1997), a must-read for scholar-fans.

${ }^{174}$ Lovecraft insists that the typical horror in James is "touchedbefore it is seen" ("Supernatural Horror in Literature" 433). 
the sense of hesitation and slowing-down, as is demonstrated by this passage from another James story, "The Ash-Tree":

The Vicar looked and saw the moving creature, but he could make nothing of its colour in the moonlight. The sharp outline, however, seen for an instant, was imprinted on his brain, and he could have sworn, he said, though it sounded foolish, that, squirrel or not, it had more than four legs. (32) Another passage from the same story again shows how much can be done to create a horrible and even gory or sickening affect with suggestive equivalencies: ${ }^{175}$

There is very little light about the bedstead, but there is a strange movement there; it seems as if Sir Richard were moving his head rapidly to and fro with only the slightest possible sound. And now you would guess, so deceptive is the half-darkness, that he had several heads, round and brownish which move back and forward, even as low as his chest. It is a horrible illusion. Is it nothing more? (39)

\section{The Unspeakable}

Closely related to the glimpse is the affective element of the Unspeakable. The unspeakable, or the impossibility of speaking the unknowable, is another literary affect which does not really translate well into film although it more closely matches Lewton's ideal of the "dark patch" in a horror film than the glimpse. The hesitation of the latter destabilizes the

${ }^{175}$ In his Jamesian pastiche "The Guide," Ramsey Campbell sums up the essence of James's horror in the final lines as his protagonist struggles against "what might be done to him to make him look" (Year's Best Fantasy and Horror XVIII, 323). 
reader's certainty, as we have already seen, whereas the Unspeakable breaks down certainty altogether, filling it with terrifying possibilities. It is, as I said above, the obstinately blank metaphor to the glimpse's negative similes. The telling of the tale founders completely upon the impossibility of describing something outside the narrator's experience, leaving a "dark patch" which the reader may attempt to fill in with his or her own ideas of horror. ${ }^{176}$ This dark patch is concretely literalized in the Joyce Carol Oates story that renders the unspeakable in a visual form, a black rectangle that is the locus of the terror ("-" 9). Interestingly, Gerald Porter has connected the lacunae or gap with oral narrative in folk music, arguing that

$[u]$ nlike the 'rounded' characters of realist novels, the personages of narrative song are incomplete and partially realised, standing more easily alongside the characters of a murder mystery, who represent a prismatic breaking up of the circumstances of the crime, or the fragmentary figures of fantasy. (9)

Filling in the dark patch for a film or television audience is seldom as effective. In Jerome Bixby's paean to authoritative parenting, "It's A Good Life," the monstrous telepathic child Anthony who has cut an entire small town adrift from its moorings in reality punishes one dissident with an unspeakable transformation:

${ }^{176} 1$ find that the use of sound in film is a better indicator of the unspeakable. For example, in the film Open Water (2003), based on the true story of a holidaying couple accidentally left behind in the ocean during a scuba diving excursion, one of the characters undergoes some horrible final moments during a shark attack. The screen goes completely black which in a movie theatre is a terrifying effect, and sounds occupy the viewer instead: splashing, thrashing, gasps and groans of the character who is being eaten alive by the sharks, while the other character screams and weeps. In Henry: Portrait of a Serial Killer, the acoustic flashbacks to Henry's murders, broadcast over the still-life tableaux of the aftermath, function effectively as part-glimpse, part-unspeakable device for the viewer to complete. 
"Bad man," Anthony said, and thought Dan Hollis into something like nothing anyone would have believed possible, and then he thought the thing into a grave, deep deep in the cornfield. (28)

In the 1961 adaptation of this short story for the series The Twilight Zone, the transformation of the dissident Dan Hollis (Don Keefer) remains chilling. He becomes a monstrous Jack-inthe-box, whose nodding shadow on the wall is defdy cut with close-ups of Hollis's sad, frozen face nodding back and forth, but this lacks the power of the "something like nothing anyone would have believed possible" of the story. ${ }^{177}$ The unspeakable is often used to convey the sublime affect of the supernatural, for example, through the use of sound as with this excerpt from William Hope Hodgson's "The Whistling Room." Note that the narrator insists that the sound is impossible to describe, but attempts anyway to describe it:

As the door flew open the sound beat out at us with an effect impossible to describe to one who has not heard it - with a certain horrible, personal note in it, as if in the darkness you could picture the room rocking and creaking in a mad vile glee to its own filthy piping and whistling and nooning, and yet all the time aware of you in particular. $(157)^{178}$

The unspeakable has been theorized, but more either as a thematic signifier of the repressed than as a narrative affect. (Diane Jonte-Pace, Speaking the Unspeakable: Religion, Misogyny, and the Uncanny Mother in Freud's Cultural Texts (2001)) or as a linguistic category of narration by Ann Banfield in Unspeakable Sentences: narration and representation in the language of fiction (1982). Nowhere is horror's "unspeakable" adequately covered by such theories.

${ }^{178}$ Dennis Wheadey seems to have borrowed Hodgson's occult terms for his own very popular occult tales. 
Carroll mentions this affect, which he calls the "indescribability" of the monster (20), but a description of sorts does occur, even though the narrator insists it is impossible. In Priestly's "The Grey Ones," for example, the unspeakability of the frightening things is evoked by sight rather than sound which, again, the narrator attempts to describe: "Whoever or whatever they'd been waiting for was down there on the platform. I knew that definitely. But I couldn't see him or it. All I could make out was a sort of thickening and whirling of the air down there" (813). If it does not summon the supernatural outright, the unspeakable can convey a sense of the appalling or monstrous, as with Seaton's strange aunt in the Walter de la Mare story: "Her face was set in a deep reverie beneath the shadow of a big loose sun-hat. It was deeply lined, crooked, and in a way I can't describe, fixedly vacant and strange" (833).

The unspeakable serves not only as an affect but as another means of stretching out and heightening tension by hinting that something is not only difficult but actively painful and unpleasant to describe. In M. R. James's "The Treasure of Abbot Thomas" for example, the narrative does not just "lean forward" as Moretti puts it, but strains forward to catch sight of the culminating horror - the guardian of the Abbot's treasure: "But, if you don't mind, I'll say no more about that until — until it becomes necessary" (26). In "Casting the Runes," the unspeakable is conveyed as second-hand information that is, even filtered, too horrible to know: "Also, after a judicious interval, Harrington repeated to Dunning something of what he had heard his brother say in his sleep: but it was not long before Dunning stopped him" (145). Identification here is simultaneously launched and constrained by the idea that narration is as terrifying as reading, another connection with the orality of the tale. The sight of a mythical monster in one of Manly Wade Wellman's "Silver John" stories is similarly agonizing for the teller of the tale to recall: 
The Behinder flung itself on his shoulders. Then I knew why nobody's supposed to see one. I wish I hadn't. To this day I can see it, plain as a fence at noon, and for ever I'll be able to see it. But telling about it is another matter. ("The Desrick on Yandro" 170)

The unspeakable can also serve and amplify the effect of identification: Dickens' narrator in "The Signalman" who has previously described the "frozen finger" down his spine, states "I cannot describe the thrill that seized upon me . . ., [tjhe nameless horror that oppressed me" (217). For another example of the unspeakable mixed with the identification affect, we return to the awful voice in Poe's "The Facts in the Case of M. Valdemar," "... a voice — such as it would be madness in me to attempt describing" (103). Again, the narrator insists on unspeakability, but then attempts to describe the voice nonetheless, while continuing to insist upon the unspeakability of his "own impressions [which] I would not pretend to render intelligible to the reader" (103).

If M. R. James is the master of the glimpse, the poet laureate of the unspeakable is H. P. Lovecraft. This effect is such a key component of Lovecraft's hyperbolic style that it is instantly recognizable in Lovecraft's many disciples and imitators, including Robert Bloch in his short story "The Mannikin": "Do not ask me to describe it to you in detail. I can't. There are some times when the senses are mercifully numbed, because complete acuteness would be fatal" (68). Undoubtedly one of the reasons for Lovecraft's cult success and wide imitation is the enticement to fill in his mythical lacunae of the sublimely unspeakable Elder Gods with Mythos tales of one's own that retain the sublimity of Lovecraft's frenzied descriptions. As Graham Harman observes: "[tjhe near-incoherence of [Lovecraft's] descriptions undercuts any attempt to render them in visual form. The very point of the 
descriptions is that they fail, hinting only obliquely at some unspeakable substratum of reality" (339). Harman adds:

There is nothing inherently compelling about a humanoid dragon with an octopus for a head; any teenager could draw such a thing while scaring noone. The horror comes instead from the declared insufficiency of the description, combined with a literary world in which this monster is a genuine player rather than a mere image. (357)

Harman finds great similarities between the "meandering" style of Lovecraft and Poe, about which, I agree, "too little has been said" (359), ${ }^{179}$ noting the "deliberate" "circumlocution" in a passage from Poe which "creates a gap between object and profile that is concealed in everyday experience" (360). This gap points to the relationship between the unspeakable and the sublime - an event so overpowering, so far beyond ordinary experience, that it literally cannot be communicated. Unlike the Romantic or Gothic sublime, however, horror's sublime unspeakable is demonstrably malignant and awful, rather than majestic. The Lovecraft influence is unmistakable in the following passage (compare this to the sight of great Cthulhu in "The Call of Cthulhu"):

Then something rose up in the water. It towered over man and child, and as the ocean fell away from it, it revealed smooth surfaces that glittered and writhed. The world was bathed with light and George saw it plain. And yet, he could not later recall much detail. It was as though his mind refused entry

${ }^{179} \mathrm{~S}$. T. Joshi has exhaustively covered Lovecraft's work - for that reason, I will not spend too much time on Lovecraft here. 
to this monstrous thing, substituting other images — maggots winking from the eye flesh of some dead animal, flesh growing on a ruined structure of dead metal — and while those images in memory were hideous enough and would not let him sleep, another part of his mind shrank from the knowledge that he had confronted something more hideous and ancient than his reason could acknowledge. ("The Ocean and All Its Devices" 116)

\section{The Appalling}

So far, we have been circumnavigating the actual sight of something horrifying, conveyed, as my examples show, in a roundabout fashion through the glimpse, a faltering description or a breakdown of description altogether. All of the above affects roughly correspond to Stephen King's typology of terror, which involves scaring the reader without actually showing something "physically wrong" (Danse Macabre 35). But what happens when we do actually "see something" in the text? Horror film critics such as Williams and Pinedo have circulated the idea of "body horror" which is used with no great finesse to indicate bodies either in extremity, uncannily altered or gorily dismembered (splattered). Considerable attention has also been paid to the idea of the monstrous while monsters, lumped together as a single entity, have been theorized by Wood, Carroll and Halberstam as central to horror.

In literary horror, an important affect is missing from such "accounts," an affect that lies somewhere between body horror and the monstrous, which I will christen "the appalling," using this term to indicate certain descriptions of abject bodies in extremity, such as a corpse or corpse-like, possessed or dying body, that are not monstrous, that are still recognizably human, but that, in their extremity, hold the power to shock and horrify the 
reader. The word "appalling" is derived from die Latin pallescere, meaning "to grow pale," and I am using diis word to connote both the changes wrought upon the body in extremis and what the sight of such a body might do to the viewer or reader. Consider the narrator of Ray Russell's "Sardonicus" recalling his first sight of Mr. Sardonicus:

... the gendeman before me was the victim of some terrible affliction that had caused his lips to be pulled perpetually apart from each other, baring his teeth in a continuous ghasdy smile .... A pallor approaching phosphorescence completed his astonishing appearance. (42)

Here is another example of the corpse-like body in a description from Ben Pastor's "Achilles' Grave": "He seemed as one drowned and left in the water to float supine under the surface, there and not there, blindly groping. The eyes in his face, dull, jellylike, were horribly open and as spoiled drops of milk, pupils curdled and void" (YBFH 14 85). Poe's M. Valdemar is not a monster to begin with, but a dying man: " [h]is face wore a leaden hue; the eyes were utterly lustreless; and the emaciation was so extreme that the skin had been broken through by the cheekbones" (100). Shades of M. Valdemar can be found in "Et in Sempiternum Pereant":

It was emaciated beyond imagination; it was astonishing, at the appalling degree of hunger revealed, that the man could walk or move at all, or even stand as he was now doing, and turn that dreadful skull from side to side . . . the deep burning eyes in the turning face of bone .... (625)

and in Karl Edward Wagner's "Sticks":

It was a lich's face — dessicated flesh tight over its skull. Filthy strands of hair were matted over its scalp, tattered lips were drawn away from broken 
yellowed teeth, and, sunken in their sockets, eyes that should be dead were bright with hideous life. (213)

The appalling displays Julia Kristeva's abject, die rejected corpse, filled with putrid wastes and decaying matter. Using such a category, however, refines Kristeva's "powers of horror" to cover specific texts and specific creatures, such as the "lich" in the Wagner tale above. Zombies, I would argue, are far more appalling than they are monstrously interstitial, in Carroll's sense. There is a close relationship between the effect of the appalling and the effect of the sickening. For example, Charles Johnson's story "Exchange Value" about a couple of enterprising urban youths who break into the apartment of an eccentric old lady only to discover her decomposing body, oscillates between these two affective elements, the "gross-out" description of the decay and the appallingly piteous sight of the abject corpse:

Miss Bailey be in her long-sleeved flannel nightgown, bloated, like she'd been blown up by a bicycle pump, her old face caved in with rot, fly-blown, her fingers big and colored like spoiled bananas. Her wristwatch be ticking softly beside a half-eaten hamburger. Above the bed, her wall had roaches squashed in little swirls of bloodstain. Maggots clustered in her eyes, her ears, and one fist-sized rat hissed inside her flesh. (401)

Both the appalling and the sickening can be conveyed by a horrific metonymy, indicating the body's movement or transformation, body parts transformed or contorted, and abnormal or unnatural motions. This effect is particularly frightening combined with suddenness, as this passage from M.R. James's "A View from a Hill" shows:

Something stirred in the blackness, and then, to his intense horror, a hand emerged - a clean right hand in a neat cuff and coat-sleeve, just in the 
attitude of a hand that means to shake yours. He wondered whether it would be rude to let it alone. But as he looked at it, it began to grow hairy and dirty and thin, and also to change its pose and stretch out as if to take hold of his leg. (296-7)

Another example of appalling motion is Stephen Graham Jones's story "Raphael" about a twelve-year-old girl who is thrown into the lake, revealing that she is something not human, "her hair a black shroud around her": "She looked across the water at us, her eyes the only thing human on her anymore, pleading with me, it seemed, and then whipped around, started running over the surface on all fours" (428). This scene reverses the appalling scene in VJngu (1998), where the drowned girl Sadako with her veil of dark hair comes crawling out of her well and lurches inexorably, with grotesquely jerky and uneven motions towards the cowering protagonist and the audience. The affect created by unnatural motion and transformation in these examples is powerful, recalling the motion of animated figures, which Freud, reading the E. T. A. Hoffmann story, marked as one indicator of the uncanny in his famous essay in 1919 (226). Uncanny motion is therefore another instance of overlap between affective elements. Poe's M. Valdemar furnishes an important example of the appalling transformation:

While I spoke, there came a marked change over the countenance of the sleep-waker. The eyes rolled themselves slowly open, the pupils disappearing upwardly; the skin generally assumed a cadaverous hue, resembling not so much parchment as white paper; and the circular hectic spots which, hitherto, had been strongly defined in the centre of each cheek, went out [Poe's emphasis] at once. I use this expression because the suddenness of 
their departure put me in mind of nothing so much as the extinguishment of a candle by a puff of the breath. The upper lip, at the same time, writhed itself away from the teedi, which it had previously covered completely; while the lower jaw fell with an audible jerk, leaving the mouth widely extended, and disclosing in full view the swollen and blackened tongue. I presume that no members of the party then present had been unaccustomed to death-bed horrors; but so hideous beyond conception was die appearance of M. Valdemar at this moment, that there was a general shrinking back from the region of the bed. (295)

In the Charles Williams story quoted above, the appalling lich eventually moves: The bones mat were his legs and feet jerked up and down. The head turned from side to side. He ran circularly, round and again round, crossing and recrossing, looking up, down, around, and at last, right in the centre of the room, coming to a halt, where, as if some terrible pain of starvation gripped him, he bent and twisted downward until he squatted grotesquely on the floor. ("Et in Sempiternum Pereant" 626)

Reggie Oliver's frightening story of possession, "Among the Tombs" likewise presents this effect of a contorted body going through horribly unnatural movements: Then I saw that it was not an animal of any kind but a man on all fours, his legs slighdy bent, his long arms serving as forelegs, so that his whole body was arched and leaning forward. I thought the man would soon stand up and assume a natural posture but he did not. He bounded forward in an ungainly way, but with surprising speed and agility, using all four of his limbs. 
Moreover the man was naked. The limbs were hairy and scored with red marks and blotches. Something attracted its attention to me and it turned its head in my direction. The face was that of Harry Mason, but the eyes did not have a human expression in them. There was an instant of feral recognition before the creature started to bound away from me at extraordinary speed. $(57)^{180}$

In Carroll's terms, the thing described above would be monstrous because Mason has become a bestial figure, like a werewolf. However, this is not accurate. Mason has retained his human form, but it has been grotesquely altered, become "ungainly" but can move with frightening suddenness and "extraordinary speed." The narrator variously describes the thing as a "man" and an "it," creating unease and a sense of ongoing transformation as the narrator looks on the thing. The eyes are without "human expression" but it is not explained what expression is in them, leaving the reader to imagine what is inhabiting the body. Later, Mason's corpse is discovered and again the effect is not monstrous but appalling: The bestial connotation of hairiness is challenged by the startling appearance of the eyes and the grinning rictus of the corpse.

It was the body of a naked man, horribly emaciated and scarred, the limbs and chest covered in coarse dark hairs, sparse but unnaturally long. The open

${ }^{180}$ This transformation can be compared with the possession of Regan McNeil (Linda Blair) in The Exorcist. The affect of Regan's possession is not adequately described by the terms "body horror" and "the monstrous." In fact, one of Regan's transformations closely mirrors the passage from "M. Valdemar" above. The added scene known as "the spider walk" in the later cut of the film, The Version You've Never Seen (2000), is another dramatic instance of the appalling as I am describing it here. The Exorcism of Emily Rose (2005) depicts similar appalling contortions. 
eyes were completely black without whites or irises, and the half open mouth was prognathous, insensately grinning. (57)

Similarly, Robert Louis Stevenson's "Thrawn Janet" depicts the appalling sight of a possessed corpse, enriched by the dialogical voice of an unnamed parishioner:

For there was Janet comin' doun the clachan,--her or her likeness, nane could tell,- - wi $^{1}$ her neck thrawn, and her heid on ae side, like a body that has been hangit, and a girn on her face like an unstreakit corp. By-an'-by they got used wi' it, and even speered at her to ken what was wrang; but frae that day forth she couldnae speak like a Christian woman, but slavered and played click wi' her teeth like a pair o' shears; and frae that day forth the name o' God cam' never on her lips. Whiles she wad try to say it, but it michtnae be. Them that kenned best said least; but they never gied that Thing the name o' Janet M'Clour; for the auld Janet, by their way o't, was in muckle hell that day. $(235)^{181}$

Finally, the appalling, which I have been distinguishing from the monstrous as a depiction of a recognizably human body in extremis, is employed to connote the presence of a monster, as Thrawn Janet indicates the presence of the devil, but with specific reference to transformed human features as an index of monstrosity. Again, in its catalogue of features, the appalling conveys a metonymic affect. Poe, for example, extensively describes M. Valdemar's features such as die circles on his cheeks, his tongue and his voice, which

i8i "Thrawn" $i_{\mathrm{s}}$ defined as "twisted, crooked, bent from the straight; mis-shapen, drawn awry, distorted" by Jess Nevins's Victoriana site at <http://www.geocities.com/ jessnevins/victu.html> Accessed July 2009. 
become finally monstrous in his extremity, which oscillates bewilderingly and rapidly between living and dead, creating the crowning horrific effect of the story:

There was an instant return of the hectic circles on the cheeks; the tongue quivered, or rather rolled violendy in the mouth (although the jaws and lips remained rigid as before); and at length the same hideous voice which I have already described, broke forth: "For God's sake! — quick! — quick! — put me to sleep - or, quick! - waken me! - quick! - I say to you that I am dead. ${ }^{1 "}(104)$

Consider also the description of the equally unpleasant Edward Bellingham in Conan Doyle's mummy tale "Lot No. 249," first seen as the narrator and his friend rescue him from a fainting fit. The narrator's friend exclaims "What a face it has on it!":

It was indeed a strange and most repellent face, for colour and outline were equally unnatural. It was white, not with the ordinary pallor of fear, but with an absolutely bloodless white, like the under side of a sole. He was very fat, but gave the impression of having at some time been considerably fatter, for his skin hung loosely in creases and folds, and was shot with a meshwork of wrinkles. Short, stubby brown hair brisded up from his scalp, with a pair of thick, wrinkled ears protruding at the sides. His light-grey eyes were still open, the pupils dilated and the balls projecting in a fixed and horrid stare. (Best Horror Stories 93)

Carroll's "categorically interstitial" rather than the appalling, is invoked when comparisons with animals - "a sole" in this instance — are made and a "conflation of species" is evoked (32). The being in Leslie Alan Horvitz's "The Ragman" possesses "[a] face of such transcendent horror that it was almost possible to discover a beauty in it: the beauty of 
tarantulas, the beauty of slugs, the beauty of sulphuric creatures lifted from great depths . . . (103). Carroll's "fantastic biologies" theory of monsters is useful as one horrific affect among many, rather than as a central feature of a horror genre. ${ }^{182}$ However, I argue that the appalling still needs to be upheld as a category that captures a more nuanced affect of horror than the category-violating, fissioned or fused monster.

It is sometimes difficult to distinguish between the monstrous, the uncanny and the appalling as I have outlined them as all these elements can mingle in one passage or revelation. In E. F. Benson's "Mrs. Amworth," for example, the monstrosity of the vampiric titular character is signaled by her literally appalling (growing pale) facial transformation: "I have never seen so horrible a change pass over a human face as that which now blanched hers to the colour of a gray mist" (78). ${ }^{183}$ Jane Yolen's more pitiable vampirized mother in "Mama Gone," on the other hand, presents a less monstrous and more appalling sight to her daughter, rendered even more appalling by the grotesque juxtaposition with delicate and beautiful connotations of hummingbirds and nectar flowers, rather than tarantulas and "sulphuric creatures": "She turned toward me as a hummingbird toward a flower, and she raised her face up and it was gray and bony. Her mouth peeled back from her teeth and I

${ }^{182}$ Carroll describes the fusion monster as "the compounding of ordinary disjoint or conflicting categories in an integral, spatio-temporally unified individual" (44). Therefore, he classifies possession as fusion. Fission, on the other hand, occurs when "the contradictory elements are, so to speak, distributed over different, though metaphysically related, identities" (46). Werewolves, for Carroll, are fission figures.

${ }^{183}$ Benson's ghost in "The House with the Brick-Kiln" is also appalling rather than merely monstrous, because of the description of bodily state that indicates that there is something wrong: "[a]ll around the edge of his clothes, at his collar and at his wrists, there were little flames playing, little white licking flames." 
saw that they were pointed and her tongue was barbed" (203). Sympathy for the familiar rendered monstrous, as in this case, where the daughter tenderly banishes her vampire mother, tends to create an appalling effect, as in this example from Clive Barker's "Coming to Grief:

She stood by the dizzying edge, and the face of her dread swam up from the bottomless night to look at her. It was her mother's face. Horribly bloated to two or three times its true size, her jaundiced eyelids flickering to reveal whites without irises, as though she were hanging in the last moments between life and death. (125)

The affect of the appalling reserves the possibility of the reader's ambivalence, then, towards the horrific sight. In "Disturb Not My Slumbering Fair" by Chelsea Quinn Yarbro, we find ourselves disturbingly rooting for the ghoulish Deirdre in her attempts to find a safe place to hole up and indulge her appetite for human flesh. Rather than assigning all such transformations and horrific sights simply to a broad category of the monstrous, I argue, it is important to consider affects such as these. I propose the appalling as a state which borders on the monstrous but which is yet or was once recognizably human, abject and tormented. ${ }^{184}$

${ }^{184}$ Deleuze and Guattari's theory of "faciality" supports my idea of the appalling evoked by transformed facial features and bodies: "A broad face with white cheeks, a chalk face with eyes cut in for a black hole. Clown head, white clown, moon-white mime, angel of death, Holy Shroud." To this appalling pallor, however, they add a tinge of the monstrous, "there is . .. something absolutely inhuman about the face" as a border which polices and proclaims transgressions (Year Zero: Faciality, 1987, p. 170. See Anna Powell on Deleuze and the horror film for a more elaborate reading. Patricia McCormack interprets faciality as choosing "from binaries, which indicate gender, race, [and] converge in order to create the unity of a passable or un-passable face" ("Pleasure, Perversion and Death: Three Lines of Flight for the Viewing Body"

<http://www.cinestatic.com/transmat/MacCormack/PPDcontents.htm>. McCormack 


\section{The Monstrous}

The monstrous has long been the privileged signifier of horror, theorized conclusively by Noel Carroll as mat which is impure and categorically interstitial, and which violates boundaries. This theorizing, as well as Carroll's fission or fusion-based "recipe" for monster-making (see my footnote earlier) may in fact be so well-known as to determine all contemporary understanding of monsters both in fiction and in film. Antonia S. Byatt's story "A Lamia in the Cevennes," for example, explicitly refers to Mary Douglas's work, which Carroll draws from, on categories of impurity and "mixed things" (YBFH 9 376). Matt Hills suggests that the monster produces an affect of "ontological shock" as we struggle to fit it into our known categories of normal/abnormal, human/animal, dead/living and so on (Pleasures of Horror AY). The frightening affect of the monstrous, frightening, Carroll insists, because of its categorical impurity and because of the threat such an impurity represents, can be conveyed by the introduction of a discourse of animal-like traits as we have seen: monstrosity, however, more forcefully and directly than the appalling, removes the link with the human. Joshi observes, for example, that the monstrously transformed Fleete, punished for his bestial colonial behaviour by being turned into a werewolf, becomes an "it" in the latter pages of the story (Mark of the Beast xii), while John Collier's "Evening Primrose" creepily hints at the monstrosity of the snobbish creatures who live in the department store:

compares the faciality of Deleuze and Guattari with the exteriority of Emmanuel Levinas: "[w]here Deleuze and Guattari see the face as representative of the inhuman machine of pure signification, Levinas sees in the face consideration of pure alterity and of God, and the face is therefore the prime site of ethics." 
They are very pleasant to me, though. They are pleased that a poet should have come among them. Yet I cannot like them entirely. My blood is a little chilled by the ease with which even the old ladies can clamber spider-like from balcony to balcony. (64)

The mummy in Conan Doyle's "Lot No. 249" is another example of the appalling (the corpse) made monstrous through animalistic comparisons and menacing impurity:

The features, though horribly discoloured, were perfect, and two litde nutlike eyes still lurked in the depths of the black, hollow sockets. The blotched skin was drawn tighdy from bone to bone, and a tangled wrap of black, coarse hair fell over the ears. Two thin teeth, like those of a rat, overlay the shriveled lower lip. In its crouching position, with bent joints and craned head, there was a suggestion of energy about the horrid thing which made Smith's gorge rise. (96)

An important reason for the overarching significance of the monster in horror is that this effect appears to cross cultural boundaries. Monsters, hybrids and liminal creatures may be observed in the folklore and fiction of many different cultures. Here is another example of an appalling-monstrous affect in the nineteenth-century Spanish author Pedro Antonio de Alarcon's description of the horrible titular creature of "The Tall Woman":

a very tall, large woman, about sixty years of age, whose bold, malignant, and lashless eyes were fixed on me like two daggers, while her huge toothless mouth grinned at me horribly .... The first surprising thing about this woman, as I must call her, was her great height and the breadth of her bony shoulders; next the size and roundness of her enormous owl-like eyes, the 
size of her nose, and the hideous gap which served her as a mouth, made still more hideous by the malignant grin which would have disfigured the fairest mouth in existence, and finally, the strange coquetry of her dress; the brightcoloured handkerchief which was draped over her ugly forehead and fastened beneath the chin, and a very small fan which she held open in her hand, and which she flirted in an affection of modesty before her face and figure. Nothing could be more grotesque or ridiculous than the sight of that tiny fan in those enormous hands, like a scepter of weakness for a giantess so old, so bony, so hideous. The same effect was produced by the gay cotton handkerchief in contrast to the huge deformed nose, and the coarse face which made me ask myself for a moment if this were not a man in woman's dress. But no. The expression was that of a wicked woman, of a witch, of a sorceress, of one of the Fates, of a Fury. (225)

Note the procession of gendered norm border violations here: the "great height," "bony shoulders" and "enormous hands" of what appears to be "a giantess"; "a man in woman's dress." The ultimate fused monster, according to theories of monstrosity such as Carroll's, is the Frankenstein monster, dead-alive, fashioned from corpses, or the hapless victim of the scientific experiment gone horribly wrong in Langelaan's "The Fly":

Until I am totally extinct, nothing can, nothing will ever make me forget that dreadful white hairy head with its low flat skull and its two pointed ears. Pink and moist, the nose was also that of a cat, a huge cat. But the eyes! Or rather, where the eyes should have been were two brown bumps the size of saucers. Instead of a mouth, animal or human, was a long hairy vertical slit from 
which hung a black quivering trunk that widened at the end, trumpet-like, and from which saliva kept dripping. (252)

It is clear how such creatures differ from the pitiably human yet appalling corpse or dying Valdemar. Rather than being unnaturally stretched, their dimensions, although monstrous, are logical to their monstrosity, as with this example from P. Schuyler Miller's "The Thing on Outer Shoal":

Out of the water a hundred feet away rose a face. Long hanks of grizzled hair hung over it, and out between them stared two huge, black, goggling eyes. There was a smear of white flesh between them where it should have had a nose. Its mouth stretched halfway across its head right under those staring eyes, and it was filled with litde sharp pegs of teeth. The gills began below - a purple frill of flesh, opening and closing as it breathed. As it rose higher its mouth gaped open to suck in air, and I could see that it had no tongue. (153) Along with animals, monsters can be composed of hybrids of inert, animated matter, such as the slime-thing in Joseph Payne Brennan's famous story "Slime" (215), and the mud-thing in Theodore Sturgeon's "It," which is:

a massive caricature of a man: a huge thing like an irregular mud doll, clumsily made. It quivered and parts of it glistened and parts of it were dried and crumbly. Half of the lower left part of its face was gone, giving it a lopsided look. It had no perceptible mouth or nose, and its eyes were crooked, one higher than the other, both a dingy brown with no whites at all. It stood quite still looking at her, its only movement a steady unalive quivering. (53) 
It is easy to discern what is impure about both Payne Brennan's and Sturgeon's monsters, but more difficult to find impurity in every monster in fiction, particularly when the categorical violation concerns less obviously repellent inert substances. The affect of monstrosity in this story by Algernon Blackwood depends for its horror upon a more appalling transformation: "The face for an instant made me think of one of those toys of green indiarubber that children pull. It grew enormous" ("The Transfer" 234) while Marly Youmans's "An Incident at Agate Beach" creates a merman who is compared to stone: "... something about him was not right - not just the blue and turquoise flush to the skin but the whole muscularity of him, the too-handsome, chiseled face, and the irises of the eyes that were cool but radiant like two pieces of sagenite set in stone" (46). The pulp classic "Vault of the Beast" by A.E. Van Vogt evokes metal and organic matter:

With a whimpering cry, the creature dissolved. The pull of the metal twisted it horribly into thick half metal. The struggle to be human left it a malignant structure of bulbous head, with one eye half gone and two snakelike arms attached to the half metal of the body. (21)

Impurity and an affect of category violation is easier to locate in monstrous children, which are a common convention of horror that has been frequendy discussed in film. ${ }^{185}$ Here is Joyce Carol Oates's monstrous baby (reminiscent of the baby-thing in Eraserhead) in "The Family," replete with abnormality and animalistic traits:

See, for example, Robin Wood, who posits the "devil child" as a disruptor of the (patriarchal, capitalist) societal norm of the nuclear family 
Though it had not matured in die normal fashion Lona's baby weighed now about thirty pounds; but it was soft as a slug is soft, or an oyster; widi an oyster's general shape; apparendy boneless; the hue of unbaked bread dough, and hairless. As its small eyes lacked an iris, being entirely white, it must have been blind; its nose was but a rudimentary pair of nostrils, holes in the center of its face; its fish-like mouth was deceptive in that it seemed to possess its own intelligence, being ideally formed, not for human speech, but for seizing, sucking and chewing. (Masters of Darkness III 264)

Also central to the affect of the monster, and something that is perhaps much less discussed, is that the monster is not simply a static example of impure category violations to be dissected by critics. It has a job to do in the plot of the story: the monster must convey menace, which means monstrosity is about more than simply being impure. This menace is often associated again with childhood; numerous critics since James Twitchell have documented the power of horror to return the reader to the susceptible and vulnerable state of childhood, a state which horror stories ask us to revisit through affects such as identification and conjuring monstrosity. Greg Egan's "Neighbourhood Watch" is an explicit, lovingly satirical reference to the well-documented role of the monster as the disruptor of order in a horror tale, the vanquishing of which then restores order, and to the importance of childhood in such narratives. The monster in this story has been harnessed by a well-meaning but faintly ludicrous group, Citizens against Crime, to keep order in their town and is under contract to hunt criminals.

The criminals the monster pursues, however, are also faintly ludicrous and disturbingly petty. Among its victims are a bored seventeen-year-old shoplifting, for 
example, or a young woman with spray paint who is defacing a poster she considers sexist pornography (38). The monster (who narrates the tale) dreams about breaking its bonds to turn on the unwitting humans who think they have it under control. However, the child it wants to kill above all others exercises a strange power over it and laughs at it even as he fears it because he knows that he in fact has invented the monster and that killing him will mean the end of the monster-narrator too, a claim which is left as a distinct possibility by the story's ending. August Derleth's story "The Lonesome Place" invokes the imaginary monster of two small boys in a string of taut, descriptive phrases. The menace is heightened by the fact that only the two small boys know of the monster while their elders neither know nor believe:

She never knew how something could lie up in those old trees, lie right along those old limbs across the sidewalk and drop down without a sound, clawing and tearing, something without a face, with ugly clawed feet like a softshelled turde's, with scales and a tail like a dragon, something as big as a house, all black, like the darkness in that place. (195)

This wonderstruck narration of the monster's power is a technique of monstrous menace that Ray Bradbury and Stephen King have also used to great effect in conjunction with monsters, particularly the monsters of childhood. King describes a toy monkey in simple, repetitive, nursery-rhyme phrases (another characteristic feature of his prose style), culminating with a frightening disclosure of the monkey's teeth: "Its body rocked and humped on the shelf. Its lips spread and closed, spread and closed, hideously gleeful, revealing huge and carnivorous teeth" (Skeleton Crew 173). 
Another fine and chilling example that plays with the idea of the childhood monster is Theodore Sturgeon's "The Professor's Teddy Bear," in which the professor of the tide is forced as a precocious child to hurt and enjoy hurting people by something that resembles a teddy bear, and which feeds hungrily from him in a grotesque parody of nursing as the boy, in a dream-like state, describes their suffering (an alternative, more psychoanalyticallyinflected interpretation of this story, of course, is possible). His resistance to this monster brings dire consequences when, in his own future which the little boy has anticipated in his dream-like state, he is talking to one of his students and she undergoes a sudden, horrible transformation that he has caused in his carefree past and which only he can see:

Her face shrank, shrivelled. Her eyes lengthened. Her ears grew long, until they were like donkey 's ears, like rabbit's ears, like horrible, long hairy spider's legs. Her teeth lengthened into tusks. Her arms shrivelled into jointed straws, and her body thickened. It smelled like rotten meat. There were filthy claws scattering out of her open-toed shoes. There were bright sores. There were - other things. And all the while, she - it - held his hand and looked at him with pity and friendliness. (336)

By playing with the reader's perceptions, the horror tale asks us to exercise our sense of wonder and suspend disbelief in order to affect us. The "cancer vampires" in Dan Simmons's "Metastasis" are similarly monsters that can only be seen by the narrator (invoking the glimpse discussed earlier in several stories), while "Mimic" by Donald A. Wollheim asks its readers to adjust their perceptions to envision, in a reversal of Kafka's "The Metamorphosis," an insect posing as a human being: 
We turned over the stranger, took the cloak off. For several instants we saw nothing amiss and then gradually — horribly - we became aware of some things that were wrong. His hair was short and curly brown. It stood straight up in its inch-long length. His eyes were open and staring. I noticed first that he had no eyebrows, only a curious dark line in the flesh over each eye. It was then I realized he had no nose. But no one had ever noticed that before. His skin was oddly mottled. Where the nose should have been were dark shadowings that made the appearance of a nose, if you only just glanced at him. Like the work of a skilful artist in a painting. His mouth was as it should be and slighdy open - but he had no teeth. His head perched upon a thin neck. The suit was — not a suit. It was part of him. It was his body. $(25-26)^{186}$ This sight invokes a body horror that is far more than appalling or "splatter," that creates a fantastic hesitation over how one is supposed to react. Richard Matheson's groundbreaking horror tale "Born of Man and Woman" (1950) also belongs here in its evocation of the monster-child's voice as pitiful and yet menacing, describing horrifying abuse and its own abject existence. ${ }^{187}$ This tale, too, incorporates the glimpse affect of horror, describing and revealing without seeming to, thereby urging readers to fill in the "dark patch" and imagine their own versions of the monster-narrator:

This day when it had light, mother called me retch. You retch she said . . .

${ }^{186}$ see the Guillermo del Toro adaptation, 1997.

${ }^{187}$ Another Matheson story "Day of Reckoning" revisits the disturbing theme of child abuse by depicting the horrific psychological abuse of a boy by his mother. 
In this day when it got dark I had eat my food and some bugs. I hear laughs upstairs. I like to know why there are laughs for. I took the chain from the wall and wrapped it around me. I walked squish to the stairs. They creak when I walk on them. My legs slip on them because I dont walk on stairs. My feet stick to the wood ....(145)

The anger came in his eyes. He hit me. I spilled some of the drip on the floor from one arm. It was not nice. It made ugly green on the floor . . Ohgod he said. And only eight.... She took the stick and hit me with it. I didnt cry. I cant do that. But the drip ran all over the bed. (146) ${ }^{188}$

Kathe Koja's story "Teratisms" is a continuation of the idea of the sympathetic yet horrible monster and the cursed family forced to endure the child-monster: "Alex wiping uselessly at the scabby drip of his actions, even then you had to watch him all the time" (374). Al Sarrantonio's "Father Dear" is another tale of a monstrous child in the tradition of "Born of Man and Woman" that evokes the real life horror of child abuse, but whose monstrousness is, in fact, real.

The monstrous, bordering now upon the affect of the uncanny, which I will discuss next, may also be used as an affect of suggestion, presenting an irrevocably monstrous "twist" upon a mundane, "normal" perspective. For example, the secluded and perpetually terrified narrator of Tanith Lee's "Gemini" sees the world outside her house as nightmarish, much like Catherine Deneuve in Repulsion (1965), summoning the reader to an uneasy

${ }^{188}$ Rather than using [sic], which I find overly intrusive in this context, I point out here that the misspellings in Matheson's story are all deliberate and designed very effectively to convey and amplify the childlike recitative of abuse. 
identification through taut and powerful similes that evoke Picasso's displaced facial features (another instance of "faciality"): "The streets surge with people. Their teeth glint like eyes; their eyes, like teeth, bite my peeled face" (210). The British writer Ramsey Campbell makes frequent and skillful use of the "everyday monstrous" as in this description of an old woman, spider-like, corpse-like, from his story "The Brood":

Her face peered out of the frame of her grey scarf, as though from a web. As she circled she was muttering incessantly. Her tongue worked as though her mouth were too small for it. Her eyes were fixed as the heads of grey nails impaling her skull. (201)

Algernon Blackwood's story "The Damned" suggests a doubling of vision to what elsewhere in the story, the narrator calls not impure but monstrously "un-pure":

For I saw, as with the eyes of a child, what I can only call a goblin garden house, grounds, trees, and flowers belonged to a goblin world that children enter through the pages of their fairy tales. And what made me first aware of it was the whisper of the wind behind me, so that I turned with a sudden start, feeling that something had moved closer. An old ash tree, ugly and ungainly, had been artificially trained to form an arbour at one end of the terrace that was a tennis lawn, and the leaves of it now went rustling together, swishing as they rose and fell. I looked at the ash tree, and felt as though I had passed that moment between doors into this goblin garden that crouched behind the real one. (117)

A similar twisted perspective informs the suggestive power and horrific affect of Charlotte Perkins Gilman's classic feminist horror story "The Yellow Wallpaper," as her 
vulnerable and oppressed narrator gradually slips into an insanity that renders her as frightening as the creature she begins to see in the wallpaper:

Sometimes I think there are a great many women behind, and sometimes only one, and she crawls around fast, and her crawling shakes it all over. Then in the very bright spots she keeps still, and in the very shady spots she just takes hold of the bars and shakes them hard. And she is all the time trying to climb through. But nobody could climb through that pattern - it strangles so; I think that is why it has so many heads. They get through, and then the pattern strangles them off and turns them upside down, and makes their eyes white! (469)

What begins as a glimpse becomes a frightening perspective that renders the narrator ultimately monstrous, revealing that she is the "madwoman in the attic," dragging her tethered body or "creeping" endlessly around a room with her shoulder pressed against the walls, hoarding her secrets. What signals the monstrosity in "The Yellow Wallpaper," however, is the "strange-making" focalization of the narrator as recounted above, rendering uncanny such a mundane item as wallpaper or a garden. I will next draw attention to the uncanny, following Freud's definition of Das Unheimlich.

\section{The Uncanny}

Freud's well-known definition of the uncanny is "that class of the frightening which leads back to what is known of old and long familiar" (220). Freud noted that further aesthetic enquiry was required into his psychoanalytic theory (247), remarking that the "uncanny as it is depicted in literature, in stories and imaginative productions, merits in truth 
a separate discussion" (249). Here I would argue that, whatever the uncanny may be in psychoanalysis, in literature it constitutes only one affective element at play among others. ${ }^{189}$ Somewhere between plot and affect, the uncanny, Freud's Das Unheimlich or "unhomely" — the familiar made strange and frightening — is most closely associated with the "creeps" and a sense of dread in horror that arises from the introduction of a note of jarring wrongness into a familiar and comforting scene that I mentioned earlier in conjunction with E. F. Benson. For example, in Robert Reed's creepy story "Mrs. Greasy" which relates the tale of a succubus-type monster, the phrase "the woman crouched" is all that is needed to convey that note (463). The uncanny effect is the essence of Miall and Kuiken's "foregrounding"; it creates what is often called "atmosphere" building to a climactic moment. Henry James, for example, strings suspenseful sentences together joined by hyphens in a chain of signification that culminate in an uncanny affect when he writes that "a charm of stillness" was actually "that hush in which something gathers or crouches .... actually like the spring of a beast" in "The Turn of the Screw" (25). It is an incongruous simile, but one which works to jar the complacency of the reader, not to mention preparing them for the final climactic scene when the reference to the "beast," this time outside the window, returns.

Richard Christian Matheson's "Making Cabinets" also imparts this sense of a jolting turn on everyday perception, this time the result of the traumatized perspective of the spouse of a recently apprehended cannibalistic serial killer first encountered vainly trying to order a restaurant meal:

${ }^{189}$ In "Fiction and Its Phantoms," Helene Cixous cleverly unsettles the emphasis on castration at the centre of Freud's text and points out the uncanniness of fiction as the "very strange thing" itself (547). 
She scans gourmet adjectives. Imagines soups, meats. Their dark succulence, piquant sauce. All of it horror. She searches more dishes, stomach a sick pit. Maybe a salad, no dressing. But the tomatoes; the cook would slice them open, their seededflesh unprotected, seeping helplessly. (359)

Another example of this creation of atmosphere is the scene from "Casting the Runes" where the paper containing the runes flutters up the chimney and is burnt up, it is implied, by the operation of the sinister forces which are persecuting the doomed victim Harrington. Harrington's brother, the teller of his tale, afterwards recounts:

"Well," I said, "you can't give it back now." He said nothing for a minute, then rather crossly, "No I can't; but why you should keep on saying so I don't know." I remarked mat I didn't say it more than once. "Not more than four times, you mean," was all he said. (140)

In Miall and Kuiken's terms, this implied repetition or "foregrounding" of the ominous phrase would delay the normal process of reading, enacting a defamiliarization on the part of the reader, who will linger over the echo of "you can't give it back now," thus producing a defamiliarizing affect. The reader will then attempt to make a "refamiliarizing" move to fit this meaning within the logic of the tale, noting that the uncanny echo signals that Harrington cannot rid himself of the demonic presence by giving the rune back to Karswell, thus the echo is dooming poor Harrington, for whom the bell now tolls. Uncanniness functions thus as a building-block of the tale. It asks the reader to put two and two together, in this case quite literally, to not simply accept that a diabolical force caused Harrington's brother's sentence to ring out four times, but to interject the reader's own idea of how that must have sounded for Harrington (which also engages the identification affect). 
The "uncanny quickness" of the runes escaping is duplicated a second time when Harrington's brother manages to prevent the slip of paper from similarly fluttering out of Dunning's documents. At this point in the story, there is no further doubt and, I would argue, this is the point where the reader's disbelief becomes successfully suspended, partly as a result of engaging the reader by means of the previous tale of Harrington. The fate which befalls Harrington effectively convinces, not only Dunning, the next victim and therefore, in a way, Harrington's alter ego, who must hunt down Karswell to return the curse, but also the reader.

In the former example, James makes very effective use of sound - the echo whereas the turning point for the uncanny in "Smoke Ghost" returns us to the visual. The smoke ghost, it is implied, possesses the protagonist's administrative assistant who then pursues the protagonist, but there is no real sense, at first, that anything is wrong with her until the following passage:

She fumbled at her stuffed oblong purse. He noticed that she was absentmindedly holding it shut with one hand while she tried to open it with the other. Then, under his very eyes, he saw her bend back the thick prongs of metal locking the purse as if they were tinfoil, or as if her fingers had become a pair of steel pliers. (638)

Philip K. Dick's story "The Father-Thing" (published in 1954, the same year as Jack Finney's The Body Snatchers) plays upon a similar paranoia where the reader awaits the "proof that the parents have really been replaced by monstrous things. To take more recent examples, the creeping, gradually overwhelming sense of wrongness that Thomas Ligotti's best work conveys, such as the story "The Glamour" (1991) is an example of the pervasive 
uncanny in Ligotti's style, which Ellen Datlow describes as "subtly disquieting" and as being able to "project dread and unease" (YBFH 5 341). Similarly, Dan Chaon's creepy story "The Bees" evokes a subde air of monstrous menace; there is something subdy wrong with the first son in the story (17). The revelation of what "ought to have remained secret and hidden but has come to light," as Freud put it, is part of the uncanny's affect but the reader has been subdy prepared for this revelation by the wrong notes struck in the narrative. Unlike the next affect which I shall now discuss, the uncanny is closer to the "quiet horror" side of the spectrum. It may well convey repulsion, but the details are left up to the reader to experience and imagine.

\section{The Sickening}

Earlier, I discussed splatterpunk, which makes liberal use of the "gross-out" in a cartoonish and comedic sense that approximates Brophy's concept of horrality and that also launches a direct challenge to normative tastes. The affect I describe as sickening here comprises such texts. It is akin to Stephen King's gross-out in that it encompasses revulsion or disgust affecting the senses. It is an indicator of a specifically abject type of monstrosity without the touch of pity conveyed by the appalling. It is the essence of the "body horror" described by film critics such as Pinedo. Its markers in the text are physical aversion and an emphasis upon violations of touch, taste and hearing. As I have already stated, the "grossout" is that particular strategy which is principally celebrated by contemporary horror fans and aficionados, either as a display of skill in the field (at least one annual horror convention boasts a "Gross-out" competition) or as a prevalent technical fetish to which the success of the fanzine Fangoria attests. However, the sickening effect is not always as crass as the term 
"gross-out" and its deployment by "splatterpunk" suggests. To return to one of the examples I have been frequently using, that of Poe's story: 'M. Valdemar's unspeakable voice] impressed me ... as gelatinous or glutinous matters impress the sense of touch" (103). M. Valdemar is repulsive to the senses in every way, as the narrator reports:

The first indication of revival was afforded by a partial descent of the iris. It was observed, as especially remarkable, that this lowering of the pupil was accompanied by the profuse outflowing of a yellowish ichor (from beneath the lids) of a pungent and highly offensive odour. (104)

Valdemar becomes "a nearly liquid mass of loathsome — of detestable - putridity" (105) similar to Lovecraft's thing on the doorstep. In a story by Gerald Kersh, entitled "Men Without Bones," the weird humanoids of the title also melt:

$\ldots$ as the sun rose higher, the thing liquefied, melted, until by nine o'clock there was nothing but a glutinous gray puddle, with two green eyes swimming in it... And these eyes - I can see them now - burst with a thick pop, making a detestable sticky ripple in that puddle of corruption ... (52) The sickening monster is described as being anathema to the touch, causing those it touches to lose control of their bodies (Carroll cites some good examples of this revulsion also):

On the lips and chin and paps were scatterings of long hairs, and there were clotted tufts in the armpits. Its coloring was dead and litchlike, and the skin

${ }^{1}$ This story appears in an anthology entitled Stories That Scared Even Me, edited by Alfred Hitchcock. Much has been written about Hitchcock's horror films, but much less has been said about the fact that Hitchcock lent his eminently marketable name to numerous anthologies of short fiction. 
glistened with a dewy sheen. Edgel felt that if he himself had no mind at all, even, and no sense or reckoning, that if he should feel the creature touch against him ever so briefly or slighdy, that his body of its own would recoil and quake and fling itself, babbling, away. (Davidson 32)

His arm reached out and plucked at the disintegrating trousers. A piece came away in his hand, a cold, slimy writhing lump like wet clay. The feel of it was too much. His gorge rising in disgust, he faltered in his stride. (A.E. Van Vogt "Vault of the Beast" 10)

The horrible creature that haunts the upper berth in F. Marion Crawford's oftanthologized "The Upper Berth" is appalling in its corpse-likeness, "like the body of a man long drowned, and yet it moved, and had the strength of ten men living" but it is likewise figured in sickening terms as "the slippery, oozy, horrible diing-the dead white eyes seemed to stare at me out of the dusk; the putrid odour of rank sea-water was about it, and its shiny hair hung in foul wet curls over its dead face" (20). A sickening quality may signal that there is something wrong with a character early on in the story: "Denham's skin was repulsively cold and moist, like that of a bloated leech. I shuddered, and looked at the man closely" (Powers "Monsters of the Pit" 131).

The sickening affect often creates bizarre biologies, as Carroll has noted, that resemble the less appealing specimens of nature, such as larval insects. ${ }^{191}$ Peter Crowther's "The Visitor" features disgusting, invasive parasites that occupy bodies similarly to

Obviously the notorious chest-burster scene from Alien is an oft-remarked instance of this type of "body horror" in film. 
Cronenberg's phallo-fecal teratisms in Shivers (1975), while R. Chetwynd Hayes's story "The Frankenstein Syndrome" describes repulsive maggots created by a deranged scientist. Bendey Little's story "From the Mouths of Babes" has similar creatures and is definitely not for the queasy. Interestingly, I have quoted the Monteleones who publish the anthology Borderlands elsewhere as strongly rejecting the "steaming pile of organs" school of writing, but they have high praise for Little as "a wonderful writer" (206), proving such critique highly subjective.

A (recently filmed) Clive Barker story, "Dread," describes the torture of a vegetarian woman locked up in a room with a joint of beef as the only food available to her. The character who locks her in describes the dilemma he has put her in: "If the meat revolted when it was fresh, what about her disgust at rotted meat? .... The longer she waits to eat, the more disgusted she becomes with what she's been given to feed on" (Books of Blood Vol. 2 18). Here, the sickening affect is accomplished through identification on the part of a focalizing character and thus on the part of the reader: "Steve seemed to taste the rotten flesh in the back of his throat. His mind found a stench to imagine, and created a gravy of putrescence to run over his tongue. How could she do it?" This technique is taken even further in Steve Rasnic Tern's story "Jesse" (Psycho-paths), where the narrator imagines death and putridity everywhere.

\section{The Bad Death}

In cinematic terms, the affect of a lengthy description of the bad death or ordeal corresponds to scenes in the famous slasher or, more recendy, the "torture porn" film, as well as keeping the concept of body horror, at least as that body is tormented and dispatched. This element is obviously related to the level of the plot but should be 
considered in closer detail as strongly affective, stretching out the reading experience. This passage from Harlan Ellison's "I Have No Mouth and I Must Scream" where the characters are eternally terrorized by a merciless and hate-filled computer "AM" who is constandy inventing ways to torture them is an exercise in cringing while simultaneously admiring the ingenuity of the torturer:

AM said it with the sliding cold horror of a razor blade slicing my eyeball. AM said it with the bubbling thickness of my lungs filling with phlegm, drowning me from within. AM said it with the shriek of babies being ground beneath blue-hot rollers. AM said it with the taste of maggoty pork. (25)

While this ingenuity is compelling and clearly exercises a hold on our imaginations, as the abundance of fascinated critical interpretations of the slasher film genre, such as Men, Women and Chainsaws, Serial Killers and Skin Shows demonstrates, another aspect of the bad death involves affect, reading and feeling more deeply the pain of death and dying, what the poet Pat Mora characterizes as the skeletal "La Muerte" in her poem of the same tide, the "unholy death" (280). ${ }^{192}$ Gary Braunbeck 's memorable story "Safe" about a mass murder and the lone survivor 's struggle to understand what happened and cope with the ghosts of the victims is a horror story that refuses to celebrate the killer even as it painstakingly recounts the graphic and painful details of the murders. The story is similar in technique to the film Henry: Portrait of a Serial Killer $m$. that it presents the tale in flashbacks and initially hones in on the aftermath of the violence - the cleaning crew mopping up bloodstains 198). 
rather than wallowing in the violence itself. Reading this story is intensely disturbing as it involves graphic descriptions of murdering family members, including children, but having to "work through" such an atrocity via fiction is, as I suggested in Chapter One in my discussion of trauma-narratives such as The White Hotel'and One Day o/Ufe, an unflinching retelling of such disturbing events that engages more than simply our prurient interest. As Braunbeck's narrator remarks towards the conclusion: "It is easier by far to imagine the complicated financial maneuverings of Wall Street kingpins than an isolated burst of homicidal rage in a small Midwestern city" (147).

Horror is an experience which here strongly diverges from the fantastic while sharing the same sensibility that "what has been imagined, however preposterous, has a place in the world and in our lives" (Manguel xviii), with the attendant apprehension that we would not wish for such a life — or such a death as befalls the victim of the slime-thing in Payne Brennan's story here:

The monster had pounced upon Luke Matson. Now, as Fred watched, literally paralysed with horror, it spread itself over and around the form of Luke until he was completely enveloped. The faint writhing of his limbs could be seen. Then the thing squeezed, swelling into a hood and flattening itself again, and the writhing ceased. ("Slime" 227)

Clive Barker has a particularly stylized and inventive approach to "body horror" and the bad death. His vision of human books of blood is taken up in Grant Morrison's story "The Braille Encyclopedia" which recalls Barker's framing story for The Books of B/ood which inscribes, like the torture machine in Kafka's penal colony, its texts upon a human body and proclaims punningly as its motto, "Every body is a book of blood. Wherever we're opened, 
we're red." For example, here is a scene from Barker's "Rawhead Rex" diat depicts an awful death indeed and, to heighten the horror of die death, diis happens to a child (which, as we saw earlier with Argento's Jenifer, is taboo):

Ian knew he was beyond salvation from the beginning, because he'd died this way in his sleep on a hundred occasions and Daddy never got diere in time. The mouth was wider even than he'd dreamed it, a hole which he was being delivered into, head first. It smelt like the dustbins at the back of the school canteen, times a million. He was sick down its diroat, as it bit the top of his head off (72).

The powerful monster in Egan's "Neighbourhood Watch" kills the "self-righteous, self-appointed" and apdy named Mrs. Bold of the Citizens against Crime committee in a sickening way that is comparable to Barker:

I float her on her back a few feet above the ground, then I tilt her head and force open her jaws. First her tongue and esophagus, then rich fragments from the walls of the digestive tract, rush from her mouth to mine. We are joined by a glistening cylinder of offal. (46)

Under the category of the bad deadi, I will also include bodily mutilations, such as this one from Keene's updated version of "The King in Yellow" that includes an element of suddenness: "Still singing, the woman bent over and plucked up her soup spoon from the mess on the floor, dien used it to gouge out her eyes. Red and white pulp dribbled down her face" (121). Chuck Palahniuk 's Haunted: a Novel in Stories features some spectacularly bad deaths, particularly in "Hot Potting" where death by first boiling, tihen being devoured by wolves, is dwelt on in detail: 
The typical thermal feature along the White River Fault is a vent that opens to a pool crusted around the edge with a layer of that crystallized mineral. The average temperature of thermal features along the White River being 205 degrees Fahrenheit. One second in water this hot, and pulling your socks off will pull off your feet. The cooked skin of your hands will stick to anything you touch and stay behind, perfect as a pair of leather gloves. (351)

Equally disturbing if not quite as graphic is Joyce Carol Oates' "Landfill," a story about a drunken fraternity student who is trying to fit in at university. In a bizarre accident, somewhat attributable to his friends' indifference to his state, he ends up falling into the trash compactor. Oates imagines his bad death, juxtaposing this with his parents' grief and the voices of his amorally uncaring, self-centred dorm-mates for a devastating effect. The student is "wasted" in every way and we feel the horror of this waste.

Horror, as we have seen, does not flinch from examining the consequences of torture, not only on the tortured but on the torturers. Obviously, a prototype for the "body horror" of torture, which never gets mentioned in discussions of "torture porn," is Franz Kafka's "In the Penal Colony" which envisions death by bureaucracy, an idea later taken up by Terry Gilliam's Brazil (1985), where the condemned has no chance to defend himself from the machine which literally inscribes his crime on his body with acidic needles. The most common horror tale to employ this affect is the tale of vengeance. For example, two British pulp stories written by Raymond Williams, "The Assassin" and "The Coffin Makers" feature characters receiving dubiously just desserts. In "The Assassin," a man has his eyes put out with a poker by the enraged husband he has just tried to assassinate; die wife who was in on the plot decides she does not want either of them, poisons the husband and drops 
a brazier full of burning coals on the blinded head of the torture victim. In The Coffin Makers," the desecrator of a corpse is subjected to that apotheosis of bad deaths which crops up with great frequency in horror stories: buried alive with his tongue and fingers cut off.

The contemplation of a bad death, however, need not be linked solely to revenge; it also reflects existential and ethical problems. For example, in Donald Westlake's harrowing tale of two men trapped in a room in a ship that sinks; resting on the sea bed with the lights flickering out, the doomed passengers face terrible choices about how to relate to each other ("Journey to Death"). Patricia Highsmith's story "The Quest for Blank Claveringi" punishes nothing but certain hubris on the part of a zoology professor being devoured by giant snails. $^{193}$

To drown or be eaten alive? the professor wondered. He was waist-deep when he stumbled, waist-deep but head under when the snail crashed down on him, and he realized as the thousands of pairs of teeth began to gnaw at his back that his fate was both to drown and be chewed to death. (25)

${ }^{193}$ Highsmith wrote another fatalistic snail horror story: "The Snail Watcher" about a man whose consuming passion is collecting snails - eventually his study is taken over by them and he dies a gruesome death when snails slither into his mouth and cut off his air. Highsmith was very fond of snails, her biographer Andrew Wilson described how she kept hundreds of snails and used to carry them around with her in a handbag, but the horror stories described here display another aspect to her fascination. 


\section{The Sudden}

The sudden is a relatively simple and obvious affect compared to the uncanny, although the two may overlap. In film, it corresponds to the jump-scare or the "bus" and it may be illustrated by one or two examples, such as in this scene from Kim Newman's "The Man Who Fell off the Ghost Train" when the little girl Vanessa without any warning whatsoever plunges a fork into a woman's throat and speaks shockingly in a deep man's voice, indicating she is possessed, an affect reminiscent, and given Hills's discussion of Newman's intertextuality, probably deliberately so, of the sudden onset of the possessions in EvilDead (1981). Suddenness in this way creates an abrupt shift in the tone of the story, tipping the reader, who may have been lulled into somewhat different expectations, into a rude awakening to a horrific sequence of events. This is reminiscent of David Lodge summarizing "the [Stanley] Fish effect": the reader's "hypotheses and expectations about the meaning that is going to be delivered at the end of the sentence, or paragraph, or text" are then "disconfirmed" (Lodge Language of Fiction 53). At the same time, the sudden works to vividly evoke a horrific image that is all the more shocking for being so incongruous and unexpected. In the Dylan Thomas story, "The Old Woman Upstairs":

Martha put her fingers round the old woman's throat. One o clock now she said, and knocked the old woman's head against the wall. It needed but three

little knocks and the head burst like an egg. (156)

Another fine example of a brutally sudden and disconcerting "disconfirmation" is found in Harlan Ellison's story, "The Time of the Eye":

Then I ran my hands across her face, feeling the beauty of her, letting my fingertips soak up the wonder of her. My smallest finger's tip happened to 
encounter her eye. It was not moist. I paused, and a gleam of smile broke at the edge of her wondrous mouth. "True," she said, and popped her eyes into the palm of her hand. (243)

An over-reliance upon the sudden scare as the only affect to produce fright, perhaps resulting from horror's over-association with film, has caused it to be held in contempt as cheap tactics by many writers in the field who aim at a more lasting effect. For example, Douglas Winter writes:

[tjoo many purveyors of the 'gross-out' work from the proposition that the purpose of horror fiction is to shock the reader into submission. They indulge in cheap tactics like those movie directors call 'pop-ups'; the hand thrusting into view, the sudden close-up of a ravaged corpse. Yet shock is a visceral experience, a sensory overload from which most of us recover quickly. Great horror fiction is not about shock, but about emotion; it digs beneath our skin and stays with us. (19)

Steve Rasnic Tern echoes this view when he declares, "I'm a firm believer in the 'infection' theory of dark fantasy ${ }^{194} \ldots$. Fright in and of itself is simply too transitory" (236). Earlier, I commented upon the stretching-out of violence; the importance of time and duration in the experience of horror's effects has been significantly under-theorized. Yet, the emphatic power of the sudden jolt in written fiction, which also overlaps with the effect of identification and works most effectively when horror has already been building up through

${ }^{194}$ Dark fantasy is often used synonymously with "quiet horror": see, for example, Don Hutchinson's insistence in Northern Frights that his collections are dark fantasy and not "formulaic horror" (3). 
the use of other devices, such as the glimpse, should not be dismissed as a cheap tactic, particularly when it has been so neglected in the poetics of horror literature. In "The Return" by Algernon Blackwood, a character suddenly turns "with a horrid start, for the uneasiness had of a sudden leaped within him like an animal. There was someone in the flat" (Tales of the Mysterious and Macabre 219). Another memorable shock comes at the conclusion of Elizabeth Bowen's story "The Demon Lover"; note the contrast between the suddenness of the action and the "eternity" following:

The driver braked to what was almost a stop, turned round and slid the glass panel back: the jolt of this flung Mrs. Drover forward until her face was almost into the glass. Through the aperture driver and passenger, not six inches between them, remained for an eternity eye to eye. Mrs. Drover's mouth hung open for some seconds before she could issue her first scream. $(122-3)^{195}$

I do not experience such passages as transitory: on the contrary, because of their shocking and disconcerting affect, they tend to linger, resonate, and stay with me for an uncomfortably long period of time. In Pedro Antonio de Alarcon's "The Tall Woman," suddenness delivers another powerful jolt. The narrator has just encountered the titular monster and describes how he keeps walking, haunted by the horrible vision and gradually becomes convinced that the woman is following him. A scene follows where the narrator deliberates with a hesitation familiar to the readers of M. R. James or "The Ancient Mariner"

${ }^{195}$ This conclusion is duplicated at both the beginning and the end of the second of the Nightmare on Elm Street films (1984 and 1985) when Freddy Krueger turns out to be the driver of a school bus making off with the screaming students into a nightmarish place. 
— "Dare I look round?" — and "having almost calmed myself," proceeds to turn his head only to have his worst fear confirmed; the woman, like Coleridge's frightful fiend, is indeed close behind and almost touching him, creating the effect of a nightmare:

Oh, Gabriel, Gabriel, how shall I convey my feelings to you at what I saw?

The tall woman had followed me with soundless footsteps, she was towering over me, almost touching me with her fan, her head bent so that it nearly touched my shoulder. (227)

A similar effect, this one decidedly tinged with the uncanny, is conveyed by the supernatural quickness with which the vampiric Mrs. Amworth encircles her prey:

I dreamed that I awoke and found that both my bedroom windows were shut. Half suffocating, I dreamed that I sprang out of bed and went across to open them. The blind over the first one was drawn down, and pulling it up I saw, with the indescribable horror of incipient nightmare, Mrs. Amworth's face suspended close to the pane in the darkness outside, nodding and smiling at me. Pulling down the blind again to keep that terror out, I rushed to the second window on the other side of the room, and there again was Mrs. Amworth's face. $(76)^{196}$

The famous scene in M. R. James's "Casting the Runes" also creates an effect of uncanny suddenness in its pacing, slowed down momentarily by commas that mirror the terrifying stages of discovery as Dunning encounters something under his pillow:

${ }^{196}$ Compare this scene from "Mrs. Amworth" with the 1979 television adaptation of Stephen King's Salem's Lot (1975) and the scene where Danny Glick (Brad Savage), the child vampire floats uncannily outside the window. 
So he put his hand into the well-known nook under the pillow: only, it did not get so far. What he touched was, according to his account, a mouth, with teeth, and with hair about it, and, he declares, not the mouth of a human being. (137)

The sudden jolt, perhaps best represented iconically by the image of a hand closing around the ankle, an image often repeated in King, or, in the words of Karl Edward Wagner in "Sticks," "[sjomething [that] closed on his wrist, set icy nails into his flesh" (212), often announces a shift to a faster-paced or escalated action in the text through warding off an attack: "[i]n one hideous second it hunched itself into an unspeakable, glistening hood and rolled forward with fearful speed" (Brennan "Slime" 227). In "What Was It?" by Fitz-James O'Brien: " [a] Something dropped, as it seemed, from the ceiling plum upon my chest, and the next instant I felt two bony hands encircling my throat, endeavouring to choke me" (868). In W. W. Jacobs' classic "The Monkey's Paw," the crash of the piano is the "bus" that lends the movement of the paw a feeling of suddenness:

"I wish for two hundred pounds," said the old man distinctly. A fine crash from the piano greeted the words, interrupted by a shuddering cry from the old man. His wife and son ran toward him. "It moved," he cried, with a glance of disgust at the object as it lay on the floor. "As I wished, it twisted in my hand like a snake." (515)

Jacobs' heart-stopping affect of suddenness created through doubling with two things happening at once is duplicated further on in the story. This time, instead of a crash from the piano and the twist of the dead morsel in the old man's hand, there is a pause to light a match coupled with a "stealthy" knock: 
At the foot of the stairs the match went out, and he paused to strike another; and at the same moment, a knock, so quiet and stealthy as to be scarcely audible, sounded on the front door. (520)

Stephen King has also developed this type of doubling technique as a scene from "The Monkey" illustrates:

Hal came back, almost asleep again. . . and suddenly the monkey began to beat its cymbals together in the darkness. Jangjangjang-jang - He came fully awake, as if snapped in the face with a cold wet towel. His heart gave a staggering leap of surprise, and a tiny, mouselike squeak escaped his throat. He stared at the monkey, eyes wide, lips trembling. Jang-jang-jang-jang. (172) In "The Monkey's Paw," the sudden gives way to a succession of panicked actions on the part of the old man who realizes he has unwittingly summoned a horror at his wife's insistence in the form of their "mutilated son": "... her husband was on his hands and knees groping wildly on the floor in search of the paw. If he could only find it before the thing outside got in" ("The Monkey's Paw" 521). Many horror stories depend upon this sense of urgent action for much of their effect. Richard Matheson's story "Prey" is a series of attacks by an animated fetish doll upon a young woman (prior to its famous twist ending). ${ }^{197}$ As we have seen with other tense moments in horror fiction, the technique used is to combine a series of terse clauses with few conjunctions, evoking extreme urgency, as with this example from "Et in Sempiternum Pereant":

197 This one invites comparison with Stephen King's story "Battleground" about a toy army in Night Shift "Prey" was made into a terrifying short in Trilogy of Terror (1975) starring Karen Black as the besieged young woman who battles the doll. 
Arglay cried out and sprang forward, catching the arm, trying to press it down, catching the other shoulder, trying to press it back. He achieved nothing. He held, he felt, he grasped; he could not control. The long limb remained raised, the fierce teeth gnawed. (626)

In another gorier version of this attack from Harlan Ellison:

Benny was eating Gorrister's face, Gorrister on his side, thrashing snow, Benny wrapped around him with powerful monkey legs crushing Gorrister's waist, his hands locked around Gorrister's head like a nutcracker, and his mouth ripping at the tender skin of Gorrister's cheek (30).

\section{The Twist}

The final affective element of the horror story on my list is also one that borders upon plot - the twist in the tale. Earlier in the chapter, I discussed the centrality of the tale structure to horror fiction. The twist cements the tale, anchors it, so to speak, while trailing off with the sense that the horror described at the end was completely unexpected and will therefore linger longer in the reader's mind, ${ }^{198}$ an affect far more difficult to accomplish in the novel, where Poe's "unity of effect" was never present. "The Yellow Wallpaper" is a wonderful example of a twist ending for which the reader has been gradually and expertly prepared throughout the course of the tale. The narrator's brisk, cheerful tone never wavers,

${ }^{198}$ For further analysis of twist endings, see Marie-Laure Ryan Cheap Plot Tricks, Plot Holes, and Narrative Design Narrative - Volume 17, Number 1, January 2009, pp. 56-75, and for a sense of how much the endings of the novel differ from those of short stories, see Peter Rabinowitz, "Reading Beginnings and Endings" in Narrative dynamics: essays on time, plot, closure, and frame, 2002. 
even recounting her slow downward spiral into a degraded and monstrous insanity, chewing on her bed and creeping around her wall tethered by a rope to die waist. It is such a powerful ending that the cumulative shock persists as we are left alone in the room with the narrator "creeping" over her husband's body: "Now why should that man have fainted? But he did, and right across my path by the wall, so that I had to creep over him every time!" $(471)$.

Again, as with the bad death, there is the importance of a certain ingenuity exercised in the twist ending. For example, Ramsey Campbell speaks admiringly of "the kind of juggling act that W. F. Harvey achieves so brilliandy in 'August Heat' where the narrator tells the reader everything without ever suspecting what he has revealed" (Masters of Darkness 1289). The twist ending points to the craftsmanship of a tale well told. However, the twist as a plot device for the "weird tale" has become somewhat conventional. David J. Schow fumes about the "dumbass 'rules'" that horror fictions seem to have to follow, including "the assumed 'requirement' of a twist ending, going all the way back to [Saki] H. H. Munro" (258). However, the twist in the tale might be more accurately traced to the conte cruel, a term coined by Villiers de 1 'Isle Adam in his 1883 collection of short stories. The term became applied to "a subgenre of short fiction whose cynical and skeptical worldview is neatly encapsulated in ironic climactic twists"(Stableford 73). Robert Bloch classifies his own stories as falling into two "genres": supernatural fantasy and the conte cruel, with horror being the common ingredient $\left\{\right.$ Psycho-paths 285)., ${ }^{199}$

${ }^{199}$ Bloch welcomes the invention of the term "psychological suspense" as a godsend for the reception of his stories - otherwise, he claims, being a "horror story writer" would have shut him out from acceptance (Psycho-paths-284). 
S. T. Joshi also follows Bloch in suggesting that serial killer psycho stories are either "pseudonatural" or contes cmels. The term, however, is applicable to all types of horror short fiction, which evidently favours "ironic, climactic twists" and helps to draw horror into a more mainstream perspective, as the twist ending is certainly not restricted to horror alone. If we focus solely upon the twist ending as plot, horror stories seem more approachable or, to use Gelder's word again, "accommodating" of more mainstream tastes. For example, Evelyn Waugh's "The Man Who Liked Dickens" is certainly a horror tale, but apart from its twist ending, it contains very few other elements of actual horror such as I have been discussing; the plot is a horror story only in its creeping sense of entrapment and enmeshment, evident at the very end. The Algis Budrys tale "The Master of the Hounds" is another example of a non-horror horror story with a twist. ${ }^{200}$ A twist ending can hinge upon a question or leave the reader dangling on a cliff-hanger, an invitation to imagine the worst or present an unforeseen horrific turn. More mainstream horror tales often end on a climactic high note where the horrific denouement is left mainly to the reader's imagination, as with the ending of "The Master of the Hounds" where a protagonist has the master's hounds (Doberman Pinschers) unleashed on him, the final word of the story being their code for "Kill" ("Kiss!"). ${ }^{201}$

${ }^{200}$ In Masters of Darkness III: Algis Budrys remarks: "Perhaps the reason I wrote so much for science fiction markets was that there weren't any horror markets at the time" (173).

${ }^{201}$ The recent film Pontypool uses this linguistic trick in another way when a character's escalating madness is forestalled by the calming insistence of the protagonist that "kill" means "kiss." 
Many horror stories strategically use their twists as narrative affect and not just plot. For example, in Lisa Tuttle's "Closet Dreams," the victim of a kidnapper / child molester dreams of escaping, but the twist is that she has never really escaped the kidnapper's closet in which she has been imprisoned, in a horrific updating of Ambrose Bierce's "An Occurrence at Owl Creek Bridge." Ray Russell's short story "The Cage"features a shudder-inducing and ingenuous twist ending of the sort for which O. Henry was renowned: an adulterous young Countess has, it is implied, been given eternal life and beauty by her demon lover, only to spend it screaming in a bricked-up dungeon underground as her demon lover promptly betrays her to her husband, and then betrays her husband to his enemies who raze his castle to the ground, burying her forever. These types of tales were disqualified by Carroll from his theory of art-horror (42).

A frequent twist ending in horror is often the final revelatory moment of another affect such as the sickening or the bad death. Ray Bradbury's "The October Game" (and its imitators) mentioned earlier is a classic example of the twist that leaves the reader suspended, waiting for the lights to be turned on by "some fool," but also revolted and appalled as it quickly becomes apparent (although it is never explicitly stated), just what the "fake" body parts were that were being passed around by the tormented husband. The twist ending of Al Sarrantonio's "Pumpkin Head," which concludes with the horrible echo of the monster who has showed up at the children's Halloween party, "My breakfast and lunch. My lunch and dinner" can be read as a tribute to Bradbury's short story. Another instance of the twist ending reflecting upon itself is provided by Richard Christian Matheson's "Groupies" 
(186). ${ }^{202}$ In this story, the horror is derived from the narrator's compulsion to repeatedly watch an atrocity which also, it is suggested, implicates the reader:

I ran the tape again, trying to understand what got the guy off about a bleeding girl, tied to a bed, screaming. I ran it over and over, trying to comprehend. Trying to find the point. I must've watched it a hundred times, by now. (186)

Unlike Bradbury's tale, most horror stories are not able to successfully leave us in the dark, imagining die worst, but reveal all (and revel in it all) at the end. For example, the impatient and gullible Thurlow, fooled by the upper-class accents of die maverick "Dr. Matthews," falls victim to a peculiar form of dentistry in Christopher Fowler's bloody bodyhorror story "On Edge"; in the final scene, he sees what has been done to him in the name of "art in dentistry" (Fowler 1992).

Thurlow's face was unrecognizable. His lips had been cut and peeled back in fleshy strips, then pinned to his cheeks with steel pins. Most of his teetii had been filed into angular shapes, some pointed, odiers merely slanting. His upper gums had been opened to expose the pale bone beneadi. A number of screws had been driven into his flayed jaws, and were attached by cables. The last two inches of his tongue — the lump he had felt in his throat — were missing completely. He watched as the leaking stump jerked obscenely back and forth like a severed snake. ... 'I know what you're thinking,' whispered

${ }^{202}$ This one fits well with Henry: Portrait of a Serial Killer too, and Otis's demand to watch it again. 
Matthews. 'It's special, but not spectacular. You haven't seen the best bit yet. This isn't merely art, it's — kinetic dental futurism. Watch.' Matthews reached up and turned a tiny silver handle on the left of Thurlow's jaw. The springs and wires pulled taut. The cogs turned. Thurlow's mouth grimaced and winked, the flaps of his lips contorting back and forth as his face was twisted into a series of wide-mouthed grins and tight sour frowns. On a separate spring, the end of his tongue flickered in and out of his own ear (26).

This grand Guignol display is very typical of the horror story's twist ending which "brings it home" to the reader. The conclusion of Robert Bloch's story "The Final Performance" in Such Stuff as Screams Are Made Of (every story in this collection contains a twist ending), a woman 's corpse is turned into a ventriloquist's dummy through what turns out to be a "huge foot-long gash extending from the back of her neck down across her shoulders" (212). This echoes the Lovecraft tale "The Whisperer in Darkness," substituting the psycho killer for Lovecraft's alien monsters. ${ }^{203}$ In another tale from this collection, Bloch, echoing George Romero's Martin (1977) and Richard Matheson's 1959 short story "There's No Such Thing as a Vampire," examines the danger of being taken too seriously as a monster: "It was only when the stake came down that he realized there's such a thing as playing a role too well. .." (Such Stuffas Screams Are Made of 229).

The twist also works to confirm what I discussed earlier as "the suspension of disbelief." Both J. B. Priestly's "The Grey Ones" and Stephen King's "The Boogeyman" are

${ }^{203}$ This story might be said to be very typical of Bloch, who began as an adoring Lovecraft disciple and ended up working with psychological suspense instead of just writing Mythos stories. 
very similar stories as an example of the twist in the tale. In both, a panicked character narrates a tale that seems bizarre but is proved to be true, with unfortunate consequences for the character himself. There is also the twist ending of David Ely's "The Academy" (1965), which works through gradual revelation. Finally, Michael Marshall Smith's "More Tomorrow" (1995), which I believe to be possibly the first Internet short horror story, has a particularly nasty twist ending where the protagonist attempts to stop the object of his affections from being displayed in a degrading manner on the Internet but becomes caught up in the stream of disturbing images of her being posted from an unknown location as she is tortured and mutilated, with the accompanying promise of "more tomorrow." Smith's story again engages the horror reader, increasingly, the web surfer, in a reflection on his or her tastes and practices of consumption. 


\section{Conclusion}

In this dissertation, I have devoted much time to the breakdown and analysis of prevalent narrative and aesthetic elements of horror fictions. I see these elements recurring in short horror stories, mainly in the Anglo-American tradition, but they may also be evident in the horror stories of other cultures. Manlio Argueta's siguanaba shows that not only can the literature of horror indicate the chasms between realities and representations, as with the serial killer fictions of North America, but it can indicate a continuum between those realities and the oral traditions that continue to delineate the borders of certain communities. Horror fiction is grounded in transnational migrations and encounters. In the collaborationist area of film, directors, writers, crews and actors may hail from different parts of the world and come together to jointly produce horror work. In the area of literature, translations, adaptations and horror's refusal to fetishize originality, its willingness to freely poach and borrow from many traditions ensures a continued fertile growth as well as ongoing avenues for comparative study. It is my hope that this dissertation will stimulate further explorations across borders, whether those borders surround genres, medias or cultures. Certainly the splatterpunk zombie genre, for example, is discernible in the horror cinema of other cultures, but, as I hope I have shown, cinema is but one part of a rich and rewarding pattern. In formulating my typology of affect, I hope that I have indicated some fertile territory for cross-cultural comparisons across cinemas and literatures that can resist the reinscription of western dominance and universalizing gestures.

My observations significantly expand the field and pave the way for others to perform interpretations and readings of horror that take into consideration the range and complexity of written texts. If at times I have seemed overly "appreciative" in my approach 
to these fictions, I defend such an approach on die grounds that I think all criticism begins with appreciation, horror criticism in particular. I approached the topic believing, as a horror fan, that a lack of attention had been paid to horror generally, and I remain firmly convinced that this unfortunate lack of attention is the case in literary, if not in film, studies. In literary studies, there is still an unconscionable and unacceptable neglect of horror literature and, particularly, of short stories. It is an odd state of affairs, given that so many short horror stories are heavily anthologized in texts for education at the post-secondary level and have given the horrific elements present in so many canonical works. My dissertation has sought to challenge the prevailing assumption that horror cannot be explored in a literary fashion by calling attention to this neglect. It also challenges the idea that certain responses (e.g. those of fans) have little to no value and seeks to avoid categorizations such as the Gothic, which prematurely foreclose on the range of horror's affective qualities.

A major challenge of working in the horror field is its sheer breadth. It is continually and rapidly expanding, and questions of aesthetic merit and voyeuristic prurience continually arise with new texts that are generated with dizzying rapidity. In general, I have tried to touch upon but to avoid getting mired in these inevitable questions in order to ask some different questions about what horror fictions can do to their readers, informed by cultural studies theorists of fan culture. Following these theorists working with horror film, I have both theorized and practiced a fan(g)dom of horror literature that does not construct an artificial divide between fan(g)dom and scholarship. In so doing, I have deliberately chosen non-canonical texts to discuss, glancing here and there at the more canonical works such as Dracula, but leaving them largely to the excellent critical scrutiny they have enjoyed for many years. Somewhat like the fabled vampire, horror criticism requires "new blood" in the form 
of different texts and fresh insights. I believe that the kind of analysis I have performed on less well-known horror stories is central to understanding how horror works and what horror does, rather than simply subjecting such texts to theories that, with the canonical works at their centres, have sweeping observations to make about horror, but much less to say about the fictions themselves.

In attempting to cover the field, I am keenly aware that at times, I may have sacrificed more in-depth analysis of particular texts in favour of mentioning as many noncanonical textual examples as possible. Such an approach can be ascribed both to the vastness of the field, and to my eagerness to prove that so much interesting horror writing not only flourishes in the fan $(\mathrm{g})$ dom but deserves the attention of literary scholars. I look forward to devoting more time and detailed analysis to particular works.

Given that little scholarly writing exists on horror literature, I have had to either work "from scratch" or borrow copiously from film studies. Film theory's applicability to literature can be tenuous, but some clear parallels have been established, notably with respect to framing devices and other narrative elements, particularly in adaptations and remediations. The growing number of horror remakes, as I have indicated, furnishes interesting possibilities for future study: will the "originals" themselves become regarded as "Gothicized" or "literary" in relation to their remakes, and what does the remake craze signify for horror fan $(\mathrm{g})$ dom? In joining the film scholars, I have hoped to restore some balance to the discussion of horror with the inclusion of numerous examples of written horror that I hope will enrich cinematic considerations. My formulation of a type of "poetics" of horror will be applicable in some ways to films as well, and the time is ripe for a more complete scholarly reckoning with horror's aesthetic and narrative affects. 
My own reckoning has involved connecting critical theories of narrative foregrounding and defamiliarization to horror and arguing that these practices of reading, typified through certain elements specific to experiencing horror fictions, constitute important affective responses that can be used to interpret horror fiction's place in different cultural contexts. As a qualitative rather than an empirical analysis, it can certainly be tried and tested against the responses of many readers and fans. It is my sincere hope that such tests will be made, and that these tests will serve to continue to broaden the borders of horror fictions everywhere. 


\section{Works Cited}

Aguirre, Manuel. The Closed Space: horror literature and western symbolism. Manchester UP, 1990.

Ahmad, Aijaz. "Jameson's Rhetoric of Otherness and the 'National Allegory'." Ashcroft 7784.

Aickman, Robert. Dark Forces. New York: New American Library, 1989.

Alarcon, Pedro Antonio de. "The Tall Woman." Manguel.

Argueta, Manlio. One Day of Life. Translated by Bill Brow. New York: Vintage, 1983.

Artaud, Antonin. The Theatre and Its Double. Translated by Victor Corti. London: John Calder, 1970.

Arthur, Robert, ed. Alfred Hitchcok Presents: Stories for Tate at Night. New York: Random House 1971.

Ashcroft, Bill, ed. The Post Colonial Studies Reader. London: Roudedge, 1995.

Ashley, Mike and Contento, William G. The SupernaturalIndex: A Listing of Fantasy, Occult, Weird and Horror Anthologies. Green wood Publishing Group, 1995.

Atwood, Margaret. Strange Things: the Malevolent North in Canadian Literature. Oxford: Clarendon Press, 1995.

—. Survival: A Thematic Guide to Canadian Literature. Toronto: Anansi, 1972.

Auerbach, Nina. Our Vampires, Ourselves. Chicago: University of Chicago Press, 1997.

Austen, Jane. Northanger Abbey (1818). Edited by John Davie, Oxford Classics edition. Oxford University Press, 1980.

Badley, Linda. Film, Horror and the Body Fantastic. London: Greenwood Press, 1995.

Baird, Robert. "Starde and the Threat Scene." Images: a journal of film and popular culture, issue 3. Accessed. Nov. 2009. <http://www.imagesjournal.com/issue03/features/stardel.htm>

Bakhtin, Mikhail. The Dialogic Imagination. Ed. Michael Holquist. Trans. Caryl Emerson and Michael Holquist. Austin: U of Texas P, 1981.

Baldick, Chris, ed. The Oxford Book of Gothic Tales. Oxford University Press, 1992. 
Barker, Clive. Books of Blood. Volumes 1-3. London: Time Warner, 1988.

—. Books of Blood. Volume Six. London: Sphere Books, 1985.

—. "Coming to Grief." Winter Prime 101-128.

Barker, M., ed. The Video Nasties: freedom and censorship in the media. London: Pluto Press, 1984.

—. "The Newson Report: a case study in 'common sense'." M. Barker \& J.

Pedey, eds, III Effects. The Media I Violence Debate (pp. 27-46). London: Roudedge. 1997.

—.Ill Effects: the media/violence debate, London: Roudedge, 1997.

Barth, John. "The Literature of Exhaustion." The Atlantic Monthly, August 1967. Print.

Barthes, Roland. S/Z, Hill and Wang, 1970.

—. "Textual analysis of a Tale of Poe." Narrative Theory: Special Topics, ed. Mieke Bal, New York: Routledge, 2004.

Baudrillard, Jean. The Transparency of Evil: Essays on Extreme Phenomena. Tr. James Benedict. London/New York: Verso, 1993.

Benshoff, Harry M. Monsters in the Closet: homosexuality and the horror film. Manchester UP, 1997.

Benson, E.F. "Mrs. Amworth." Hoke 69-82.

—. "The House with the Brick Kiln." Thin Air. Glasgow: Blackie and Sons Ltd. 1972.

Berenstein, Rhona J. Attack of the Leading Ladies: Gender, Sexuality and Spectatorship in Classic Horror Cinema. New York, Columbia UP, 1996.

Bhabha, Homi K. The Location of Culture. New York: Roudedge, 2004.

—. "Signs Taken for Wonders." Ashcroft 29-35.

—. "Cultural Diversity and Cultural Differences". Ashcroft 206-212.

Bierce, Ambrose. "An Occurrence at Owl Creek Bridge," Twenty-first Annual Collection. Datiow, Ellen, and Link, Kelly, and Grant, Gavin J. 222-34.

Bixby, Jerome. "It's A Good Life." http://nickelkid.net/docs/greats/its a good life.html. 
Blackwood, Algernon. "The Willows." Hartwell 909-943.

—. "The Damned," Tales of the Mysterious and Macabre. London: Spring Books, 1967.

—. "The Transfer". Tales of the Mysterious and Macabre. London: Spring Books, 1967.

Blatty, William Peter. The Exorcist. New York: HarperCollins, 1971.

Bloch, Robert. Psycho. New York: Warner Books, 1959.

—.Psycho-paths, New York: Tor, 1991.

—. "You Could Be Wrong" in Atoms and Evil, Connecticut: Fawcett Publications, 1962.

—. "The Mannikin" Danby $7^{\text {th }}$ 53-70.

—. "Heritage of Horror" (Introduction) The Best ofH.P. Lovecraft. bloodcurdling tales of horror and the macabre. NY:Del Rey, 1987.

—. Atoms and Evil Gold Medal Books 1962.

Bloch, Ernst. Halley, Anne and Suvin, Darko. "Entfremdung Verfremdung: Alienation, Estrangement". The Drama Review: TDR, Vol. 15, No. 1. Autumn, 1970. Print.

Bohrer, Karl Heinz. Suddenness: on the moment of aesthetic appearance. New York: Columbia UP, 1994.

Borges, Jorge Luis. "On Exactitude in Science" A Universal History of Infamy, Tr. Norman Thomas de Giovanni. London: Penguin Books, 1975.

Botting, Fred. Gothic. New York: Routledge, 1996.

Bourdieu, Pierre. Distinction: A social critique of the judgement of taste. New York: Routledge, 1984.

Bowen, Elizabeth. "The Demon Lover," Stories for the Dead of Night. New York: Dell, 1957.

Braunbeck, Gary. "Union Dues," Borderlands. White Wolf Publishing, 1995.

—. "Safe," BzAo-sv Eleventh 120-148.

Brennan, Joseph P. "Slime." O'Shaughnessy 215-230.

Bretnor, Reginald. "The Beasts That Perish." Fears ed. Charles L. Grant, Berkley: Berkley UP, 1983. 
Brite, Poppy Z. Exquisite Corpse: A Novel. New York: Simon \& Schuster, 1996.

—. Wormwood. Formerly titled Swamp Foetus. New York: Random House, 1994.

Britton, Andrew, Richard Lippe, Tony Williams and Robin Wood. American Nightmare: Essays on the Horror Film. Toronto: Festival of Festivals, 1979.

Bronfen, Elisabeth. Over Her Dead Body: Death, Femininity and the Aesthetic. New York: Routledge, 1992.

Brooke-Rose, Christine. A Rhetoric of the Unreal: studies in narrative and structure, especially of the fantastic. Cambridge: Cambridge University Press, 1981.

Brooks, Peter. Reading for the Plot: design and intention in narrative, New York: Vintage, 1984.

Brooks, Max. World WarZ. New York: Three Rivers Press, 2006.

-. The Zombie Survival Guide: Complete Protection from the Uving Dead. New York: Three Rivers Press, 2003.

Brophy, Philip. "Horrality." Gelder.

Brydon, Diana. "The White Inuit Speaks: Contamination as Literary Strategy." Ashcroft 146142.

Budrys, Algis. "The Master of the Hounds." Etchison Masters 141-173.

Calinescu, Matei. Five Faces of Modernity: Modernism, Avant-Garde, Decadence, Kitsch, Postmodernism. Durham: Duke UP, 1987.

Campbell, Ramsay. "The Quality of Terror." Cut! Horror Writers on Horror Film. Golden, Christopher S., ed. New York: Berkley Books, 1992.

—. "The Brood." Dark Forces. New York: New American Library, 1989.

—. "A Street was Chosen," Ghosts and Grisly Things, New York: Tor Books, 1998.

—. "The Words that Count." Masters of Darkness. New York: Tor Books, 1986.

Campbell, Joseph. The Hero With A Thousand Faces, New York: MFJ Books, 1949.

Carroll, Noel. The Philosophy of Horror or Paradoxes of the Heart. New York: Routledge, 1990. 
Caruth, Cathy. Unclaimed Experience: Trauma, Narrative and History. Baltimore: Johns Hopkins UP, 1996.

Chabon, Michael. "In the Black Mill." Datlow Eleventh 251-266.

Chandra, Vikram. "Dharma." Datlow Eleventh 474-490.

Chaon, Dan. "The Bees." Datlow Seventeenth 407-420.

Charnas, Suzy McKee. The Vampire Tapestry. Albuquerque: Living Batch Press, 1980.

Chatman, Seymour. "What Novels Can Do that Film Can't (and Vice Versa)." Critical Inquiry, Chicago: University of Chicago Press, 1980.

Cherry, Brigid. "Refusing to Refuse to Look: Female Viewers of the Horror Film." The Film Reader. Horror, ed. Mark Jancovich. Routledge, 2001.

Chesterton, G.K. The Defendant. http://www.docstoc.com/docs/16126596/The-Defendant. Accessed October 2009.

Chomsky, Noam and Herman, Edward S. Manufacturing Consent: the political economy of the mass media. New York: Pantheon Books, 1988.

Christian, Barbara. The Race for Theory. University of Minnesota Press, 1987.

Cixous, Helene. "Fiction and Its Phantoms: a reading of Freud's Das Unheimliche (the "uncanny")." New Literary History 7.3. 1976.

Clemens, Valdine. The Return of the Repressed: Gothic Horror from The Castle ofOtranto to Alien. New York: SUNY, 1999.

Clover, Carol. Men, Women and Chainsaws: gender in the modem horror film. Princeton: Princeton UP, 1992.

Compagnon, Antoine. Uterature, Theory and Common Sense, Princeton: Princeton UP, 2004.

Coleridge, Samuel Taylor. Biographia Uteraria, ch. 12, taken here from The Oxford Dictionary of Quotations, Oxford UP, 1980.

Collier, John. "Evening Primrose." Arthur 60-70.

Crane, Jonathan. Terror and Everyday Life: singular moments in the history of the horror film. Thousand Oaks, California: Sage, 1994. 
Crawford, F. Marion. "The Screaming Skull. The Screaming Skull and other great American ghost stories. New York: Tor, 1995.

—. The Upper Berth. Kessinger Publishing, 2004.

Creed, Barbara. The Monstrous-Feminine: Film, Feminism, Psychoanalysis, London: Roudedge, 1993.

Cross, John Keir, ed. Best Horror Stories. London: Faber and Faber, 1957.

Crow, Charles L., ed. American Gothic: an anthology 1787' - 1916. Maiden, Mass.: Blackwell Publishers, 1999.

Crowther, Peter. "Too Short A Death". Dadow Ninth 217-242.

—. "The Visitor." Dark Voices 4: The Pan Book of Horror, ed. Sutton \& Jones, New York: Pan, 1992.

Cull, Nick. "The Exorcist. Film in Context." History Today, v.50, i.5. May, 2000.

Danby, Mary, ed. The $7^{\text {th }}$ Fontana Book of Great Horror Stories. London: Fontana, 1972.

Daniels, Les, ed. Dying of Fright: Masterpieces of the Macabre. New York: Charles Scribner's Sons, 1976.

—. Uving in Fear A History of Horror in the Mass Media. New York: Charles Scribner's Sons, 1975.

—. "The Good Parts." Book of The Dead. New York: Mark V. Ziesing, 1989.

Dadow, Ellen, and Windling, Terri. eds. The Year's Best Fantasy and Horror: Third Annual Collection. New York: St. Martin's Griffin, 1990.

—. The Year's Best Fantasy and Horror. Fourth Annual Collection. New York: St. Martin's Griffin, 1991.

—.The Year's Best Fantasy and Horror: Fifth Annual Collection. New York: St. Martin's Press, 1992.

—. The Year's Best Fantasy and Horror: Ninth Annual Collection. New York: St. Martin's Press, 1996.

—. The Year's Best Fantasy and Horror: Tenth Annual Collection. New York: St. Martin's Press, 1997. 
—. The Years Best Fantasy and Horror: Eleventh Annual Collection. New York: St. Martin's Press, 1998.

—. The Year's Best Fantasy and Horror: Fourteenth Annual Collection. New York: St. Martin's Press, 2001.

Datlow, Ellen, and Link, Kelly, and Grant, Gavin J. The Year's Best Fantasy and Horror. Seventeenth Annual Collection. New York: St. Martin's Press, 2004.

—. The Year's Best Fantasy and Horror: Nineteenth Annual Collection. New York: St. Martin's Press, 2006.

-. The Year's Best Fantasy and Horror. Twentieth Annual Collection. New York: St. Martin's Press, 2007.

—. The Year's Best Fantasy and Horror: Twenty-first Annual Collection. New York: St. Martin's Press, 2008.

Davenport-Hines, Richard. Gothic: Four hundred years of excess, horror, evil and ruin. London: Fourth Estate, 1998.

Davidson, Avram. "The Tenant." Masters of Darkness HI, New York: Tor, 1991.

Debord, Guy and Knabb, K. Society of the Spectacle. London: Rebel Press, 1994.

Decerteau, Michelle. The Practice of Everyday Life. tr. Stephen Randall. University of California Press, 1988.

Dedman, Stephen. "Never Seen by Waking Eyes." Datlow Tenth 206-225.

De La Mare, Walter. "Seaton's Aunt." Hartwell 731-752.

Derleth, August. "The Lonesome Place." American Gothic Tales. Ed. Joyce Carol Oates. New York: Penguin, 1996.

Dick, Philip K. "The Father-Thing." Urban Horrors. New York: Daw, 1993.

Dickens, Charles. "The Signalman." Manguel 206-218.

Dickstein, Morris. "The Aesthetics of Fright." Planks of Reason: essays on the horror film. Metuchen, N.J.: Scarecrow Press, 1984.

Dixon, Wheeler Winston. Visions of the Apocalypse: spectacles of destruction in American cinema. London: Wallflower Press, 2003. 
Dorland, Michael and Walton, Priscilla. UntanglingKarla's web:post-national arguments, crossborder crimes, and the investigation of Canadian culture. American Review of Canadian Studies. Spring, 1996.

Doyle, Arthur Conan. "The Horror of the Heights." Danby $7^{\text {th }} 71-87$.

—. "The Leather Funnel." The Best Horror Stories of Arthur Conan Doyle. Chicago: Academy Chicago Publishers, 1989.

—. "Lot No. 249." The Best Horror Stories of Arthur Conan Doyle. Chicago: Academy Chicago Publishers, 1989.

Dozois, Gardner. "Flash Point." Masters of Darkness, New York: Tor, 1986.

Due, Tananarive. The Living Blood. New York: Simon \& Schuster, 2001.

Eagleton, Terry. Literary Theory: an Introduction, Minneapolis: University of Minnesota, 1983.

Edelstein, David. "Torture Porn: the Sadistic Movie Trend." Accessed March 2009. $<$ http://nymag.com/movies/features/15622/> Web.

Edmundson, Mark. Nightmare on Main Street: Angels, Sadomasochism, and the Culture of Gothic. Cambridge: Harvard UP, 1997.

Egan, Greg. "Neighbourhood Watch." Year's Best Horror Stories XVI, ed. Karl Edward Wagner, New York: Daw Books, 1988.

Ellis, Bret Easton. American Psycho. New York: Random House, 1991.

Ellison, Harlan. Deathbird Stories. New York: Bluejay Books, 1983.

—. "I have no Mouth and I must Scream." Alone Against Tomorrow. Toronto: CollierMacmillan, 1972.

—. "The Time of the Eye" Alone Against Tomorrow. Toronto: Collier-Macmillan, 1972.

—. "Lonelyache". Alone Against Tomorrow. Toronto: Collier-Macmillan, 1972.

Elmer, Jonathan. Reading at the social limit: affect, mass culture, and Edgar Allan Poe. Stanford University Press, 1995.

Ely, David. "The Academy." The Playboy Book of Horror and the Supernatural. Chicago: Playboy, 1967.

Etchison, Dennis. "The Blood Kiss." Winter Prime 75-99. 
— ed., Masters of Darkness III, New York: Tor, 1991.

Farris, John. Cut! Horror Writers on Horror Film. Golden, Christopher S., ed. New York: Berkley Books, 1992.

Faust, Christa. "Tighter." The Mammoth Book of Best New Horror Stories, vol. 16. Running Press, 2005.

Firestone, Shulamith. The Dialectic of Sex, the Case for Feminist Revolution. London: Bantam, 1979.

Fish, Stanley. Is There a Text in this Class? The Authority of Interpretive Communities, Harvard UP, 1980.

Fleenor, Juliann E., ed. The Female Gothic. Montreal, London: Eden Press, 1983.

Ford, Jeffrey. "The Boatman's Holiday." Datlow Nineteenth 143-152.

Forster, E.M. "The Story of a Panic." Manguel 919-939.

Foucault, Michel. Discipline <\& Punish: The Birth of the Prison. Translated by Alan Sheridan. New York: Vintage Books, 1977.

—. The History of Sexuality, Vol. 1: An Introduction. New York: Vintage 1990.

Fowler, Christopher. "On Edge." Dark Voices 4: Pan Book of Horrors. New York: Pan, 1992.

Freeland, Cynthia. The Naked and the Undead: evil and the appeal of horror. Boulder, Colo., Westview Press, 2000.

French, Jacqueline. A Derrida Reader: between the blinds. Columbia UP, 1991.

Freud, Sigmund. "The Uncanny". The Standard Edition of the Complete Psychological Works of Sigmund Freud. Volume 17. London: Hogarth Press, 1953.

Fusco, Adam Corbin. "N0072-JK1." Dadow Seventeenth 255-259.

Gadamer, Hans-Georg. "The Play of Art." The Relevance of the Beautiful and other essays. Cmbridge: Cambridge Universtiy Press, 1986.

Gaiman, Neil. "Forbidden Brides of the Faceless Slaves in the Nameless House of the Night of Dread Desire." The Mammoth Book of Best New Horror, vol. 16. Running Press, 2005. 
Geary, Robert F. The Supernatural in Gothic Fiction: Horror, Belief, andUterary Change. Lewiston, NY: Edwin Mellen Press, 1992.

Gelder, Ken, ed. The Horror deader. London: Routiedge, 2000.

Gilbert, Sandra and Gubar, Susan. The Madwoman in the Attic, Yale University Press, 1979.

Giles, Dennis. "Conditions of Pleasure in Horror Cinema." in Planks of Reason: essays on the horror film. Metuchen, N.J.: Scarecrow Press, 1984.

Gilman, Charlotte Perkins. "The Yellow Wallpaper." American Gothic Tales. Ed. Joyce Carol Oates. New York: Penguin, 1996.

Girard, Rene. Ideas. CBC, January 11th, 2002. Radio.

Goldberg, Carey. "The Shunned: For Those Who Dress Differently, an Increase in Being Viewed As Abnormal." The New York Times. May 1,1999. Print.

Grant, Barry Keith, ed. Planks of Reason: essays on the horror film. Metuchen, N.J.: Scarecrow Press, 1984.

—. The Dread of'Difference: gender and the horrorfilm. Austin: University of Texas, 1996.

Graves, Robert. "The Shout." The Shout and Other Stories, Middlesex: Penguin, 1979.

Grixti, Joseph. Terrors of Uncertainty. London: Routiedge, 1989.

Gross, Louis S. Redefining the American Gothic: from Wieland to Day of the Dead. Ann Arbor/London: UMI Research Press, 1989.

Grunenberg, Christoph, ed. Gothic: Transmutations of Horror in luite Twentieth Century Art. Cambridge, Mass.: MIT Press, 1997.

Haining, Peter. Ed. Classics of the Supernatural, Pan Macmillan, 1998.

Halberstam, Judith. Skin Shows: Gothic Horror and the technology of monsters. Durham, NC: Duke UP, 1995.

Hand, Richard, and Michael Wilson. Grand-Guignol: The Trench Theatre of Horror. University of Exeter Press, 2002.

Hantke, Steffen. "Shudder as We Think: Reflections on Horror and / or Criticism." Paradoxa No. 17, December 2002 < http://paradoxa.com/excerpts/17intro.htm $>$. 
-. Ed. Academic Film Criticism, the Rhetoric of Crisis, and the Current State of American Horror Cinema: Thoughts on Canonicity and Academic Anxiety. College Literature - 34.4, Fall 2007.

Hardy, Phil. The Overlook Film Encyclopedia: Horror. Overlook TP, 1995

Hardy, Sarah. "A poetics of immediacy: oral narrative and the short story." Style, Northern Illinois University, Fall 1993

Harman, Graham. "On the Horror of Phenomenology: Lovecraft and Husserl," Collapse TV. Urbanomic, 2008.

Harris, Thomas. Red Dragon. London: Dutton, 2000.

—. Silence of the Lambs. New York: St. Martin's Press, 1988.

—. Hannibal. New York: Dellacorte Press, 1999.

—. Hannibal Rising. New York: Dellacorte Press, 2006.

Hartley, L.P. "W.S." Hoke 150-160.

Hartwell, David, ed. The Dark Descent. London: St. Martins Press, 1987.

Harvey, W.S. "August Heat." Cross 78-84.

Hasenbank, Andrea. Icons of Horror and the Supernatural: an encyclopedia of our worst nightmares. Greenwood, 2006.

Hawkins, Joan. Cutting Edge: Art-Horror and the Horrific Avant-Garde. Minneapolis: University of Minnesota Press, 2000.

Hawthorne, Nathaniel. Rappaccini's Daughter(1844). London: Hesperus Press, 2003.

Hayes, R. Chetwynd. "The Frankenstein Syndrome." Dark Voices 4: The Pan Book of Horror. ed. Sutton \& Jones, New York: Pan, 1992.

Hebdige, Dick. Subculture: The Meaning of Style. London and New York: Methuen, 1979.

Hersey,John. Hiroshima. New York: Alfred A. Knopf, 1946.

Highsmith, Patricia. "The Quest for Blank Claveringi," The 6th Fontana Book of Great Horror Stories. London: Fontana, 1971.

Hills, Matthew. Fan Cultures. New York: Roudedge, 2002. 
—. The Pleasures of Horror. London and New York: Continuum Press, 2005.

—. "Whose 'postmodern' horror? Alejandro Amenabar's Tests". Kinoeye Vol. 3 Issue 5. May 2003. < http://www.kinoeye.org/03/05/hills05.php $>$.

Hirshberg, Glen. "Mr. Dark's Carnival." Dadow Fourteenth 156-182.

Hodgson, William Hope. "The Voice in the Night." More Tales to Tremble By. Western Publishing Company, 1968.

—. "The Whistling Room." Arthur 154-169.

Hoffmann, Nina Kiriki. "Zombies for Jesus". Book of The Dead. New York: Mark V. Ziesing, 1989.

Hoke, Helen, ed. Terrors, Torments and Traumas. Nashville: Thomas Nelson, 1978.

Horkheimer, M. and Adorno, T.W. The Culture Industry: Enlightenment as Mass Deception. Continuum International Publishing Group, 1976.

Horvitz, Leslie Alan. "The Ragman." Fears ed. Charles L. Grant, Berkley: Berkley UP, 1983.

Howard, Jacqueline. Reading Gothic Fiction: A Bakhtinian Approach. Oxford: Clarendon Press, 1994.

Hughes, Fielden. "Dear Ghost." Hoke 53-68.

Huhn, Thomas. "The Kantian Sublime and the Nostalgia for Violence." The Journal of Aesthetics and Art Criticism, 53:3, Summer 1995.

Hutcheon, Linda. A Theory of Adaptation. New York: Routledge, 2006.

-. "Historiographic Metafiction: Parody and the Intertextuality of History". Intertextuality and Contemporary American Fiction. Eds. O'Donnell, Patrick and Robert Con Davis. Baltimore: The Johns Hopkins University Press, 1989.

Hutchings, Peter. "Tearing Your Soul Apart: Horror's New Monsters." Sage, Victor and Allan Lloyd Smith, eds. Modern Gothic: a reader. Manchester: Manchester UP, 1996.

Hutchison, Don, ed. Northern Frights. Oakville: Mosaic Press, 1992.

—. Northern Frights 2. Oakville: Mosaic Press, 1994.

—. Northern Frights 3. Oakville: Mosaic Press, 1995. 
—. Northern Frights 4. Oakville: Mosaic Press, 1997.

—. Northern Frights 5. Oakville: Mosaic Press, 1999.

Iser, Wolfgang. "Readers and die Concept of die Implied Reader." The Act of Reading: A Theory of Aesthetic Response. Johns Hopkins UP, 1978.

Ingebretsen, Edward. At Stake: Monsters and the Rhetoric of Fear in Public Culture. University of Chicago Press, 2001.

Jakobson, Roman. Style in Language, ed. Thomas A. Sebeok. Cambridge, MA: MIT Press, 1960.

Jancovich, Mark, ed. Horror: The Film Reader. London: Roudedge, 2002.

JanMohamed. Abdul R. "The Economy of Manichean Allegory." Ashcroft 18-23.

James, M.R. Collected Ghost Stories, Hertfordshire: Wordsworth Editions Ltd. 1992.

—. "A View From A Hill". Collected Ghost Stories 291-305. Hertfordshire: Wordsworth

Editions Ltd. 1992.

—. "The Ash Tree". Collected Ghost Stories 30-40. Hertfordshire: Wordsworth Editions Ltd. 1992.

—. "Casting the Runes". Collected Ghost Stories 128-145. Hertfordshire: Wordsworth Editions Ltd. 1992.

—. "Oh Whisde and I'll Come to You, My Lad". Collected Ghost Stories 65-81. Hertfordshire: Wordsworth Editions Ltd. 1992.

—. "The Treasure of Abbott Thomas". Collected Ghost Stories'82-97. Hertfordshire:

Wordsworth Editions Ltd. 1992.

—. The Turn of The Screw. Dover: Courier Dover, 1991.

Jeff. Horror in Film and Literature Ustserv. Feb 10, 2003

Jenkins, Henry. "Historical Poetics." cited by Schneider, Stephen J. "Toward an Aesthetics of Cinematic Horror". The Horror Film, ed. Stephen Prince, Rutgers University Press, 2004.

—. Textual Poachers: Television fans and Participatory Culture. New York: Routledge, 1992.

Johnson, Charles. "Exchange Value." American Gothic Tales. Ed. Joyce Carol Oates. New York: Penguin, 1996. 
Jones, Darryl. Horror: A Thematic History in Fiction and Film (Paperback). Arnold, 2002.

Jones, Jonathan. "The Joy of Gore: How Surrealism Inspired Horror Films." The Guardian, Saturday 7 February 2004, pi 8.

<http://www.guardian.co.uk/artanddesign/2004/feb/07/artl>. Accessed June 29, 2009.

Jones, Stephen. Clive Barker's A-Z of Horror. New York: HarperCollins, 1996.

—. The Mammoth Book of Best New Horror Stories, Vol 18. Running Press, 2007.

—. "Raphael." Dadow Twentieth 419-434.

Joshi, S. T. The Weird Tale. Austin: University of Texas Press, 1990.

—. Evolution of the Weird Tale. New York: Hippocampus Press, 2004.

—. The Modern Weird Tale: A Critique of Horror Fiction McFarland, 2001.

—. The American Horror Film ed. Humphries, Reynold. Edinburgh UP, 2002.

- Introduction to Kipling, Rudyard. The Mark of the Beast and Other Horror Tales, Dover: Courier Dover Publications, 2000.

-. Icons of Horror and the Supernatural: An Encyclopedia of Our Worst Nightmares, Greenwod Publishing Group, 2006.

Kauffman, Linda S. Bad Girls and Sick Boys: fantasies in contemporary art and culture. University of California Press, 1998.

Kavanagh, Thomas. The Eimits of Theory. Stanford: Stanford UP, 1989.

Kawin, Bruce. "TheFunhouse and The Howling" American Horrors. Ed. Gregory A. Waller. University of Illinois Press, 1987.

Kendrick, Walter. The Thrill of Fear: 250 Years of Scary Entertainment, Grove Press Books, 1991.

Kenrick, D. A. Times Literary Supplement, May 261982. Print.

Keene, Brian. '"The King' in: Yellow." Mammoth Book of Best New Horror, vol. 16. Running Press, 2005.

Kermode, Mark. "I Was a Teenage Horror Fan: or how I learned to stop worrying and love Linda Blair." Ill Effects: the media/violence debate, eds. Barker and Petley, London: Routledge. 
1997.

Kersh, Gerald. "Comrade Death." Danby $7^{\text {th }} 24-62$.

—. "Men Without Bones." Stories That Scared Even Me, ed. Alfred Hitchcock, New York: Random House, 1967.

Killmeier, Matthew. "Supernatural Soundscapes: Hall of Fantasy, Horror Radio and Cultural History." MidAtlantic Popular/American Culture Association 20th Annual Conference. Airport Hilton. Boston MA. 5 November 2009. Reading.

Kilpatrick, Nancy. The Vampire Stories of Nancy Kilpatrick. Oakville: Mosaic Press, 2000.

King, Stephen. Danse Macabre. New York: Berkley Books, 1981.

—. Night Shift. Toronto: Random House, 1978.

—.Different Seasons. Toronto: Penguin, 1982.

—. Skeleton Crew. Bergenfield NJ: Signet, 1985.

—. "The Monkey." Skeleton Crew. Bergenfield NJ: Signet, 1985.

—. Needful Things. Bergenfield NJ: Signet, 1991

—.Nightmares and Dreamscapes, Toronto: Penguin, 1993.

King, Thomas. The Truth about Stories: a Native Narrative. CBC Massey Lecture, House of Anansi, 2003.

Kipling, Rudyard. "The Mark of the Beast." The Mark of the Beast and Other Horror Tales, Dover: Courier Dover Publications, 2000.

Klein, Naomi. The Shock Doctrine: The Rise of Disaster Capitalism. Toronto: Knopf Canada, 2007.

Koja, Kathe. "At Eventide." Datlow Fourteenth 120-126.

—. "Teratisms," Datlow Fifth 370-376.

Koontz, Dean. "Twilight of the Dawn." Etchison, Masters 268-302.

Kristeva, Julia. Powers of Horror essays on abjection. New York: Columbia UP, 1982. 
—. Desire in Language: A Semiotic Approach to Literature and Art. New York: Columbia University Press, 1980.

Kuznetsov, Anatoli. Babi Yar. London: Farrar, Strauss and Giroux, 1970.

Laity, K. A. "From SBIGs to Mildred's Inverse Law of Trailers: Skewing the Narrative of Horror Fan Consumption." Horror Film: Creating and Marketing Fear. Ed. Steffen Hantke. Jackson, MS: University Press of Mississippi, 2004.

Lanagan, Margo. "A Pig's Whisper." Datlow Twentieth 323-328.

Langelaan, George. "The Fly." Arthur 225-255.

Langer, Lawrence L. The Age of Atrocity: Death in Modern Literature. Boston: Beacon Press, 1978.

Lansdale, Joe. " A Hard-On for Horror: Low-Budget Excitement." Cut!'Horror Writers on Horror Film. Golden, Christopher S., ed. New York: Berkley Books, 1992.

—. "On the Far Side of the Cadillac Desert with Dead Folks." Book of The Dead. New York: MarkV. Ziesing, 1989.

Larson, Charles. "Heroic Ethnocentrism: The Idea of Universality in Literature." Ashcroft 62-65.

Lasch, Christopher. The Culture of Narcissism: American Life in an Age of Diminishing Expectations. New York: W. W. Norton \& Co., 1979.

Laws, Stephen. "The Crawl." Datlow Eleventh 438-458.

Lee, Tanith. "Gemini." Datlow Third 316-339.

Leiber, Fritz. "Smoke Ghost" Hartwell 629-640.

Leffler, Yvonne. Horror as Pleasure. Gothenburg: Almquiest \& Wiksell, 2000.

Levin, Ira. The Stepford Wives. New York: Random House, 1972.

Lewis, Matthew G. The Monk. Louis F. Peck, ed., New York: Grove Press, 1952.

Leyton, Eliott. Hunting Humans. New York: McClelland and Stewart, 1995.

Little, Bentley. "From the Mouths of Babes," Borderlands. White Wolf Publishing, 1995.

Lodge, David. After Bakhtin: essays on fiction and criticism. New York: Routledge, 1990. 
—. Language of Fiction. London: Routledge, 1984.

Lovecraft, Howard Phillips. "Pickman's Model". The Dunwich Horror and Others. Arkham House, 1965.

—. "Supernatural Horror in Literature". Dagon and Other Macabre Tales. Arkham House, 1965.

—. "The Whisperer in Darkness". The Dumvich Horror and Others. Arkham House, 1965.

Lukacs, Georg. The Theory of the Novel. Cambridge: M.I.T. Press, 1971.

Lukas, Scott A. and Marmysz, John. In Tear, Cultural Anxiety and Transformation: Horror, Science Fiction, and Fantasy Films Remade. Lanham MD: Lexington Books, 2008.

Lumley, Brian. "The Thin People." Year's Best Horror Stories XVI, ed. Karl Edward Wagner, New York: Daw Books, 1988.

Lyotard, Jean-Francois. The Postmodern Condition: A Report on Knowledge. University of Minnesota Press, 1984.

Malin, Irving. New American Gothic. Carbondale: Southern Illinois UP, 1962.

Manguel, Alberto, ed. Black Water: the Anthology of Fantastic Literature, London: Picador, 1983.

Manson, Marilyn. "Columbine: Whose Fault Is It?" Rolling Stone. June 24,1999. Accessed October 2009.

http://www.rollingstone.com/news/story/5923915/columbine\%20whose $\% 20$ fault $\% 20$ is $\%$ 20 it.

Marcus, Greil. Interview with Misstress Venus. Lipstick Traces: A Secret History of the Twentieth Century. Cambridge MA: Harvard UP, 1990.

Martin, George R.R. "The Monkey Treatment." Masters of Darkness II, New York: Tor, 1988.

Massumi, Brian, ed. The Politics of Everyday Fear. Minneapolis: University of Minnesota Press, 1993.

Matheson, Richard. I Am Legend. New York: Tom Doherty Associates, 1995.

—. "Making Cabinets." Mammoth Book of Best New Horror, vol. 18. Running Press 2007.

-. "Born of Man and Woman." O'Shaughnessy 145-147.

—. "Prey." Urban Horrors New York: Daw, 1993. 
--. "Groupies." Shock Rock Volume 1. New York: Pocket 1992.

McDonald, T.L. "The Horrors of Hammer: The House That Blood Built." Cut! Horror Writers on Horror Film. Golden, Christopher S., ed. New York: Berkley Books, 1992.

Miall, David S. and Kuiken, Don. "Foregrounding, Defamiliarization, and Affect: response to literary stories." Poetics, 22. Elsevier, 1994.

Miller, Henry. The Air-Conditioned Nightmare. Volume One. New York: New Directions, 1945.

Miller, P. Schuyler. "The Thing on Outer Shoal." O'Shaughnessy 148-155.

Miller, William Ian. The Anatomy of Disgust. Cambridge: Harvard UP, 1997.

Mishra, Vijay. The Gothic Sublime. SUNY, 1994.

Mitchell, W. J. T. Picture Theory. University of Chicago Press, 1994.

Modleski, Tania. "The Terror of Pleasure: the contemporary horror film and postmodern theory". Studies in Entertainment: critical approaches to mass culture. "Indiana University Press, 1986.

Moore, Alan, and Eddie Campbell. From Hell: being a melodrama in sixteen parts. Paddington, Australia: Eddie Campbell Comics, 1989,1999, 2000.

Moore, Alan and Kevin O'Neill. The League of Extraordinary Gentlemen. America's Best Comics, 1999-2007. Print.

Mora, Pat."La Muerte." Datlow Eleventh 278-280.

Moretti, Franco. "The Novel: History and Theory." New Left Review, Vol. 52, 2008, <http://www.newleftreview.org/?view=2735>.

Mulvey, Laura. "Visual Pleasure and Narrative Cinema." Media and Cultural Studies eds. Durham, Kellner. Keyworks, 2006.

—. "The Pre-Oedipal Father: the Gothicism oiBlue Velvet." Modern Gothic: a reader. Manchester: Manchester UP, 1996.

Muzzatti, Stephen L. "Criminalising Marginality and Resistance: Marilyn Manson, Columbine and Cultural criminology." Cultural Criminology Unleashed. Ed. Ferrel et al. n. p. 2004

Nabokov, Vladimir. Lectures on Literature. Ed. Fredson Bowers. Houghton Mifflin Harcourt, 2002. 
Newman, Kim. 'Going to Series." Dark Terrors 5, London: Gollancz, 2001.

—. "The Man Who Fell Off The Ghost Train." The Mammoth Book of Best New Horror Vol. 18. Running Press, 2007.

—. "Where the Bodies are Buried 3: Black and White and Red All Over." Dark Terrors: the Gollanc\%Book of Horror. London: Victor Gollancz, 1995.

Nolan, Justin M. and Gery W. Ryan. "Fear and Loathing at the Cineplex: gender differences in descriptions and perceptions of slasher films." Sex Roles: a journal of research, Jan 2000.

Nolan, William.F. "Him Her Them." Psycho-paths ed. Bloch, R. New York: Tor, 1991.

Oates, Joyce Carol. Beasts. New York: Carroll \& Graf, 2002.

—. "Landfill." Dadow Twentieth 128-138.

—. "The Family." Masters of Darkness III, New York: Tor, 1991.

—. "-." Dadow, Ninth 473-484.

—. Haunted: Tales of the Grotesque. New York: Dutton (Penguin), 1994.

—. Night-Side: Eighteen Tales. New York: Vanguard Press, 1977.

—. The Collector of Hearts: New Tales of the Grotesque. New York: Dutton (Penguin), 1998.

—. The Goddess and Other Women. New York: Vanguard Press, 1974.

—. The Hungry Ghosts: Seven Allusive Comedies. Los Angeles: Black Sparrow Press, 1974.

-. The Poisoned Kiss and Other Stories from the Portuguese. Written as 'Fernandes.' New York: Vanguard Press, 1975.

—. Zombie. New York: Dutton (Penguin), 1995.

O'Brien, Fitz-James. "What Was It?" Hartwell 864-873.

Oliver, Reggie. "Among the Tombs." Dadow Nineteenth 47-59.

O'Shaughnessy, Michael, ed. The Monster Book of Monsters. London: Xanadu, 1988.

Page, Norman. A Kipling Companion. New York: McMillan, 1984. 
Palahniuk, Chuck. Hot Potting. Datlow Nineteenth 348-54.

Palmer, Bryan D. Cultures of Darkness: night travels in the histories of transgression (from medieval to modern). New York: Monthly Review Press, 2000.

Patterson, David. Berger, Alan L. and Cargas, Sarita. "Anatoli Kuznetsov." Encyclopedia of Holocaust literature. Westport CT: Oryx Press, 2002.

Perez, Gilberto. The Material'Ghost:Films andtheirMedium. Baltimore: Johns Hopkins, 1998.

Pinedo, Isabel Cristina. Recreational Terror: women and the pleasures of horror film viewing. SUNY Press, 1997.

Poe, Edgar Allan. "The Fall of the House of Usher." in Complete Tales and Poems, New Jersey: Castle Books, 2001.

—. "The Philosophy of Composition." Graham's Magazine, vol. XXVIII, no. 4, April 1846.

Porter, Gerald. "Meaning and the Lacuna in Oral Narrative." accessed October 2009, http://lipas.uwasa.fi/hut/english/meaning_and_the_lacuna.rtf.

Powell, Anna. Deleu^e and Horror Film. Edinburgh: Edinburgh University Press, 2005.

Powers, Paul S. "Monsters of the Pit." O'Shaughnessy 126-135.

Priesdey, J.B. "The Grey Ones." Manguel 800-815.

Prince, Stephen. "Dread, Taboo and The Thing, toward a social theory of the horror film." Wide Angle, 10:3,1988.

Propp, Vladimir, Morphology Of The Folktale. Austin: University of Texas Press, 1968.

Punter, David. The Literature of Terror: a history of Gothic fictions from 1765 to the present day. London: Longman, 1980.

Quiroga, Horatio. "The Feather Pillow." Manguel 816-819.

Radcliffe, Ann. The Mysteries ofUdolpho. Oxford: Oxford University Press, 1998.

Ramsland, Katherine. Inside the minds of serial killers: why they kill, New York, Greenwood Publishing, 2006.

Riquelme, John Paul. "Toward a History of Gothic and Modernism: dark modernity from Bram Stoker to Samuel Beckett." Modern Fiction Studies. 46:3, 2000. 
Rampo, Edogawa. Japanese Tales of Mystery \& Imagination, tr. James B. Harris. Tokyo: Charles E. Turtle, 1956.

Reed, Robert. "Mrs. Greasy." Datlow Ninth 455-472.

Rockett, Will H. Devouring Whirlwind: Terror and Transcendence in the Cinema of Cruelty. London: Greenwood Press, 1988.

Russell, Ray. "Sardonicus." The Playboy Book of Horror and the Supernatural, Playboy Press, 1967.

—. "The Cage." Stories That Scared Even Me, ed. Hitchcock, New York: Random House, 1967.

Sage, Victor. Horror Fiction in the Protestant Tradition. Basingstoke: Macmillan, 1988.

Sage, Victor and Allan Lloyd Smith, eds. Modern Gothic: a reader. Manchester: Manchester UP, 1996.

Said, Edward. Culture and Imperialism. Vintage, 1994.

Sarrantonio, Al, ed. 999: Twenty-nine Original Tales of Horror and Suspense. New York: Perennial HarperCollins, 1999.

—. "Father Dear." Masters of Darkness II, New York: Tor, 1988.

—. "Pumpkin Head." 13 Horrors of Halloween, ed. Isaac Asimov. Avon, 1983.

Schneider, Kirk J. Horror and the Holy: wisdom teachings of the monster tale. Illinois: Open Court Publishing, 1993.

Schneider, Steven Jay, ed. Fear Without Frontiers: horror cinema across the globe. Surrey: Fab Press, 2003.

— and Tony Williams eds. Horror International: contemporary approaches to film and television. Wayne State University Press, 2005.

—. "World Horror Cinema and the U.S.: bringing it all back home." Media in Transition 2: globalisation and convergence. Cambridge: MIT Press, 2007.

—. "Toward an Aesthetics of Cinematic Horror." The Horror Film, ed. Stephen Prince, Rutgers University Press, 2004.

Schow, David. "Jerry's Kids Meet Wormboy." Book of The Dead. New York: Mark V. Ziesing, 1989

—. "Pick Me Up." Psycho-paths ed. Bloch, R. New York: Tor, 1991. 
Seltzer, Mark. Serial Killers: Death and life in America s Wound Culture. New York: Routledge, 1998.

Shlain, Leonard. The Alphabet Versus the Goddess. New York: Viking Penguin, 1998.

Sieg, George. Collapse I. Falmouth: Urbanomic, 2008.

Skipp, John and Spector, Craig. Cut! Horror Writers on Horror Film. Golden, Christopher S., ed. New York: Berkley Books, 1992.

—. Book of The Dead. New York: Mark V. Ziesing, 1989

Smith, Michael Marshall. "More Tomorrow." Dark Terrors: the Gollanc ${ }^{\wedge}$ Book of Horror. London: Victor Gollancz, 1995.

Sontag, Susan. AIDS and Its Metaphors. New York: Farrar, Straus and Giroux, 1989.

—. Regarding the Pain of Others. New York: Farrar, Straus and Giroux, 2003.

—. "The Imagination of Disaster." Science Fiction: a collection of critical essays. New Jersey:

Prentice-Hall, Inc., 1976.

Spencer, William Browning. "The Ocean and All Its Devices." Borderlands. White Wolf Publishing, 1995.

Spratford, Becky Siegel and Tammy Hennigh Clausen. The horror readers' advisory: the librarian's guide to vampires, killer tomatoes, and haunted houses. ALA Editions, 2004.

Stableford, Brian M. Historical Dictionary of Science Fiction Literature. Scarecrow Press, 2004.

Sterling, Bruce, ed. Mirrorshades: the Cyberpunk Anthology. London: HarperCollins, 1986.

Stevenson, R. L. "The Botde Imp." New York: Clarion, 1996.

Sturgeon, Theodore. "It." Creatures From Beyond. Nashville: T. Nelson, 1975.

—. "The Professor's Teddy Bear." O'Shaughnessy 329-336.

Sullivan, Jack, ed. The Penguin Encyclopedia of Horror and the Supernatural. New York: Viking Penguin, 1986.

Suzuki, Koji. Ring. tr. Robert G. Rohmer and Glynne Walley. New York: Vertical, 2003. 
Telotte, J.P. Dark Patches : Structures of Absence in Lewton's Cat People." Post Script, vol. 2 no. 1. 1982.

Tern, Steve Rasnic. " Preparations for the Game." Masters of Darkness. Ed. Dennis Etchinson, New York: Tor, 1986.

Tem, Melanie and Tern, Steve Rasnic. "The Man on the Ceiling." Dadow Fourteenth 216-231.

Thomas, D.M. The White Hotel. New York: Viking, 1981.

Thomas, Dylan. "The Old Woman Upstairs." Danby $7^{\text {th }} 153-156$.

Tithecott, Richard. Of Men and Monsters: Jeffrey Dahmer and the Construction of the Serial Killer. University of Wisconsin Press, 1997.

Todorov, Tzvetan. The Fantastic: a structural account of a literary genre, Ithaca, NY: Cornell UP, 1975.

—. "The Notion of Literature." New Literary History, Vol. 5, No. 1, What Is Literature? Autumn, 1973.

—. Genres in Discourse. Cambridge: Cambridge UP, 1990.

Tohill, Cathal, and Pete Tombs. Immoral Tales: European Sex and Horror Movies 1956-1984.

New York: St. Martin's Griffin, 1994.

Tombs, Pete. Mondo Macabro: Weird and Wonderful Cinema around the World. New York: St. Martin's Griffin, 1997.

Trilling, Lionel. Sincerity and Authenticity. Cambridge, MA: Harvard UP, 1971.

Tropp, Martin. Images of Fear: how horror stories helped shape modern culture. Jefferson: Macfarland, 1999.

Tudor, Andrew. Monsters and Mad Scientists: a cultural history of the horror movie. Oxford:

Blackwell, 1989.

Tulloch, John, and Henry Jenkins. Science Fiction Audiences. London and New York:

Routledge, 1995.

Tutde, Lisa. "Closet Dreams." The Year's Best Fantasy and Horror: Twenty-first Annual Collection. Dadow, Ellen, and Link, Kelly, and Grant, Gavin J. 415-422.

Twitchell, James. Dreadful Pleasures: an anatomy of modem horror. New York: Oxford UP, 1985. 
Van Vogt, A.E. "Vault of the Beast." 9-25.

Varma, Devendra P. The Gothic Flame: Being a history of the Gothic Novel in England: its origins, efflorescence, disintegration, and residuary influences. New York: Russell \& Russell, 1957.

—. "The Vampire in Legend, Lore, and Literature." Introduction to Varney the Vampyre. New York: Arno Press, 1970.

Vatnsdal, Caelum. They Came From Within: a history of Canadian horror cinema. Winnipeg: Arbeiter Ring Publishing, 2004.

Viera, Mark A. Hollywood Horror: From Gothic to Cosmic. New York: Harry Abrams, 2003.

Von Schiller, Friedrich. "On the Sublime." Two Essays, tr. Julias A. Elias. New York:

Frederick Ungar Publishing Co, 1966.

Wagner, Karl Edward, ed. The Year's Best Horror Stories XVIII. New York: Daw Books, 1990.

—. "Sticks." The Dark Descent. HartweU 209-224.

Wakefield, H. Russell. "The Red Lodge." More Tales To Tremble By. Western Publishing Company, 1968.

Waller, Gregory A., ed. American Horrors: essays on the modern American horror film. Urbana: University of Illinois, 1987.

Watts, James. Contesting the Gothic: Fiction, Genre and Cultural Conflict. 1764-1832. Cambridge: Cambridge UP, 2006

Waugh, Patricia. Metafiction: The Theory and Practice of Self-conscious Fiction New York: Metheun, 1984.

Weaver, Richard M. The Ethics of Rhetoric. Davis: Hermagoras Press, 1985.

Weinberg, Robert. Horror of the 2CfCentury: An Illustrated History. Portland, Oregon:

Collector's Press, 2000.

Wellman, Manly Wade. "The Desrick on Yandro." Alfred Hitchcock's Monster Museum. New York: Random House, 1965.

—. "Up Under The Roof." Masters of Darkness II, New York: Tor, 1988.

Wells, H. G. "The Inexperienced Ghost." Thin Air. London: Blackie \& Son, 1966. 
Westlake, Donald. "Journey to Death.' Stories That Scared Even Me, ed. Hitchcock, New York: Random House, 1967.

Wharton, Edith, qtd. "Foreword," Manguel xvi-xix.

White, Dennis L. "The Poetics of Horror: More than Meets the Eye." Cinema Journal, Vol. 10, No. 2. Spring, 1971.

White, T.H. "The Troll." <http://www.agora.kva.se/meetings/abisko02/story.htm>.

Williams, Anne. Art of Darkness: A Poetics of Gothic. Chicago: University of Chicago Press, 1995.

Williams, Charles. "Et in Sempiternum Pereant." Manguel 619-628.

Williams, Linda. "Film Bodies: Gender, Genre, and Excess." Film Quarterly. 44:4, Summer 1991.

—. "When The Woman Looks." The Dread of Difference: gender and the horror film. Austin: University of Texas, 1996.

Williams, Raymond. "The Assassin." Eighth Volume: The Van Book of Horror Stories. New York, Pan, 1970.

—. "The Coffin Makers." Eighth Volume: The Pan Book of Horror Stories. New York, Pan, 1970.

—. Culture and Society: Coleridge to Orwell. London: Hogarth Press, 1958.

Williams, Rosalind. Notes on the Underground: an Essay on Technology, Society, and the Imagination. Cambridge: MIT Press, 1990.

Wilson, Gahan. "The Sea Was Wet as Wet Can Be." The Playboy Book of Horror and the Supernatural, Playboy Press, 1967.

Winter, Douglas E. Stephen Yang, The Art of Darkness. Toronto: Signet, 1982.

—. ed, Prime Evil. New York: New American Library, 1988.

—. dive Barker. The Dark Fantastic: Toronto: HarperCollins Canada, 2002.

Wolf, Leonard, ed. Blood Thirst: 100 Years of Vampire Fiction. Oxford UP, 1997.

Wollheim, Donald A. "Mimic." Creatures From Beyond. Nashville: T. Nelson, 1975. 
Wood, Robin. Hollywood from Vietnam to Reagan... and beyond. New York: Columbia UP, 1986,2003.

Worland, Rick. "OWI Meets the Monsters: Hollywood Horror Films and War Propaganda, 1942 to 1945." Austin: University of Texas Press, 1997.

Wyndham, John. The Day of the Triffids. London: Michael Joseph, 1951.

Yarbro, Chelsea Quinn. "Disturb Not My Slumbering Fair." O'Shaughnessy 90-97.

Youmans, Marly. "An Incident at Agate Beach." Dadow Nineteenth 25-46.

Zicree, Marc Scott. The Twilight Zone Companion. New York: Bantam Books, 1982. 


\section{Filmography}

28 Days Later. Dir. Danny Boyle. DNA Films, 2002. DVD.

TheAddams Family. Dir. Stanley Z. Cherry, Arthur Hiller. ABC, 1964-66. Television.

Alien. Dir. Ridley Scott. Brandywine, 1979. DVD.

Aliens. Dir. James Cameron. Twentieth Centry Fox Film, 1986. DVD.

American Psycho. Dir. Mary Harron. Am Psycho Productions, 2000. DVD.

The Beast with Five Fingers. Dir. Robert Florey. Warner Borthers, 1946. DVD.

The Birds. Dir. Alfred Hitchcock. Universal Pictures, 1963. DVD.

Black Christmas. Dir. Bob Clark. Film Funding Ltd. of Canada, 1974. DVD.

Black Sabbath (Tre volti dellapaura). Dir. Mario Bava, Salvatore Billitteri. Alta Vista, 1963. DVD.

Body Double. Dir. Brian de Palma. Columbia Pictures,1984. DVD.

Bowling/or Columbine. Dir. Michael Moore. Alliance Atlantis Communications, 2004. DVD.

The Brood. Dir. David Cronenberg. Canadian Film Development Corporation, 1979. DVD.

Bram Stoker's Dracula. Dir. Francis Ford Coppola. American Zoetrope, 1992. DVD.

Brazil. Dir. Terry Gilliam. Embassy International, 1985. DVD.

Bujjy the Vampire Slayer. Prod. Joss Whedon. Mutant Enemy, 1997-2003. Television.

The Cabinet of Dr. Caligari. Dir. Robert Wiene. Decla-Bioscop AG, 1920. DVD.

Candyman. Dir. Bernard Rose. Polygram, 1992. DVD.

Cannibal Ferox. Dir. Umberto Lenzi. Dania Film, 1981. DVD

Carrie. Dir. Brian De Palma. Redbank Films, 1976. DVD

The Cat and the Canary. Dir. Paul Leni. Universal Pictures, 1927. DVD.

—. Dir. Eliott Nugent. Paramount Pictures, 1939. DVD. 
Cat People. Dir. Jacques Toumeur. RKO Radio Pictures, 1942. DVD.

—. Dir. Paul Schrader. RKO Pictures, 1982. DVD.

The Cell. Dir. Tarsem Singh. Avery Pix, 2000. DVD.

Child's Play III. Dir. Jack Bender. Universal Pictures, 1991. DVD.

A Clockwork Orange. Dir. Stanely Kubrick. Warner Bros., 1971. DVD.

The Cook, the Thief, His Wife $<\&$ Her Lover. Dir. Peter Greenaway. Allarts Cook, 1989. DVD.

The Crawling Eye. Dir. Quentin Lawrence. Tempean Films, 1958. DVD.

Creature from the Black Lagoon. Dir. Jack Arnold. Universal Internation Pictures, 1954. DVD.

Creepshow. Dir. George Romero. Creepshow Films Inc., 1982. DVD.

Dahmer. Dire. David Jacobson. Blockbuster Films, 2002. DVD.

Dawn of the Dead. Dir. George Romero. Laurel Group, 1979. DVD.

Day of the Dead. Dir. George Romero. Dead Films Inc., 1985. DVD.

Dead Alive. Dir. Peter Jackson. WingNut Films, 1992. DVD.

Dead and Breakfast. Dir. Matthew Leutwyler. Ambus Entertainment, 2004. DVD.

Dead of Night. Dir. Alberto Cavalcanti. Ealing Studios, 1945. DVD.

The Devil's Refects. Dir. Rob Zombie. Lions Gate, 2005. DVD.

Diary of the Dead. Dir. George Romero. Artfire Films. 2007. DVD.

DedSno. Dir. Tommy Wirkola. Euforia Film, 2009. DVD.

Dracula. Dir. Tod Browning. Universal Pictures, 1931. DVD.

Dressed To Kill. Brian De Palma. Filmways Pictures, 1980. DVD.

The Driller Killer. Dir. Abel Ferrara. Navaron Productions, 1979. DVD.

Ed Gein. Dir. Chick Parello. Kunert/Manes Entertainment, 2000. DVD.

The Evil Dead. Dir. Sam Raimi. Renaissance Pictures, 1981. DVD. 
EvilDeadII. Dir. Sam Raimi. DeLaurentiis Entertainment, 1987. DVD.

The Exorcism of Emily Rare. Dir. Scott Derrickson. Screen Gems, 2005. DVD.

The Exorcist. Dir. William Friedkin. Hoya Productions, 1973. DVD.

Fido. Dir Andrew Currie. Lions Gate Films, 2006. DVD.

The Ely. Dir. David Cronenberg. Brooksfilms, 1986. DVD.

Frankenstein. Dir. James Whale.Universal Pictures, 1931. DVD.

—. Dir. Kenneth Branagh. TriStar Pictures, 1994. DVD.

Friday the $13^{\text {th }}$. Dir. Sean S. Cunningham. Georgetown Productions, 1980. DVD.

Ghostwatch. Dir. Lesley Manning. BBC, 1992. Television.

Ginger Snaps. Dir. John Fawcett. Copperheart Entertainment, 2000. DVD.

Gothic. Ken Russell. Virgin Vision, 1986. DVD.

The Grudge. Takashi Shimuzu. Senator International, 2004. DVD.

Halloween. Dir. John Carpenter. Compass International Pictures, 1978. DVD.

Hannibal. Dir. Ridley Scott. MGM, 2001. DVD.

Haunted. Dir. Lewis Gilbert. October Films, 1995. DVD.

The Haunting. Dir. Robert Wise. Argyle Enterprises, 1963. DVD.

Heathers. Dir Michael Lehman. New World. 1988. DVD.

Hellraiser. Dir. Clive Barker. Cinemarque Entertainment, 1987. DVD.

Henry, Portrait of a Serial Killer. Dir. John McNaughton. Maljack Productions, 1986. DVD.

"Homecoming". Masters of Horror. Dir. Joe Dante. IDT Entertainment, 2005. DVD.

Hostel. Dir. Eli Roth. Hostel LLC, 2005. DVD.

Hostel: Part 2. Dir. Eli Roth. Lions Gate, 2007. DVD.

The House by the Cemetery. Dir. Lucio Fulci. Fulvia Film, 1981. DVD. 
House of 1000 Corpses. Dir. Rob Zombie. Spectacle Entertainment Group, 2003. DVD.

The Howling. Dir. Joe Dante. AVCO Embassy Pictures, 1981. DVD.

The Hunger dir. Tony Scott, MGM, 1983. DVD.

I Am Legend. Dir. Francis Lawrence. Warner Bros., 2007. DVD.

"Imprint". Masters of Horror. Dir. Takashi Miike. IDT Entertainment, 2005. DVD.

In The Mouth of Madness. Dir. John Carpenter. New Line Cinema, 1994. DVD.

I Spit on Your Grave. Dir. Meir Zarchi. Cinemagic Pictures, 1978. DVD.

I, The Jury. Dir. Harry Essex. Parklane Pictures, 1953. DVD.

J'Accuse. Dir. Abel Gance. Forrester-Parant Productions, 1938. DVD.

"Jenifer ". Masters of Horror. Dir. Dario Argento. IDT Entertainment, 2005. DVD.

Ju-On. Dir. Takashi Shimizu. Toei Video Company, 2000. DVD.

Koroshiya Ichi (Ichi the Killer). Dir. Takashi Miike. Omega Project, 2001. DVD.

Land of the Dead. Dir. George Romero. Universal Pictures, 2005. DVD.

The leopard Man. Dir. Jacques Tourneur. RKO Radio Pictures, 1943. DVD.

Let The Right One In. Dir. Tomas Alfredson. EFTI, 2008. DVD.

Mad Love (The Hands ofOrlac). Dir. Karl Freund. MGM, 1935. DVD.

Martin. George Romero. Laurel Entertainement, 1977. DVD.

Manson. Dir. Robert Hendrickson and Laurence Merrick. Merrick International, 1973. DVD.

Night of the Demon. Dir. Jacques Tourneur. Sabre Film Production, 1957. DVD.

Night of the Living Dead. George Romero. Image Ten, 1968. DVD.

A Nightmare on Elm Street'. Dir. Wes Craven. New Line Cinema, 1984. DVD.

Nosferatu — Line Sjmphonie des Grauens. Dir. F.W. Murnau. J-A B-J, 1921. DVD.

No Smoking. Dir. Anurag Kashyap. Big Screen Entertainment, 2007. DVD. 
Open Water. Dir. Chris Kentis. Plunge Pictures LLC, 2003. DVD.

Odishon (Audition). Dir Takashi Miike. AFDF, 1999. DVD.

The Omega Man. Dir. Boris Sagal. Warner Bros., 1971. DVD.

The Omen. Dir. Richard Donner. Twentieth Century Fox, 1976. DVD.

Pink Flamingos, Dir. John Waters. Dreamland, 1972. DVD.

The Pit and the Pendulum. Dir Roger Corman. Alta Vista Productions, 1961. DVD.

Peeping Tom. Dir. Michael Powell. Michael Powell (Theatre), 1960. DVD.

Pontypool. Dir. Bruce McDonald. Ponty Up Pictures, 2008. DVD.

Psycho. Dir. Alfred Hitchcock. Shamley Productions, 1960. DVD.

Re-Animator. Dir. Stuart Gordon. Empire Pictures, 1985. DVD.

[RECJ. Dir. Jaume Balaguer and Paco Piazza. Filmax, 2007. DVD.

Repulsion. Dir. Roman Polanski. Compton Films, 1965. DVD.

Return of the Living Dead. Dan O'Bannon. Hemdale Film, 1985. DV D.

Rang. Dir. Gore Verbinski. DreamWorks SKG, 2002. DVD.

RJngu. Dir. Hideo Nakata. Omega Project, 1995. DVD.

The Rocky Horror Picture Show. Dir. Jim Sharman. Twentieth Century Fox, 1975. DVD.

Saw. Dir. James Wan. Evolution Entertainment, 2004. DVD.

Saw II. Dir. Darren Lynn Bousman. Twisted Pictures, 2005. DVD.

Scary Movie. Dir. Keenen Ivory Wayans. Dimension Films, 2000. DVD.

Scream. Dir. Wes Craven. Dimension Films, 1996. DVD.

Shaun of the Dead. Dir. Edgar Wright. Studio Canal, 2004. DVD.

Se7en. Dir. David Fincher. New Line Cinema, 1995. DVD.

Shivers. Dir. David Cronenberg. Canadian Film Development Corporation, 1975. DVD. 
Silence of the Lambs. Dir. Jonathan Demme. Orion Pictures, 1991. DVD.

The Sixth Sense. Dir. M. Night Shyamalan. Barry Mendel Productions, 1999. DVD.

The Stepfather. Dir. Joseph Ruben. Incorporated Television Company, 1987. DVD.

The Stepford Wives. Dir. Bryan Forbes. Fadsin Cinema Associates, 1975. DVD,

Tales from the Hood. Dir. Rusty Cundieff. 40 Acres and a Mule Filmworks, 1995. DVD.

Taxi Driver. Dir. Martin Scorsese.Columbia Pictures, 1976. DVD.

The Texas Chainsaw Massacre. Dir. Tobe Hooper. Vortex, 1974. DVD.

The Texas Chainsaw Massacre II. Dir. Tobe Hooper. Cannon Films, 1986. DVD.

They Live!. Dir. John Carpenter. Alive Films, 1988. DVD.

Trainspotting. Dir. Danny Boyle. Channel Four Films, 1996. DVD.

True Blood Dir. Alan Ball. Your Face Goes Here Entertainment, 2008. HBO. Television.

Two Evil Eyes. Dir. Dario Argento and George Romero. ADC Films, 1991. DVD.

Videodrome. Dir. David Cronenberg. Canadian Film Development Corporation, 1982. DVD.

The Wizard of Gore. Dir. Herschell Gordon Lewis. Mayflower Pictures, 1968. DVD.

Wolf Creek. Dir. Greg Mclean. Australian Film Finance Corporation, 2005. DVD.

Young Frankenstein. Dir. Mel Brooks. Gruskoff/Venture Films, 1974. DVD. 